BRUNO CASTRO SILVA

AVALIAÇÃO DA EFICIÊNCIA DE COMPENSADORES DE ATRITO APLICADOS A VÁLVULAS DE CONTROLE 
BRUNO CASTRO SILVA

\section{AVALIAÇÃO DA EFICIÊNCIA DE COMPENSADORES DE ATRITO APLICADOS A VÁLVULAS DE CONTROLE}

Dissertação apresentada à Escola Politécnica da Universidade de São Paulo para obtenção do título de Mestre em Ciências. 
BRUNO CASTRO SILVA

\section{AVALIAÇÃO DA EFICIÊNCIA DE COMPENSADORES DE ATRITO APLICADOS A VÁLVULAS DE CONTROLE}

Dissertação apresentada à Escola Politécnica da Universidade de São Paulo para obtenção do título de Mestre em Ciências.

Área de Concentração:

Engenharia de Sistemas

Orientador: Prof. Dr. Claudio Garcia 
Este exemplar foi revisado e alterado em relação à versão original, sob responsabilidade única do autor e com a anuência de seu orientador.

São Paulo, 3 de setembro de 2013.

Assinatura do autor

Assinatura do orientador

\section{FICHA CATALOGRÁFICA}

Silva, Bruno Castro

Avaliação da eficiência de compensadores de atrito aplicados a válvulas de controle / B.C. Silva. - versão corr. - São Paulo, 2013.

$128 \mathrm{p}$.

Dissertação (Mestrado) - Escola Politécnica da Universidade de São Paulo. Departamento de Engenharia de Telecomunicações e Controle.

1. Controle de processos 2. Atrito 3. Válvulas de controle pneumático I. Universidade de São Paulo. Escola Politécnica. Departamento de Engenharia de Telecomunicações e Controle II. $\mathbf{t}$. 


\section{Agradecimentos}

Ao meu orientador e amigo, prof. dr. Claudio Garcia, pelas oportunidades que me deu e pelos ótimos anos em que trabalhamos em conjunto.

Aos meus pais, Helena e José Reinaldo, pelo apoio incondicional e por guiarem por tantos anos.

Ao meu irmão e meus familiares, pelo suporte e carinho que me ofereceram.

Aos meus colegas e amigos, por todos os momentos de diversão e risadas, que foram meu combustível do dia a dia.

À CAPES pelo apoio financeiro. 


\section{Resumo}

O objetivo deste trabalho é reduzir o efeito do atrito estático em malhas de controle. A não-linearidade inserida por esse fenômeno pode diminuir a eficiência de um controlador PID e até tornar o sistema em malha fechada oscilatório. Para minimizar esse problema, são testados compensadores presentes na literatura e que não necessitam de modelos internos, os quais, em princípio, podem ser implementados em CLPs e SDCDs com facilidade. Apesar dos compensadores não utilizarem um modelo da válvula em seu algoritmo, é necessário conhecer a magnitude do atrito para parametrizá-los. Por este motivo, os primeiros tópicos desta dissertação são sobre modelos de atrito e técnicas para estimar seus parâmetros. Após estes tópicos, são introduzidos os compensadores de atrito. Alguns dos métodos avaliados foram modificados para tentar aprimorar os resultados. Apesar da teoria poder ser aplicada para uma grande diversidade de processos, os algoritmos foram aplicados a uma malha de controle de vazão de água utilizando válvulas de controle. O objetivo assumido é minimizar o ITAE (Integral Time Absolute Error) e o desgaste gerado nos equipamentos, devido à movimentação excessiva da haste da válvula. Também se verifica o tempo de subida do sistema em malha fechada. Além de testar os compensadores em uma malha de controle de vazão, também foram realizados testes com os compensadores em uma malha de controle de posição, que por sua vez recebe o setpoint de uma malha de controle de vazão (controle em cascata). Os resultados mostram que, utilizando os compensadores, é possível que uma válvula com alto índice de atrito apresente um desempenho próximo ao de uma válvula com baixo índice de atrito sem compensação, ou seja, foi possível compensar o atrito na haste.

Palavras-chave: Compensação de atrito, válvulas de controle, quantificação de atrito, Knocker, Two-move, CR. 


\section{Abstract}

The aim of this work is to reduce the effect of the static friction in control loops. The non-linearity inserted by this phenomenon may decrease the efficiency of a PID controller and even make the closed loop system oscilatory. To minimize this problem some compensation methods present in the literature that do not require internal models were tested, which, theoretically, can be easely implemented in a PLC or DCS. Even though the compensation methods do not require internal models, it is necessary to know the friction magnitude in order to set their parameters. With that in mind, the first topics of this dissertation are about friction models and how to identify their parameters. After these topics the friction compensation methods are introduced. Some of these methods where modified, with the purpose of improving the results. Although the theory may be applied to a great variaty of process, these algorithms were tested in a water flow control loop using control valves. The assumed objective is to minimize the ITAE (Integral Time Absolut Error) and the wearing of the equipments due to excessive moveiment of the valve stem. The rising time of the closed loop system is also verified. Besides testing these compensation methods in a flow control loop, they were alsos tested in a position control loop, that recieve its set-point from a flow control loop (cascade control). The results show that, if the compensators are used, a high friction valve may present the same efficiency as a low friction one without compensation, which means that the friction in the stem was compensated.

Keywords: Friction compensation, control valves, friction quantification, Knocker, Twomove, CR. 


\section{Lista de Figuras}

1 Válvula de controle com atuador pneumático (ROMANO, 2009) . . . . . p. 27

2 Válvula de controle instrumentada para ensaios. . . . . . . . . . . . p. 28

$3 \quad$ P\&ID da planta piloto de vazão. . . . . . . . . . . . . . p. 30

4 Curva de assinatura padrão de uma válvula sobre efeito do stiction. . . p.32

5 a) Histerese b) Banda morta. . . . . . . . . . . . . . . . . . . p. 33

6 Curva de assinatura do modelo de um parâmetro $\left(d_{m}=4 \%\right)$. . . . . p. 34

7 Algoritmo de decisão do modelo de Kano (KANO et al., 2004) . . . . . . . . p. 35

8 Pressão no atuador das válvulas. . . . . . . . . . . . . . . . . . p. 39

9 Posição da haste. . . . . . . . . . . . . . . . . . . . . . . p. 39

10 Curvas de assinatura das válvulas de teste. . . . . . . . . . . . p. 39

11 Região da curva de assinatura onde deveria ocorrer o slip-jump (gaxetas de grafite). . . . . . . . . . . . . . . . . . p. . . . . . . . . . .

12 Autovalidação dos parâmetros do modelo de Kano (gaxetas de teflon). . p.41

13 Autovalidação dos parâmetros do modelo de Kano (gaxetas de grafite). p.41

14 Validação dos parâmetros do modelo de Kano (gaxetas de teflon). . . . $\quad$ p.42

15 Validação dos parâmetros do modelo de Kano (gaxetas de grafite). . . . p. 42

16 Autovalidação dos parâmetros do modelo de Karnopp (gaxetas de teflon). p. 45

17 Autovalidação dos parâmetros do modelo de Karnopp (gaxetas de grafite). p. 45

18 Validação dos parâmetros do modelo de Karnopp (gaxetas de teflon). p. 45

19 Validação dos parâmetros do modelo de Karnopp (gaxetas de grafite). . p.46

20 Autovalidação dos parâmetros do modelo de Karnopp obtidos por regressão linear (gaxetas de teflon) . . . . . . . . . . . . . . p. 49

21 Autovalidação dos parâmetros do modelo de Karnopp obtidos por regressão linear (gaxetas de grafite) . . . . . . . . . . . . . . . . p. p. 49

22 Validação dos parâmetros do modelo de Karnopp obtidos por regressão linear (gaxetas de teflon). . . . . . . . . . . . . . . p. 49

23 Validação dos parâmetros do modelo de Karnopp obtidos por regressão linear (gaxetas de grafite) . . . . . . . . . . . . p. 50

24 Fluxograma do algoritmo de refinamento da estimação de $S$. . . . . . $\quad$ p.54 
25 Digrama do processo de controle de vazão em malha fechada. . . . . . . p. 56

26 Resposta da válvula com gaxetas de teflon a um degrau de $15 \%$ na entrada. p. 58

27 Resposta da válvula com gaxetas de grafite a um degrau de $15 \%$ na entrada. p. 58

28 Estrutura da malha de controle de vazão com compensador CR . . . . . p. p2

29 Estrutura da malha de controle de vazão com compensador CR2. . . . $\quad$ p.62

30 Saída do compensador Knocker. . . . . . . . . . . . . . . p. p3

31 Algoritmo de desabilitação do controlador (CUADROS, 2011) . . . . . . . p. 65

32 Estrutura da malha de controle de vazão com compensador Two-move modificado. . . . . . . . . . . . . . p. 67

33 Resultados obtidos no ensaio de acompanhamento de set-point da válvula com gaxetas de teflon com controlador PI (sintonia pelo método da Síntese Direta). . . . . . . . . . . . . . . . . . .

34 Resultados obtidos no ensaio de acompanhamento de set-point da válvula com gaxetas de grafite com controlador PI (sintonia pelo método da Síntese Direta) . . . . . . . . . . . . . . . . . . . .

35 Resultados obtidos no ensaio de acompanhamento de set-point da válvula com gaxetas de teflon com controlador PI ( $T_{i}$ aumentado para 12). . . .

36 Resultados obtidos no ensaio de acompanhamento de set-point da válvula com gaxetas de grafite com controlador PI ( $T_{i}$ aumentado para 12). . .

37 Resultados obtidos no ensaio de acompanhamento de set-point da válvula com gaxetas de teflon com controlador PI ( $T_{i}$ aumentado para 16). . . .

38 Resultados obtidos no ensaio de acompanhamento de set-point da válvula com gaxetas de grafite com controlador PI ( $T_{i}$ aumentado para 16). . .

39 Resultados obtidos no ensaio de acompanhamento de set-point da válvula com gaxetas de teflon com compensador CR1 (teflon) . . . . . . . . . p.76

40 Resultados obtidos no ensaio de acompanhamento de set-point da válvula com gaxetas de grafite com compensador CR1. . . . . . . . . . . . .

41 Resultados obtidos no ensaio de acompanhamento de set-point da válvula com gaxetas de teflon com compensador CR2. . . . . . . . . . .

42 Resultados obtidos no ensaio de acompanhamento de set-point da válvula com gaxetas de grafite com compensador CR2 . . . . . . . . . . . .

43 Resultados obtidos no ensaio de acompanhamento de set-point da válvula com gaxetas de teflon com compensador Knocker. . . . . . . . . . . .

44 Resultados obtidos no ensaio de acompanhamento de set-point da válvula com gaxetas de grafite com compensador Knocker. . . . . . . . . . .

45 Resultados obtidos no ensaio de acompanhamento de set-point da válvula com gaxetas de teflon com controlador PI (sintonia por SD) e algoritmo de desabilitação do controle. . . . . . . . . . . . . . . . . . . . 
46 Resultados obtidos no ensaio de acompanhamento de set-point da válvula com gaxetas de grafite com controlador PI (Sintonia SD) e algoritmo de desabilitação do controle. . . . . . . . . . . . . . . . . . . . .

47 Resultados obtidos no ensaio de acompanhamento de set-point da válvula com gaxetas de teflon com controlador PI (sintonia I) e algoritmo de desabilitação do controle. . . . . . . . . . . . . . . . .

48 Resultados obtidos no ensaio de acompanhamento de set-point da válvula com gaxetas de grafite com controlador PI (sintonia I) e algoritmo de desabilitação do controle. . . . . . . . . . . . . . . . . . . . .

49 Resultados obtidos no ensaio de acompanhamento de set-point da válvula com gaxetas de teflon com controlador PI (sintonia II) e algoritmo de desabilitação do controle. . . . . . . . . . . . . . . . . . .

50 Resultados obtidos no ensaio de acompanhamento de set-point da válvula com gaxetas de grafite com controlador PI (sintonia II) e algoritmo de desabilitação do controle. . . . . . . . . . . . . . . . . . . . . .

51 Resultados obtidos no ensaio de acompanhamento de set-point da válvula com gaxetas de teflon com compensador CR1 e algoritmo de desabilitação do controle. . . . . . . . . . . . . . . . . . .

52 Resultados obtidos no ensaio de acompanhamento de set-point da válvula com gaxetas de grafite com compensador CR1 e algoritmo de desabilitação do controle.

53 Resultados obtidos no ensaio de acompanhamento de set-point da válvula com gaxetas de teflon com compensador CR2 e algoritmo de desabilitação do controle. . . . . . . . . . . . . . . . . . . . .

54 Resultados obtidos no ensaio de acompanhamento de set-point da válvula com gaxetas de grafite com compensador CR2 e algoritmo de desabilitação do controle. . . . . . . . . . . . . . . . . . . . .

55 Resultados obtidos no ensaio de acompanhamento de set-point da válvula com gaxetas de teflon com compensador Knocker e algoritmo de desabilitação do controle. . . . . . . . . . . . . . . . .

56 Resultados obtidos no ensaio de acompanhamento de set-point da válvula com gaxetas de grafite com compensador Knocker e algoritmo de desabilitação do controle. . . . . . . . . . . . . . . . . . . . .

57 Resultados obtidos no ensaio de acompanhamento de set-point da válvula com gaxetas de grafite com o compensador Two-move.

58 Resultados obtidos no ensaio para o problema regulatório da válvula com gaxetas de teflon com controlador PI (Sintonia SD). . . . . . . . . . . .

59 Resultados obtidos no ensaio para o problema regulatório da válvula com gaxetas de grafite com controlador PI (Sintonia SD).

60 Resultados obtidos no ensaio para o problema regulatório da válvula com gaxetas de teflon com controlador PI (Sintonia I) . . . . . . . . . . . 
61 Resultados obtidos no ensaio para o problema regulatório da válvula com gaxetas de grafite com controlador PI (Sintonia I) . . . . . . . . . . . .

62 Resultados obtidos no ensaio para o problema regulatório da válvula com gaxetas de teflon com controlador PI (Sintonia II). . . . . . . . . . .

63 Resultados obtidos no ensaio para o problema regulatório da válvula com gaxetas de grafite com controlador PI (Sintonia II) . . . . . . . . . . .

64 Resultados obtidos no ensaio para o problema regulatório da válvula com gaxetas de teflon com compensador CR1. . . . . . . . . . . . .

65 Resultados obtidos no ensaio para o problema regulatório da válvula com gaxetas de grafite com compensador CR1. . . . . . . . . . . .

66 Resultados obtidos no ensaio para o problema regulatório da válvula com gaxetas de teflon com compensador CR2. . . . . . . . . . . .

67 Resultados obtidos no ensaio para o problema regulatório da válvula com gaxetas de grafite com compensador CR2. . . . . . . . . . . . . .

68 Resultados obtidos no ensaio para o problema regulatório da válvula com gaxetas de teflon com compensador Knocker. . . . . . . . . . . . .

69 Resultados obtidos no ensaio para o problema regulatório da válvula com gaxetas de grafite com compensador Knocker. . . . . . . . . . . . .

70 Resultados obtidos no ensaio para o problema regulatório da válvula com gaxetas de grafite com compensador Two-move. . . . . . . . . . .

71 Estrutura das malhas de controle de posição e de vazão em cascata. . .

72 Resultados obtidos no ensaio para o problema servo da válvula com gaxetas de teflon com controlador PI (controle em cascata). . . . . . . . .

73 Resultados obtidos no ensaio para o problema servo da válvula com gaxetas de grafite com controlador PI (controle em cascata). . . . . . . .

74 Resultados obtidos no ensaio para o problema servo da válvula com gaxetas de teflon com compensador CR1 (controle em cascata). . . . . . .

75 Resultados obtidos no ensaio para o problema servo da válvula com gaxetas de grafite com compensador CR1 (controle em cascata). . . . . .

76 Resultados obtidos no ensaio para o problema servo da válvula com gaxetas de teflon com compensador CR2 (controle em cascata). . . . . . .

77 Resultados obtidos no ensaio para o problema servo da válvula com gaxetas de grafite com compensador CR2 (controle em cascata). . . . . .

78 Resultados obtidos no ensaio para o problema servo da válvula com gaxetas de teflon com compensador Knocker (controle em cascata). . . . .

79 Resultados obtidos no ensaio para o problema servo da válvula com gaxetas de grafite com compensador Knocker (controle em cascata). . . .

80 Resultados obtidos no ensaio para o problema servo da válvula com gaxetas de grafite com compensador Two-move (controle em cascata). . . 
81 Oscilações presentes na malha de controle de posição no ensaio para o problema servo da válvula com gaxetas de teflon. . . . . . . . . . . . .

82 Resultados obtidos no ensaio para o problema regulatório da válvula com gaxetas de teflon com controlador PI (controle em cascata). . . . . . . . p. 100

83 Resultados obtidos no ensaio para o problema regulatório da válvula com gaxetas de grafite com controlador PI (controle em cascata). . . . . . .

84 Resultados obtidos no ensaio para o problema regulatório da válvula com gaxetas de teflon e compensador CR1 (controle em cascata). . . . . . .

85 Resultados obtidos no ensaio para o problema regulatório da válvula com gaxetas de grafite e compensador CR1 (controle em cascata). . . . . . .

86 Resultados obtidos no ensaio para o problema regulatório da válvula com gaxetas de teflon e compensador CR2 (controle em cascata). . . . . . .

87 Resultados obtidos no ensaio para o problema regulatório da válvula com gaxetas de grafite e compensador CR2 (controle em cascata). . . . . . .

88 Resultados obtidos no ensaio para o problema regulatório da válvula com gaxetas de teflon e compensador Knocker (controle em cascata). . . . .

89 Resultados obtidos no ensaio para o problema regulatório da válvula com gaxetas de grafite e compensador Knocker (controle em cascata). . . . .

90 Resultados obtidos no ensaio para o problema regulatório da válvula com gaxetas de grafite e compensador Two-move (controle em cascata). . .

91 Resposta da malha de controle de posição no ensaio para o problema servo da válvula com gaxetas de teflon com controlador PI (controle em cascata) . . . . . . . . . . . . . . . . .

92 Resposta da malha de controle de posição no ensaio para o problema servo da válvula com gaxetas de grafite com controlador PI (controle em cascata) . . . . . . . . . . . . . . . . .

93 Resposta da malha de controle de posição no ensaio para o problema servo da válvula com gaxetas de teflon com compensador CR1 (controle em cascata). . . . . . . . . . . . . . . . . . . .

94 Resposta da malha de controle de posição no ensaio para o problema servo da válvula com gaxetas de grafite com compensador CR1 (controle em cascata). . . . . . . . . . . . . . . . . . .

95 Resposta da malha de controle de posição no ensaio para o problema servo da válvula com gaxetas de teflon com compensador CR2 (controle em cascata). . . . . . . . . . . . . . . . . . .

96 Resposta da malha de controle de posição no ensaio para o problema servo da válvula com gaxetas de grafite com compensador CR2 (controle em cascata). . . . . . . . . . . . . . . . . . . . . . . . . 
97 Resposta da malha de controle de posição no ensaio para o problema servo da válvula com gaxetas de teflon com compensador Knocker (controle em cascata). . . . . . . . . . . . . . . . . . .

98 Resposta da malha de controle de posição no ensaio para o problema servo da válvula com gaxetas de grafite com compensador Knocker (controle em cascata). . . . . . . . . . . . . . . . . . . . .

99 Resposta da malha de controle de posição no ensaio para o problema servo da válvula com gaxetas de grafite com compensador Two-move (controle em cascata).

100 Resposta da malha de controle de posição no ensaio para o problema regulatório da válvula com gaxetas de teflon com controlador PI (controle em cascata). . . . . . . . . . . . . . . . . . . .

101 Resposta da malha de controle de posição no ensaio para o problema regulatório da válvula com gaxetas de grafite com controlador PI (controle em cascata) . . . . . . . . . . . . . . . . . . . .

102 Resposta da malha de controle de posição no ensaio para o problema regulatório da válvula com gaxetas de teflon com compensador CR1 (controle em cascata). . . . . . . . . . . . . . . . . .

103 Resposta da malha de controle de posição no ensaio para o problema regulatório da válvula com gaxetas de grafite com compensador CR1 (controle em cascata).

104 Resposta da malha de controle de posição no ensaio para o problema regulatório da válvula com gaxetas de teflon com compensador CR2 (controle em cascata). . . . . . . . . . . . . . . . . . .

105 Resposta da malha de controle de posição no ensaio para o problema regulatório da válvula com gaxetas de grafite com compensador CR2 (controle em cascata).

106 Resposta da malha de controle de posição no ensaio para o problema regulatório da válvula com gaxetas de teflon com compensador Knocker (controle em cascata).

107 Resposta da malha de controle de posição no ensaio para o problema regulatório da válvula com gaxetas de grafite com compensador Knocker (controle em cascata).

108 Resposta da malha de controle de posição no ensaio para o problema regulatório da válvula com gaxetas de grafite com compensador Twomove (controle em cascata). . . . . . . . . . . . . . . . . .

109 Resultados obtidos no ensaio para o problema servo da válvula com gaxetas de grafite com compensador CR1 (considerando erro de $-20 \%$ na estimação de $S$ ).

110 Resultados obtidos no ensaio para o problema servo da válvula com gaxetas de grafite com compensador CR1 (considerando erro de $-10 \%$ na estimação de $S$ ). 
111 Resultados obtidos no ensaio para o problema servo da válvula com gaxetas de grafite com compensador CR1 (considerando erro de $-5 \%$ na estimação de $S$ ). . . . . . . . . . . . . . . . .

112 Resultados obtidos no ensaio para o problema servo da válvula com gaxetas de grafite com compensador CR1 (sem considerar erros na estimação $\operatorname{de} S) \ldots \ldots \ldots \ldots \ldots \ldots \ldots \ldots$

113 Resultados obtidos no ensaio para o problema servo da válvula com gaxetas de grafite com compensador CR1 (considerando erro de $+5 \%$ na estimação de $S)$. . . . . . . . . . . . . . . . . .

114 Resultados obtidos no ensaio para o problema servo da válvula com gaxetas de grafite com compensador CR1 (considerando erro de $+10 \%$ na estimação de $S)$. . . . . . . . . . . . . . . . . . . .

115 Resultados obtidos no ensaio para o problema servo da válvula com gaxetas de grafite com compensador CR1 (considerando erro de $+20 \%$ na

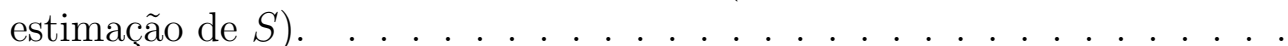

116 Resultados obtidos no ensaio para o problema servo da válvula com gaxetas de grafite com compensador Knocker (considerando erro de $-20 \%$

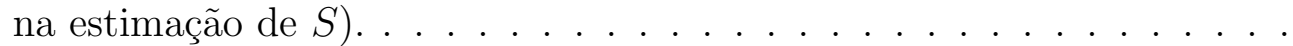

117 Resultados obtidos no ensaio para o problema servo da válvula com gaxetas de grafite com compensador Knocker (considerando erro de $-10 \%$

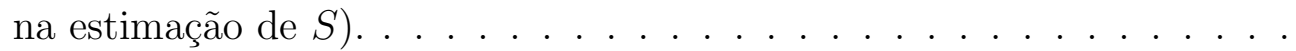

118 Resultados obtidos no ensaio para o problema servo da válvula com gaxetas de grafite com compensador Knocker (considerando erro de $-5 \%$ na estimação de $S) \ldots \ldots \ldots$. . . . . . . . . . . . . . .

119 Resultados obtidos no ensaio para o problema servo da válvula com gaxetas de grafite com compensador Knocker (sem considerar erros na estimação de $S$ ). . . . . . . . . . . . . . . . . . . . .

120 Resultados obtidos no ensaio para o problema servo da válvula com gaxetas de grafite com compensador Knocker (considerando erro de $+5 \%$ na estimação de $S) \ldots \ldots \ldots \ldots \ldots \ldots$

121 Resultados obtidos no ensaio para o problema servo da válvula com gaxetas de grafite com compensador Knocker (considerando erro de $+10 \%$

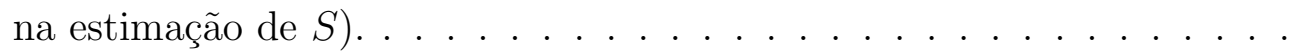

122 Resultados obtidos no ensaio para o problema servo da válvula com gaxetas de grafite com compensador Knocker (considerando erro de $+20 \%$

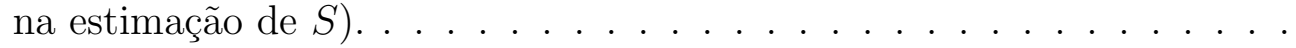




\section{Lista de Tabelas}

1 Resultados obtidos pelo método de identificação de Kano. . . . . . . . . . p.41

2 Resultados obtidos pelo método de identificação de Garcia (2007). . . . p. 44

3 Resultados obtidos pelo método de identificação de Romano (2009). . . p. 48

4 Resultados das identificações dos parâmetros de atrito. . . . . . . . . . p. 52

5 Resultados do refinamento dos valores identificados de $S \ldots \ldots$. . . . . 53

6 Resultados do refinamento dos valores identificados de $J$. . . . . . . . $\quad$ p. 55

7 Constantes identificadas do modelo de primeira ordem do processo. . . $\quad$ p.57

8 Sintonias obtidas pelo método da Síntese Direta para o controlador PI. p.61

9 Índices de desempenho dos ensaios de acompanhamento de set-point com sintonias diferentes do controlador (válvula com gaxetas de teflon). . . p. p.75

10 Índices de desempenho dos ensaios de acompanhamento de set-point com sintonias diferentes do controlador (válvula com gaxetas de grafite). . .

11 Índices de desempenho dos ensaios de acompanhamento de set-point com os compensadores de atrito (válvula com gaxetas de teflon) . . . . . . p. 78

12 Índices de desempenho dos ensaios de acompanhamento de set-point com os compensadores de atrito (válvula com gaxetas de grafite) . . . . . .

13 Índices de desempenho dos ensaios de acompanhamento de set-point com os compensadores de atrito e algoritmo de desabilitação do controle (válvula com gaxetas de teflon). . . . . . . . . . . . . . . .

14 Índices de desempenho dos ensaios de acompanhamento de set-point com os compensadores de atrito e algoritmo de desabilitação do controle (válvula com gaxetas de grafite). . . . . . . . . . . . . . .

15 Índices de desempenho dos ensaios de acompanhamento de set-point (válvula com gaxetas de teflon). . . . . . . . . . . . . . . . .

16 Índices de desempenho dos ensaios de acompanhamento de set-point (válvula com gaxetas de grafite). . . . . . . . . . . . p. 85

17 Índices de desempenho dos ensaios para o problema regulatório com sintonias diferentes do controlador (válvula com gaxetas de teflon). . . . .

18 Índices de desempenho dos ensaios para o problema regulatório com sintonias diferentes do controlador (válvula com gaxetas de grafite). . . . $\quad$ p. 88

19 Índices de desempenho dos ensaios para o problema regulatório (teflon). p.91

20 Índices de desempenho dos ensaios para o problema regulatório (grafite). p. 92 
21 Sintonias obtidas pelo método da Síntese Direta para o controlador PI de posição (controle em cascata). . . . . . . . . . . . . . p. p. . . . .

22 Sintonias obtidas pelo método da Síntese Direta para o controlador PI de vazão (controle em cascata). . . . . . . . . . . . . . p. p. 94

23 Índices de desempenho dos ensaios de acompanhamento de set-point com a estrutura de controle em cascata (válvula com gaxetas de teflon). . p.99

24 Índices de desempenho dos ensaios de set-point com a estrutura de controle em cascata (válvula com gaxetas de grafite) . . . . . . . . . . p. 100

25 Índices de desempenho dos ensaios para o problema regulatório com a estrutura de controle em cascata (válvula com gaxetas de teflon). . . . p. 104

26 Índices de desempenho dos ensaios para o problema regulatório com a estrutura de controle em cascata (válvula com gaxetas de grafite). . . . p. p.104

27 Índices de desempenho dos ensaios de robustez do compensador CR1. . p. 105

28 Índices de desempenho dos ensaios de robustez do compensador Knocker. p. 106 


\section{Lista de Símbolos}

\begin{tabular}{|c|c|}
\hline Símbolo & Descrição \\
\hline$d_{m}$ & $\begin{array}{l}\text { Banda de agarramento \Slip-jump } \quad \text { (modelo de um } \\
\text { parâmetro) }\end{array}$ \\
\hline$S$ & Banda morta mais banda de agarramento \\
\hline$J$ & Banda de agarramento \Slip-jump \\
\hline$s t p$ & Hasta da válvula parada (1) ou em movimento (0) \\
\hline$d$ & Direção do movimento da haste \\
\hline$u_{s}$ & $\begin{array}{l}\text { Amplitude do sinal de entrada do modelo da válvula } \\
\text { quando a haste parou de se mover pela última vez }\end{array}$ \\
\hline$m$ & Massa das partes móveis da válvula \\
\hline$F_{\text {pressão }}$ & Força aplicada pela pressão de ar no atuador da válvula \\
\hline$S_{a}$ & Área do diafragma do atuador da válvula \\
\hline$P$ & Pressão de ar do atuador da válvula \\
\hline$F_{\text {mola }}$ & Força aplicada pela mola \\
\hline$K$ & Constante de elasticidade da mola \\
\hline$x$ & posição da haste da válvula \\
\hline$F_{\text {atrito }}$ & Força de atrito atuando na haste da válvula \\
\hline$F_{\text {fluido }}$ & $\begin{array}{l}\text { Força aplicada pelo fluido do processo sobre o obturador } \\
\text { da haste }\end{array}$ \\
\hline$F_{i}$ & Força de assentamento do obturador na sede da válvula \\
\hline$v$ & Velocidade da haste \\
\hline$D V$ & $\begin{array}{l}\text { Mínimo módulo da velocidade para que se considera que } \\
\text { a haste está se movendo (modelo de Karnopp) }\end{array}$ \\
\hline$F_{\text {dinâmico }}$ & Força de atrito dinâmico \\
\hline$F_{e}$ & $\begin{array}{l}\text { somatório das forças externas atuando na haste da } \\
\text { válvula }\end{array}$ \\
\hline$F_{S}$ & Força de atrito estático máximo \\
\hline$F_{C}$ & Força de atrito de Coulomb \\
\hline$F_{v}$ & Coeficiente da força de atrito viscoso \\
\hline$v_{S}$ & Velocidade de Stribeck \\
\hline$\epsilon$ & $\begin{array}{l}\text { Variação máxima entre duas amostras consecutivas da } \\
\text { posição da haste em que se considera que não ocorreu } \\
\text { movimentação }\end{array}$ \\
\hline$\tilde{u}$ & $\begin{array}{l}\text { Máxima variação da entrada da válvula em um intervalo } \\
\text { em que a mesma estava parada }\end{array}$ \\
\hline$\tilde{x}$ & $\begin{array}{l}\text { Máxima variação da saída da válvula em um intervalo } \\
\text { em que a mesma estava parada }\end{array}$ \\
\hline
\end{tabular}




\begin{tabular}{|c|c|}
\hline Símbolo & Descrição \\
\hline$\epsilon_{u}$ & $\begin{array}{l}\text { Valor mínilo de } \tilde{u} \text { para que se considere aue a válvula } \\
\text { estava parada devido ao stiction }\end{array}$ \\
\hline$\epsilon_{x}$ & $\begin{array}{l}\text { Valor máximo de } \tilde{x} \text { para que se considere aue a válvula } \\
\text { estava parada devido ao stiction }\end{array}$ \\
\hline$\rho$ & $\begin{array}{l}\text { Índice que aponta a probabilidade do processo estar } \\
\text { sendo afetado pelo stiction }\end{array}$ \\
\hline$\theta_{p}$ & Vetor de variáveis do modelo que serão estimadas \\
\hline$\varphi$ & Vetor de regressão \\
\hline$\delta v$ & $\begin{array}{l}\text { Valor de } D V \text { que será utilizados na identificação do mo- } \\
\text { delo da válvula }\end{array}$ \\
\hline$R^{2}$ & $\begin{array}{l}\text { Coeficiente de correlação entre o vetor de posição da } \\
\text { haste simulado e real }\end{array}$ \\
\hline$a m p$ & $\begin{array}{l}\text { Amplitude do degrau a ser utilizado nos ensaios do } \\
\text { método de refinamento das estimativas }\end{array}$ \\
\hline$h$ & $\begin{array}{l}\text { Precisão desejada para o método de refinamento das es- } \\
\text { timativas }\end{array}$ \\
\hline$H$ & $\begin{array}{l}\text { Define a região de busca do método de refinamento das } \\
\text { estimativas }\end{array}$ \\
\hline passo & $\begin{array}{l}\text { Região de busca na iteração atual do algoritmo do } \\
\text { método de refinamento das estimativas }\end{array}$ \\
\hline$G_{c}$ & Função de transferência do controlador \\
\hline$N$ & Função descritiva do stiction \\
\hline$G_{p}$ & Função de transferência do processo \\
\hline$U_{c}$ & Magnitude da harmônica da saída do controlador \\
\hline$K_{p}$ & Ganho do processo \\
\hline$\tau$ & Constante de tempo do processo \\
\hline$\theta$ & Tempo morto do processo \\
\hline$K_{c}$ & Ganho do controlador \\
\hline$T_{i}$ & Tempo de integração do controlador \\
\hline$G_{M F}$ & Função de transferência do processo em malha fechada \\
\hline$\theta_{M F}$ & Tempo morto do processo em malha fechada \\
\hline$\tau_{M F}$ & $\begin{array}{l}\text { Constante de tempo desejada do processo em malha fe- } \\
\text { chada }\end{array}$ \\
\hline$u_{k}$ & Saída do compensador \\
\hline$m v$ & Sinal de controle enviado para a válvula \\
\hline$e$ & Erro da variável controlada \\
\hline$a$ & Amplitude dos pulsos do compensador Knocker \\
\hline$\tau_{k}$ & Duração dos pulsos do compensador Knocker \\
\hline$h_{k}$ & Período entre os pulsos do compensador Knocker \\
\hline$\delta_{1}$ & $\begin{array}{l}\text { Valor máxima da derivada de } e \text { para que o controle seja } \\
\text { desabilitado }\end{array}$ \\
\hline$\delta_{2}$ & Erro mínimo para que o controle não seja habilitado \\
\hline$\delta$ & Erro aceitável para a variável controlada \\
\hline$D_{v}$ & Índice da variabilidade da posição da haste da válvula \\
\hline$D_{I P}$ & Índice da variabilidade da pressão no atuador da válvula \\
\hline$t_{r}$ & Tempo de subida \\
\hline
\end{tabular}




\section{Lista de Abreviações}

\begin{tabular}{ll}
\hline \multicolumn{1}{c}{ Abreviação } & \multicolumn{1}{c}{ Descrição } \\
\hline CLP & Controlador Lógico Programável \\
SDCD & Sistema Digital de Controle Distribuído \\
ITAE & Integral Time Absolute Error \\
CR & Constant Reinforcement \\
PID & Proporcional Integral Derivativo \\
P\&ID & Piping and Instrumentation Diagram \\
IP & Corrente para pressão \\
BM & Banda Morta \\
ADC & Algoritmo de Desabilitação do Controle
\end{tabular}




\section{Sumário}

1 Introdução $\quad$ p. 19

1.1 Motivação . . . . . . . . . . . . . . . . . . . . . . . p. 19

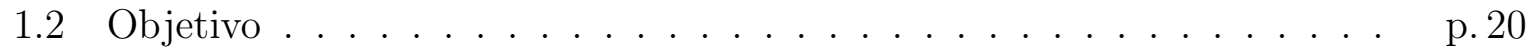

1.3 Revisão da Literatura . . . . . . . . . . . . . . . . . . p. 21

1.4 Estrutura do trabalho . . . . . . . . . . . . . . . p. 24

2 A planta Experimental e Equipamentos em Teste p. 26

2.1 Válvulas de controle com atuador pneumático . . . . . . . . . . . p. 26

2.2 Planta piloto de vazão . . . . . . . . . . . . . . . . . . . p. 28

3 Análise e Quantificação do Stiction p. 31

3.1 Definição do stiction . . . . . . . . . . . . . . . . . . p. 31

3.2 Modelagem do stiction . . . . . . . . . . . . . . . . . . p. 33

3.2 .1 Modelos empíricos . . . . . . . . . . . . . p. 33

3.2 .2 Modelo físico . . . . . . . . . . . . . . . . p. 35

3.3 Quantificação do stiction . . . . . . . . . . . . . . . . . . . p. 38

3.3.1 Estimação dos parâmetros do modelo de Kano . . . . . . . . . p. p.40

3.3.2 Estimação dos parâmetros do modelo de Karnopp . . . . . . . . p. 42

3.3.2.1 Identificação por avaliação do balanço de forças . . . . p. 43

3.3.2.2 Identificação por regressão linear . . . . . . . . . . p. 46

3.4 Conversão dos parâmetros . . . . . . . . . . . . p. p . 50

3.5 Proposta para refinamento das estimativas dos parâmetros de atrito . . p.52

4 Compensação do Atrito p. 56

4.1 Efeito do atrito na malha de controle . . . . . . . . . . p. 56

4.2 Sintonia do Controlador PI . . . . . . . . . . . . . . . . p. 59

4.3 Métodos de compensação . . . . . . . . . . . . . . . . p. 61

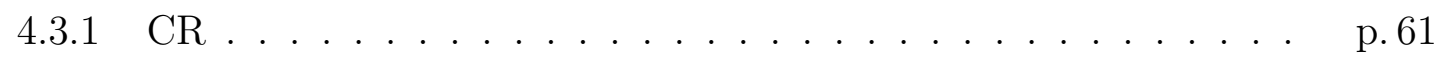




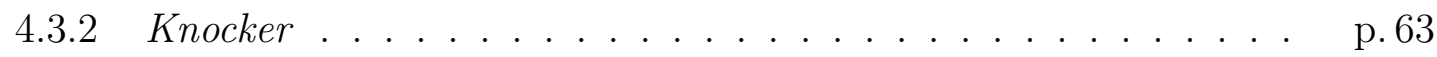

4.3.3 Algoritmo de desabilitação do controle . . . . . . . . . . . . p. 64

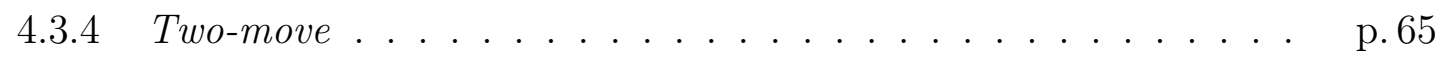

5 Resultados Experimentais $\quad$ p. 70

5.1 Compensadores atuando no controle de vazão . . . . . . . . . . . . . p.71

5.1.1 Ensaios para o problema servo . . . . . . . . . . p. 71

5.1.2 Ensaios para o problema regulatório . . . . . . . . p. 85

5.2 Compensadores atuando no controle de posição . . . . . . . . . . . . . p.92

5.2.1 Ensaios para o problema servo . . . . . . . . . . p. 94

5.2.2 Ensaios para o problema regulatório . . . . . . . . . p. 100

5.3 Ensaios de robustez dos compensadores . . . . . . . . . . . . . p. 104

6 Conclusões $\quad$ p. 107

6.1 Modelos de atrito em válvulas de controle e identificação de parâmetros de atrito . . . . . . . . . . . . . . . . . . p. 107

6.2 Análise dos compensadores de atrito atuando na malha de controle de vazão . . . . . . . . . . . . . . . . . . . . p. 108

6.3 Análise dos compensadores de atrito atuando na malha de controle de posição em cascata com a malha de controle de vazão . . . . . . . . . . p.110

6.4 Robustez dos compensadores . . . . . . . . . . . . . . p. 110

6.5 Proposta de trabalhos futuros . . . . . . . . . . . . p. 111

Anexo A - Resposta da malha de controle de posição na estrutura de $\begin{array}{lr}\text { controle em cascata } & \text { p. } 112\end{array}$

A.1 Ensaios de acompanhamento de set-point . . . . . . . . . . . . p. 112

A.2 Ensaios para o problema regulatório . . . . . . . . . . p. 116

Anexo B - Gráficos dos ensaios de robustez do compensador CR1 p. 120

Anexo C - Gráficos dos ensaios de robustez do compensador Knocker p. 123

$\begin{array}{lr}\text { Referências Bibliográficas } & \text { p. } 126\end{array}$ 


\section{Introdução}

\subsection{Motivação}

O atrito estático é um fenômeno muito comum em atuadores com partes móveis. Como consequência, qualquer processo que utilize estes elementos estará sujeito a uma redução do desempenho na malha de controle. Um equipamento de alta qualidade e bom estado de conservação apresenta baixo índice de atrito, portanto não prejudica o controle em malha fechada. Porém, a tendência ao longo dos anos é o índice de atrito aumentar devido ao desgaste das peças, implicando em perda de produtividade, decréscimo na qualidade do produto ou aumento do custo de produção. Na literatura esta não linearidade é denominada stiction (static friction).

No âmbito das válvulas de controle, no qual este trabalho foi desenvolvido, Srinivasan e Rengaswamy (2005) afirmam que 90\% destes equipamentos possuem atuadores pneumáticos. Ainda neste trabalho os autores apontam que $20 \%$ a $30 \%$ das malhas de controle oscilam devido à presença de stiction ou histerese nas válvulas. Estes dados estão de acordo com os apresentados por Hägglund (2002), que menciona que 30\% das malhas de controle auditadas em uma indústria de papel canadense apresentavam variabilidade devido à não linearidade nas válvulas de controle. Em (CHOUDHURY; THORNHILL; SHAH, 2005) é ressaltado que uma pequena melhora na eficiência energética ou na manutenção dos controladores pode acarretar em uma economia de centenas de milhares de dólares para as indústrias de processo, o que evidencia o impacto do fenômeno descrito anteriormente. A correta manutenção dos equipamentos é a melhor atitude a ser tomada, porém, novamente de acordo com Srinivasan e Rengaswamy (2005), as paradas programadas de uma planta ocorrem em média entre um período de seis meses a três anos de operação. Isto implica que muitas vezes será necessário operar com um equipamento em condições inadequadas. Portanto, malhas de controle oscilando devido à não linearidades em válvulas de controle não apenas são situações comuns na indústria, mas também geram perdas para a mesma, justificando o tema deste trabalho. 
A deteção e quantificação do atrito são temas muito presentes na literatura. A quantificação, em particular, é necessária para definir os parâmetros dos compensadores, como é visto mais adiante. Além disso, a quantificação de atrito serve para averiguar quando há a necessidade de realizar manutenção em válvulas atuando em um processo, o que, conforme (CHOUDHURY et al., 2006), diminui o custo de manutenção da malha de controle. Os mesmos autores separam os métodos para mensurar o atrito em duas categorias: métodos invasivos e métodos não invasivos. Na primeira categoria é necessário assumir o controle da malha para enviar sinais específicos à válvula, o que significa que é necessário parar o processo de produção. A segunda categoria, por sua vez, utiliza dados históricos do sinal de controle e da variável controlada, portanto o processo pode continuar operando normalmente. Neste trabalho são usados métodos da primeira categoria e se empregam as medidas da posição da haste e pressão no atuador da válvula de controle para estimar o atrito na mesma. Certamente esses métodos têm pouco valor prático, pois essas variáveis normalmente não são medidas em válvulas de controle, mas fornecem uma estimação mais exata, permitindo uma avaliação precisa dos compensadores de atrito.

\subsection{Objetivo}

O objetivo proposto é avaliar o desempenho de três compensadores de atrito, que não utilizam modelos da válvula, em uma malha de controle de vazão. O primeiro método foi proposto em (HÄGGLUND, 2007) e se resume em adicionar um valor constante ao sinal de controle. Posteriormente, Ivan e Lakshminarayanan (2009) propuseram uma versão levemente modificada desta técnica e a batizaram de Constant Reinforcement (CR). A segunda técnica, chamada de Knocker, foi proposta por Hägglund (2002), porém foi em (SRINIVASAN; RENGASWAMY, 2005) que se determinou como sintonizar a técnica proposta a partir de uma estimação do atrito estático. A última técnica, proposta em (ELY; LONGHI, 2011), é uma variante do método Two-move, proposto por Srinivasan e Rengaswamy (2008) para remover a variabilidade do sistema em malha fechada.

Para aumentar o desempenho obtido pelos dois primeiros compensadores citados anteriormente, Cuadros (2011) propôs um algoritmo que desabilita a ação do controlador e dos compensadores, caso a variável controlada estabilize próximo ao valor de referência. O desempenho dos compensadores atuando em conjunto com este algoritmo também é avaliado, assim como o desempenho do algoritmo sem compensadores.

Segundo Mohammad e Huang (2012), para processos simples, de primeira ou segunda ordem, é possível minimizar, ou até eliminar, as oscilações provocadas pela presença do stiction em uma malha de controle, apenas definindo uma sintonia adequada para o con- 
trolador. Os autores estimaram, para diversos casos, como se deve realizar tal sintonia. Os resultados obtidos por esta técnica também são verificados neste trabalho.

Os compensadores e o controlador PID são implementados no ambiente Simulink do Matlabß. A partir de uma placa de aquisição de dados e envio de sinais analógicos, é possível receber os sinais medidos em campo e enviar o sinal de comando para a válvula. As técnicas previamente mencionadas são testadas e seus desempenhos são avaliados, levando em consideração não apenas a integral do erro absoluto vezes o tempo, mas também a variabilidade induzida na posição da haste de válvula e na pressão no atuador pneumático e o tempo de subida do sistema. Também foram realizados testes utilizando os compensadores como posicionadores, ou seja, atuando em um controlador PID que controla a posição da haste da válvula. O set-point deste controlador nesta malha em cascata é proveniente de um outro controlador PID, cuja variável controlada é a vazão.

\subsection{Revisão da Literatura}

O atrito é um assunto muito frequente na literatura. Ao longo dos anos, diversos modelos foram propostos para este fenômeno. Em (OLSSON, 1996) foi apresentada uma coletânea destes modelos, datados desde 1947 até a data do trabalho. Todos os modelos mencionados são baseados em uma análise fenomenológica do atrito, porém, mais recentemente, novos modelos foram criados baseados na relação entrada-saída de uma válvula de controle. O primeiro desses métodos foi introduzido em (STENMAN; GUSTAFSSON; FORSMAN, 2003), onde foi proposto um modelo empírico com apenas um parâmetro. Posteriormente (CHOUDHURY; THORNHILL; SHAH, 2005), (KANO et al., 2004) e (HE et al., 2007) apresentaram novos modelos, cada um com dois parâmetros.

Diante de uma gama tão grande de opções, Garcia (2008) selecionou oito modelos para realizar uma comparação de desempenho, sendo eles: modelo de Tustin (1975), modelo de Karnopp (1985), modelo dos sete parâmetros (ARMSTRONG-HÉLOUVRY, 1991), modelo de Lugre (WIT et al., 1995), modelo de um parâmetro (STENMAN; GUSTAFSSON; FORSMAN, 2003), modelo de Choudhury, Thornhill e Shah (2005), modelo de Kano et al. (2004) e modelo de He et al. (2007). A conclusão do trabalho foi que os modelos de Karnopp, Lugre e Kano são os que melhor representam o atrito em uma válvula de controle, pois foram aprovados em todos os testes realizados. Neste trabalho foram selecionados um modelo físico e um modelo empírico para o atrito, sendo eles o modelo de Karnopp, por ser mais simples que o de Lugre, e o modelo de Kano. 
Diversos trabalhos com o objetivo de detectar a presença do atrito estático em malhas de controle foram propostos. Em (HORCH, 1999) foi proposta uma técnica para detectar a presença do atrito estático a partir da correlação cruzada entre o sinal de controle e a saída do processo. Porém, este método é restrito a processos não integradores. Por esse motivo, em (HORCH, 2000) a técnica foi aprimorada para permitir a detecção também em processos integradores. Posteriormente, Rossi e Scali (2004) desenvolveram um método chamado de teste do relé, onde se aproxima a variável controlada por uma onda quadrada, triangular ou senoidal. Em (CHOUDHURY; SHAH; THORNHILL, 2004) foi proposta uma técnica baseada em estatística de alta ordem.

Um método simples para estimar os parâmetro do modelo de Karnopp foi apresentado em (GARCIA, 2007). A proposta analisa a resposta da válvula a um sinal triangular e seleciona pontos em que, de acordo com a estrutura do modelo, seja possível calcular os parâmetros individualmente. Em (RAVANBOD-SHIRAZI; BESANÇON-VODA, 2003) foi proposto outro método para quantificar os parâmetros do modelo de Karnopp, baseado em uma regressão linear. Originalmente o método estimava apenas dois dos três parâmetros do modelo, por isso em (ROMANO; GARCIA, 2007) o método foi aplicado a válvulas de controle e uma metodologia para estimar o terceiro parâmetro foi incluída, a partir de pontos em que a válvula está para iniciar seu movimento. Ambos os métodos necessitam de medidas da pressão no atuador e posição da haste, porém, o segundo pode ser aplicado à dados históricos. As duas propostas foram comparadas em (ROMANO; GARCIA, 2007) e apresentaram resultados semelhantes.

Diversas propostas foram feitas para o cálculo dos parâmetros do modelo de Kano. Em sua maioria as técnicas são desenvolvidas considerando dados históricos da variável manipulada e da variável controlada, ou seja, dados facilmente acessados em uma planta industrial. Neste trabalho, o primeiro método proposto em (KANO et al., 2004) foi utilizado considerando a pressão no atuador e a posição da haste, eliminando, desta forma, os efeitos das dinâmicas do processo e do conversor I/P, assim como possíveis perturbações.

Em (UEHARA, 2009) o método citado anteriormente foi avaliado, juntamente com o método de detecção e quantificação de atrito em válvulas de controle propostos em (CHOUDHURY et al., 2006) e o método descrito em (HÄGGLUND, 2007). O último pode ser aplicado a válvulas de controle somente se for considerado que esta não-linearidade insere apenas uma banda morta no processo. Choudhury, Jain e Shah (2008) propuseram um método para identificar os parâmetros de atrito e o modelo do processo simultaneamente. Posteriormente, Romano e Garcia (2009) apresentaram uma extensão deste método. Jelali (2008), por sua vez, apresentou um método para quantificação do atrito a partir de 
uma otimização global. Uma proposta mais recente foi apresentada em (CUADROS, 2011) para detecção e quantificação do atrito.

Os primeiros métodos para compensar o efeito do atrito em uma malha de controle, como os métodos citados em (ARMSTRONG-HÉLOUVRY; DUPONT; WIT, 1994), eram baseados em sinais de alta frequência. Mais recentemente foram apresentadas metodologias específicas para a aplicação desejada. Em (KAYIHAN; DOYLE III, 2000) a técnica de linearização entrada-saída (IOL) foi aplicada a válvulas de controle. Como o próprio nome sugere, a ideia do compensador é, a partir de um modelo do atuador e suas não-linearidades, tornar a relação entre a entrada e a saída linear. Os testes realizados por Gury (2008) apontaram este método como um dos compensadores de melhor desempenho. Porém, este método necessita de um modelo interno da válvula, o que dificulta sua implementação em um CLP ou SDCD. Além disso, é necessária a medição da posição da haste, o que não é comum na indústria. Por estes motivos, o método citado não é objeto de estudo neste trabalho.

Em (HÄGGLUND, 2002) foi apresentado um método mais simples para compensar o efeito do stiction. A proposta se resume a adicionar pulsos ao sinal de controle, porém a escolha correta da amplitude, período e largura do pulso são de extrema importância. Segundo o autor, os pulsos do compensador ideal devem fornecer apenas a energia suficiente para superar o atrito. Porém, como não é possível saber exatamente esta valor, os pulsos devem fornecer uma pequena quantidade de energia. Desta forma, quando o compensador atua em conjunto com um compensador com ação integral, após algum tempo os pulsos irão gerar pequenos movimentos na haste. Posteriormente, em (SRINIVASAN; RENGASWAMY, 2005) foi proposta uma sintonia deste compensador a partir do modelo de um parâmetro.

Um estudo sobre o efeito do backlash em malhas de controle foi apresentado em (HÄGGLUND, 2007). A consequência deste fenômeno é a inserção de uma banda morta no sistema, o que também é uma das consequências do atrito estático em atuadores. Para compensar este efeito, o autor propôs que sempre que houver uma mudança de direção do sinal de controle, o mesmo realize um salto para superar a banda morta. Uma proposta muito semelhante foi apresentada em (IVAN; LAKSHMINARAYANAN, 2009), onde o compensador foi nomeado como Reforço Constante (CR) e foi desenvolvido com base no modelo proposto por Kano.

Os compensadores mencionados anteriormente apresentam um mesmo inconveniente: 
inserem uma alta variabilidade no atuador pneumático. Isto pode causar redução da vida útil do equipamento. Levando em conta este fator, em (SRINIVASAN; RENGASWAMY, 2008) é proposto um compensador para remover a variabilidade da variável controlada, sem aumentar a variabilidade do sinal de controle. O método é chamado de Two-Move, pois leva a haste até a posição de equilíbrio da variável controlada em dois movimentos. Porém, esta posição é considerada conhecida, assim como o nível do sinal de controle que mantém a haste nesta posição. Estes dados normalmente não são conhecidos e muitas vezes, devido a perturbações, não são únicos.

Baseados no compensador anterior, Ely e Longhi (2011) desenvolveram um novo método de compensação. Este método consiste na análise da saída do controlador. Se este sinal estiver variando lentamente, significa que são necessários pequenos ajustes na posição da haste da válvula. Nesta situação se aplica o mesmo princípio do compensador Two-Move para gerar uma pequena movimentação. Porém, neste método não são necessários os dados de posição da haste e sinal de controle que estabilizam o processo. Por esse motivo, esta variante foi utilizada neste trabalho.

Em (CUADROS, 2011) foi proposto um algoritmo para interromper o controlador e o compensador Knocker, uma vez que a variável controlada esteja estabilizada próxima do set-point. Desta forma, a variabilidade introduzida no atuador é minimizada, pois neste ponto os pulsos não são mais necessários. Apesar do algoritmo ter sido aplicado ao compensador Knocker, o autor aponta que também poderia ser utilizado em conjunto com o compensador CR.

Diversas abordagens utilizando técnicas de controle não lineares foram avaliadas em (BAEZA, 2013). Os métodos necessitam de um modelo interno da válvula para compensar o efeito do atrito no controle de posição da haste. Por este motivo, não foram incluídos neste trabalho.

\subsection{Estrutura do trabalho}

O Capítulo 2 deste trabalho apresenta o laboratório onde foram realizados todos os experimentos, assim como os equipamentos utilizados. Além disso, o funcionamento de uma válvula de controle pneumática é descrito neste capítulo. O Capítulo 3, por sua vez, apresenta a definição do termo stiction e fornece uma explicação mais detalhada de seu efeito em uma válvula de controle. Também são selecionados modelos para representar 
este fenômeno e são utilizados métodos da literatura para identificar seus parâmetros. No final do capítulo é proposto um método para refinar as estimações obtidas.

Os compensadores de atritos utilizados neste trabalho são detalhados no Capítulo 4. Os ensaios realizados e resultados obtidos estão no Capítulo 5. Neste capítulo também são feitas diversas análises sobre os resultados. Por fim, o Capítulo 6 contém as conclusões do trabalho e propostas para trabalhos futuros. 


\section{A planta Experimental e Equipamentos em Teste}

A primeira seção deste capítulo descreve o funcionamento das válvulas de controle e por que estão sujeitas ao efeito do atrito. A seguir o ambiente de testes é apresentado. Todos os ensaios deste trabalho foram realizados na planta piloto de vazão do Laboratório de Controle de Processos Industriais (LCPI). O laboratório pertence ao Departamento de Engenharia de Telecomunicações e Controle da Escola Politécnica da Universidade de São Paulo.

\subsection{Válvulas de controle com atuador pneumático}

Válvulas de controle com atuadores pneumáticos são equipamentos muito comuns na indústria em geral. Estes dispositivos são utilizados para controlar a vazão de determinado fluido por uma tubulação, porém a sua aplicação se estende a diversos tipos de malhas de controle. Por exemplo, é possível controlar o nível de um tanque atuando na vazão de líquido entrando ou saindo do mesmo ou controlar a temperatura de um fluido através da vazão de vapor fornecida a um trocador de calor.

A Figura 1 retrata os elementos de um válvula de controle com atuador pneumático. O corpo da válvula é onde ocorre a interação com o fluido do processo. Um obturador está fixado na ponta de uma haste móvel e, conforme a posição desta haste se move em relação à sede da válvula, aumenta ou diminui a perda de carga, alterando portanto a vazão que está fluindo pelo equipamento. A posição da haste, por sua vez, é alterada pelo atuador. A pressão inserida no atuador gera uma força no diafragma, que tende a empurrar a haste, e por sua vez uma mola gera uma força contrária. Para cada valor de pressão dentro do limite de operação, as forças se anulam em uma posição diferente, garantindo que a posição da haste varie de forma linear com relação à pressão no atuador (ROMANO, 2009). 


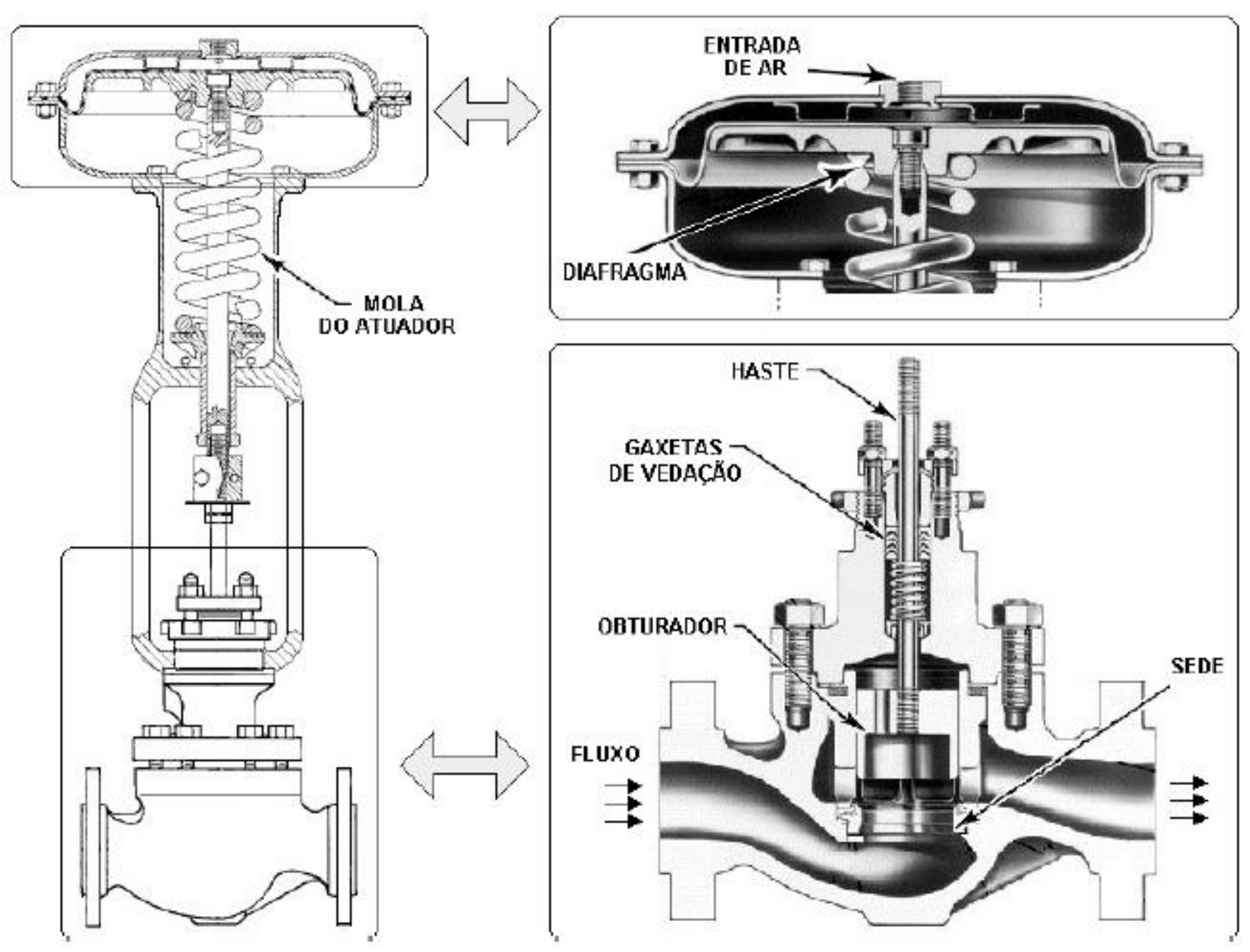

Figura 1: Válvula de controle com atuador pneumático (ROMANO, 2009).

Para permitir a passagem da haste da válvula para dentro do seu corpo, existe um orifício no mesmo, normalmente na parte superior. Portanto, para impedir que o fluido do processo saia por esse orifício, são inseridos anéis de vedação, também chamados de gaxetas. Estes elementos estão em contato com a haste, gerando portanto atrito entre os dois.

Neste trabalho são usadas duas válvulas de teste, de mesmo modelo, mas com gaxetas de materiais diferentes. Uma das válvulas possui gaxetas de teflon enquanto a outro possui gaxetas de grafite, elemento indicado para operar com fluidos em altas temperaturas. Em temperatura ambiente as gaxetas de grafite apresentam um alto índice de atrito, portanto a válvula com gaxetas desse material irá representar um instrumento com necessidade de manutenção. 


\subsection{Planta piloto de vazão}

A planta piloto de vazão se resume a um circuito fechado de vazão de água à temperatura ambiente, com equipamentos industriais para ensaios de válvulas de controle. Uma bomba, com um inversor de frequência para controlá-la, bombeia água de uma caixa d'água por um circuito de PVC de $60 \mathrm{~mm}$ de diâmetro nominal. Como mencionado na seção anterior, existem duas válvulas de controle nesta linha, cada uma com gaxetas de material diferentes. Uma terceira válvula é usada apenas para gerar perturbações.

A pressurização do atuador é realizada por um conversor I/P, que converte um sinal de 4-20 mA para um sinal de 6-30 psi. Uma segunda opção é operar as válvulas por meio de posicionadores digitais. Além disso, cada válvula de teste possui um medidor de pressão relativa no atuador e um medidor de posição da haste. A vazão na linha é medida por uma placa de orifício. A Figura 2 mostra uma das válvulas de teste com a instrumentação instalada, que consiste de: 1- Sensor de pressão, 2- Válvula para seleção entre o posicionador e o conversor IP, 3- Sensor de posição, 4- Conversor IP e 5- Posicionador digital.

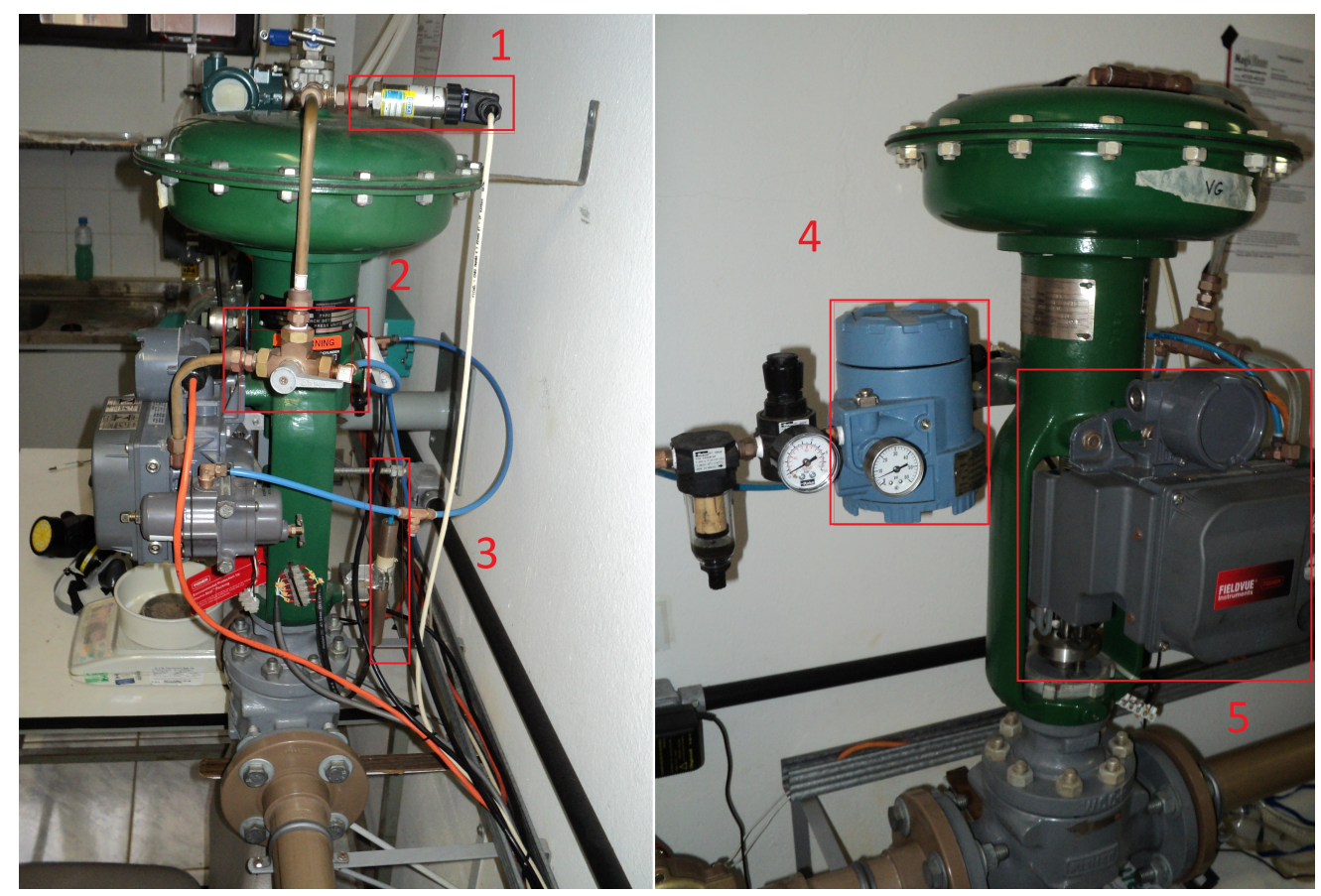

Figura 2: Válvula de controle instrumentada para ensaios.

O controle da planta pode ser implementado em dois ambientes diferentes. Uma placa de aquisição de dados realiza a interface entre um computador e os instrumentos de campo. O driver deste equipamento permite que todas as variáveis analógicas de entrada e saída sejam acessadas diretamente pelo ambiente Simulink do Matlabß. Por se tratar 
de uma ferramenta com diversos recursos e fácil manuseio, as lógicas de controle são implementadas e testadas neste ambiente. O diagrama P\&ID da Figura 3 retrata a planta e seus instrumentos. 


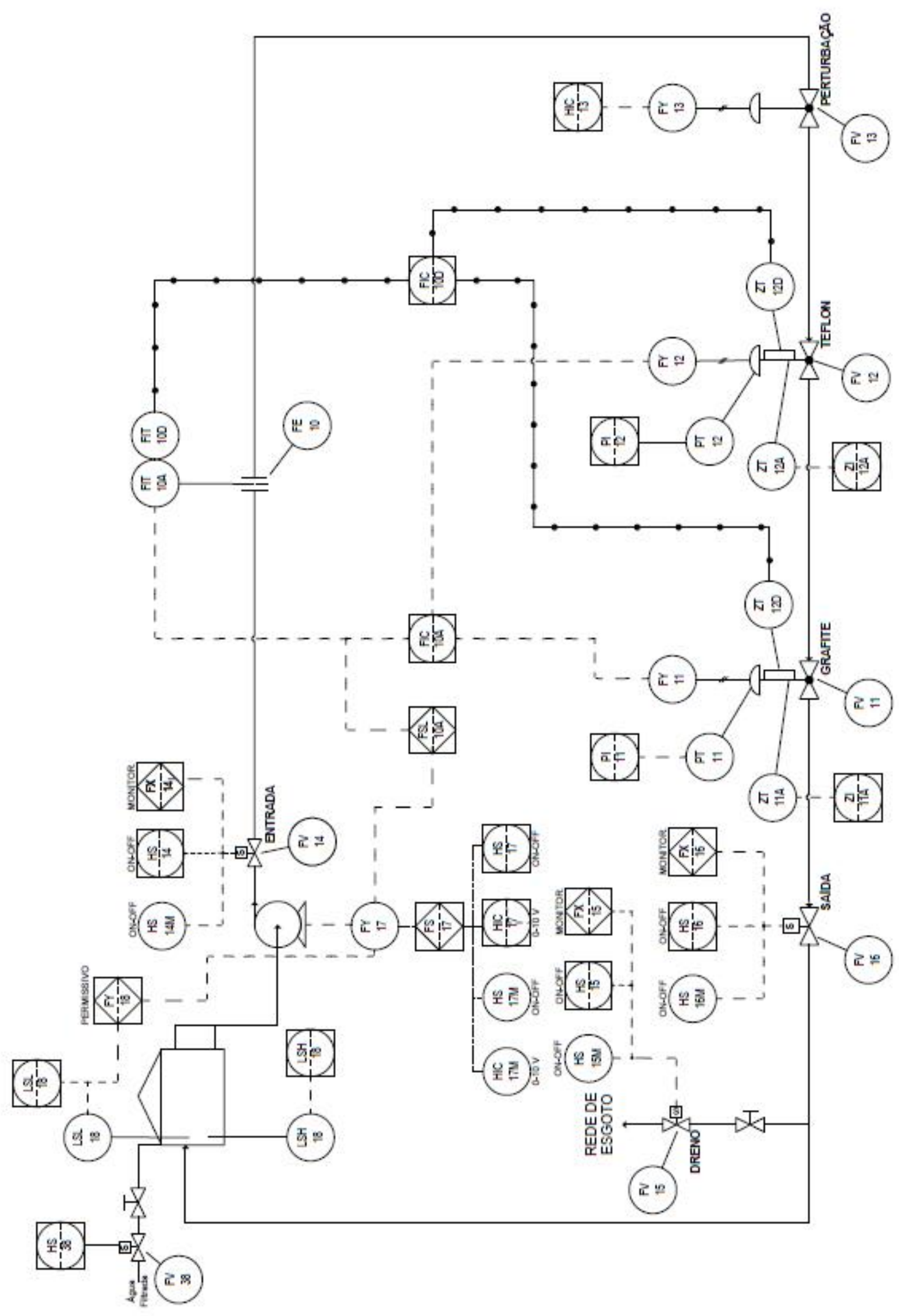

Figura 3: P\&ID da planta piloto de vazão. 


\section{Análise e Quantificação do Stiction}

A primeira parte deste capítulo descreve o efeito do atrito em válvulas de controle pneumáticas com maiores detalhes e define o termo stiction. A seguir as válvulas são modeladas levando em consideração esta não-linearidade. Na parte final do capítulo os parâmetros de atrito são estimados e validados.

\subsection{Definição do stiction}

A definição adotada neste trabalho para o stiction é a proposta por Choudhury, Jain e Shah (2008) e traduzida para o Português por Cuadros (2011), como se segue:

Stiction é uma propriedade de um elemento de tal forma que sua movimentação suave, em resposta a uma entrada variável, seja precedida por uma parte estática (banda morta + banda de agarramento) seguida por um salto abrupto repentino, chamado slip-jump. O slip-jump é expresso como uma porcentagem da faixa de saída. Sua origem em um sistema mecânico é o atrito estático, o qual excede o atrito dinâmico (Choudhury, Jain, Shah, 2008, p. 233).

O fenômeno descrito pode ser melhor visualizado na Figura 4. O gráfico representa a relação entrada-saída de uma válvula sobre o efeito do stiction, chamada de curva de assinatura da válvula de controle. Ainda de acordo com (CHOUDHURY; JAIN; SHAH, 2008) é possível dividir este gráfico em quatro regiões: banda morta, banda de agarramento, slip-jump e fase de movimento.

Na Figura 4 considere que no ponto A a válvula está parada e o sinal de controle acabou de sofrer uma reversão de sentido. Desta forma a válvula só irá voltar a se mover quando a variação da entrada for superior ao valor da banda morta (segmento AB) mais o valor da banda de agarramento (segmento BC). Conforme a definição de stiction, quando a válvula supera o atrito estático ocorre um movimento abrupto chamado slip-jump (seg- 


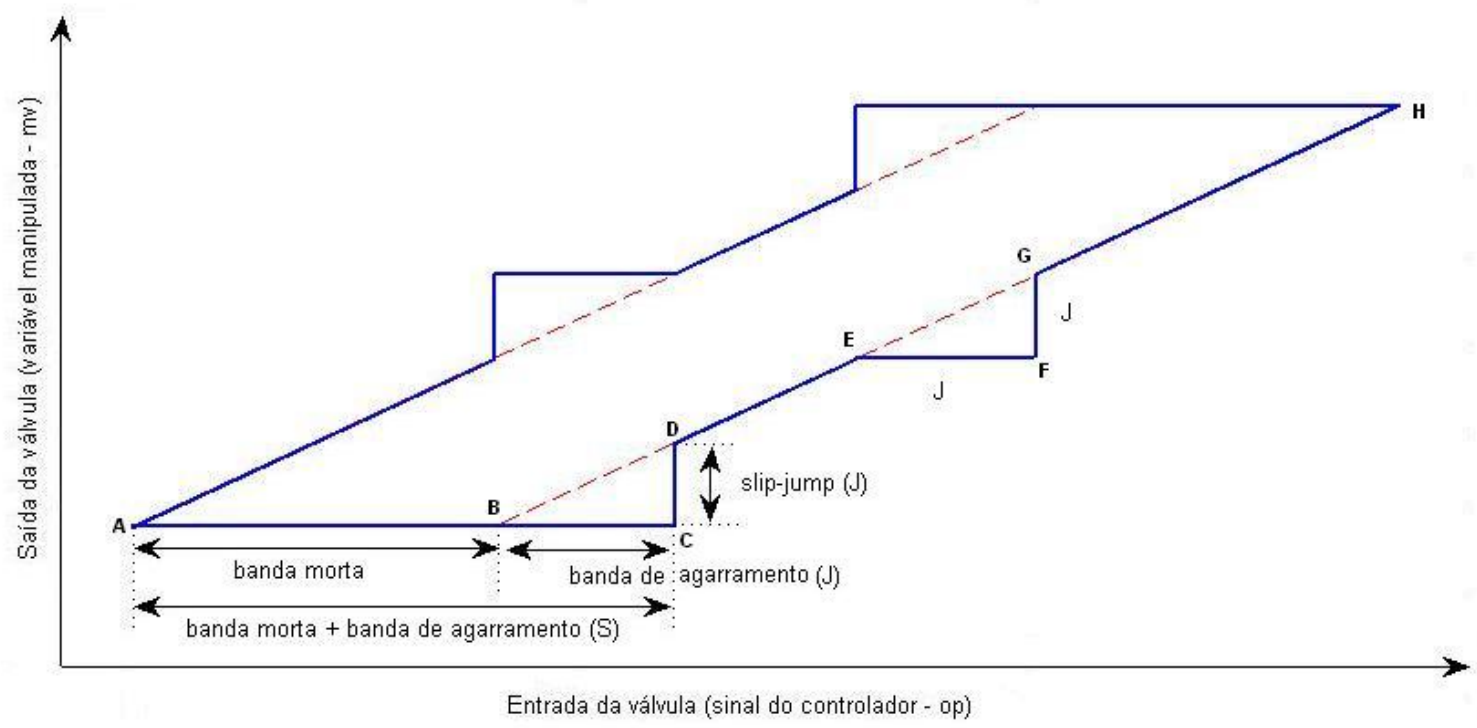

Figura 4: Curva de assinatura padrão de uma válvula sobre efeito do stiction.

mento CD), devido ao fato do atrito dinâmico ser inferior ao atrito estático. Após o slip-jump, a válvula entra na fase de movimento, onde a entrada e a saída apresentam uma relação linear (segmento DE). No ponto E assuma que a velocidade de movimento da haste da válvula esteja muito baixa e a válvula voltou a "agarrar". Para que a saída volte a variar na mesma direção é necessário superar a banda de agarramento novamente (segmento EF) e por consequência novamente há a presença do slip-jump (segmento FG). Note que como não houve troca de direção, não foi necessário superar a banda morta, portanto é necessária uma menor variação da entrada para que a válvula volte à fase de movimento. Finalmente, no ponto $\mathrm{H}$ ocorre uma nova reversão e o processo descrito se repete no sentido contrário.

O termo "banda morta" foi definido pela American National Standards Institution (ANSI) e pela International Society of America (ISA) como sendo a variação máxima que pode ser aplicada no sinal de entrada, quando ocorre uma reversão de direção, sem iniciar uma mudança observável no sinal de saída (ISA, 1979). Note que este termo é diferente da histerese, definida pelas mesmas instituições como a propriedade de um elemento evidenciada pela dependência do valor de saída, dada uma certa excursão da entrada, pelo histórico das excursões anteriores e pela direção atual do sinal. Enquanto a banda morta é normalmente representada como uma porcentagem do sinal de entrada, a histerese é representada como uma variação do sinal de saída. Outra diferença entre os dois termos é que um elemento que apresenta apenas histerese sofre uma mudança no sinal de saída sempre que há variação no sinal de entrada, mesmo que ocorra troca de direção, o que não ocorre quando um elemento está sujeito a uma banda morta. A Figura 5 evidencia essa diferença. 


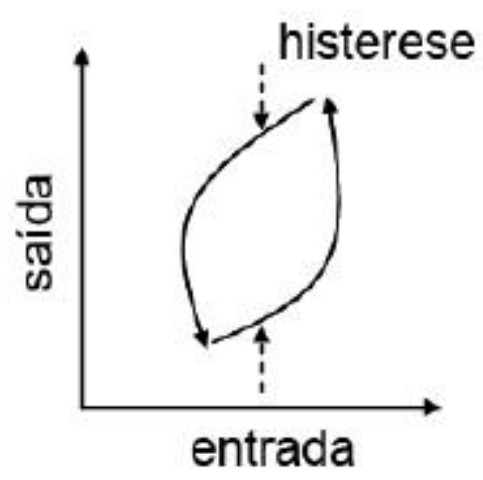

a)

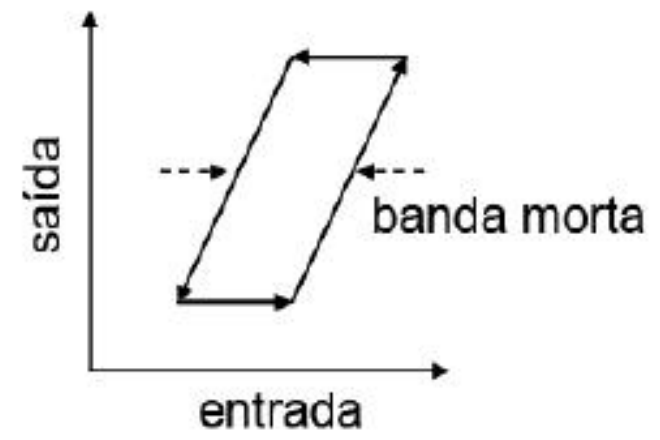

b)

Figura 5: a) Histerese b) Banda morta.

\subsection{Modelagem do stiction}

Os modelos de válvulas sob o efeito do stiction podem ser divididos em dois grupos: modelos empíricos e modelos físicos. O primeiro grupo tenta reproduzir a relação entre a entrada e a saída apresentada na Figura 4. Os modelos físicos, por sua vez, utilizam o balanço de forças atuando na válvula para prever seu movimento. Neste trabalho foi selecionado um modelo de cada grupo.

\subsubsection{Modelos empíricos}

O primeiro modelo empírico para representar o efeito do stiction foi apresentado em (STENMAN; GUSTAFSSON; FORSMAN, 2003). De acordo com os autores, o modelo foi proposto por Hägglund em uma comunicação privada. O modelo é descrito como se segue:

$$
x(k)= \begin{cases}x(k-1) & \text { se }|u(k)-x(k-1)| \leq d_{m} \\ u(k) & \text { caso contrário }\end{cases}
$$

onde $x(k)$ e $u(k)$ são a saída e a entrada da válvula, respectivamente, em porcentagem da faixa de medição e $d_{m}$ é o único parâmetro do modelo, que corresponde à banda de agarramento em porcentagem da entrada.

Porém este modelo apresenta alguns defeitos. Primeiramente, ele não considera a 
existência da banda morta, apenas da banda de agarramento, o que caracteriza uma situação totalmente oposta da obtida nos ensaios realizados com as válvulas de teste (Figura 10). Além disso, só é necessário superar a banda de agarramento quando a válvula está parada, porém o modelo não verifica se a válvula já está em movimento ou não, ou seja, após cada slip-jump a válvula volta a agarrar, independentemente do sinal de entrada. A Figura 6 mostra a curva de assinatura deste modelo de stiction.

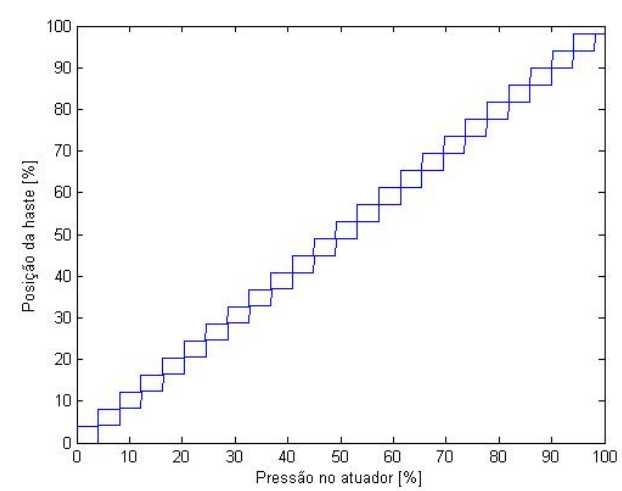

Figura 6: Curva de assinatura do modelo de um parâmetro $\left(d_{m}=4 \%\right)$.

Em (CHOUDHURY; THORNHILL; SHAH, 2005) um novo modelo empírico foi proposto, utilizando dois parâmetros, $S$ e $J$. O primeiro parâmetro corresponde à soma da banda morta com a banda de agarramento, ou seja, representa o quanto é possível variar o sinal de entrada, após uma reversão, sem que a saída se altere. O parâmetro é estimado em porcentagem do sinal de entrada. O modelo assume que, se as unidades da entrada e da saída estiverem em porcentagem de sua variação total, a amplitude da banda de agarramento e do slip-jump serão iguais, este valor corresponde ao parâmetro $J$. Porém este modelo apresenta bons resultados apenas para sinais de entrada determinísticos. Em (KANO et al., 2004), um novo modelo utilizando os mesmo parâmetros foi proposto, capaz de lidar com sinais determinísticos e estocásticos. Um terceiro modelo com dois parâmetros, mais simples que os anteriores, foi apresentado por He et al. (2007).

Uma análise entre os algoritmos para modelagem do stiction foi feita em (GARCIA, 2008), onde se concluiu que, entre os modelos empíricos, o proposto por Kano é o que apresenta o melhor desempenho. Por esse motivo, ele foi utilizado neste trabalho para modelar o efeito do atrito. Seu algoritmo está representado no diagrama da Figura 7 .

Observe que o modelo possui três variáveis internas. A variável de estado stp indica se a haste da válvula está ou não em movimento e, portanto, se está sob o efeito do atrito estático. A variável $d$ representa a direção do último movimento da válvula. Por fim, $u_{S}$ 


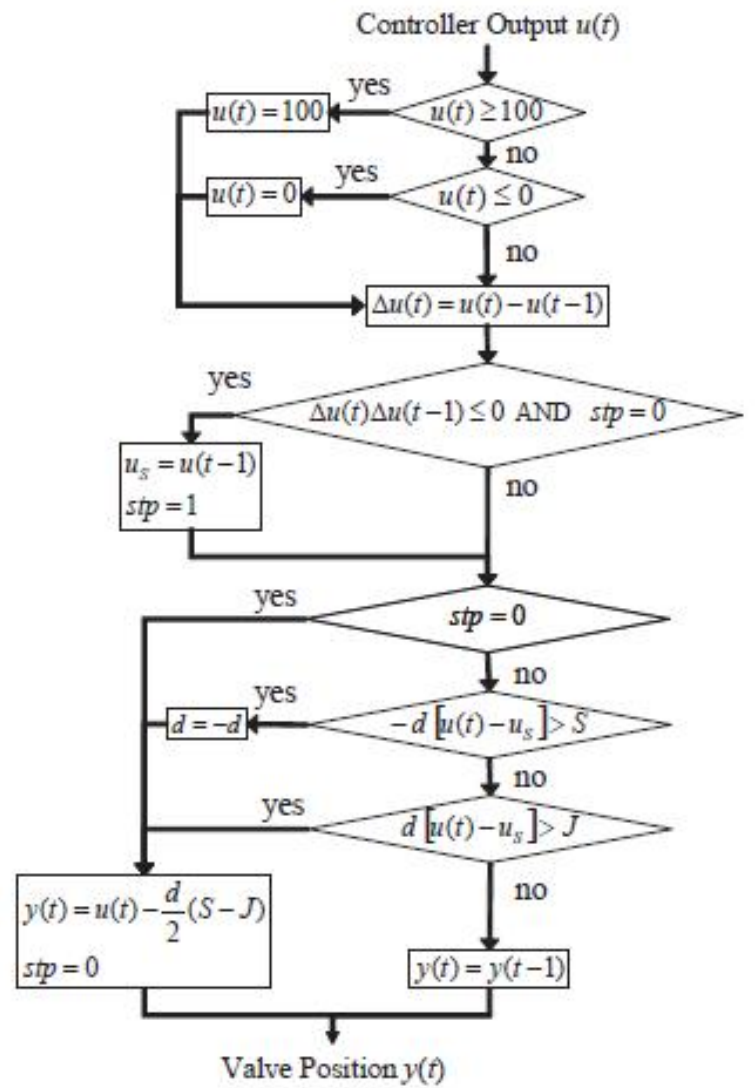

Figura 7: Algoritmo de decisão do modelo de Kano (KANO et al., 2004).

armazena o valor da entrada no instante em que a válvula cessou seu movimento.

\subsubsection{Modelo físico}

Uma alternativa para os modelos empíricos são os modelos físicos, que se baseiam no balanço de forças atuando na haste da válvula, de acordo com a segunda lei de Newton. A Equação (3.2) demonstra esse balanço.

$$
m \frac{d^{2} x}{d t^{2}}=F_{\text {pressão }}-F_{\text {mola }}-F_{\text {atrito }}-F_{\text {fluido }}-F_{i}
$$

onde:

- $F_{\text {pressão }}=S_{a} P$ é a força aplicada pela pressão no diafragma do atuador, sendo $S_{a}$ a área do diafragma e $P$ a pressão no atuador; 
- $F_{\text {mola }}=K x$ é a força aplicada pela mola do atuador, sendo $K$ a constante elástica da mola;

- $F_{\text {atrito }}$ é a força de atrito na haste da válvula;

- Ffluido é a força aplicada pelo fluido de processo no obturador da válvula;

- $F_{i}$ é uma força extra de assentamento do obturador na sede da válvula;

- $m$ é a massa das partes móveis (obturador + haste);

- $x$ é a posição da haste da válvula.

A força $F_{\text {fluido }}$ pode ser desconsiderada, por ser muito pequena perante as outras forças envolvidas. $F_{i}$ também será desconsiderada para simplificar o problema, uma vez que esta força age apenas no fim da excursão da haste. Estas considerações foram assumidas pela primeira vez por (KAYIHAN; DOYLE III, 2000), porém o trabalho anterior não apresenta resultados para comprovar que $F_{\text {fluido }}$ de fato pode ser desconsiderada. Para verificar esta hipótese foi realizado um teste simples com a válvula com gaxetas de teflon: com a válvula fechada aplicou-se um degrau para gerar uma pequena abertura e depois a rotação da bomba foi elevada manualmente de $0 \%$ para $80 \%$. Como a válvula estava quase fechada a perda de carga na válvula é grande, portanto $F_{\text {fluido }}$ está próximo do seu valor máximo para uma rotação fixa. Conforme a rotação da bomba aumenta, $F_{\text {fluido }}$ também aumenta. Se a variação desta força for grande o suficiente para superar o atrito estático, o aumento desta força irá gerar uma movimentação na haste da válvula. Por esse motivo se utilizou a válvula de baixo índice de atrito para o teste. Além disso, a válvula estava inicialmente fechada para que, após o degrau no sinal de controle da válvula, não fosse necessário superar a banda morta para gerar movimento. Não foi possível detectar nenhuma movimentação na haste durante o teste, o que significa que é seguro assumir que $F_{\text {fluido }}$ pode ser desconsiderada para as válvulas do laboratório. Desta forma, o novo balanço de forças é:

$$
m \frac{d^{2} x}{d t^{2}}=F_{\text {pressão }}-F_{\text {mola }}-F_{\text {atrito }}
$$

A diferença entre os diversos modelos físicos de válvulas de controle está na forma como 
$F_{\text {atrito }}$ é calculada. Pelos resultados obtidos por Garcia (2008), dos modelos físicos, o modelo proposto em (KARNOPP, 1985) e o modelo de Lugre são os que apresentaram resultados mais coerentes. Por simplicidade é utilizado o primeiro modelo citado, representado por (3.4):

$$
F_{\text {atrito }}= \begin{cases}F_{\text {dinâmico }}(v) & \text { se }|v| \geq D V \\ F_{e} & \text { se }|v|<D V \text { e }\left|F_{e}\right| \leq F_{S} \\ F_{S} \operatorname{sgn}\left(F_{e}\right) & \text { se }|v|<D V \text { e }\left|F_{e}\right|>F_{S}\end{cases}
$$

onde $F_{\text {dinâmico }}(v)$ é a força de atrito dinâmico, $F_{e}$ é soma das forças externas $\left(F_{\text {pressão }}\right.$ $\left.F_{\text {mola }}\right), \operatorname{sgn}(x)$ é a função sinal dada pela Equação $(3.5)$ e $F_{C}, F_{S}$ e $F_{v}$ são os parâmetros do modelo e correspondem aos coeficientes de atrito de Coulomb, estático e viscoso, respectivamente. O modelo dinâmico segue a mesma estrutura dos chamados modelos clássicos, como definido por (OLSSON, 1996), com a diferença que neste modelo a velocidade é considerada nula no intervalo $]-D V, D V[$, ou seja, nesta região a força de atrito corresponde a $F_{e}$ até atingir o limite $F_{S}$. Esta alteração foi proposta justamente para incrementar o resultado deste tipo de modelo em simulações. O autor do modelo não define porém a forma como $F_{\text {dinâmico }}(v)$ deve ser calculada. Em (GARCIA, 2008) este termo é calculado de acordo com a proposta de (TUSTIN, 1975), dada pela Equação (3.6).

$$
\begin{gathered}
\operatorname{sgn}(x)= \begin{cases}-1 & \text { se } x<0 \\
0 & \text { se } x=0 \\
1 & \text { se } x>0\end{cases} \\
F_{\text {dinâmico }}(v)=\left[F_{C}+\left(F_{S}-F_{C}\right) e^{-\left(\frac{v}{v_{S}}\right)^{2}}\right] \operatorname{sgn}(v)+F_{v} v
\end{gathered}
$$

onde $v_{S}$ é a velocidade de Stribeck(STRIBECK, 1902).

Observe que o modelo apresenta uma transição suave do atrito estático para o dinâmico, o que de acordo com Gury (2008) gera uma representação mais precisa do efeito do slipjump do que os modelos empíricos. Porém, este modelo apresenta algumas desvantagens em relação aos últimos. Para implementar o modelo, além de identificar os parâmetros, 
é necessário possuir dados da válvula, como a área do diafragma e a massa das partes móveis. Além disso, é preciso simulá-lo com um passo de integração de $10^{-6} \mathrm{~s}$, enquanto os modelos empíricos podem utilizar uma passo de integração de $10^{-3} \mathrm{~s}$, o que aumenta significativamente o tempo de simulação (GARCIA, 2008).

\subsection{Quantificação do stiction}

Uma vez definido os modelos que serão utilizados, é necessário quantificar seus parâmetros de atrito. Estes valores são necessários para sintonizar adequadamente os compensadores de atrito. Foram testados três métodos de quantificação de atrito, um para o modelo empírico e dois para o modelo físico. Os três métodos estudados são aplicados sobre o mesmo conjunto de dados, coletados a uma frequência de $1000 \mathrm{~Hz}$. O teste foi feito aplicando um sinal triangular com três ciclos completos ao conversor I/P. Para minimizar o efeito do ruído, os dados foram filtrados com um filtro de Savitzky-Golay de terceira ordem, com uma janela móvel de 51 pontos $^{1}$ (SAVITZKY; GOLAY, 1964).

Por se tratar do mesmo modelo de atuador e de conversor I/P, a pressão no atuador de ambas as válvulas (com gaxetas de teflon e de grafite) apresentam comportamento muito semelhante (Figura 8). Uma análise visual da Figura 9 deixa clara a diferença do nível de atrito entre as duas válvulas, pois a válvula com gaxeta de grafite demora mais para iniciar seu movimento após cada reversão, o que corresponde a uma maior variação na pressão do atuador para que a mesma entre na fase de movimento. O mesmo pode ser concluído observando a Figura 10 (que representa a relação entre a a pressão no atuador e a posição da haste), uma vez que as bases dos paralelogramos formados nos gráficos têm tamanhos muito diferentes. Porém, não é possível detectar visualmente a presença do slip-jump nem mesmo na válvula de alto atrito, onde se esperava uma influência mais acentuada do mesmo.

A Figura 11 realça a região onde deveria ocorrer o slip-jump. Observe que quando a válvula começa a se mover, a haste apresenta uma velocidade levemente superior à velocidade normal de movimento. Entretanto, não é possível afirmar que se trata do slip-jump, uma vez que esta diferença é muito pequena e pode ser uma deformação causada pelo ruído de medição.

\footnotetext{
${ }^{1}$ Até a data de conclusão deste trabalho não existia nenhuma técnica na literatura para a determinação dos parâmetros do filtro de Savitzky-Golay. Por esse motivo esses parâmetros foram determinados por tentativa e erro. O sinal filtrado é analisado visualmente pelo usuário e os parâmetros são alterados até que se atinja um resultado aceitável.
} 


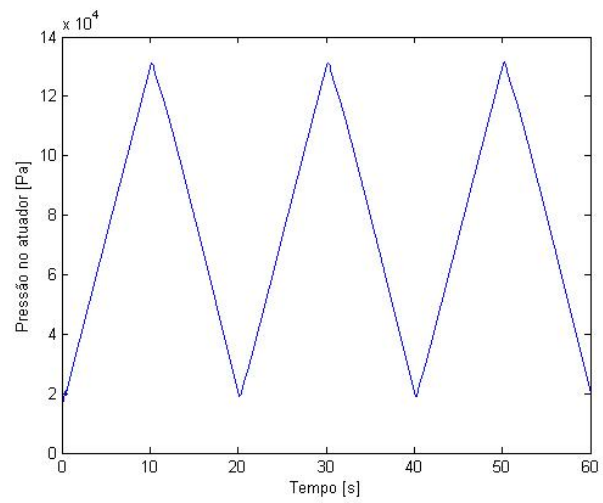

(a) Válvula com gaxetas de teflon

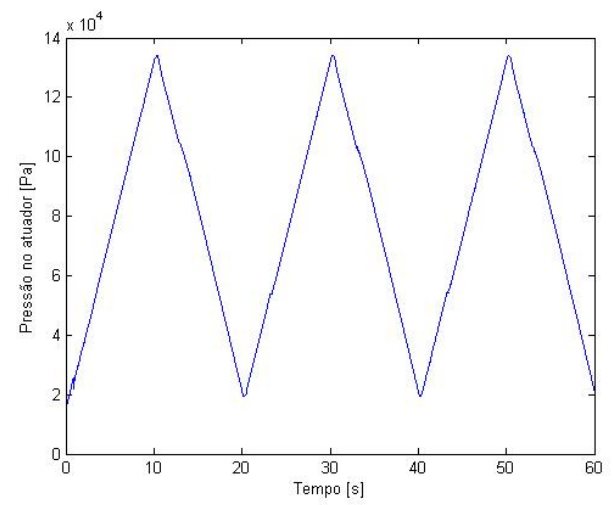

(b) Válvula com gaxetas de grafite

Figura 8: Pressão no atuador das válvulas.

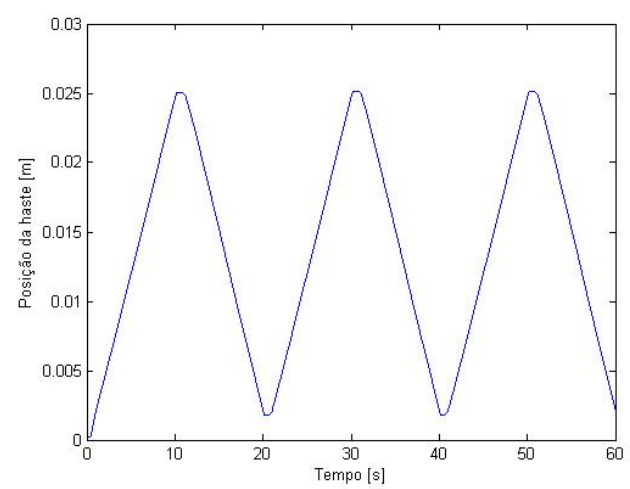

(a) Válvula com gaxetas de teflon

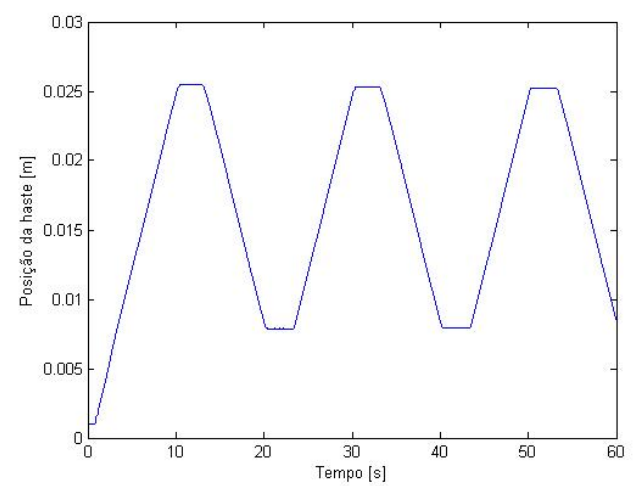

(b) Válvula com gaxetas de grafite

Figura 9: Posição da haste.

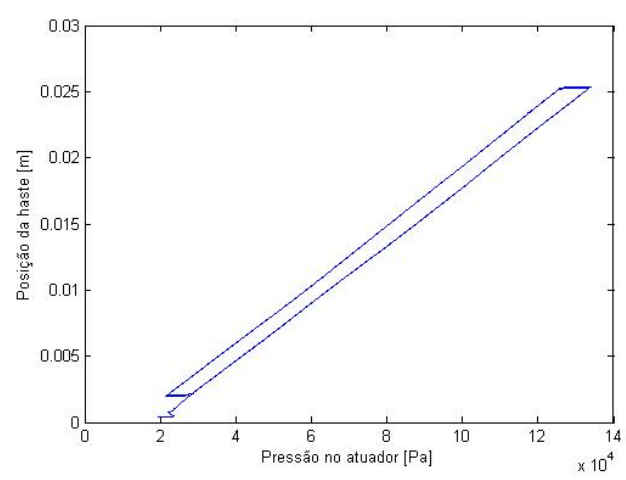

(a) Válvula com gaxetas de teflon

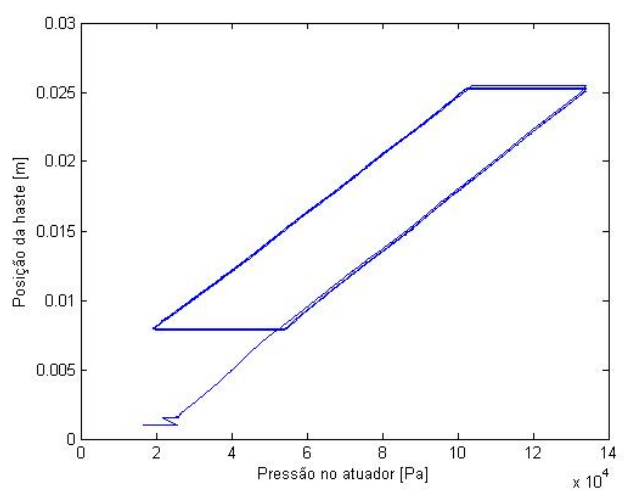

(b) Válvula com gaxetas de grafite

Figura 10: Curvas de assinatura das válvulas de teste.

A seguir são apresentadas as técnicas de estimação dos parâmetros de atrito utilizadas e os resultados obtidos. Para avaliar estes resultados, cada modelo estimado é validado com dois testes distintos. O primeiro teste é a autovalidação, ou seja, a validação do 


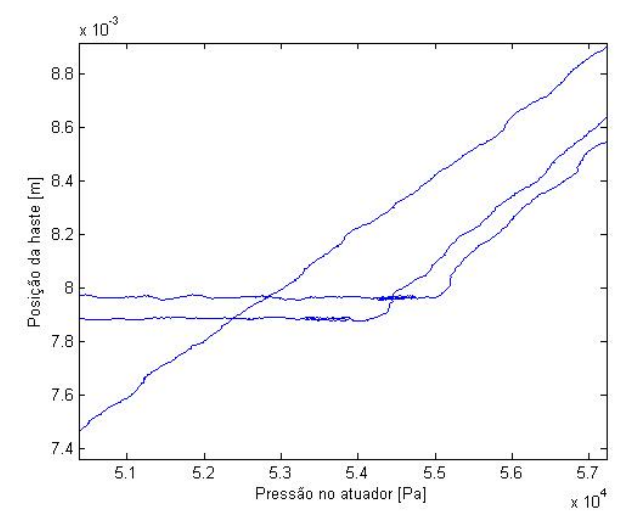

Figura 11: Região da curva de assinatura onde deveria ocorrer o slip-jump (gaxetas de grafite).

modelo utilizando os mesmos dados usados para a identificação. A segunda validação é feita com os dados obtidos ao inserir uma série de degraus positivos e negativos no sinal de controle da válvula. Em todos os testes, os dados de pressão no atuador são inseridos na entrada do modelo e a posição da haste simulada é comparada com a posição da haste real.

\subsubsection{Estimação dos parâmetros do modelo de Kano}

O autor do modelo também propôs uma técnica para estimar o parâmetro $S$, quando o efeito do slip-jump $(J)$ é desprezível (KANO et al., 2004). Primeiramente é necessário calcular a variação da posição da haste, como mostrado na Equação (3.7).

$$
\Delta x(t)=x(t)-x(t-1)
$$

Então são definidos intervalos de tempo nos quais o módulo da variação de posição é sempre menor que um valor $\epsilon$ (definido pelo usuário). Estes intervalos são considerados períodos em que a válvula não se moveu. O valor de $\tilde{u}$ é definido como a diferença entre o máximo e o mínimo da pressão no atuador em cada um desses intervalos de tempo. Por sua vez, $\tilde{x}$ é definido analogamente para a posição da haste. Considera-se que a haste esteja parada devido ao stiction apenas nos intervalos onde $\tilde{u}>=\epsilon_{u}$ e $\tilde{x}<=\epsilon_{x}$, onde $\epsilon_{u}$ e $\epsilon_{x}$ são limites definidos pelo usuário de acordo com a aplicação. A média dos valores de $\tilde{u}$ nesses intervalos corresponde ao valor estimado de $S$. O autor sugere também o cálculo de $\rho$ como sendo a fração da soma do comprimento dos intervalos onde ocorreram stiction pela soma total dos intervalos detectados na primeira etapa. Quanto mais próximo esse valor for de 1, maior a probabilidade de que a válvula esteja de fato sob o efeito do stiction. 
Para uma aplicação prática, este método pode utilizar a saída do controlador no lugar da pressão no atuador e a variável controlada ao invés da posição da haste. Além disso, pode ser aplicado a dados históricos do processo. Porém, desta forma há diversos fatores influenciando a relação entre a entrada e a saída, o que prejudica a estimação do atrito.

Este algoritmo foi aplicado aos dados coletados conforme mostrado no início desta seção. Para diminuir o efeito do ruído, as variáveis foram reamostradas a $10 \mathrm{~Hz}$. Os resultados obtidos estão na Tabela 1.

Tabela 1: Resultados obtidos pelo método de identificação de Kano.

\begin{tabular}{|c|c|c|}
\hline Material das Gaxetas & $S$ & $\rho$ \\
\hline Teflon & $4,14 \%$ & 1 \\
\hline Grafite & $19,82 \%$ & 1 \\
\hline
\end{tabular}

As Figuras 12 e 13 mostram os resultados da autovalidação dos parâmetros identificados.

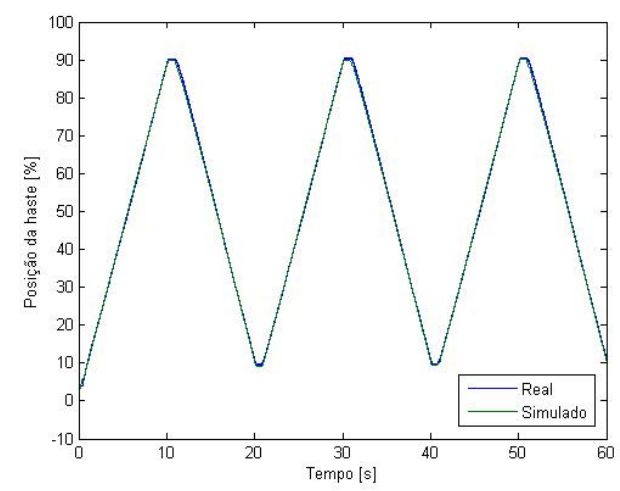

Figura 12: Autovalidação dos parâmetros do modelo de Kano (gaxetas de teflon).

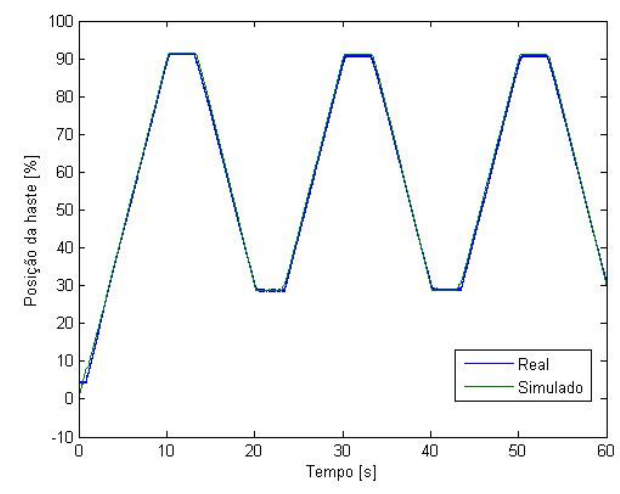

Figura 13: Autovalidação dos parâmetros do modelo de Kano (gaxetas de grafite). 
Os resultados se mostram muito satisfatórios para o sinal triangular. O mesmo ocorre com a série de degraus, representada nas Figuras 14 e 15.

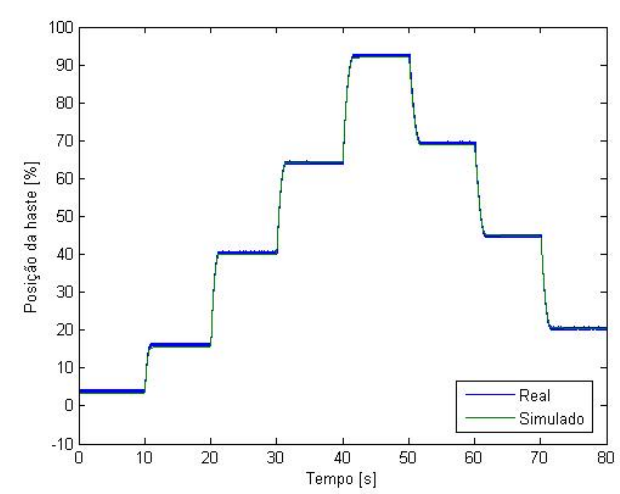

Figura 14: Validação dos parâmetros do modelo de Kano (gaxetas de teflon).

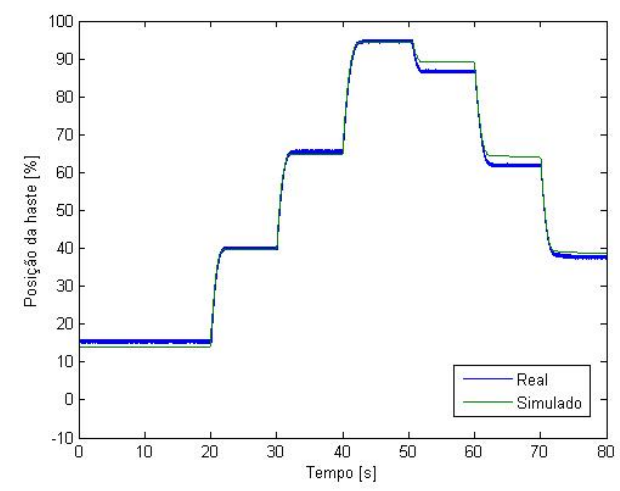

Figura 15: Validação dos parâmetros do modelo de Kano (gaxetas de grafite).

\subsubsection{Estimação dos parâmetros do modelo de Karnopp}

Para identificar os parâmetros do modelo físico foram propostos dois métodos distintos. Em (RAVANBOD-SHIRAZI; BESANÇON-VODA, 2003) foi proposta uma metodologia baseada em uma regressão linear para estimar os parâmetros do modelo de Karnopp, com exceção do parâmetro $F_{S}$. Este método foi adaptado por Romano e Garcia (2007) para válvulas de controle, incluindo a força aplicada pela mola e propondo um novo método para estimar o valor de $F_{S}$. Entretanto, Garcia (2007) propôs um sistema mais simples para realizar a estimação, proporcionando resultados com qualidade próxima à do primeiro método (ROMANO; GARCIA, 2007). Os dois métodos foram usados para identificar os parâmetros do modelo de Karnopp das válvulas de teste. 


\subsubsection{Identificação por avaliação do balanço de forças}

Para realizar a identificação é necessário coletar dados da pressão no atuador e posição da haste da válvula quando esta recebe três períodos completos de um sinal de controle triangular (GARCIA, 2007).

Nas rampas de subida e descida da haste a velocidade está estável e portanto tem-se uma aceleração nula. De acordo com as Equações (3.3), (3.4) e (3.6), selecionando-se dois pontos distintos de uma mesma rampa o balanço de forças em cada um é:

$$
\begin{aligned}
& 0=S_{a} P_{1}-F_{C} \operatorname{sgn}(v)-K x_{1}-F_{v} v \\
& 0=S_{a} P_{2}-F_{C} \operatorname{sgn}(v)-K x_{2}-F_{v} v
\end{aligned}
$$

Subtraindo-se a primeira equação da segunda é possível calcular o valor de $K$, uma vez que $S_{a}, P$ e $x$ são conhecidos.

$$
\begin{array}{r}
0=S_{a}\left(P_{1}-P_{2}\right)-K\left(x_{1}-x_{2}\right) \\
K=\frac{S_{a}\left(P_{1}-P_{2}\right)}{x_{1}-x_{2}}
\end{array}
$$

Uma vez estimado o valor de $K$, é possível estimar $F_{S}$ escolhendo um ponto em que a válvula esteja na eminência de movimento. Dessa forma, a força de atrito estático está no seu limite máximo e a velocidade e aceleração são nulas. Neste ponto, o balanço de forças é:

$$
\begin{array}{r}
0=S_{a} P-K x+F_{S} \\
\text { ou } \\
0=S_{a} P-K x-F_{S}
\end{array}
$$

dependendo da direção em que válvula irá iniciar seu movimento.

Originalmente o método estimava $m$ e $F_{v}$. Porém, para estimar $m$ é necessário calcular o valor da aceleração da haste, ou seja, a derivada de segunda ordem da posição. Como o ruído de medição é amplificado quando o sinal é derivado, a estimação de $m$ não apresenta bons resultados. Neste trabalho, a massa das partes móveis é considerada conhecida e o termo $m \frac{d x^{2}}{d^{2} t}$ é desconsiderado no balanço de forças, uma vez que a massa e 
a aceleração neste processo são pequenas. Portanto, subtraindo-se o balanço de forças de dois pontos em que a válvula se move na mesma direção e com velocidades diferentes é possível calcular $F_{v}$.

$$
\begin{array}{r}
0=S_{a} P_{1}-K x_{1}-F_{C} \operatorname{sgn}\left(v_{1}\right)-F_{v} v_{1} \\
0=S_{a} P_{2}-K x_{2}-F_{C} \operatorname{sgn}\left(v_{2}\right)-F_{v} v_{2} \\
F_{v}=\frac{S_{a}\left(P_{2}-P_{1}\right)-K\left(x_{2}-x_{1}\right)}{\left(v_{2}-v_{1}\right)}
\end{array}
$$

onde a velocidade é calculada da seguinte forma:

$$
v(t)=\frac{x(t)-x(t-1)}{\Delta t}
$$

Por fim, a Equação (3.19) pode ser aplicada em qualquer região em que haja movimento com velocidade constante.

$$
\begin{array}{r}
0=S_{a} P-K x-F_{C} \operatorname{sgn}(v)-F_{v} v \\
F_{C}=\left(S_{a} P-K x-F_{v} v\right) \operatorname{sgn}(v)
\end{array}
$$

A aplicação deste método no mesmo conjunto de dados do método anterior resultou nos valores da Tabela 2. Cada parâmetro foi calculado cinco vezes em pontos diferentes e a média foi considerada como o valor estimado. Teoricamente, o valor de $F_{S}$ não pode ser inferior ao valor de $F_{C}$, como ocorre na identificação da válvula com gaxetas de teflon. Este fenômeno é consequência da imprecisão na estimação dos parâmetros. As Figuras 16 e 17 apresentam a autovalidação dos parâmetros identificados.

Tabela 2: Resultados obtidos pelo método de identificação de Garcia (2007).

\begin{tabular}{|c|c|c|c|c|}
\hline Material das Gaxetas & $K$ & $F_{S}$ & $F_{v}$ & $F_{C}$ \\
\hline Teflon & $200350 \mathrm{~N} / \mathrm{m}$ & $113,664 \mathrm{~N}$ & $7064 \mathrm{~N} \mathrm{~s} / \mathrm{m}$ & $127,895 \mathrm{~N}$ \\
\hline Grafite & $210490 \mathrm{~N} / \mathrm{m}$ & $773,504 \mathrm{~N}$ & $23206 \mathrm{~N} \mathrm{~s} / \mathrm{m}$ & $684,069 \mathrm{~N}$ \\
\hline
\end{tabular}

A segunda validação, com uma sequência de degraus, é mostrada nas Figuras 18 e 19. Os resultados obtidos mostram que há coerência entre o modelo e o sistema real. 


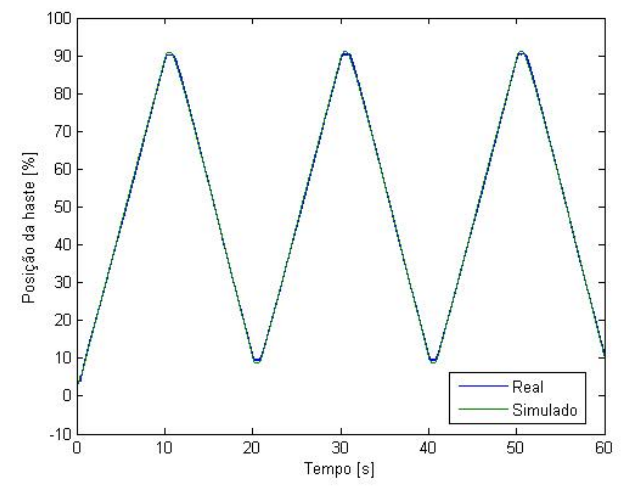

Figura 16: Autovalidação dos parâmetros do modelo de Karnopp (gaxetas de teflon).

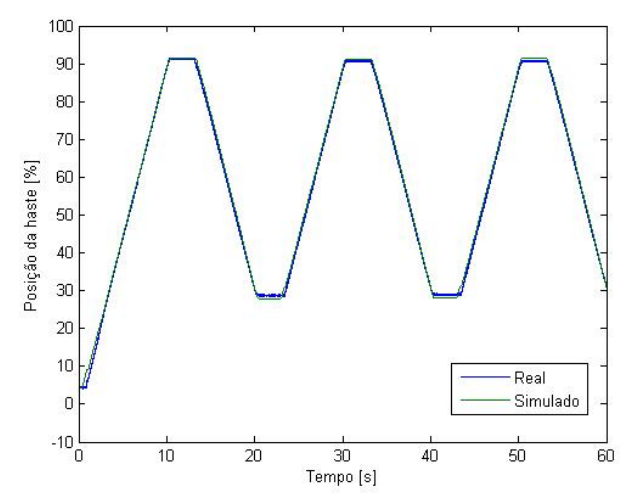

Figura 17: Autovalidação dos parâmetros do modelo de Karnopp (gaxetas de grafite).

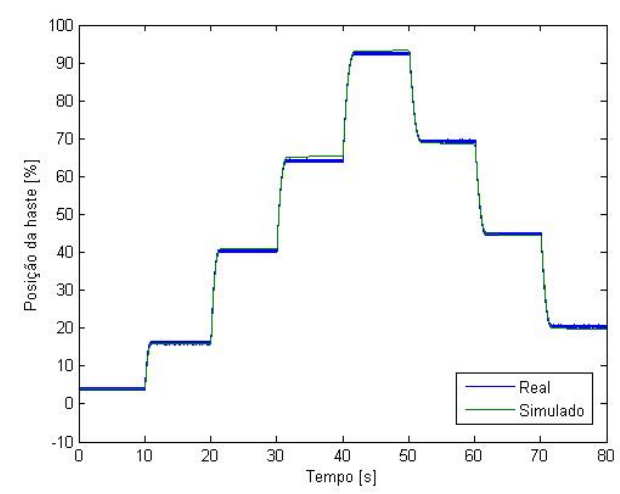

Figura 18: Validação dos parâmetros do modelo de Karnopp (gaxetas de teflon). 


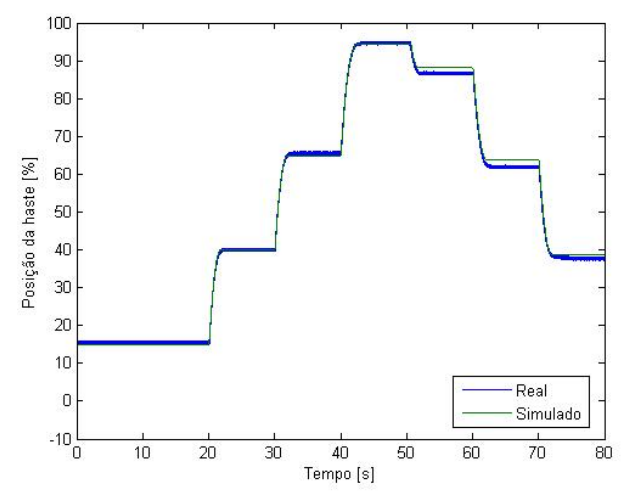

Figura 19: Validação dos parâmetros do modelo de Karnopp (gaxetas de grafite).

\subsubsection{Identificação por regressão linear}

A proposta para identificação dos parâmetros do modelo de Karnopp apresentada em (ROMANO, 2009) consiste em realizar uma regressão linear para estimar $m, F_{v}, F_{C}$ e $K$. Desta forma, define-se um vetor de variáveis como na Equação (3.20).

$$
\theta_{p}=\left[\begin{array}{llll}
m & F_{C} & F_{v} & K
\end{array}\right]
$$

A identificação destes parâmetros é realizada considerando apenas os pontos em que a haste está em movimento, ou seja, pontos em que $|v| \geq D V$. O balanço de forças neste ponto, considerando as Equações (3.3), (3.4), (3.6), é:

$$
F_{\text {pressão }}(t)=S_{a} P(t)=m \frac{d^{2} x}{d t^{2}}+F_{C} \operatorname{sgn}(v(t))+F_{v} v(t)+K x(t)
$$

Observe que $F_{\text {pressão }}(t)$ é uma função linear do vetor de variáveis $\theta$. Desta forma é possível aplicar a técnica dos mínimos quadrados para estimar os elementos deste vetor. 


$$
\hat{\theta}=\underset{\theta_{p}}{\arg \min } \sum_{t}\left[F_{\text {pressão }}(t)-\hat{F}_{\text {pressão }}(t)\right]^{2}
$$

onde

$$
\hat{F}_{\text {pressão }}(t)=\varphi(t) \theta_{p}^{T}
$$

Na Equação (3.23) $\varphi(t)$ é o vetor de regressão dado por:

$$
\varphi(t)=\left[\begin{array}{llll}
\dot{v}(t) & \operatorname{sgn}(v(t)) & v(t) & x(t)
\end{array}\right]
$$

O método proposto considera que $D V$ também é desconhecido. Desta forma não é possível determinar os pontos em que se considera que a haste da válvula esteja em movimento, ou seja, o conjunto de pontos utilizados para realizar a regressão. Para sanar este problema se utiliza uma variável $\delta v(s)$, dada por:

$$
\delta v(s)=s \frac{|v|_{\max }}{Z}, s=1,2, \ldots, s_{\max }
$$

Na Equação (3.25) $Z$ e $s_{\max }$ são parâmetros definidos pelo usuário, respeitando as seguintes condições: $Z \gg 1$ e $s_{\max }<Z$. O vetor $\theta_{p}$ é estimado para cada valor de $s$, considerando apenas o conjunto de pontos tal que $|v|>\delta v(s)$. Para selecionar qual valor de $s$ apresenta resultados mais coerentes, utiliza-se o coeficiente de correlação. Porém, o cálculo deste coeficiente neste trabalho não segue a metodologia descrita em (ROMANO, 2009) e (RAVANBOD-SHIRAZI; BESANÇON-VODA, 2003), mas é feito de acordo com a Equação (3.26).

$$
R^{2}(s)=\frac{\operatorname{cov}\left(\hat{F}_{\text {pressão }}^{s}, F_{\text {pressão }}^{s}\right)}{\sqrt{\operatorname{var}\left(\hat{F}_{\text {pressão }}^{s}\right) \operatorname{var}\left(F_{\text {pressão }}^{s}\right)}}
$$


onde:

$$
\begin{aligned}
& \operatorname{cov}\left(\hat{F}_{\text {pressão }}^{s}, F_{\text {pressão }}^{s}\right)=\sum_{t}\left[\left(\hat{F}_{\text {pressão }}^{s}(t)-\overline{\hat{F}}_{\text {pressão }}^{s}\right)\left(F_{\text {pressão }}^{s}(t)-\bar{F}_{\text {pressão }}^{s}\right)\right] \\
& \operatorname{var}\left(\hat{F}_{\text {pressão }}^{s}\right)=\sum_{t}\left[\hat{F}_{\text {pressão }}^{s}(t)-\overline{\hat{F}}_{\text {pressão }}^{s}\right]^{2} \\
& \operatorname{var}\left(F_{\text {pressão }}^{s}\right)=\sum_{t}\left[F_{\text {pressão }}^{s}(t)-\bar{F}_{\text {pressão }}^{s}\right]^{2}
\end{aligned}
$$

Nas equações anteriores $F_{\text {pressão }}^{s}$ e $\hat{F}_{\text {pressão são a força externa e sua estimativa, conside- }}^{s}$ rando apenas os pontos em que $|v|>\delta v(s)$. Por sua vez, $\bar{F}_{\text {pressão }}^{s}$ e $\overline{\hat{F}}_{\text {pressão }}^{s}$ são as médias temporais de $F_{\text {pressão }}^{s}(t)$ e $\hat{F}_{\text {pressão }}^{s}$, respectivamente. Quanto mais perto $R^{2}(s)$ for de 1 mais próxima a estimativa da força externa está do valor real. Portanto, utiliza-se o valor de $s$ que apresenta o maior valor de $R^{2}(s)$.

Para se estimar o valor de $F_{S}$ é sugerido simular o modelo de Karnopp para vários valores deste parâmetro, em busca do valor que minimize o erro quadrático da velocidade. Porém esse processo requer uma grande carga computacional, uma vez que o modelo de Karnopp deve ser simulado com um passo de tempo de $10^{-6} \mathrm{~s}$. Como alternativa, se utiliza o mesmo sistema da proposta da subseção anterior (Equações (3.12) e (3.13)).

Novamente, o termo $m \frac{d x^{2}}{d^{2} t}$ foi desconsiderado no balanço de forças, reduzindo o vetor de variáveis em um elemento. Os resultados obtidos por este método são apresentados na Tabela 3. Comparando estes resultados com os obtidos pelo método anterior se verifica que há uma grande variação nos valores do parâmetro $F_{v}$. Este parâmetro possui um efeito muito pequeno no modelo, quando comparado com os outros três. Por este motivo e pelo fato de estar relacionado com a derivada de um sinal ruidoso $(v)$ é difícil de estimar com precisão o valor deste parâmetro. Apesar das identificações do parâmetro não gerarem valores confiáveis, os modelos apresentam uma resposta próxima à do sistema real.

Tabela 3: Resultados obtidos pelo método de identificação de Romano (2009).

\begin{tabular}{|c|c|c|c|c|}
\hline Material das Gaxetas & $K$ & $F_{S}$ & $F_{v}$ & $F_{C}$ \\
\hline Teflon & $203100 \mathrm{~N} / \mathrm{m}$ & $153,0669 \mathrm{~N}$ & $4049 \mathrm{~N} \mathrm{~s} / \mathrm{m}$ & $145,8271 \mathrm{~N}$ \\
\hline Grafite & $208330 \mathrm{~N} / \mathrm{m}$ & $744,0288 \mathrm{~N}$ & $1575 \mathrm{~N} \mathrm{~s} / \mathrm{m}$ & $728.3232 \mathrm{~N}$ \\
\hline
\end{tabular}

Novamente os testes de validação de modelo foram realizados com os parâmetro obtidos e estão representados nas Figuras 20 a 23. 


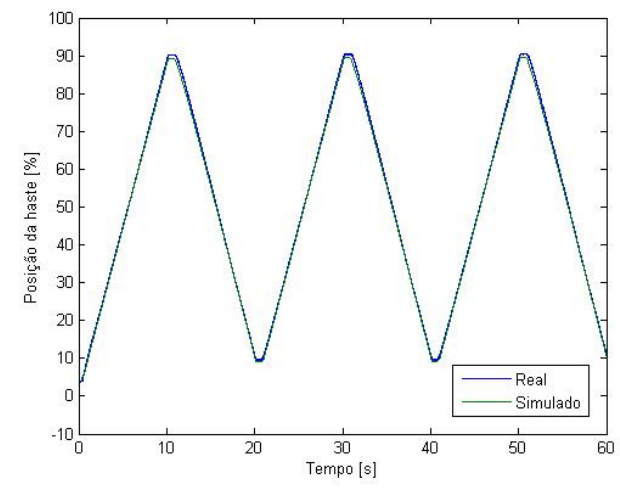

Figura 20: Autovalidação dos parâmetros do modelo de Karnopp obtidos por regressão linear (gaxetas de teflon).

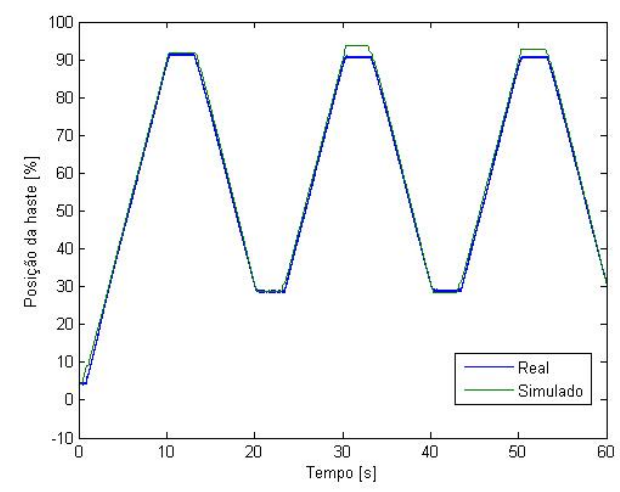

Figura 21: Autovalidação dos parâmetros do modelo de Karnopp obtidos por regressão linear (gaxetas de grafite).

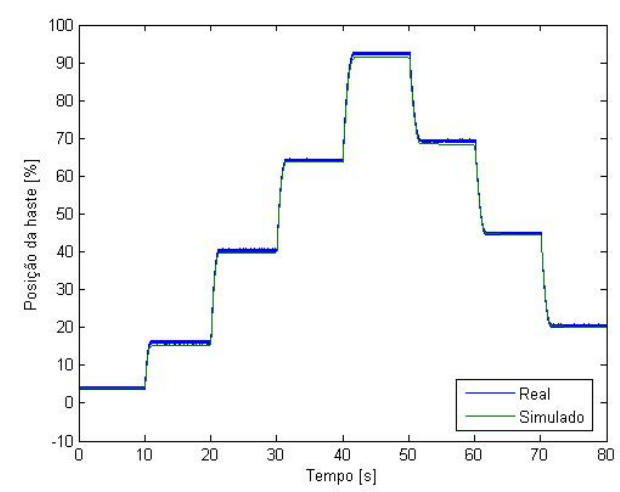

Figura 22: Validação dos parâmetros do modelo de Karnopp obtidos por regressão linear (gaxetas de teflon). 


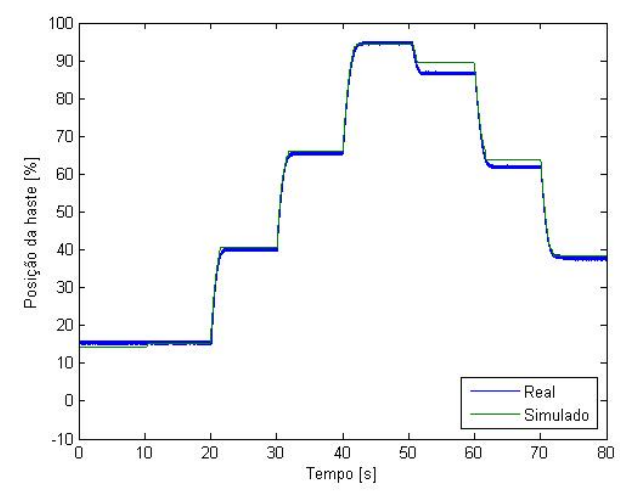

Figura 23: Validação dos parâmetros do modelo de Karnopp obtidos por regressão linear (gaxetas de grafite).

\subsection{Conversão dos parâmetros}

Os valores de $S$ e $J$ são justamente os valores necessário para os compensadores que são implementados neste trabalho. Por esse motivo e para que seja possível comparar os parâmetros identificados pelas três metodologias, os parâmetros do modelo de Karnopp são convertidos para os parâmetros do modelo de Kano. Em (UEHARA; GARCIA; ROMANO, 2008) foi apresentado um método para realizar tal conversão.

Quando a haste da válvula está em movimento, o termo $e^{-\left(\frac{v}{v_{S}}\right)^{2}}$ da Equação (3.6) pode ser considerado nulo, uma vez que $v \gg v_{S}$. Desta forma, o balanço de forças da Equação (3.3) se torna:

$$
m \frac{d^{2} x}{d t^{2}}=S_{a} P-K x-F_{c} \operatorname{sgn}(v)-F_{v} v
$$

Porém, conforme a válvula se aproxima do seu ponto de parada, os termos $m \frac{d^{2} x}{d t^{2}}$ e $F_{v} v$, que já eram consideravelmente menores que os outros termos do balanço de forças, ficam ainda menores e podem ser desprezados (ROMANO; GARCIA, 2008). Sendo assim, tem-se que:

$$
0=S_{a} P-K x-F_{c} \operatorname{sgn}(v)
$$

Conforme a velocidade diminui, o termo $e^{-\left(\frac{v}{v_{S}}\right)^{2}}$ não pode ser mais desconsiderado, entretanto do momento em que este termo começa a fazer efeito até o momento de parada da válvula, é possível considerar que haja um deslocamento ínfimo da haste. Portanto, a 
Equação (3.31) continua válida, porém a velocidade agora é nula e o termo $F_{C}$ é somado ou subtraído, de acordo com a direção em que a válvula estava se movendo antes de parar. Desta forma, é possível calcular a pressão no atuador no momento da parada da haste como na Equação (3.32).

$$
P_{p}= \begin{cases}\frac{K x_{p}+F_{c}}{S_{a}} & \text { caso a haste estivesse subindo antes de parar } \\ \frac{K x_{p}-F_{c}}{S_{a}} & \text { caso a haste estivesse descendo antes de parar }\end{cases}
$$

Na Equação (3.32) $P_{p}$ é a pressão no atuador no momento da parada da haste, enquanto $x_{p}$ é a posição da haste no mesmo instante. Pelas Equações (3.3) e (3.4), uma vez cessado o movimento, a haste só irá reiniciá-lo quando o módulo do somatório das forças externas superar o atrito estático $\left(F_{S}\right)$. A pressão necessária para que isto ocorra é:

$$
P_{m}= \begin{cases}\frac{K x_{m}+F_{S}}{S_{a}} & \text { caso a haste esteja iniciando uma subida } \\ \frac{K x_{m}-F_{S}}{S_{a}} & \text { caso a haste esteja iniciando uma descida }\end{cases}
$$

Na Equação (3.33) $P_{m}$ e $x_{m}$ correspondem à pressão no atuador e posição da haste, respectivamente, no momento em que a haste está na iminência de movimento. Uma vez que a válvula não chegou a se mover desde sua parada, tem-se que $x_{p}=x_{m}$.

Os parâmetros $S$ e $J$ do modelo de Kano representam qual a máxima variação na entrada, após uma parada, que não gere movimento na haste no sentido contrário e no mesmo sentido do último movimento realizado, respectivamente. O módulo da diferença entre as Equações (3.32) e (3.33), uma vez que todas as variáveis presentes são positivas, pode ser calculado da seguinte forma:

$$
\Delta P= \begin{cases}\frac{F_{S}+F_{c}}{S_{a}} & \text { caso ocorra uma reversão na direção } \\ \frac{F_{S}-F_{c}}{S_{a}} & \text { caso o movimento seja retomado na mesma direção }\end{cases}
$$

O que corresponde exatamente aos parâmetros mencionados anteriormente. Porém, estes parâmetros são normalmente calculados em porcentagem, enquanto os valores calculados na Equação (3.34) estão em Pa. Para realizar a conversão é preciso dividir pela variação máxima de pressão no atuador da válvula e multiplicar por 100.

$$
S=\frac{F_{S}+F_{c}}{S_{a} \Delta P_{\max }} 100
$$




$$
J=\frac{F_{S}-F_{c}}{S_{a} \Delta P_{\max }} 100
$$

A Tabela 4 mostra uma comparação entre os parâmetros do modelo de Kano identificados anteriormente e os obtidos pela conversão dos parâmetros de Karnopp.

Tabela 4: Resultados das identificações dos parâmetros de atrito.

\begin{tabular}{|c|c|c|c|c|c|c|}
\hline \multirow{2}{*}{ Material das Gaxetas } & \multicolumn{3}{|l|}{ Valor identificado } & \multicolumn{2}{|c|}{$\begin{array}{c}\text { Valor convertido } \\
\text { (GARCIA, 2007) }\end{array}$} & $\begin{array}{c}\text { Valor convertido } \\
\text { (ROMANO, 2009) }\end{array}$ \\
\cline { 2 - 7 } & $S$ & $J$ & $S$ & $J$ & $S$ & $J$ \\
\hline Teflon & $4,14 \%$ & - & $3,44 \%$ & $-0,2 \%$ & $4.25 \%$ & $0,1 \%$ \\
\hline Grafite & $19,82 \%$ & - & $19,76 \%$ & $1,21 \%$ & $19,96 \%$ & $0,21 \%$ \\
\hline
\end{tabular}

Para ambas as válvulas, o valor de $J$ convertido dos parâmetros de Karnopp foram muito pequenos, portanto ao desprezá-lo no modelo de Kano não foi introduzido um erro muito grande. Note que, para os valores da primeira identificação dos parâmetros do modelo de Karnopp, o valor convertido de $J$ para a primeira válvula foi negativo, o que na prática não é possível. Porém o valor é tão pequeno que pode ser desconsiderado. Os valores de $S$ estão condizentes nos três casos, porém a válvula com gaxetas de Teflon apresenta uma diferença considerável entre o valor estimado e o convertido do primeiro método de estimação. Também é possível observar uma variação no valor de $J$ para a válvula com gaxetas de grafite nos valores convertidos dos dois métodos da subseção 3.3.2.

\subsection{Proposta para refinamento das estimativas dos parâmetros de atrito}

A partir da estimação inicial do parâmetro $S$, é possível refinar o valor obtido através de uma busca exaustiva. Pela definição, o valor deste parâmetro corresponde à maior variação possível na entrada da válvula de forma que, após uma mudança de direção, não ocorra mudanças na posição da haste. Para identificar este valor com precisão é proposto um ensaio de resposta ao degrau:

- Elevar a pressão no atuador de $0 \%$ para $50 \%$

- Aguardar até que a pressão no atuador e posição da haste estejam estáveis 
- Aplicar um degrau de amplitude - amp

Inicialmente o valor de amp será o valor previamente estimado de $S$. Caso o degrau aplicado gere uma alteração na posição, a amplitude do degrau, amp, é decrementada de $h$ e o teste é realizado novamente. O processo é repetido até que o degrau na entrada não cause uma alteração na saída. Neste momento, o valor de amp será o novo valor estimado de $S$. Analogamente para o caso em que a haste não se move no teste inicial, o valor de amp é incrementado de $h$ e os ensaios devem ser repetidos até que haja alteração na posição. Nesta situação, a nova estimação de $S$ será $a m p-h$. O parâmetro $h$ deve ser escolhido de acordo com a precisão desejada para a nova estimação.

Entretanto, dependendo do erro da estimativa inicial e da escolha de $h$, este método pode se tornar muito lento. Alternativamente, é possível incorporar os conceitos de busca binária no método descrito acima. Como a ideia é apenas ajustar o valor identificado, é definida uma região $[S-H ; S+H]$, onde $S$ é a estimação inicial do parâmetro e $H$ é determinado pelo usuário (representa o erro máximo esperado para a estimativa de $S$ ). A variável $H$ deve ser suficientemente grande para que ao aplicar o ensaio em degrau com amplitude $S-H$, não haja alteração na posição da haste e o contrário ocorra para o degrau de amplitude $S+H$. Desta forma é garantido que o valor real do parâmetro está na região definida anteriormente. Novamente a variável $h$ é utilizada para definir a precisão desejada para o método. O fluxograma da Figura 24 descreve o algoritmo de refinamento da estimação.

Como ocorre em uma busca binária em um vetor de variáveis, a região de busca é diminuída pela metade em cada iteração. A variável passo do fluxograma corresponde ao tamanho atual desta região. Porém, ao invés de índices de um vetor, tem-se uma variável analógica, portanto é necessário definir um critério de parada. Assim como no processo por busca exaustiva, a variável $h$ define a precisão do algoritmo. Quando a região de busca for menor que $h$, o processo é interrompido e amp é considerada a nova estimativa de $S$. A Tabela 5 apresenta os resultados deste método, considerando as estimativas iniciais obtidas pelo método de Kano, $H$ igual a $20 \%$ destas estimativas e $h=0,1 \%$.

Tabela 5: Resultados do refinamento dos valores identificados de $S$.

\begin{tabular}{|c|c|c|}
\hline Material das Gaxetas & $S$ & $\begin{array}{c}\text { Número de } \\
\text { iterações }\end{array}$ \\
\hline Teflon & $4,90 \%$ & 4 \\
\hline Grafite & $18,76 \%$ & 6 \\
\hline
\end{tabular}




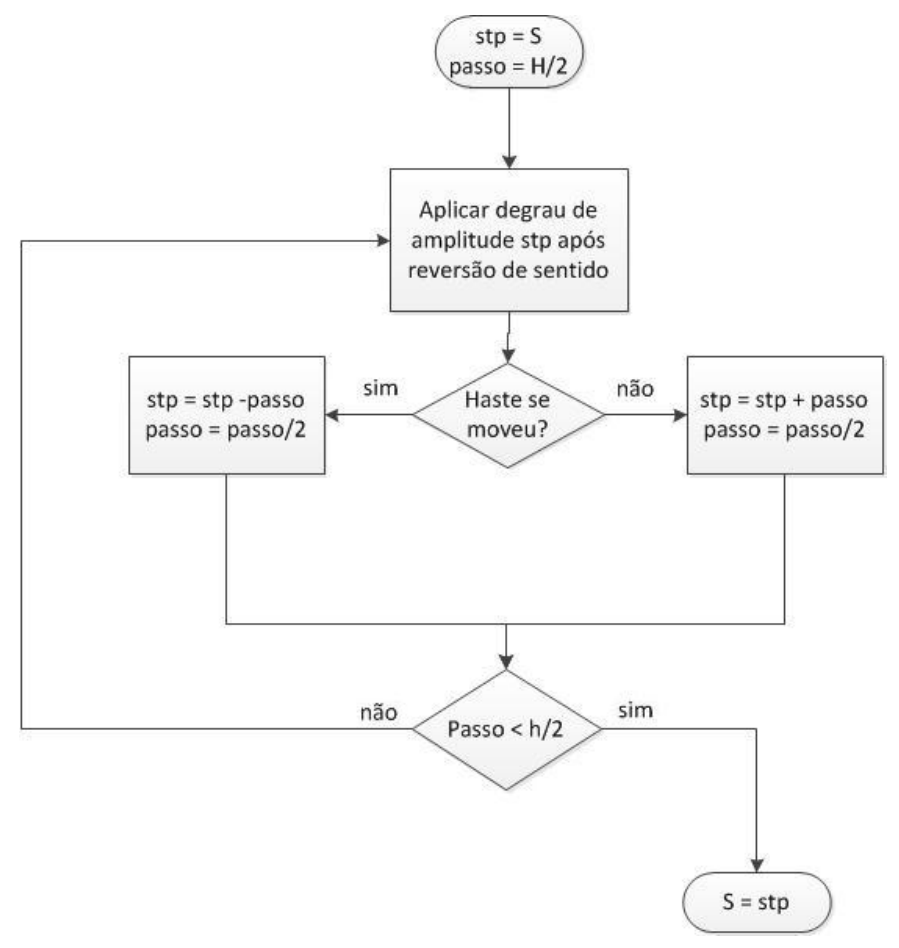

Figura 24: Fluxograma do algoritmo de refinamento da estimação de $S$.

Este método, além de fornecer medidas mais precisas dos parâmetros do modelo de Kano, também faz as estimações baseadas na resposta da válvula a um degrau. Como será apresentado no próximo capítulo, os compensadores estudados inserem variações bruscas no sinal de controle, proporcionais ao valor de $S$. Desta forma, quando este parâmetro é estimado a partir de variações rápidas, como a do método proposto, tem-se um valor mais condizente com a aplicação em questão. Por este motivo, estes valores são usados para a compensação de atrito nas válvulas de controle.

Observe que caso se altere o teste descrito no início da seção para que, ao invés de aplicar um degrau negativo seja aplicado um degrau positivo, é possível estimar também o valor de $J$. O ensaio de resposta ao degrau fica portanto:

- Elevar a pressão no atuador de $0 \%$ para $50 \%$

- Aguardar até que a pressão no atuador e posição da haste estejam estáveis

- Aplicar um degrau de amplitude amp

Utilizando novamente o algoritmo dado na Figura 24, substituindo-se $S$ por $J$, obtémse um valor refinado para a banda de agarramento. A análise visual da resposta ao sinal 
triangular e a identificação dos parâmetros do modelo de Karnopp constataram que os valores de $J$ para ambas as válvulas de teste são baixos. Por esse motivo, para aplicar o método proposto, foi utilizada como estimativa inicial $J=1,5 \%$ e $H=1,5 \%$, desta forma o valor final de $J$ é buscado entre 0 e $3 \%$. O valor de $h=0,1 \%$ foi mantido. A Tabela 6 apresenta os resultados obtidos.

Tabela 6: Resultados do refinamento dos valores identificados de $J$.

\begin{tabular}{|c|c|c|}
\hline Material das Gaxetas & $J$ & $\begin{array}{c}\text { Número de } \\
\text { iterações }\end{array}$ \\
\hline Teflon & $0,66 \%$ & 5 \\
\hline Grafite & $1,03 \%$ & 5 \\
\hline
\end{tabular}

O método apresentado resultou em uma alteração em torno de $5 \%$ dos valores estimados para $S$ no caso da válvula de alto atrito, porém este valor sobe para $20 \%$ para a válvula de baixo atrito. No segundo caso está porcentagem é muito maior devido ao fato dos valores estimados serem menores, pois a variação absoluta, em ambos os casos, é quase a mesma. O efeito deste refinimanto na compensação de atrito é apresentado no final do Capítulo 5. Já o parâmetro $J$ apresentou uma grande variação nos valores estimados inicialmente, portanto o método de refinamento permite que se adote com mais segurança um valor para ele. 


\section{Compensação do Atrito}

O atrito em válvulas de controle prejudica a eficiência da malha, podendo até introduzir uma variabilidade na variável controlada. Consequentemente, há um decréscimo na eficiência do processo, o que representa perdas para a indústria em termos financeiros. Por esse motivo, na primeira parte deste capítulo é feita uma análise do efeito desta não linearidade na planta-piloto de controle de vazão.

Para sintonizar o controlador PI da malha de vazão é utilizado o método da Síntese Direta. Este controlador irá operar em conjunto com os compensadores de atrito em válvulas de controle. Neste capítulo são descritos os compensadores CR, Knocker e 2move. Além disso, também é estudado um algoritmo para interromper a ação dos compensadores e do próprio controlador, para diminuir a variabilidade do sinal de controle.

\subsection{Efeito do atrito na malha de controle}

Em (CHOUDHURY; THORNHILL; SHAH, 2005) é feita uma análise da função descritiva do stiction, modelando-o como um ganho não linear no domínio da frequência. Desta forma, é possível predizer se haverá oscilações em malha fechada devido ao atrito. O diagrama da Figura 25 demonstra o processo modelado no domínio da frequência. O stiction é representado por $N\left(U_{c}(j w)\right)$, onde $U_{c}(j w)$ é a magnitude da harmônica da saída do controlador e $G_{p}(j w)$ e $G_{c}(j w)$ correspondem à função de transferência do processo e do controlador, respectivamente.

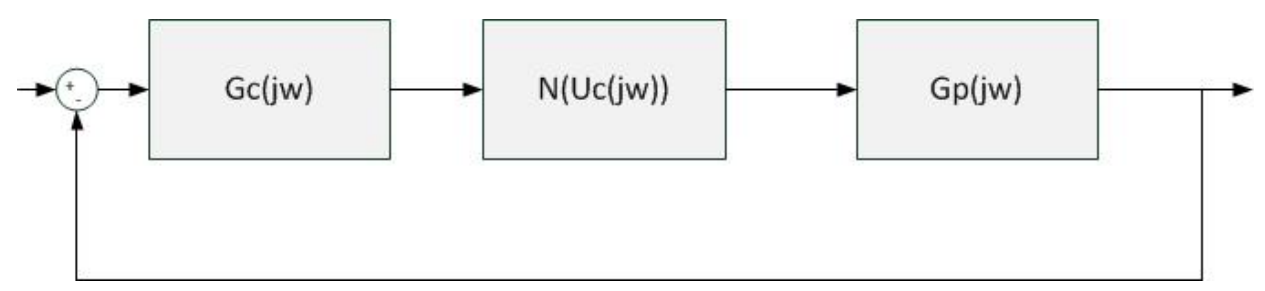

Figura 25: Digrama do processo de controle de vazão em malha fechada. 
Pelo diagrama da Figura 25 é possível concluir que o ganho do modelo em malha fechada é:

$$
G_{M F}(j w)=\frac{G_{p}(j w) G_{c}(j w) N\left(U_{c}\right)}{1+G_{p}(j w) G_{c}(j w) N\left(U_{c}\right)}
$$

Portanto, o sistema irá oscilar com ciclos limite apenas quando $G_{p}(j w) G_{c}(j w)=-1 / N\left(U_{c}\right)$. Neste trabalho o processo é modelado como sendo de primeira ordem com tempo morto, como na Equação (4.2). As constantes foram estimadas a partir da resposta do sistema a um degrau variando de $35 \%$ a $50 \%$ no sinal de controle do conversor I/P. O ganho do processo $\left(K_{p}\right)$ pode ser calculado como $\frac{\Delta V}{\Delta u}$, onde $\Delta V$ e $\Delta u$ são a variação da vazão e do sinal de controle, respectivamente. O valor do tempo morto $(\theta)$ é calculado verificando quanto tempo após o degrau a saída do processo começa a ter seu valor alterado. Por fim, a constante de tempo $(\tau)$ é numericamente igual à diferença entre o instante em que a saída do processo começa a ser alterada até o instante no qual o sistema atinge $63,2 \%$ da variação total da saída $(\Delta V)$. Os valores obtidos para cada uma das válvulas, considerando entrada e saída em porcentagem da variação máxima, são mostrados na Tabela 7. Antes do ensaio ser realizado, o sinal de controle estava em $0 \%$, portanto no instante em que ocorre o degrau não há mudança de direção e, consequentemente, não é necessário superar a banda morta para que haja movimento. Este fato é importante, pois é necessário modelar o processo desconsiderando o stiction.

$$
G_{p}(j w)=\frac{K_{p} e^{-\theta j w}}{1+\tau j w}
$$

Tabela 7: Constantes identificadas do modelo de primeira ordem do processo.

\begin{tabular}{|c|c|c|c|}
\hline Material das gaxetas & $K_{p}$ & $\tau$ & $\theta$ \\
\hline Teflon & $-0,880$ & 3,3090 & 0,44 \\
\hline Grafite & $-0,933$ & 3,6212 & 0,44 \\
\hline
\end{tabular}

Os ganhos obtidos são negativos devido às válvulas utilizadas neste trabalho serem do tipo ar para fechar. Além disso, elas têm característica de igual porcentagem, ou seja, a relação entre a posição da haste e a vazão não é linear. Pelo diagrama da Figura 7, a posição da haste em função da pressão no atuador é:

$$
y(t)=u(t)+\frac{d}{2}(S-J)
$$


Isto significa que embora tenha se usado o mesmo sinal para ensaiar ambas as válvulas, como os valores de $S$ e $J$ são diferentes, a posição da haste em relação à sede da válvula é diferente. Como o processo não é linear, os resultados obtidos são modelos aproximados em duas regiões diferentes de operação. Desta forma, mesmo as válvulas sendo idênticas, a menos das gaxetas, os resultados são diferentes para cada uma. As Figuras 26 e 27 mostram a resposta do sistema a um degrau de $15 \%$ de amplitude. A região de operação é considerada como o intervalo entre $55 \%$ e $65 \%$ da vazão máxima, pois esta região está dentro da variação obtida nos testes de identificação das duas válvulas.

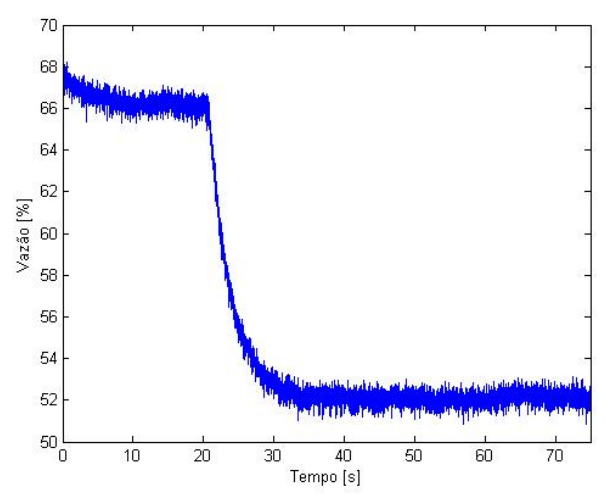

Figura 26: Resposta da válvula com gaxetas de teflon a um degrau de 15\% na entrada.

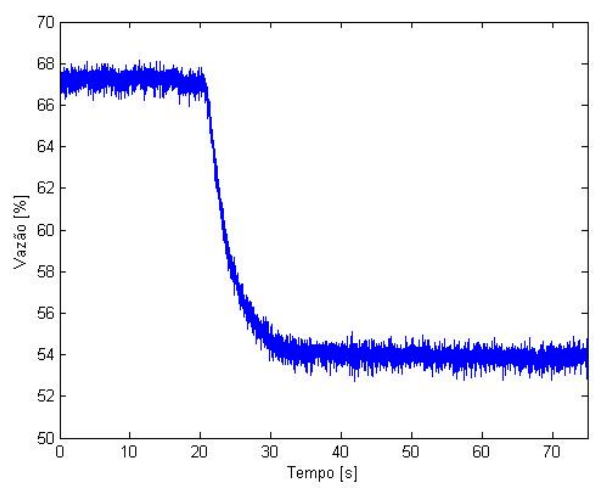

Figura 27: Resposta da válvula com gaxetas de grafite a um degrau de $15 \%$ na entrada.

A Equação (4.4) representa a função de transferência de um controlador PI.

$$
G_{c}(j w)=K_{c}\left(1+\frac{1}{T_{i} j w}\right)
$$

O único elemento da Equação (4.1) que não foi calculado é o termo relativo ao stiction $\left(N\left(U_{c}\right)\right)$. Em (CHOUDHURY; THORNHILL; SHAH, 2005) esta não-linearidade é modelada 
de acordo com:

$$
N\left(U_{c}\right)=-\frac{1}{\pi U_{c}}(A-j B)
$$

onde:

$$
\begin{aligned}
& A=\frac{U_{c}}{2} \sin 2 \phi-2 U_{c} \cos \phi-U_{c}\left(\frac{\pi}{2}+\phi\right)+2(S-J) \cos \phi \\
& B=-3 \frac{U_{c}}{2}+\frac{U_{c}}{2} \cos 2 \phi+2 U_{c} \sin \phi-2(S-J) \cos \phi \\
& \phi=\sin ^{-1}\left(\frac{U_{c}-S}{U_{c}}\right)
\end{aligned}
$$

Nas Equações (4.6), (4.7) e (4.8), $S$ e $J$ são os parâmetros do modelo de Kano. Para verificar se $G_{p}(j w) G_{c}(j w)=-1 / N\left(U_{c}\right)$ possui uma solução, os autores recomendam a utilização do método gráfico, ou seja, verificar se há sobreposição dos gráficos de $G_{p}(j w) G_{c}(j w)$ e $-1 / N\left(U_{c}\right)$.

Mais recentemente, Mohammad e Huang (2012) calculam para alguns casos específicos, baseado nas equações apresentadas anteriormente, quais as condições em que os ciclos limite estarão presentes na variável controlada. Para o caso de um controlador PI e um processo de primeira ordem, que é a situação considerada neste trabalho, os autores afirmam que se $J=0$ não irão ocorrer oscilações devido ao stiction. Caso a banda de agarramento não seja nula, se o tempo de integração do controlador for superior à constante de tempo do processo mais o seu tempo morto, também não irão ocorrer oscilações.

\subsection{Sintonia do Controlador PI}

Uma sintonia muito agressiva do controlador pode introduzir variabilidade na malha, mesmo sem a presença de não linearidades no processo. Por esse motivo é utilizado o método de sintonia da Síntese Direta a partir de um modelo linear aproximado do processo. Desta forma, é possível afirmar que qualquer oscilação no processo operando em malha fechada é devida à presença de não linearidades. A sintonia obtida é avaliada pelo método da seção anterior para verificar se o processo está sujeito a ciclos limite causados pelo stiction. 
Convertendo a Equação (4.1) para o domínio de Laplace e desconsiderando a nãolinearidade, após algumas manipulações matemáticas tem-se que:

$$
G_{c}(s)=\frac{1}{G_{p}(s)} \frac{G_{M F}(s)}{1-G_{M F}(s)}
$$

Desta forma, uma vez definido como se deseja que o sistema em malha fechada se comporte, é possível calcular a função de transferência do controlador. Porém, se $G_{M F}$ não for escolhido com cuidado, é possível que o controlador resultante não seja realizável. Por exemplo, caso se escolha $G_{M F}=1$, o controlador precisaria ter um ganho infinito. Seguindo a sugestão da literatura, o ganho em malha fechada é definido de acordo com a Equação (4.10) (SMITH; CORRIPIO; MARTIN JR., 1975).

$$
G_{M F}(s)=\frac{e^{-\theta_{M F}}}{\tau_{M F} s+1}
$$

A Equação (4.11) é obtida substituindo-se a Equação (4.10) na Equação (4.9) e considerando o modelo aproximado do processo dado pela Equação (4.2).

$$
G_{c}(s)=\frac{\tau s+1}{K_{p} e^{-\theta s}} \frac{e^{-\theta_{M F} s}}{1+\tau_{M F} s-e^{-\theta_{M F} s}}
$$

Obviamente o tempo morto do sistema em malha fechada deve ser maior ou igual ao tempo morto do processo em malha aberta. Por esse motivo é utilizado $\theta_{M F}=\theta$, que representa o menor valor possível. Porém, para que o controlador resultante tenha o formato de um controlador da família PID, o termo $e^{-\theta_{M F} s}$ no denominador da Equação (4.11) é aproximado pelos dois primeiros termos de sua expansão em série de Taylor, ou seja, $1-\theta_{M F} s$. O resultado desta aproximação é apresentado na Equação (4.12). Observe que o resultado corresponde a um controlador PI de ganho $K_{c}=\frac{\tau}{K_{p}\left(\tau_{M F}+\theta\right)}$ e tempo de integração $T_{i}=\tau$. Quanto menor for o valor de $\tau_{M F}$ mais agressivo será o controlador. O resultado obtido para $\tau_{M F}=5 \mathrm{~s}$ está representado na Tabela 8.

$$
G_{c}(s)=\frac{\tau s+1}{K_{p} e^{-\theta s}} \frac{e^{-\theta s}}{1+\tau_{M F} s-1+\theta_{M F} s}=\frac{\tau}{K_{p}\left(\tau_{M F}+\theta\right)}\left(1+\frac{1}{\tau s}\right)
$$

Segundo a avaliação da seção anterior é necessário que $T_{i}>\tau+\theta$ para que não haja oscilações no processo, portanto a sintonia obtida deve apresentar ciclos limite. No 
Tabela 8: Sintonias obtidas pelo método da Síntese Direta para o controlador PI.

\begin{tabular}{|c|c|c|}
\hline Material das gaxetas & $K_{c}$ & $T_{i}$ \\
\hline Teflon & $-0,6520$ & 3,3090 \\
\hline Grafite & $-0,7564$ & 3,6212 \\
\hline
\end{tabular}

próximo capítulo serão feitos ensaios para verificar se isto de fato ocorre e se aumentar o valor de $T_{i}$ é o suficiente para eliminar estas possíveis oscilações.

\subsection{Métodos de compensação}

Nesta seção são introduzidos os compensadores de atrito estático não baseados em modelo que serão avaliados, que, em sua maioria, utilizam o sinal de controle para definir a ação a ser tomada. Como é mostrado mais adiante, os algoritmos em questão são simples. Portanto, sua implementação em uma malha industrial não requer investimentos em novos equipamentos.

\subsubsection{CR}

Em (HÄGGLUND, 2007) é feita uma análise do fenômeno backlash. Este fenômeno insere uma banda morta, que também é um dos efeitos gerados pelo stiction. Para compensar essa não linearidade o autor propõe o seguinte algoritmo:

$$
u_{k}(t)=\frac{B M}{2} \operatorname{sgn}\left(\frac{d u_{c}(t)}{d t}\right)
$$

onde $B M$ é o tamanho da banda morta.

Posteriormente, Ivan e Lakshminarayanan (2009) utilizaram a mesma metodologia para compensar a banda morta e a banda de agarramento gerada pelo atrito, quando há mudança de direção no movimento da válvula. A Equação (4.14) representa o método proposto, considerando o parâmetro $S$ do modelo de Kano, e foi batizado pelos autores como Constant Reinforcement. A estrutura da malha de controle com este compensador pode ser visualizada na Figura 28.

$$
u_{k}(t)=\frac{S}{2} \operatorname{sgn}\left(\Delta u_{c}(t)\right)
$$




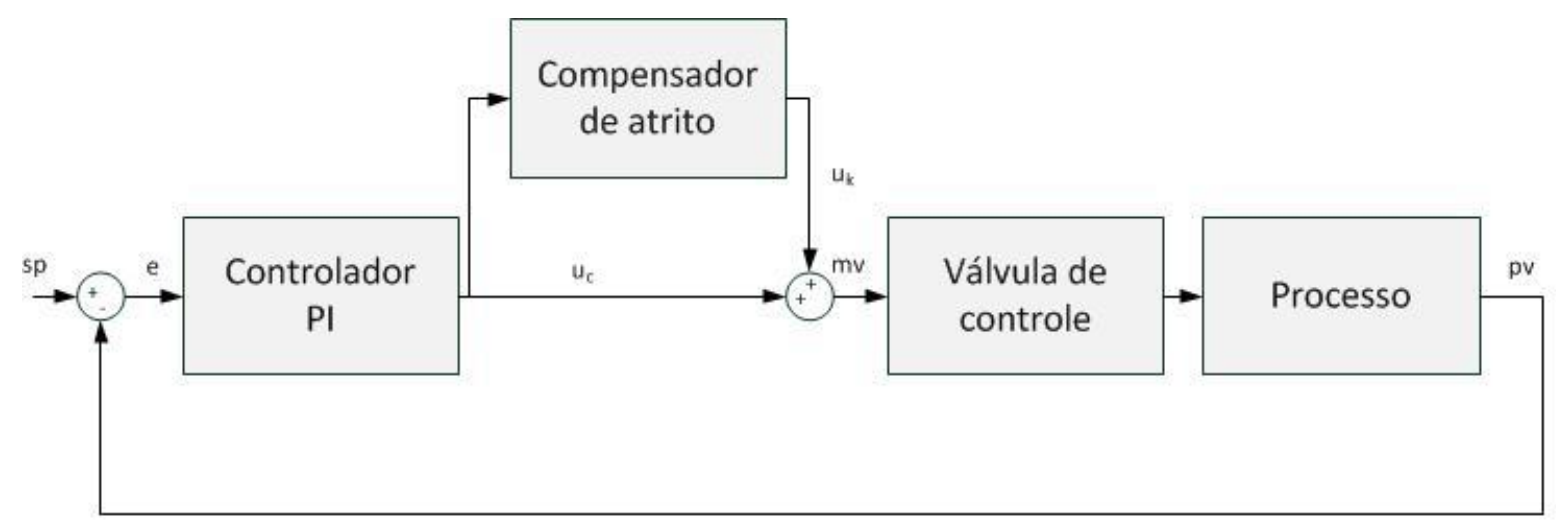

Figura 28: Estrutura da malha de controle de vazão com compensador CR.

Neste trabalho, além de utilizar o método como foi concebido, é analisada a alternativa proposta por Hägglund (2007), na qual ao invés de se considerar o sinal da derivada do sinal do controlador se considera o sinal do erro. Porém, está alteração foi aplicada ao compensador CR, como na Equação (4.15). A malha de controle neste caso é a apresentada na Figura 29. A partir deste ponto, a forma original é referenciada como CR1 e a alternativa como CR2.

$$
u_{k}(t)=\frac{S}{2} \operatorname{sgn}(e(t))
$$

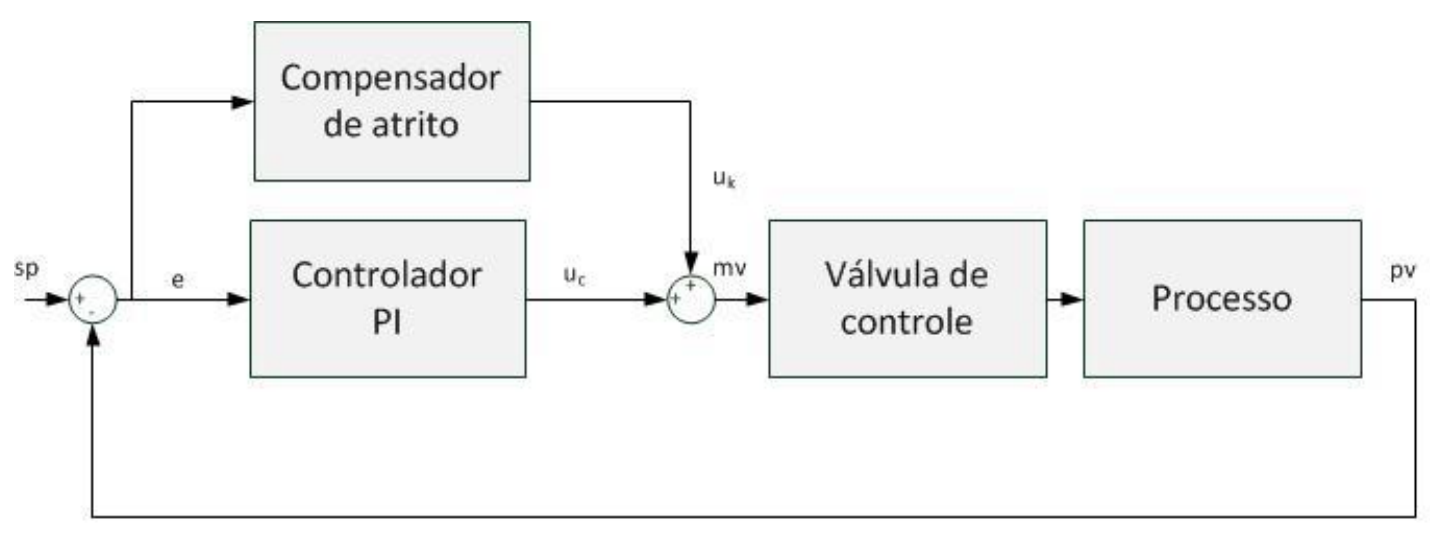

Figura 29: Estrutura da malha de controle de vazão com compensador CR2. 


\subsubsection{Knocker}

O compensador Knocker foi proposto em (HÄGGLUND, 2002). O método consiste na adição de pulsos de mesma amplitude e duração ao sinal do controlador, na mesma direção em que o sinal está sendo alterado. O objetivo é que a soma destes sinais gere pequenas variações na posição da haste a cada pulso, permitindo que a haste atinja a posição necessária para zerar o erro da variável controlada, mesmo com a presença do slip-jump. A Figura 30 apresenta o formato da saída do compensador.

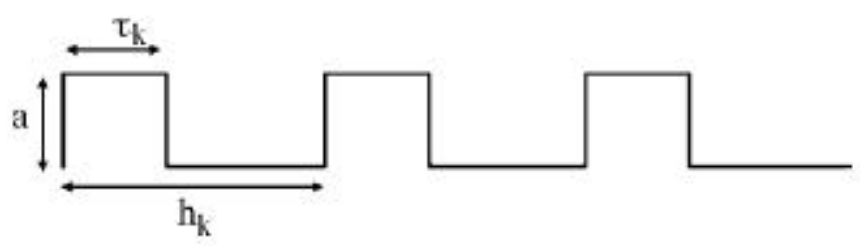

Figura 30: Saída do compensador Knocker.

O calculo da saída do compensador é feito pela Equação (4.16). A malha de controle com este algoritmo possui o mesmo formato do caso CR1 (Figura 28). Observe que o compensador possui três parâmetros a serem ajustados: a amplitude do pulso $(a)$, a largura do pulso $\left(\tau_{k}\right)$ e o intervalo entre pulsos $\left(h_{k}\right)$. A variável $t_{p}$ corresponde ao instante de início do pulso anterior.

$$
u_{k}(t)= \begin{cases}a \operatorname{sgn}\left(u_{c}(t)-u_{c}\left(t_{p}\right)\right) & t \leq t_{p}+\tau_{k}+h_{k} \\ 0 & t>t_{p}+\tau_{k}+h_{k}\end{cases}
$$

Ainda de acordo com (HÄGGLUND, 2002), a correta escolha dos valores dos parâmetros é de grande importância. Idealmente, a energia fornecida por cada pulso deve ser exatamente a necessária para superar o atrito estático, gerando portanto um pequeno movimento na haste. Porém, atingir esta sintonia ótima não é simples, por isso é recomendado utilizar pulsos de baixa energia que, somados a um controlador com ação integral, irão eventualmente gerar esses pequenos movimentos. O autor recomenda que o valor de $a$ esteja no intervalo $1 \%<a<4 \%$. Além disso, os valores recomendados para $\tau_{k}$ e $h_{k}$ são de uma a duas vezes o período de amostragem e de duas a cinco vezes o período de amostragem, respectivamente. Em seu trabalho, Srinivasan e Rengaswamy (2005) recomendaram que se utilize duas vezes o período de amostragem para $\tau_{k}$ e cinco vezes para $h_{k}$, o que está de acordo com o proposto anteriormente. Porém, os autores, após realizarem diversos 
ensaios com valores distintos de $a$, definiram um valor ótimo deste parâmetro em função da intensidade do atrito. O stiction é modelado pelo modelo de um parâmetro e, baseado neste modelo, o valor ótimo é $a=d_{m} / 2$.

Neste trabalho o valor de $h_{k}$ e $\tau_{k}$ são utilizados de acordo com a recomendação proposta por Srinivasan e Rengaswamy (2005), porém o valor de $a$ é baseado nos parâmetros do modelo de Kano. Para compensar o efeito da banda morta e da banda de agarramento/slipjump é utilizado $a=S / 2$.

\subsubsection{Algoritmo de desabilitação do controle}

Em seu trabalho, Cuadros (2011) realizou uma análise dos dois métodos de compensação descritos anteriormente. Verifica-se que, no caso de um set-point constante, após a haste atingir a posição de estabilização da variável controlada, os compensadores inserem diversas variações bruscas no sinal de controle, sem de fato mudar a posição da haste. Isso significa que estas variações são desnecessárias e o sinal de controle poderia ser mantido em um valor constante, até que o set-point seja mudado ou alguma perturbação altere o equilíbrio do sistema.

Com isso em mente, Cuadros (2011) propôs um algoritmo para fixar a saída do controlador quando a variável controlada estiver estável no valor de referência, descrito pelo diagrama da Figura 31. Quando o módulo da derivada do erro fica restrito a um valor inferior a um valor limite $\left(\delta_{1}\right)$ por um intervalo de tempo determinado $\left(T_{p}\right)$, considera-se que a haste atingiu uma posição próxima da ideal. Neste momento, o controlador PID é desativado, o que implica que, uma vez que o autor considera apenas os métodos CR1 e Knocker, o compensador de atrito também irá manter sua saída constante. Porém, caso haja alteração no set-point ou a variável controlada saia do valor de referência devido a alguma perturbação, é necessário reativar o controlador. Por isso, caso o erro da variável controlada seja superior a um segundo valor limite $\left(\delta_{2}\right)$ por quatro intervalos de amostragem seguidos, o controlador é reabilitado.

Neste trabalho é implementada uma versão levemente modificada deste algoritmo. Ao invés de considerar a derivada do erro, esta nova versão considera um erro aceitável $(\delta)$ para o processo. Se a variável controlada apresentar um erro inferior a $\delta$ por um período de $T_{p}$ segundos, o controlador é desabilitado. Para reabilitar o controlador é utilizado o mesmo sistema do método original, mas considerando o mesmo erro aceitável $(\delta)$. Esta alteração foi proposta para que o algoritmo possa ser utilizado sem a presença dos com- 


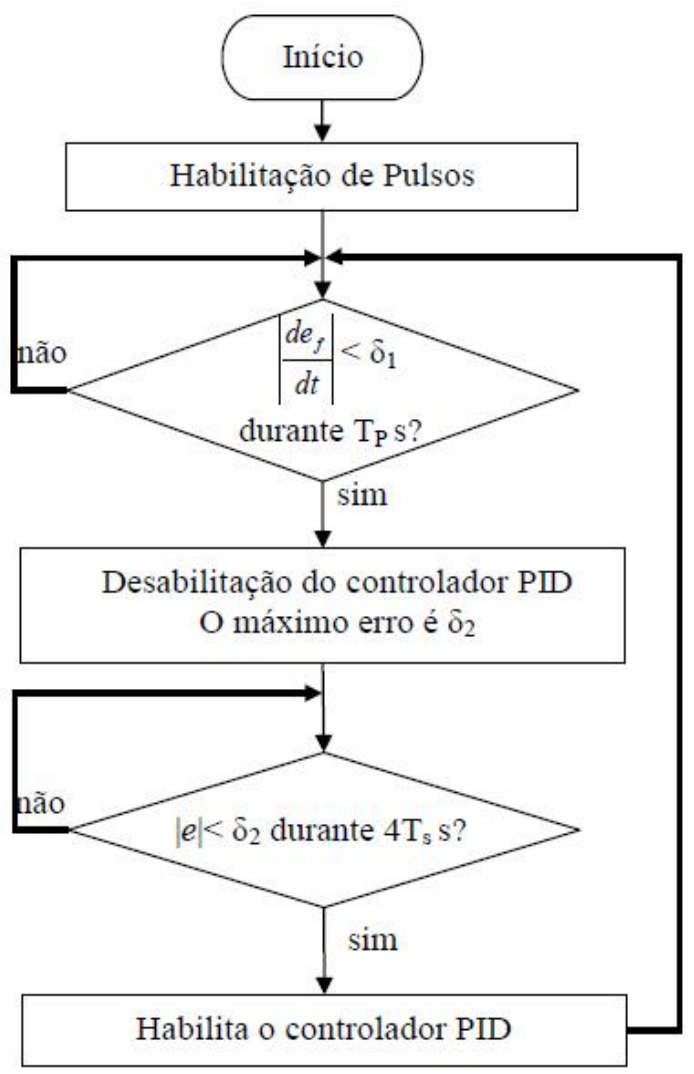

Figura 31: Algoritmo de desabilitação do controlador (CUADROS, 2011).

pensadores de atrito. Nesta situação a haste da válvula pode ficar parada por longos instantes de tempo em uma posição que não remove o erro na variável controlada. Desta forma, o algoritmo original iria desabilitar o controle sem que o erro estivesse próximo de zero.

\subsubsection{Two-move}

O compensador Two-move foi proposto em (SRINIVASAN; RENGASWAMY, 2008) com o objetivo de remover a variabilidade da variável controlada, sem incrementar a variabilidade do sinal de controle. Este compensador foi desenvolvido baseado no modelo de um parâmetro. O algoritmo deve ser iniciado quando a variável controlada estiver oscilando em torno de um set-point fixo.

Como o próprio nome sugere, o método se resume a inserir dois movimentos na válvula. O primeiro movimento afasta a válvula da posição em que o processo estabiliza no valor de referência, denominada $x_{S S}$. O segundo movimento consiste em levar a válvula exatamente à posição citada anteriormente. O primeiro movimento deve ser grande o suficiente 
para que no segundo movimento a haste atinja a posição desejada na fase de movimento e não no slip-jump. Entretanto, é necessário conhecer, além da amplitude da banda de agarramento $\left(d_{m}\right.$ - no modelo de um parâmetro, $J$ no modelo de Kano), qual valor do sinal de controle estabiliza o processo no set-point desejado. As Equações (4.17) e (4.18) descrevem o sinal de compensação que realiza os dois movimentos mencionados.

$$
\begin{aligned}
& 1^{\mathrm{o}} \text { Movimento: } u_{k}(t)=\operatorname{sgn}\left(\frac{d u_{c}(t)}{d t}\right)\left(\left|u_{c}(t)\right|+d_{m}\right) \\
& 2^{\mathrm{o}} \text { Movimento: } u_{k}(t+1)=-u_{c}(t+1)
\end{aligned}
$$

As Equações (4.17) e (4.18) foram propostas considerando que a haste atinja a posição $x_{S S}$ com um sinal de controle nulo. Para tornar o compensador mais abrangente, basta somar $u_{S S}$, que corresponde ao valor do sinal de controle que estabiliza a válvula na posição $x_{S S}$. Desta forma obtém-se:

$$
\begin{aligned}
& 1^{\mathrm{o}} \text { Movimento: } u_{k}(t)=\operatorname{sgn}\left(\frac{d u_{c}(t)}{d t}\right)\left(\left|u_{c}(t)\right|+d_{m}\right)+u_{S S} \\
& 2^{\mathrm{o}} \text { Movimento: } u_{k}(t+1)=-\left(u_{c}(t+1)-u_{S S}\right)
\end{aligned}
$$

O modelo de um parâmetro não considera a existência de uma banda morta, como é o caso das válvulas em teste. Neste caso o valor de $u_{S S}$ não é único, assumindo valores diferentes, dependendo da direção do movimento que a válvula irá realizar para atingir a posição $x_{S S}$ (CUADROS, 2011). Além disso, se o primeiro movimento for realizado com a válvula parada e tiver direção contrária ao último movimento realizado, será necessário uma variação de pelo menos $S$ no sinal de controle para que a mesma se mova. As Equações (4.21) e (4.22) são obtidas adaptando o compensador para o modelo de 2 parâmetros.

$$
\begin{aligned}
& 1^{\mathrm{o}} \text { Movimento: } u_{k}(t)=\operatorname{sgn}\left(\frac{d u_{c}(t)}{d t}\right)\left(\left|u_{c}(t)\right|+S\right) \\
& 2^{\mathrm{o}} \text { Movimento: } \begin{cases}u_{k}(t+1)=-\left(u_{c}(t+1)-u_{S}\right) & e(t+1)>0 \\
u_{k}(t+1)=-\left(u_{c}(t+1)-u_{S}-S+J\right) & e(t+1)<0\end{cases}
\end{aligned}
$$

onde $u_{S}$ corresponde ao sinal de controle que estabiliza a haste em $x_{S S}$ quando a mesma está subindo. 
Baseado nessas observações e pensando em remover a necessidade de conhecer o valor de $u_{S S}$, Cuadros (2011) desenvolveu uma nova versão deste compensador. Esta consiste de quatro movimentos ao invés de dois, como proposto no método original. O primeiro movimento afasta a haste da posição de equilíbrio do sistema. O segundo passo realiza um pequeno movimento da haste em direção à posição desejada, apenas para retirar o efeito da banda morta nos próximos movimentos. Em seguida é realizado um novo movimento na mesma direção, que é utilizado para estimar o ganho estacionário do processo. Com este ganho é possível calcular qual a amplitude do último movimento de forma a levar a haste à posição de erro nulo. Novamente esta posição deve ser atingida na fase de movimento.

Apesar de remover algumas das desvantagens do método original, esta versão ainda é sensível a perturbações no processo, tanto durante o cálculo do ganho estacionário como após o último movimento. Por esse motivo, optou-se por utilizar uma terceira variação deste compensador, proposta em (ELY; LONGHI, 2011). Neste compensador de atrito, a sua saída $(O P C)$ não é somada ao sinal do controlador, mas é o próprio sinal enviado à válvula de controle. A Figura 32 apresenta a estrutura da malha de controle com este compensador. Esta metodologia também foi desenvolvida levando em consideração o modelo de um parâmetro, com banda de agarramento $d_{m}$.

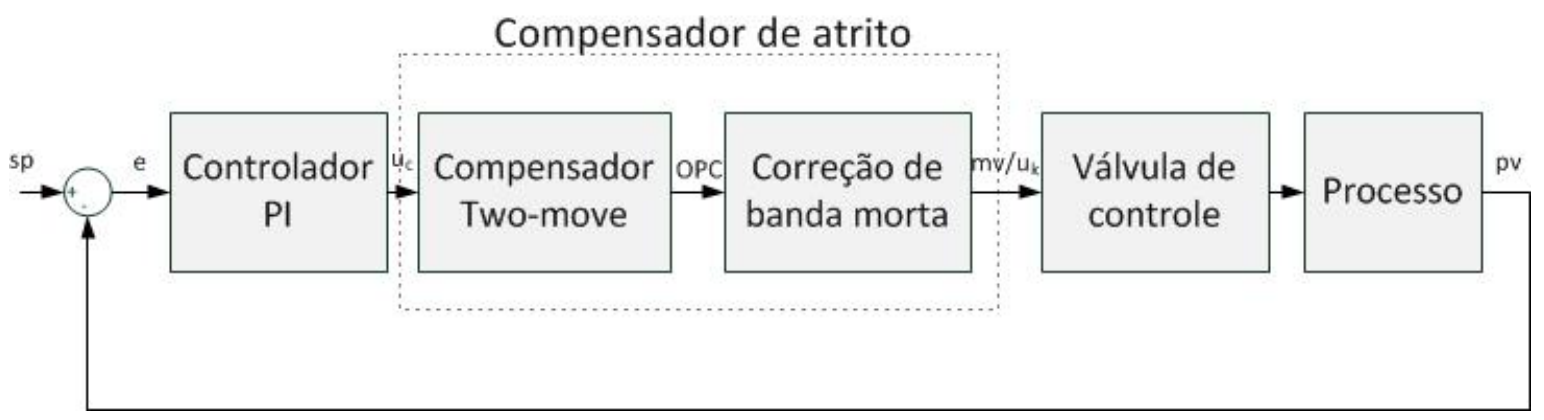

Figura 32: Estrutura da malha de controle de vazão com compensador Two-move modificado.

A ação tomada pelo compensador depende da magnitude de $\left|u_{c}\left(t_{k}\right)-O P C\left(t_{k-1}\right)\right|$, onde $t_{k}$ é a amostragem atual do sinal e $t_{k-1}$ a última amostragem. Caso este valor seja superior a $d_{m}$, o valor de $O P C\left(t_{k}\right)$ é igual ao valor de $u_{c}\left(t_{k}\right)$, pois neste caso esta variação já é suficientemente grande para que haja movimento. O segundo caso é quando $\left|u_{c}\left(t_{k}\right)-O P C\left(t_{k-1}\right)\right|$ é menor que $d_{m}$ e maior que uma banda de saída $(B O P)$. Nesta situação entende-se que o sinal do controlador está tentando gerar um movimento menor do que o slip-jump e neste ponto o conceito do compensador Two-move é aplicado. Os 
dois movimentos realizados neste caso são descritos pelas equações (4.23) e (4.24).

$1^{\mathrm{o}}$ Movimento: $O P C\left(t_{k}\right)=O P C\left(t_{k-1}\right)+\operatorname{sgn}\left(u_{c}\left(t_{k}\right)-O P C\left(t_{k-1}\right)\right)\left(\left|u_{c}\left(t_{k}\right)-O P C\left(t_{k-1}\right)\right|+d_{m}\right)$

$2^{\mathrm{o}}$ Movimento: $O P C\left(t_{k+1}\right)=O P C\left(t_{k}\right)-\operatorname{sgn}\left(u_{c}\left(t_{k}\right)-O P C\left(t_{k-1}\right)\right) d_{m}$

No caso de $\left|u_{c}\left(t_{k}\right)-O P C\left(t_{k-1}\right)\right|<B O P$ a saída do compensador não se altera. Os autores deste algoritmo ressaltam que a correta escolha do valor de $B O P$ é muito importante para o melhor desempenho do compensador. Obviamente, $B O P$ tem que ser menor que $d_{m}$, porém se a banda de saída for muito próxima da banda de agarramento, os ciclos limite do processo podem não ser eliminados. Já um valor muito pequeno para esta constante irá aumentar consideravelmente a variabilidade do sinal de controle. Os autores sugerem também a inserção de uma banda morta no ganho integral do controlador, evitando que erros muito pequenos gerem movimentações na válvula.

Como no compensador Two-Move, esta variação precisa ser adaptada para o modelo de dois parâmetros, uma vez que as válvulas de teste possuem banda morta. Inicialmente é adicionado o cálculo da direção do movimento a ser realizado $(d)$ e o parâmetro $d_{m}$ é substituído por $J$. Desta forma, a ação do compensador é:

- $1^{\circ}$ caso $\left|u_{c}\left(t_{k}\right)-O P C\left(t_{k-1}\right)\right|>J: O P C\left(t_{k}\right)=u_{c}\left(t_{k}\right)$ e $d\left(t_{k}\right)=\operatorname{sgn}\left(u_{c}\left(t_{k}\right)-\right.$ $\left.O P C\left(t_{k-1}\right)\right)$

- $2^{\circ}$ caso $B O P<\left|u_{c}\left(t_{k}\right)-O P C\left(t_{k-1}\right)\right| \leq J$ : Primeiro movimento é $O P C\left(t_{k}\right)=$ $O P C\left(t_{k-1}\right)+\left(\left|u_{c}\left(t_{k}\right)-O P C\left(t_{k-1}\right)\right|+J\right) \operatorname{sgn}\left(u_{c}\left(t_{k}\right)-O P C\left(t_{k-1}\right)\right) ; d\left(t_{k}\right)=\operatorname{sgn}\left(u_{c}\left(t_{k}\right)-\right.$ $\left.O P C\left(t_{k-1}\right)\right)$. O segundo movimento é $O P C\left(t_{k}\right)=O P C\left(t_{k-1}\right)-J_{\operatorname{sgn}}\left(u_{c}\left(t_{k}\right)-\right.$ $O P C\left(t_{k-1}\right) ; d\left(t_{k}\right)=-d\left(t_{k-1}\right)$

- $3^{\circ}$ caso $\left|u_{c}\left(t_{k}\right)-O P C\left(t_{k-1}\right)\right|<B O P$ : $O P C\left(t_{k}\right)=O P C\left(t_{k-1}\right)$ e $d\left(t_{k}\right)=d\left(t_{k-1}\right)$

A saída do compensador não é mais o sinal $\mathrm{OPC}$, mas sim a variável $u_{k}$ dada pela Equação (4.25). O intuito desta alteração é compensar a banda morta do processo de forma semelhante à proposta de Hägglund (2007). É importante lembrar que $S$ representa a soma da banda morta com a banda de agarramento, enquanto a magnitude da banda morta é $S-J$. A compensação deste fenômeno não pode ser inserida diretamente 
na variável OPC, pois isto iria influenciar no cálculo de $\left|u_{c}\left(t_{k}\right)-O P C\left(t_{k-1}\right)\right|$.

$$
u_{k}\left(t_{k}\right)=O P C\left(t_{k}\right)+d \frac{(S-J)}{2}
$$

Os ensaios com este compensador foram realizados inserindo uma zona morta de $0,5 \%$ no ganho integral do controlador, como sugerido pelos autores do método. Além disso, o controlador é desabilitado no período em que o compensador realiza os dois movimentos para correção de posição ( $2^{\circ}$ caso). O primeiro movimento terá duração de dois segundos, para que o movimento da haste não seja interrompido antes de atingir a posição final. A saída do compensador é mantida constante por quatro segundos após o segundo movimento. Durante estes movimentos, a variável controlada irá se afastar do valor desejado, portanto é necessário desabilitar o controlador. Caso contrário, o ganho integral do controlador irá gerar uma variação no saída do controlador, o que significa que após o posicionamento da haste o compensador irá movimentar a haste novamente, mesmo que se tenha atingido a posição que anula o erro da variável do processo. Ainda no caso da correção da posição, caso uma alteração de $J$ no sinal de controle não seja suficiente para gerar movimento na haste, o compensador não irá realizar pequenos ajustes na posição, portanto não será capaz de compensar o efeito do slip-jump. Por esse motivo foi adicionado $0,5 \%$ à amplitude dos movimentos de correção de posição, garantindo que quando forem realizados a haste de fato irá se mover nos dois casos. 


\section{$5 \quad$ Resultados Experimentais}

Neste capítulo são analisados os resultados obtidos com a aplicação das técnicas discutidas no capítulo anterior na planta piloto de vazão.

A análise dos resultados é feita por meio de quatro índices de desempenho. O primeiro é a integral do erro absoluto vezes o tempo (ITAE), que é usado para avaliar o desempenho do sistema em acompanhar o set-point e rejeitar perturbações. O cálculo padrão deste índice insere pesos maiores para erros que ocorrem em instantes de tempo mais distantes do ínicio do teste. Porém, os ensaios foram feitos inserindo quatro alterações no sistema a cada 1200 s (podendo ser troca de set-point ou uma perturbação). Pelo cálculo normal, a resposta do sistema à ultima alteração terá peso maior do que no resto do experimento. Para que isto não ocorra o índice foi calculado neste trabalho como a média dos ITAEs em cada uma das cinco regiões do ensaio. A Equação (5.1) respresenta esta cálculo, onde $k_{1}, k_{2}, k_{3}, k_{4}$ e $k_{5}$ correspondem ao número da última amostra de cada região e $k_{0}=0$.

O próximo índice, representado pela Equação (5.2), está associado ao desgaste gerado na válvula de controle. Analogamente, a Equação (5.3) está relacionada ao desgaste do conversor I/P. Nas equações citadas anteriormente, $\Delta t$ é o tamanho do intervalo de tempo considerado, $e(k)$ é o erro da variável controlada em relação ao set-point, $x(k)$ é a posição da haste e $P(k)$ é a pressão no atuador. O último índice é o tempo de subida $\left(t_{r}\right)$, que neste trabalho é definido como a média dos intervalos de tempo entre uma mudança no valor de referência e o primeiro cruzamento da variável controlada com o set-point.

$$
I T A E=\sum_{i=0}^{4}\left(\frac{1}{1200} \sum_{k=k_{i}+1}^{k_{(i+1)}}|e(k)(t(k)-1200 i)|\right) \frac{1}{5}
$$




$$
\begin{gathered}
D_{v}=\sum|x(k)-x(k-1)| \\
D_{I P}=\sum|P(k)-P(k-1)|
\end{gathered}
$$

\subsection{Compensadores atuando no controle de vazão}

A primeira sequência de ensaios testa a capacidade das malhas em seguir degraus no set-point. A segunda verifica a capacidade das mesmas em rejeitar perturbações na variável controlada.

\subsubsection{Ensaios para o problema servo}

Os ensaios realizados a seguir foram feitos com um período de amostragem de $0,5 \mathrm{~s}$, que é o mesmo intervalo de tempo entre cada iteração do controlador PI. O set-point de todos os ensaios é uma sequência de degraus, sendo os dois primeiros degraus positivos de $5 \%$ seguidos por dois degraus negativos de 5\%. O valor inicial do set-point é $55 \%$ da variação máxima medida pelo transmissor e a duração de cada patamar é de $1200 \mathrm{~s}$, para que sejam visualizadas possíveis oscilações na variável controlada.

Os gráficos das Figuras 33 e 34 apresentam os resultados obtidos com a sintonia pelo método da Síntese Direta, considerando que $\tau_{M F}=5 \mathrm{~s}$, e sem a presença do compensadores de atrito.

Novamente a diferença entre os níveis de atrito das duas válvulas fica evidente. Enquanto a válvula com baixo índice de atrito apresenta oscilações muito pequenas em torno do valor de referência, a segunda válvula apresenta oscilações muito maiores. Em uma planta real essas oscilações reduzem a eficiência do processo e a qualidade do produto final. Além disso, é possível verificar que, para o caso da válvula com gaxetas de grafite, 


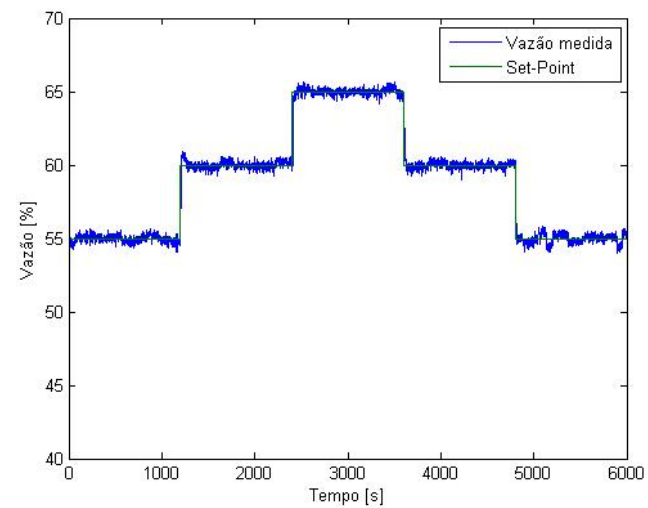

(a) Vazão

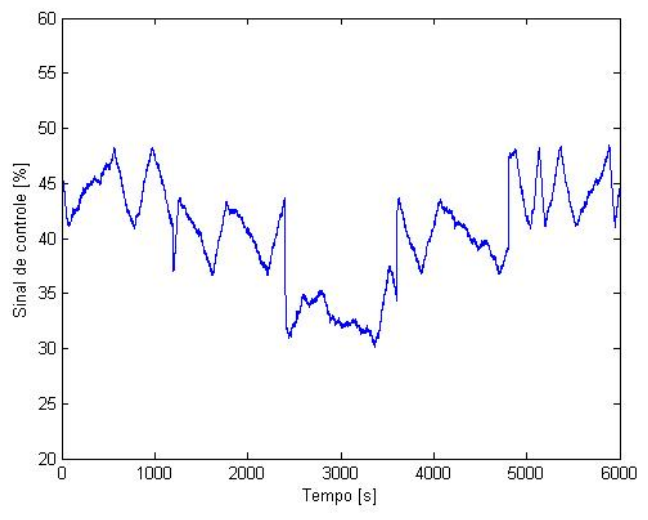

(b) Sinal de controle

Figura 33: Resultados obtidos no ensaio de acompanhamento de set-point da válvula com gaxetas de teflon com controlador PI (sintonia pelo método da Síntese Direta).

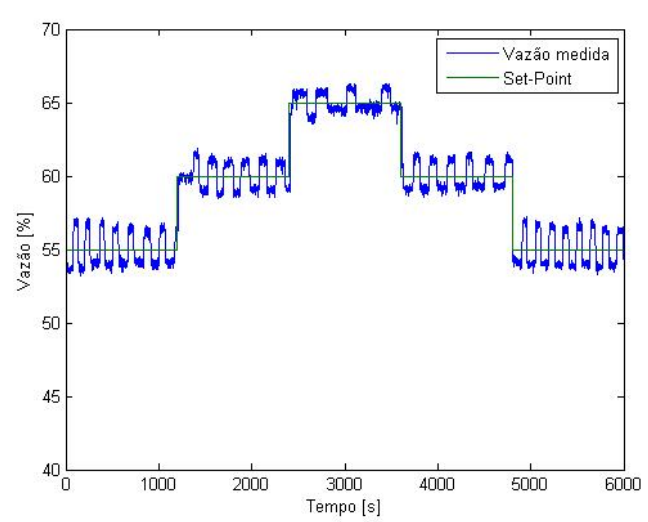

(a) Vazão

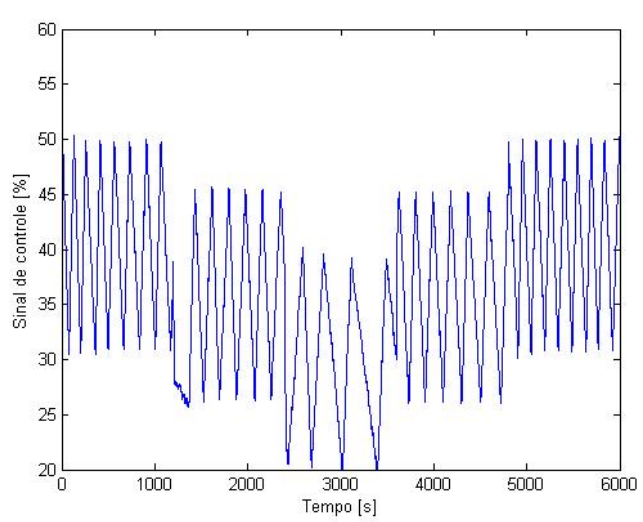

(b) Sinal de controle

Figura 34: Resultados obtidos no ensaio de acompanhamento de set-point da válvula com gaxetas de grafite com controlador PI (sintonia pelo método da Síntese Direta).

a variabilidade do sinal de controle também é muito maior do que a da primeira válvula. Esse efeito não afeta diretamente o processo, porém diminui a vida útil dos equipamentos e, conforme as gaxetas são desgastadas pelo movimento da haste, se torna necessário comprimir mais as gaxetas contra a haste para evitar vazamentos, o que agrava ainda mais o problema do atrito na válvula.

Para tentar remover estas oscilações, a sintonia do controlador foi modificada com base na teoria vista na Seção 4.1. Como foi apresentado anteriormente, as oscilações não existirão se o valor do parâmetro $T_{i}$ for maior que $\tau+\theta$. No caso da sintonia $\mathrm{SD} T_{i}=\tau$. Em (MOHAMMAD; HUANG, 2012) esta teoria é aplicada em uma planta real, aumentando o valor de $T_{i}$ para uma valor em torno de $3(\tau+\theta)$. Seguindo este experimento, os ensaios foram refeitos, utilizando $T_{i}=12 \mathrm{~s}$ e $T_{i}=16 \mathrm{~s}$ e mantendo os valores de $K_{c}$ originais. Essas sintonias são referenciadas como Sintonia I e Sintonia II, respectivamente. Os resultados 
são apresentados nas Figuras 35, 36, 37 e 38.

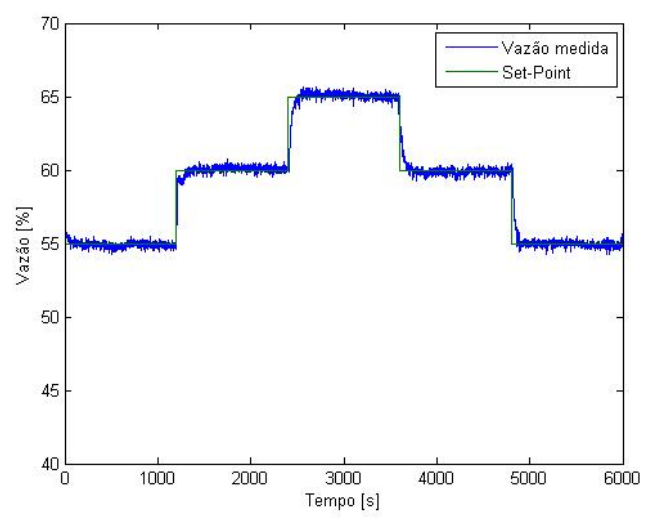

(a) Vazão

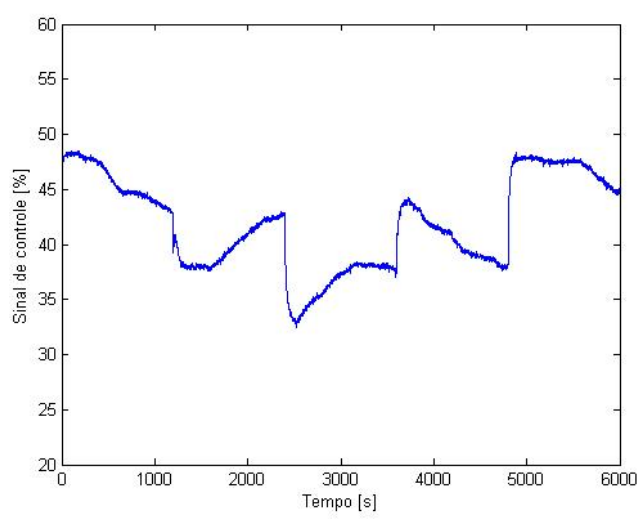

(b) Sinal de controle

Figura 35: Resultados obtidos no ensaio de acompanhamento de set-point da válvula com gaxetas de teflon com controlador PI ( $T_{i}$ aumentado para 12$)$.

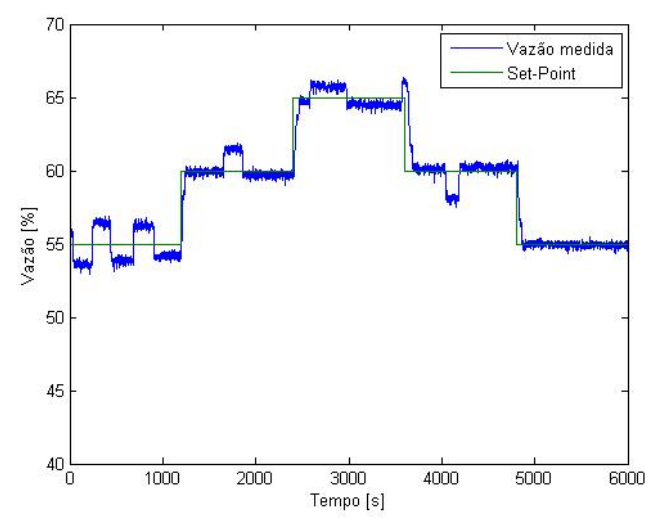

(a) Vazão

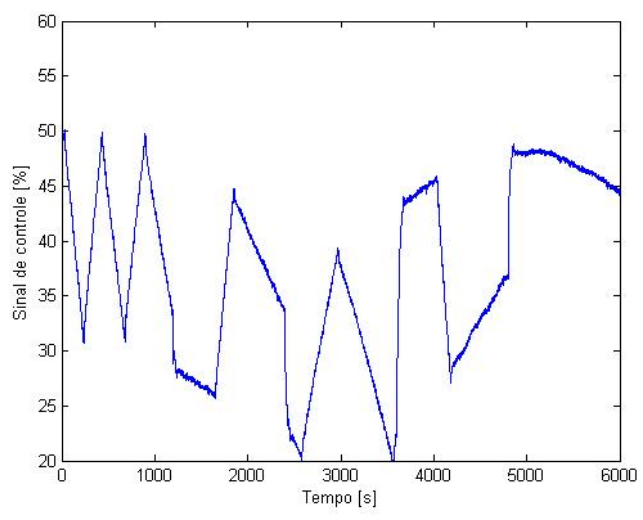

(b) Sinal de controle

Figura 36: Resultados obtidos no ensaio de acompanhamento de set-point da válvula com gaxetas de grafite com controlador PI ( $T_{i}$ aumentado para 12$)$. 


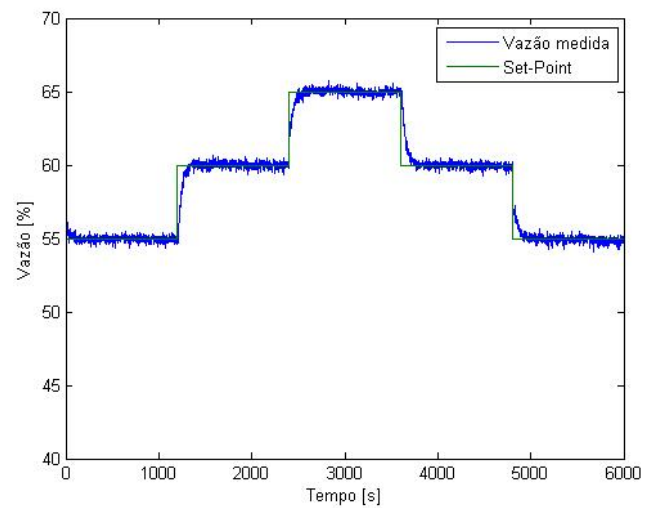

(a) Vazão

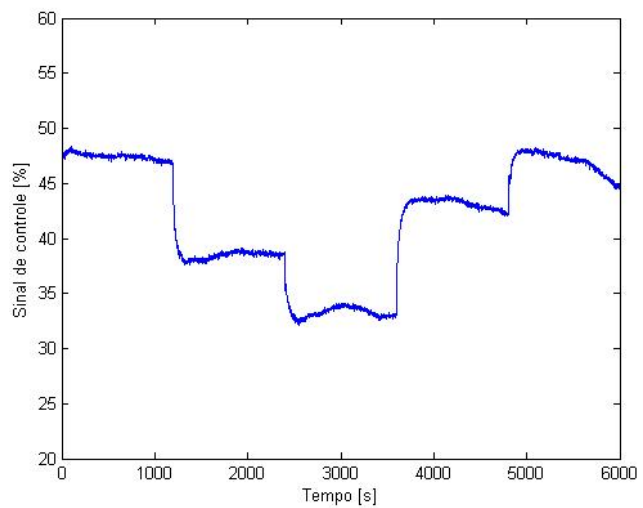

(b) Sinal de controle

Figura 37: Resultados obtidos no ensaio de acompanhamento de set-point da válvula com gaxetas de teflon com controlador PI ( $T_{i}$ aumentado para 16).

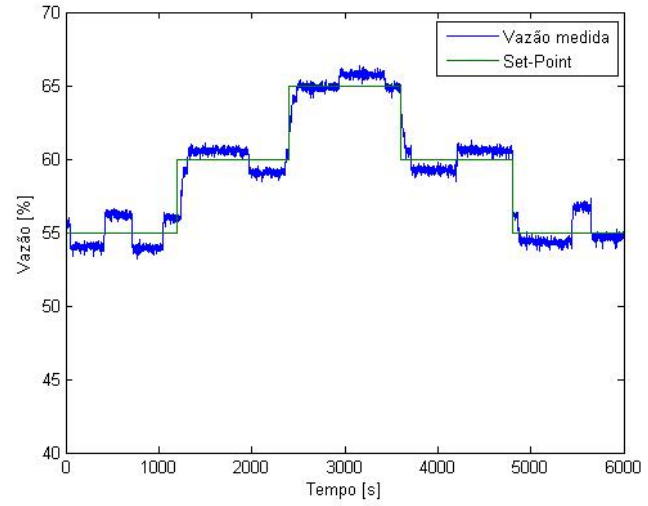

(a) Vazão

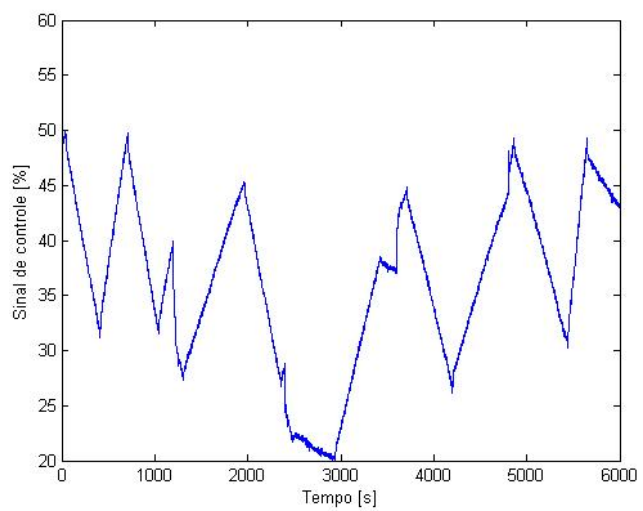

(b) Sinal de controle

Figura 38: Resultados obtidos no ensaio de acompanhamento de set-point da válvula com gaxetas de grafite com controlador PI ( $T_{i}$ aumentado para 16$)$.

As Tabelas 9 e 10 apresentam os índices de desempenho para cada ensaio nas válvulas com gaxetas de teflon e grafite, respectivamente. Para a válvula de baixo atrito, o primeiro incremento de $T_{i}$ acarreta em um pequeno decremento do ITAE e na variabilidade da haste. Porém, o segundo aumento de $T_{i}$ causa um leve incremento na variabilidade da haste. O mesmo pode ser observado para a variabilidade da pressão no atuador, porém a diferença entre a sintonia original e a segunda sintonia é muito maior que nas situações anteriores.

Enquanto a alteração da sintonia não apresenta nenhuma melhora significativa para a primeira válvula, a segunda apresenta um comportamento diferente. Quando o tempo de integração do controlador é aumentado para 12 s, o ITAE diminui quase pela metade 
do valor obtido com a sintonia original. Além disso, é observada um redução da variabilidade dos atuadores, que é ainda maior quando $T_{i}=16 \mathrm{~s}$. Porém, neste caso, o ITAE é maior, provavelmente devido à demora para a malha de controle superar a banda morta do sistema. Obviamente este recurso também causa um aumento no tempo de subida do sistema, pois a malha de controle se torna mais lenta. Portanto, apesar de representar uma técnica simples de ser implementada (considerando que seja possível modelar o processo sem a presença do stiction), sua aplicabilidade depende da importância da velocidade de resposta para o processo em questão.

Tabela 9: Índices de desempenho dos ensaios de acompanhamento de set-point com sintonias diferentes do controlador (válvula com gaxetas de teflon).

\begin{tabular}{|c|c|c|c|c|}
\hline Ensaio & ITAE [\%] & $D_{v}[\%]$ & $D_{I P}[\%]$ & $t_{r}[\mathrm{~s}]$ \\
\hline PI convencional (Síntese Direta) & 213,7376 & 78,4151 & 148,3319 & 19,875 \\
\hline PI convencional $\left(T_{i}=12\right)$ & 175,7412 & 63,9592 & 76,0415 & 84,750 \\
\hline PI convencional $\left(T_{i}=16\right)$ & 152,6927 & 74,3894 & 79,2315 & 109,250 \\
\hline
\end{tabular}

Tabela 10: Índices de desempenho dos ensaios de acompanhamento de set-point com sintonias diferentes do controlador (válvula com gaxetas de grafite).

\begin{tabular}{|c|c|c|c|c|}
\hline Ensaio & ITAE $[\%]$ & $D_{v}[\%]$ & $D_{I P}[\%]$ & $t_{r}[\mathrm{~s}]$ \\
\hline PI convencional (Síntese Direta) & 1098,7275 & 180,9013 & 786,8646 & 24,625 \\
\hline PI convencional $\left(T_{i}=12\right)$ & 624,5438 & 101,2551 & 187,9176 & 74,500 \\
\hline PI convencional $\left(T_{i}=16\right)$ & 867,4861 & 84,5418 & 163,4746 & 98,625 \\
\hline
\end{tabular}

Apesar dos resultados obtidos, todos os testes com os compensadores foram realizados com a sintonia obtida pelo método da Síntese Direta. Esta sintonia foi obtida desconsiderando o efeito do atrito e cabe aos compensadores minimizar este efeito.

Nas Figuras 39 a 44 são apresentados os resultados obtidos com os compensadores CR1, CR2 e Knocker. Os compensadores CR1 e CR2 são atualizados a cada 1 s, para evitar mudanças em sua saída em um intervalo de tempo muito pequeno. As Tabelas 11 e 12 apresentam os índices de desempenho obtidos.

A válvula com gaxetas de teflon apresenta índices piores com os compensadores do que os obtidos sem eles, com exceção do tempo de subida. Porém, novamente os métodos se mostram eficazes para a válvula de alto atrito, atingindo valores de ITAE iguais ou melhores aos obtidos na primeira válvula. Os métodos inclusive chegam a diminuir a variabilidade da haste e o tempo de subida. Entretanto, o custo desta melhora é um aumento drástico na variabilidade da pressão no atuador, chegando a valores de duas a 


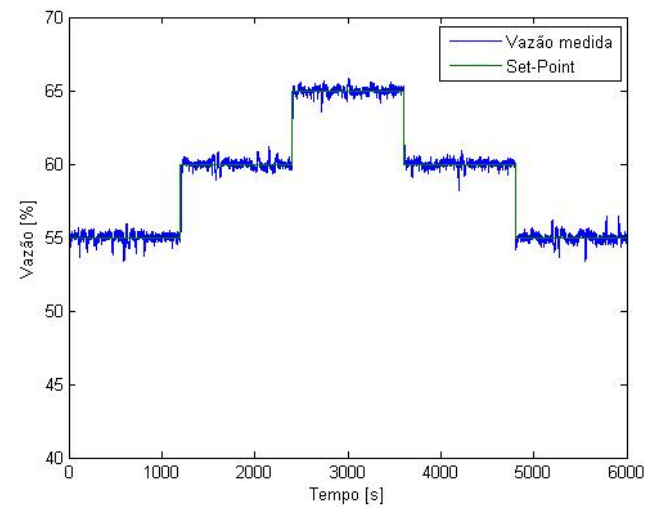

(a) Vazão

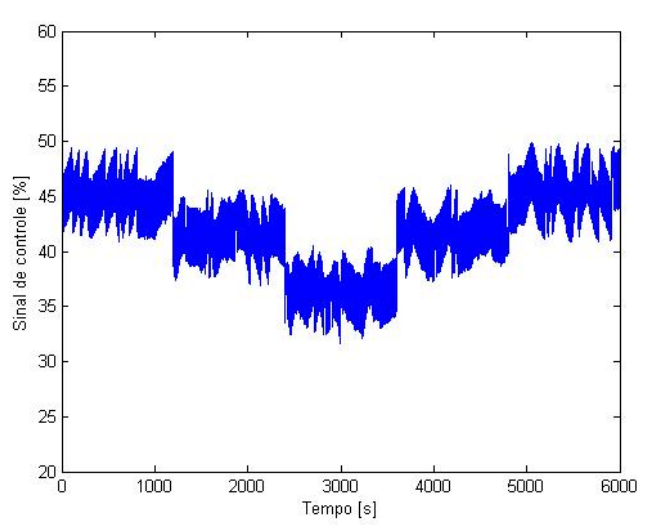

(b) Sinal de controle

Figura 39: Resultados obtidos no ensaio de acompanhamento de set-point da válvula com gaxetas de teflon com compensador CR1 (teflon).

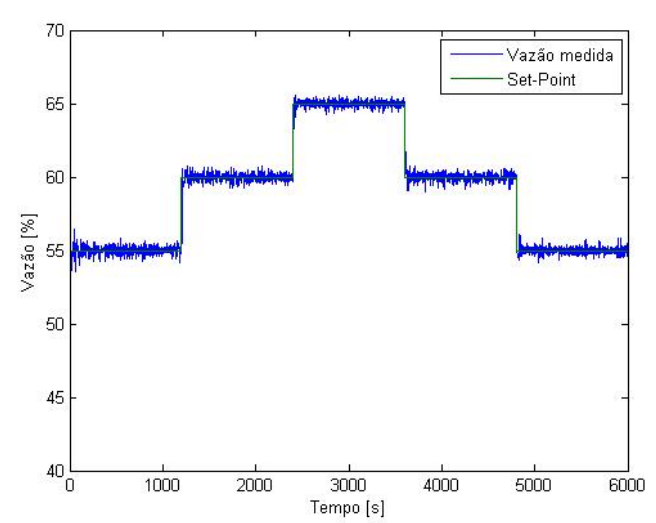

(a) Vazão

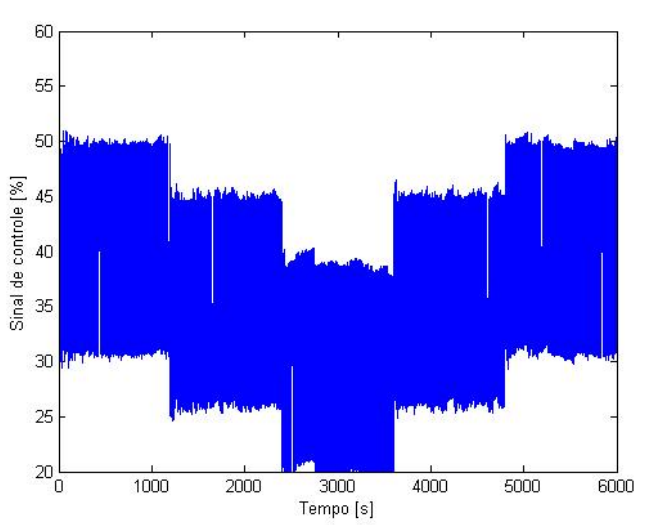

(b) Sinal de controle

Figura 40: Resultados obtidos no ensaio de acompanhamento de set-point da válvula com gaxetas de grafite com compensador CR1.

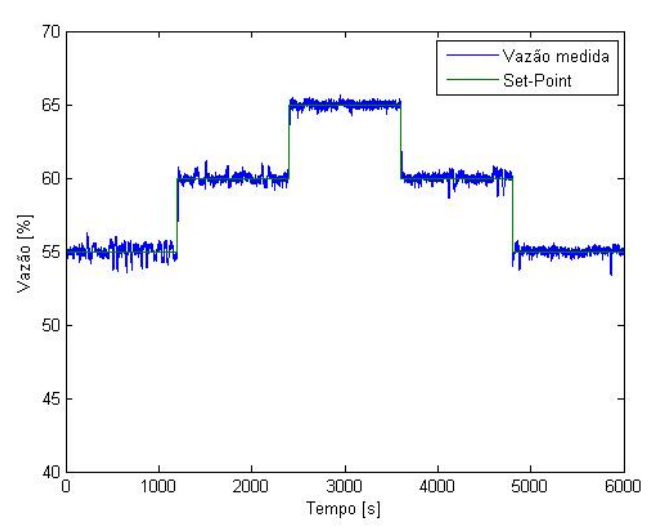

(a) Vazão

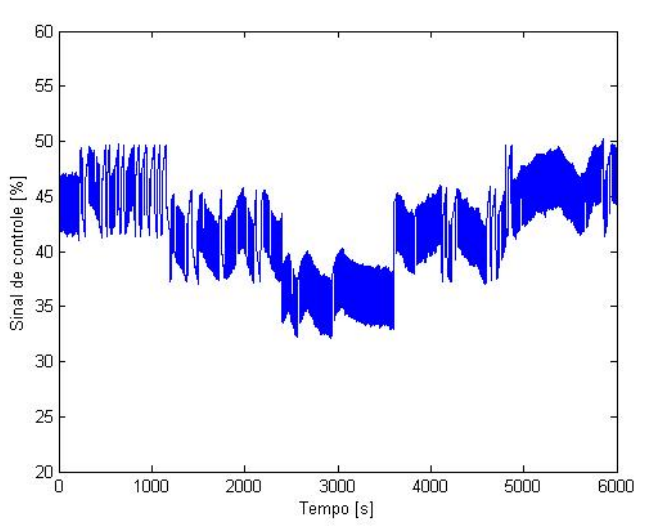

(b) Sinal de controle

Figura 41: Resultados obtidos no ensaio de acompanhamento de set-point da válvula com gaxetas de teflon com compensador CR2. 


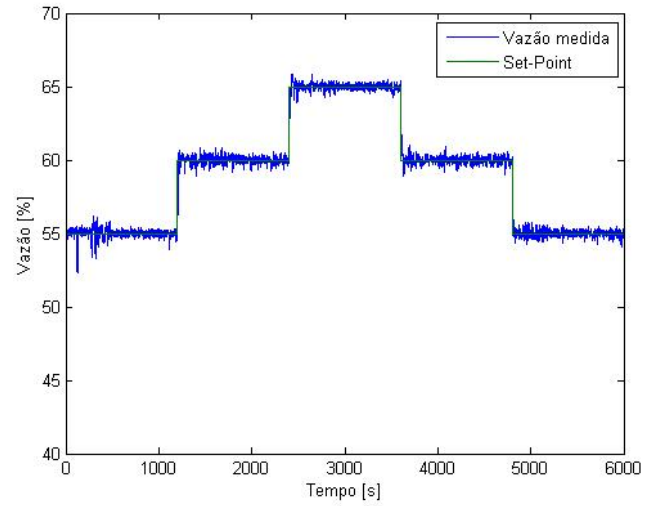

(a) Vazão

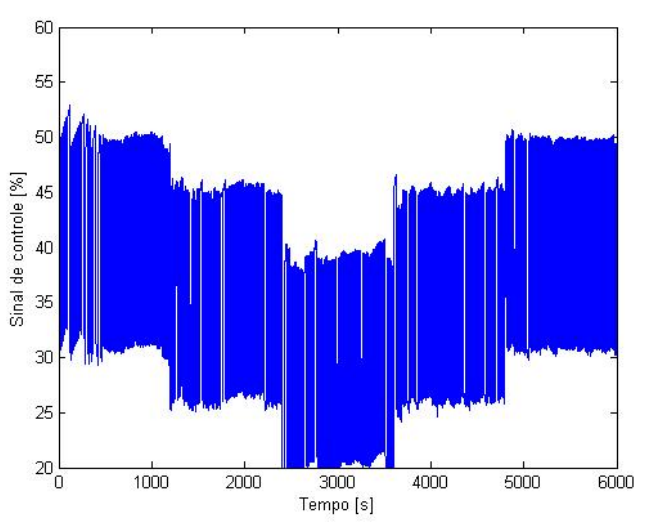

(b) Sinal de controle

Figura 42: Resultados obtidos no ensaio de acompanhamento de set-point da válvula com gaxetas de grafite com compensador CR2.

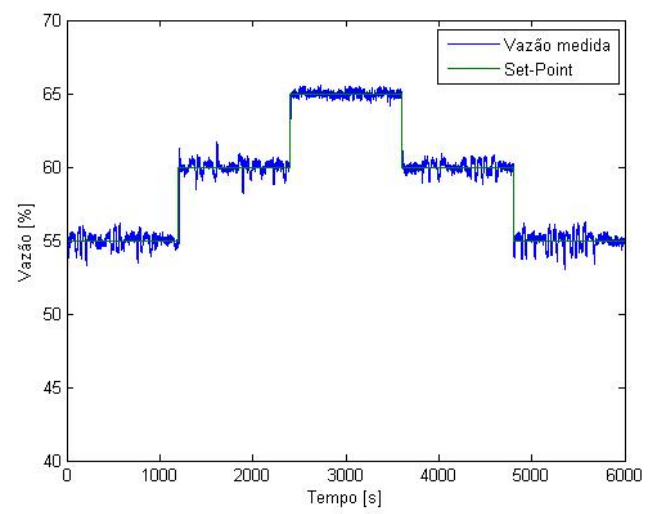

(a) Vazão

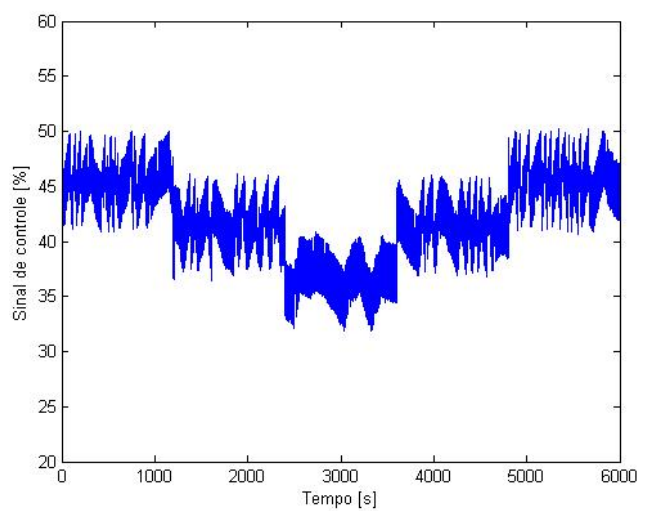

(b) Sinal de controle

Figura 43: Resultados obtidos no ensaio de acompanhamento de set-point da válvula com gaxetas de teflon com compensador Knocker.

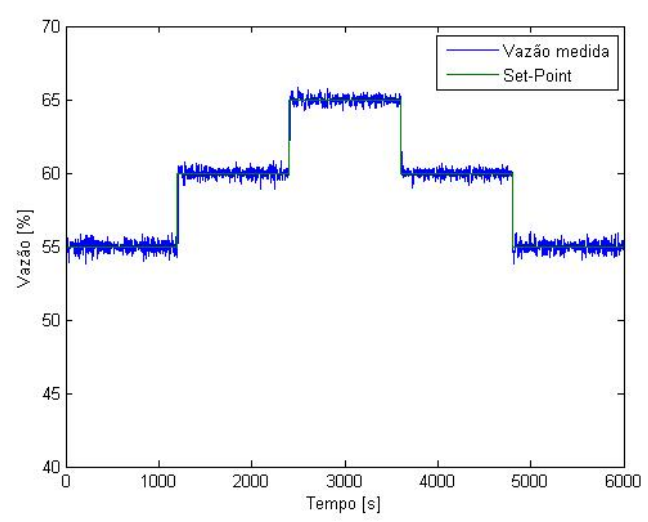

(a) Vazão

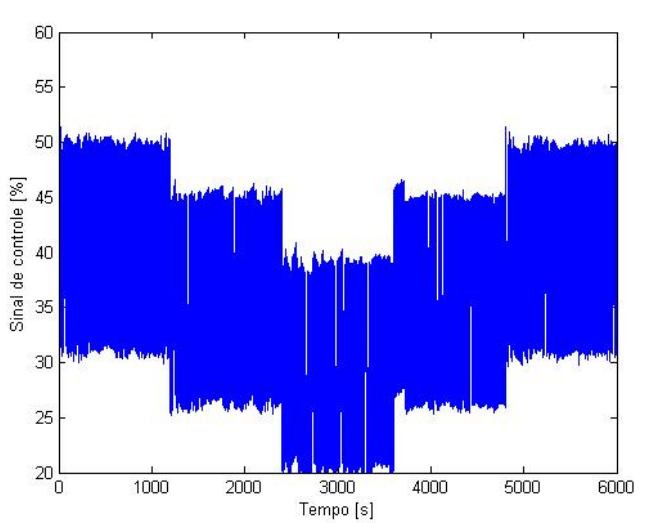

(b) Sinal de controle

Figura 44: Resultados obtidos no ensaio de acompanhamento de set-point da válvula com gaxetas de grafite com compensador Knocker. 
quatro vezes maiores do que os obtidos pelo controlador PI convencional.

Tabela 11: Índices de desempenho dos ensaios de acompanhamento de set-point com os compensadores de atrito (válvula com gaxetas de teflon)

\begin{tabular}{|c|c|c|c|c|}
\hline Ensaio & ITAE $[\%]$ & $D_{v}[\%]$ & $D_{I P}[\%]$ & $t_{r}[\mathrm{~s}]$ \\
\hline PI convencional (Síntese Direta) & 213,7376 & 78,4151 & 148,3319 & 19,875 \\
\hline CR1 & 240,7257 & 139,4258 & 750,7967 & 15,375 \\
\hline CR2 & 263,8187 & 132,3571 & 813,1765 & 11,750 \\
\hline Knocker & 331,4011 & 189,9022 & 526,1042 & 12,750 \\
\hline
\end{tabular}

Tabela 12: Índices de desempenho dos ensaios de acompanhamento de set-point com os compensadores de atrito (válvula com gaxetas de grafite)

\begin{tabular}{|c|c|c|c|c|}
\hline Ensaio & ITAE $[\%]$ & $D_{v}[\%]$ & $D_{I P}[\%]$ & $t_{r}[\mathrm{~s}]$ \\
\hline PI convencional (Síntese Direta) & 1098,7275 & 180,9013 & 786,8646 & 24,625 \\
\hline CR1 & 178,3003 & 110,289 & 2625,0390 & 13,625 \\
\hline CR2 & 177,1523 & 122,3928 & 3108,3510 & 16,875 \\
\hline Knocker & 212,699 & 118,6953 & 1736,2260 & 14,875 \\
\hline
\end{tabular}

O algoritmo de desabilitação de controle abordado na Subseção 4.3 .3 foi aplicado, não apenas em conjunto com os compensadores CR1, CR2 e Knocker, mas também com o controlador PI sem nenhum compensador de atrito. O controle é desabilitado se o módulo do erro permanecer abaixo de $0,5 \%$ por dez segundos e volta a atuar se o inverso ocorrer por dois segundos. O erro aceitável foi calculado analisando a variação máxima da variável manipulada inserida pelo ruído de medição (por meio de um ensaio em que o sinal de controle permanece fixo). Os resultados são apresentados nas Figuras 45 a 56 . Os índices de desempenho são apresentados nas Tabelas 13 e 14. Por simplicidade, o algoritmo foi referenciado como ADC nesses elementos.

Para todos os ensaios realizados com este algoritmo a variabilidade nos atuadores foi reduzida em comparação com os ensaios anteriores. Para a válvula de baixo atrito o algoritmo atuando apenas com o controlador apresenta um índice ITAE superior aos valores obtidos sem o algoritmo. Para os ensaios com os compensadores, o tempo de subida foi um pouco superior aos obtidos no ensaio sem o algoritmo de desabilitação do controle. Porém, o contrário é observado para o ITAE. Como o algoritmo permite um erro de 0,5\%, se espera que isso gere um aumento neste índice, ou, no máximo, que não haja alterações, o que não ocorreu.

Para a segunda válvula de teste os resultados dos ensaios com os compensadores foram os esperados. A inserção do algoritmo de desabilitação gera um pequeno aumento 


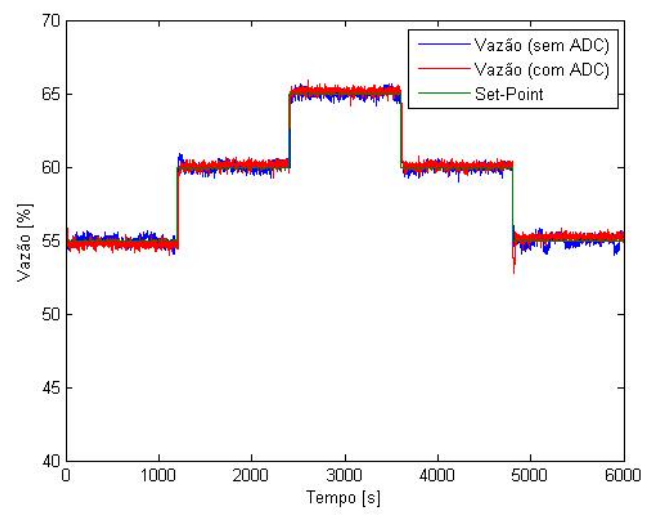

(a) Vazão

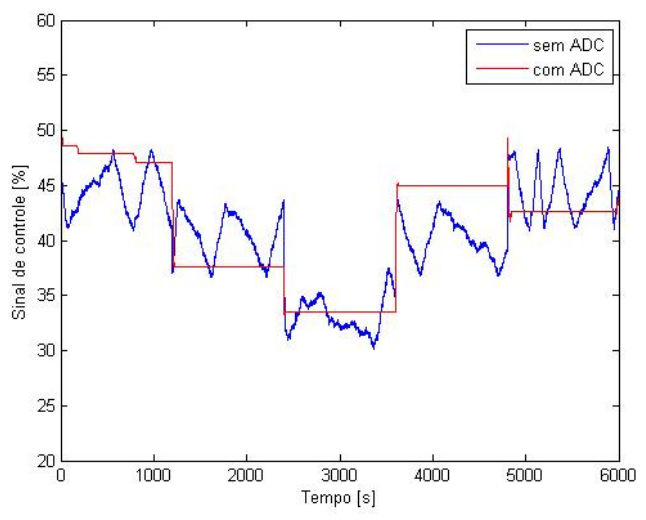

(b) Sinal de controle

Figura 45: Resultados obtidos no ensaio de acompanhamento de set-point da válvula com gaxetas de teflon com controlador PI (sintonia por SD) e algoritmo de desabilitação do controle.

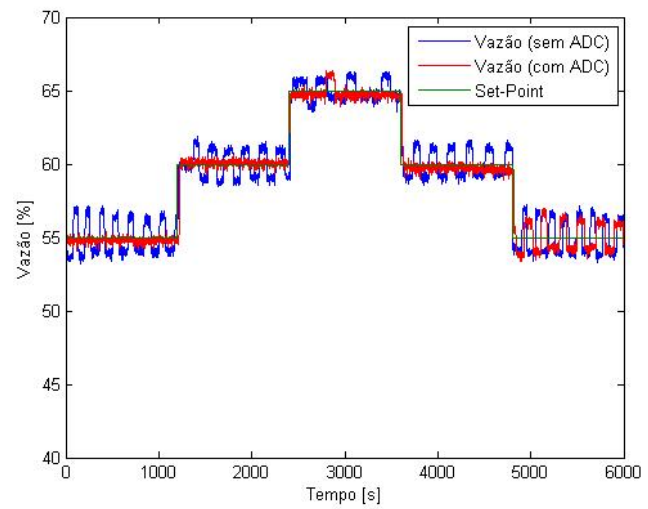

(a) Vazão

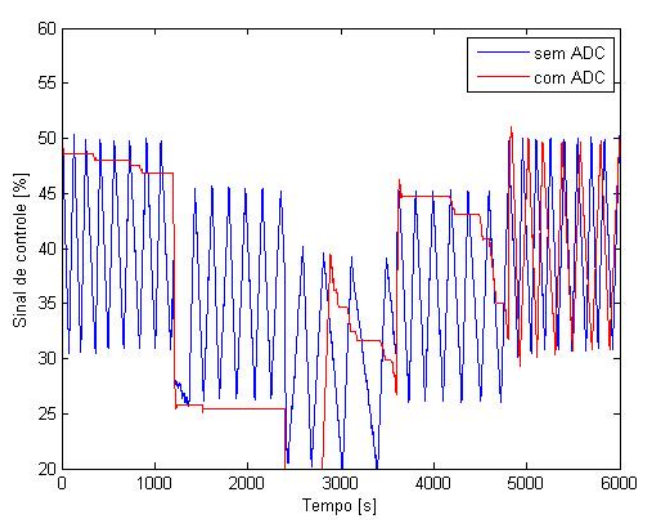

(b) Sinal de controle

Figura 46: Resultados obtidos no ensaio de acompanhamento de set-point da válvula com gaxetas de grafite com controlador PI (Sintonia SD) e algoritmo de desabilitação do controle.

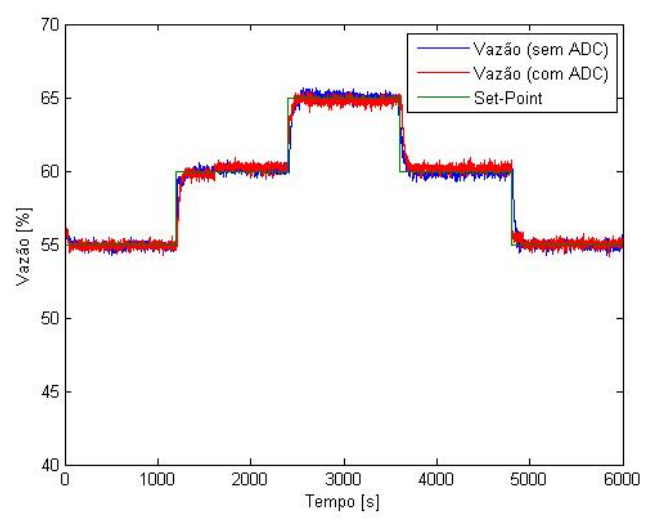

(a) Vazão

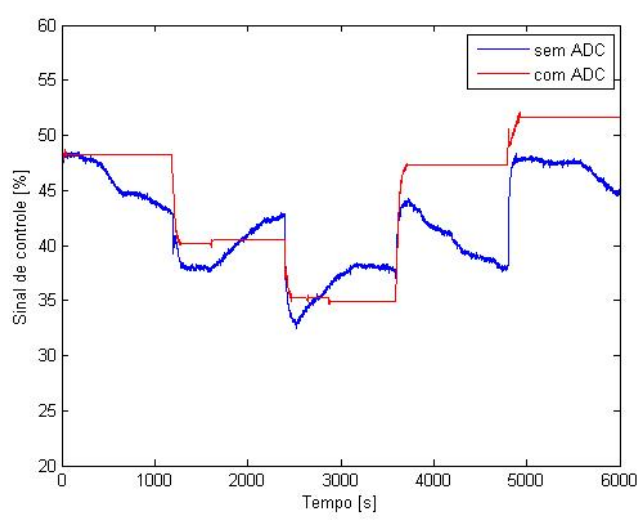

(b) Sinal de controle

Figura 47: Resultados obtidos no ensaio de acompanhamento de set-point da válvula com gaxetas de teflon com controlador PI (sintonia I) e algoritmo de desabilitação do controle. 


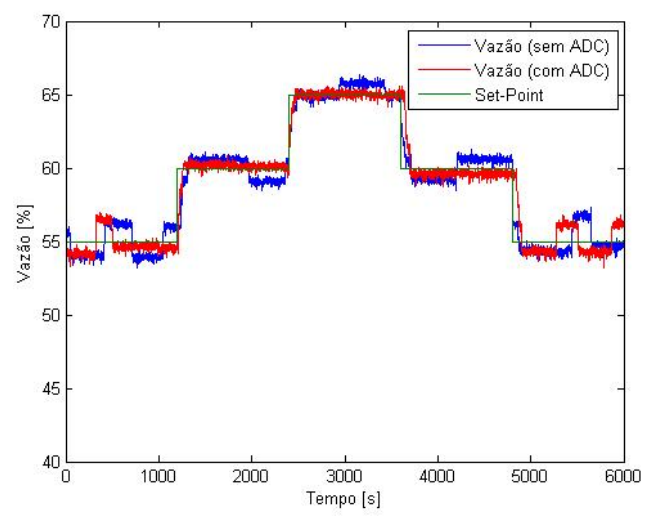

(a) Vazão

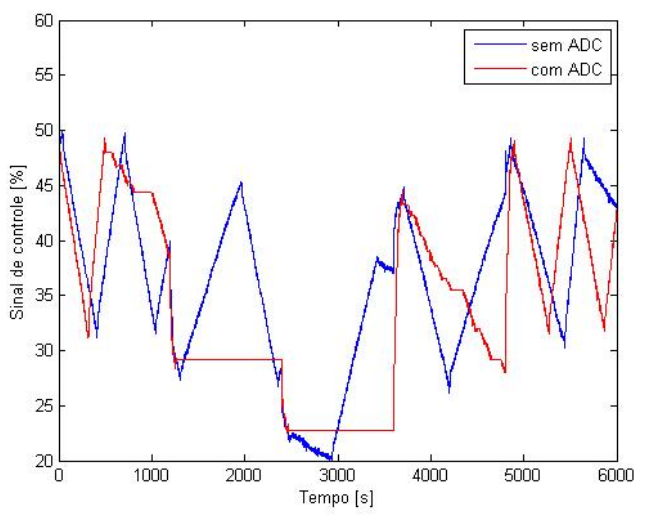

(b) Sinal de controle

Figura 48: Resultados obtidos no ensaio de acompanhamento de set-point da válvula com gaxetas de grafite com controlador PI (sintonia I) e algoritmo de desabilitação do controle.

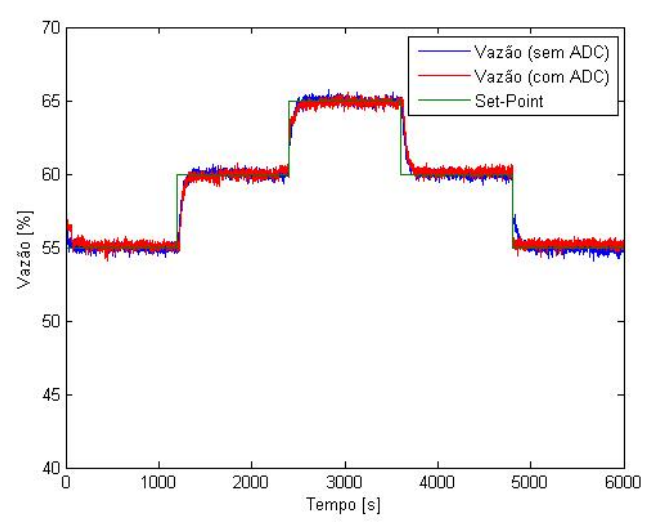

(a) Vazão

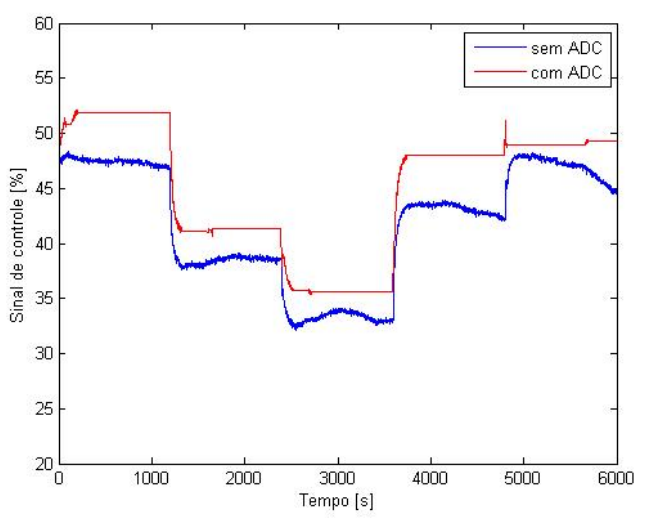

(b) Sinal de controle

Figura 49: Resultados obtidos no ensaio de acompanhamento de set-point da válvula com gaxetas de teflon com controlador PI (sintonia II) e algoritmo de desabilitação do controle.

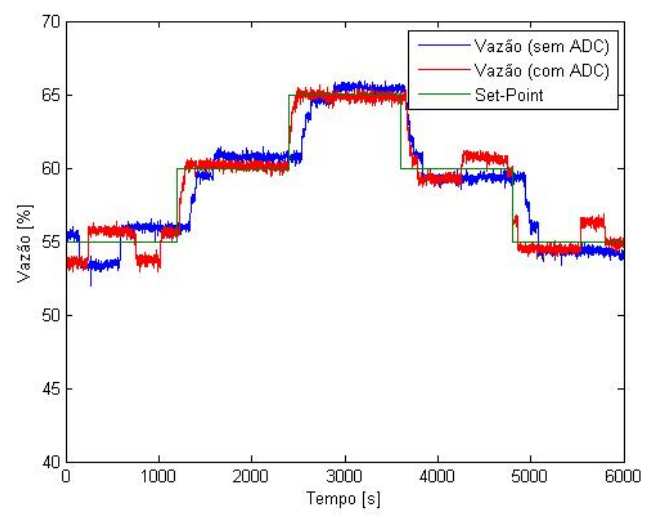

(a) Vazão

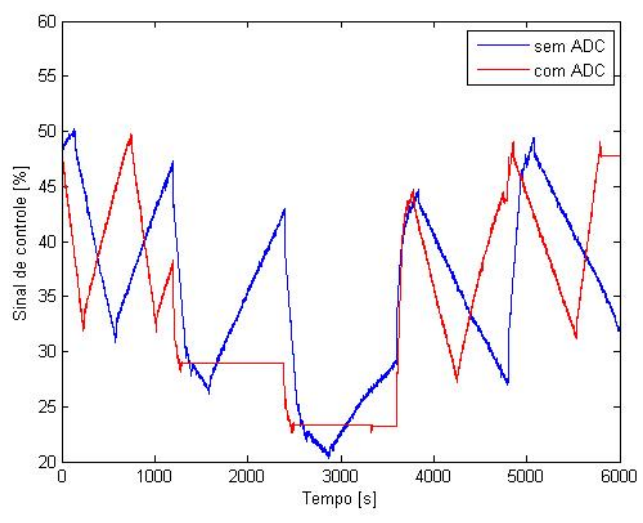

(b) Sinal de controle

Figura 50: Resultados obtidos no ensaio de acompanhamento de set-point da válvula com gaxetas de grafite com controlador PI (sintonia II) e algoritmo de desabilitação do controle. 


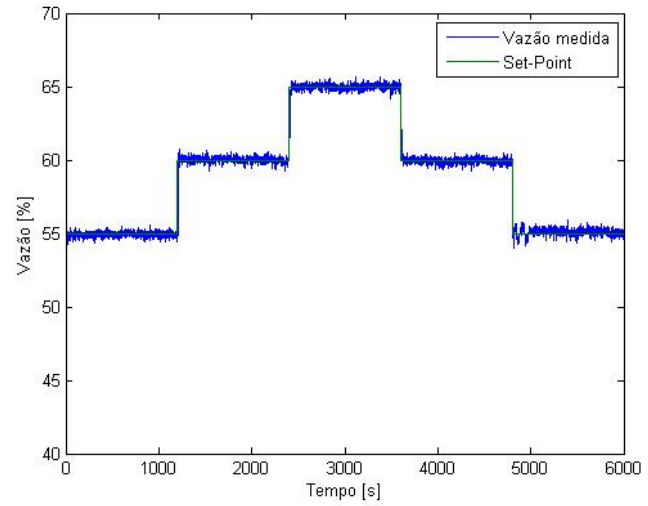

(a) Vazão

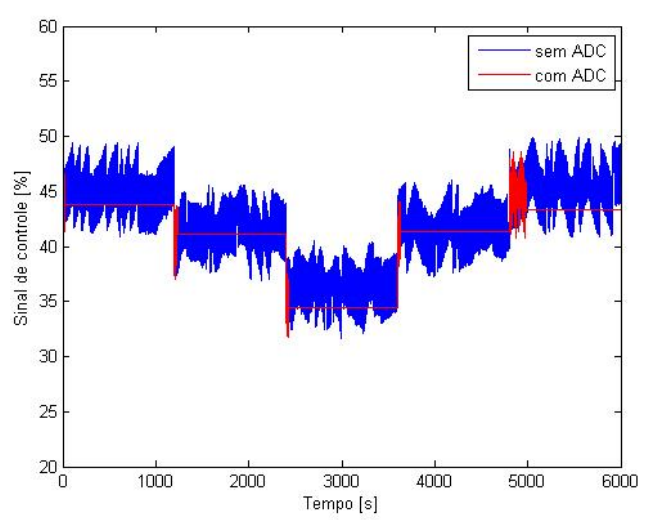

(b) Sinal de controle

Figura 51: Resultados obtidos no ensaio de acompanhamento de set-point da válvula com gaxetas de teflon com compensador CR1 e algoritmo de desabilitação do controle.

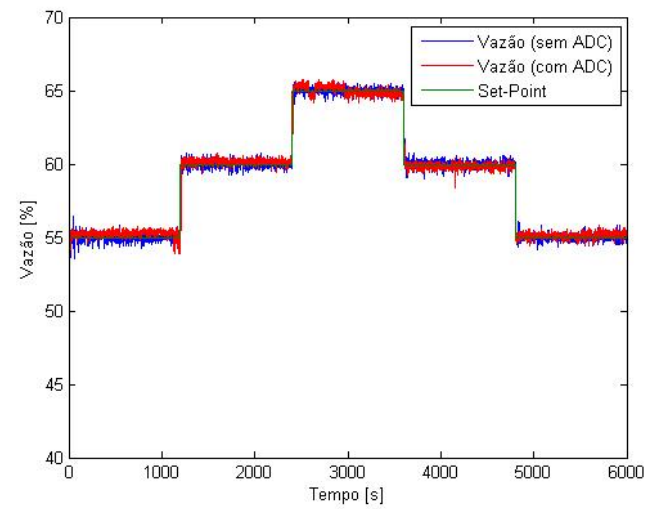

(a) Vazão

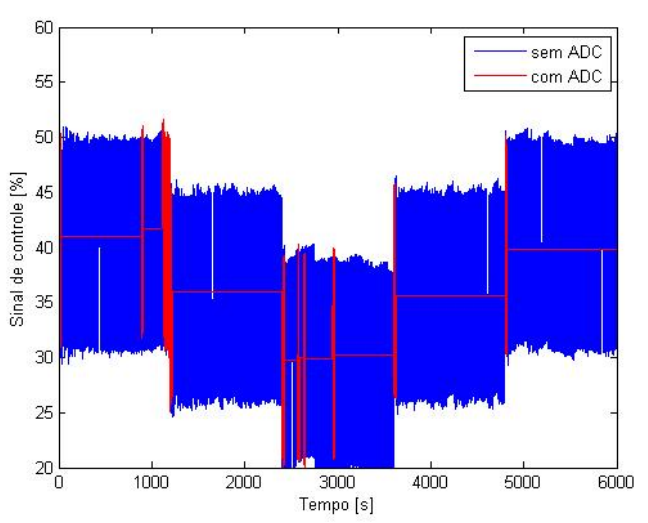

(b) Sinal de controle

Figura 52: Resultados obtidos no ensaio de acompanhamento de set-point da válvula com gaxetas de grafite com compensador CR1 e algoritmo de desabilitação do controle.

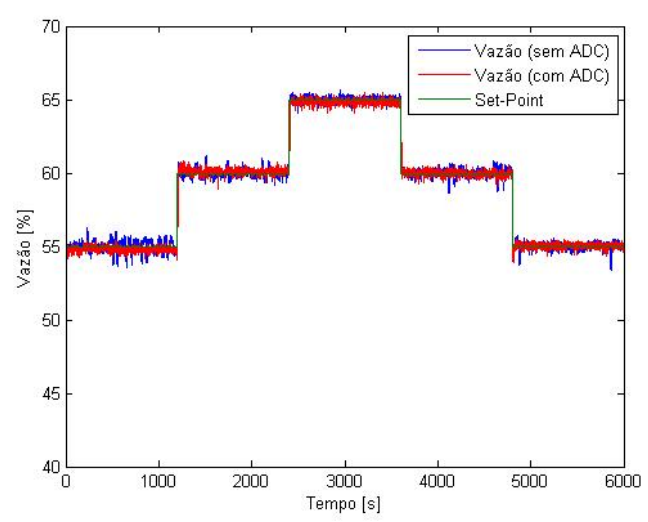

(a) Vazão

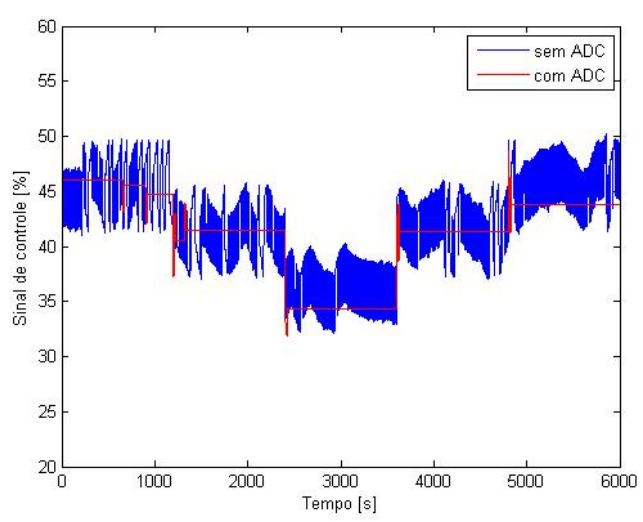

(b) Sinal de controle

Figura 53: Resultados obtidos no ensaio de acompanhamento de set-point da válvula com gaxetas de teflon com compensador CR2 e algoritmo de desabilitação do controle. 


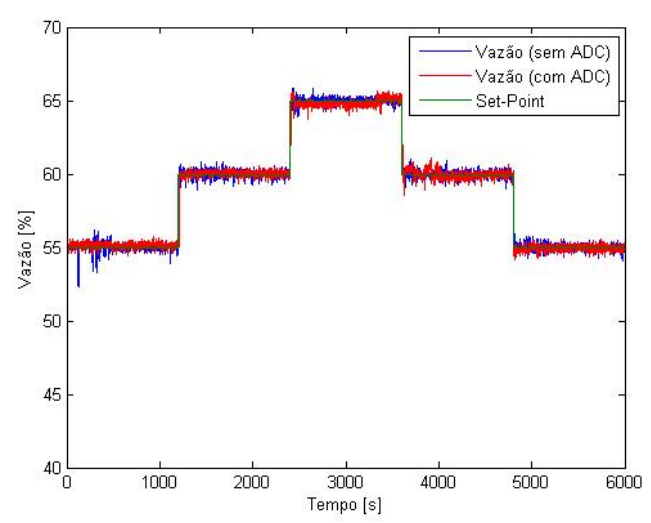

(a) Vazão

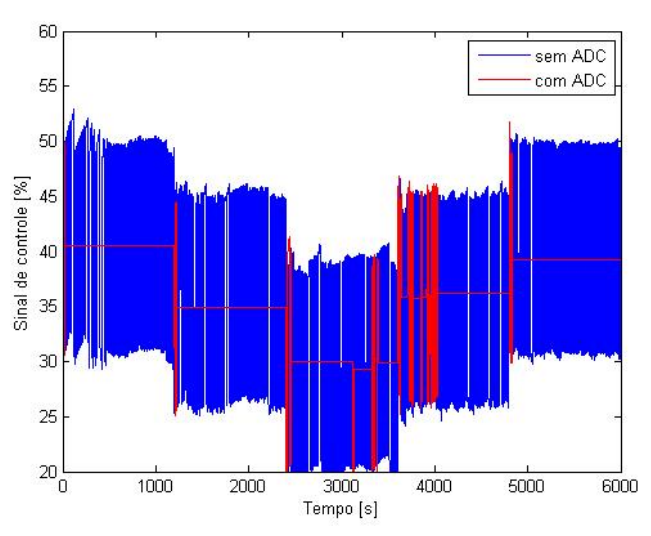

(b) Sinal de controle

Figura 54: Resultados obtidos no ensaio de acompanhamento de set-point da válvula com gaxetas de grafite com compensador CR2 e algoritmo de desabilitação do controle.

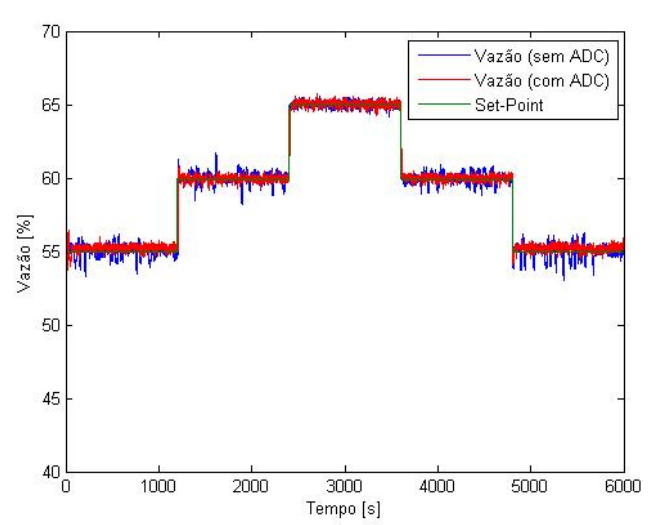

(a) Vazão

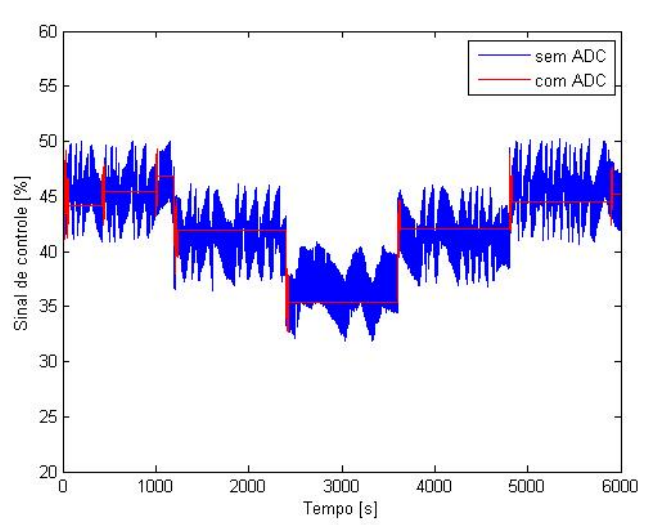

(b) Sinal de controle

Figura 55: Resultados obtidos no ensaio de acompanhamento de set-point da válvula com gaxetas de teflon com compensador Knocker e algoritmo de desabilitação do controle.

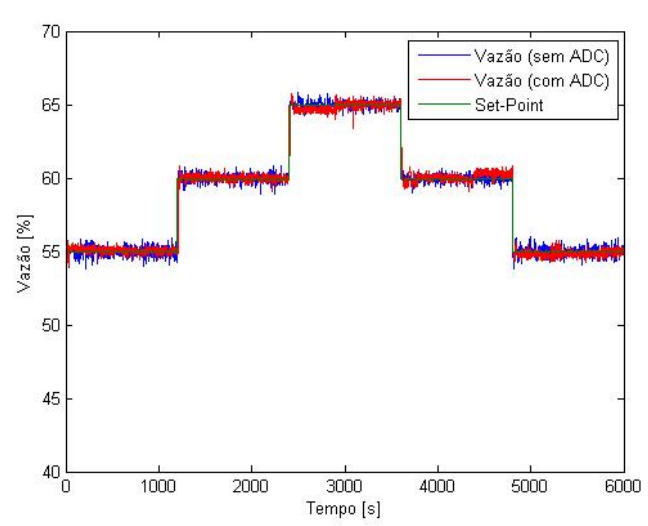

(a) Vazão

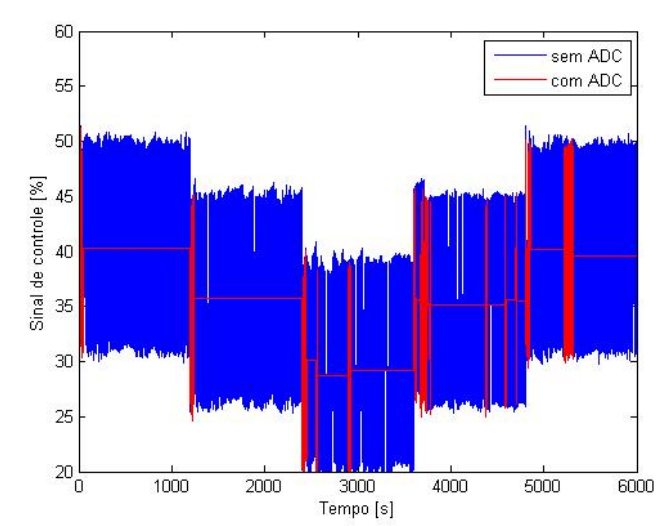

(b) Sinal de controle

Figura 56: Resultados obtidos no ensaio de acompanhamento de set-point da válvula com gaxetas de grafite com compensador Knocker e algoritmo de desabilitação do controle. 
no tempo de subida e no ITAE, porém há grande redução na variabilidade da posição da haste e pressão no atuador. Nestas condições, os resultados obtidos com a válvula de alto atrito ficam próximos aos resultados obtidos com a válvula de baixo atrito apenas com controlador PI. Este é exatamente o objetivo buscado nesta dissertação.

Ainda no caso da válvula de grafite, quando o algoritmo em questão age apenas em conjunto com o controlador, é possível observar uma redução do ITAE, se comparado com os casos onde apenas o controlador PI atua no sistema. Nestes casos, observando-se os resultados obtidos (Figuras 34, 36 e 38), é possível verificar que após cada degrau no sinal de referência, a variável controlada estabiliza, em algumas situações, em um valor de erro baixo e depois começa a oscilar. Quando se inclui o algoritmo de desabilitação, este mantém o sistema neste primeiro valor estabilizado, caso o erro seja suficientemente pequeno. Porém se esta condição não for satisfeita (por exemplo o quinto patamar da Figura 46), o algoritmo não tem nenhum efeito no sistema.

Tabela 13: Índices de desempenho dos ensaios de acompanhamento de set-point com os compensadores de atrito e algoritmo de desabilitação do controle (válvula com gaxetas de teflon).

\begin{tabular}{|c|c|c|c|c|}
\hline Ensaio & ITAE [\%] & $D_{v}[\%]$ & $D_{I P}[\%]$ & $t_{r}[\mathrm{~s}]$ \\
\hline PI convencional (Síntese Direta) & 213,7376 & 78,4151 & 148,3319 & 19,875 \\
\hline PI (Síntese Direta) com ADC & 238,41 & 74,4995 & 69,7395 & 18,000 \\
\hline PI (Sintonia I) com ADC & 238,4811 & 72,2666 & 69,3233 & 89,625 \\
\hline PI (Sintonia II) com ADC & 231,8373 & 74,4995 & 69,7395 & 18,000 \\
\hline CR1 com ADC & 167,143 & 75,6707 & 89,4499 & 16,500 \\
\hline CR2 com ADC & 196,1647 & 73,5362 & 89,5198 & 11,750 \\
\hline Knocker com ADC & 214,098 & 76,7053 & 78,3524 & 16,750 \\
\hline
\end{tabular}

Tabela 14: Índices de desempenho dos ensaios de acompanhamento de set-point com os compensadores de atrito e algoritmo de desabilitação do controle (válvula com gaxetas de grafite).

\begin{tabular}{|c|c|c|c|c|}
\hline Ensaio & ITAE $[\%]$ & $D_{v}[\%]$ & $D_{I P}[\%]$ & $t_{r}[\mathrm{~s}]$ \\
\hline PI convencional (Síntese Direta) & 1098,7275 & 180,9013 & 786,8646 & 24,625 \\
\hline PI (Síntese Direta) com ADC & 451,3912 & 85,5513 & 258,8336 & 38,000 \\
\hline PI (Sintonia I) com ADC & 511,2583 & 89,7407 & 153,6856 & 81,875 \\
\hline PI (Sintonia II) com ADC & 614,4377 & 87,3063 & 139,4174 & 100,25 \\
\hline CR1 com ADC & 262,1648 & 81,6799 & 225,4266 & 14,000 \\
\hline CR2 com ADC & 198,8916 & 100,2512 & 363,1045 & 13,500 \\
\hline Knocker com ADC & 195,0943 & 84,7981 & 228,4126 & 16,625 \\
\hline
\end{tabular}

O último ensaio foi realizado com o compensador desenvolvido por Ely e Longhi (2011). Como a válvula de baixo atrito possui uma banda de agarramento nula ou muito 
pequena, esse compensador foi testado apenas com a válvula de alto atrito. Nos casos de valores muito pequenos de $J$, o compensador teria um efeito muito semelhante ao do método CR2 com o algoritmo de desabilitação. O resultado é apresentado na Figura 57.

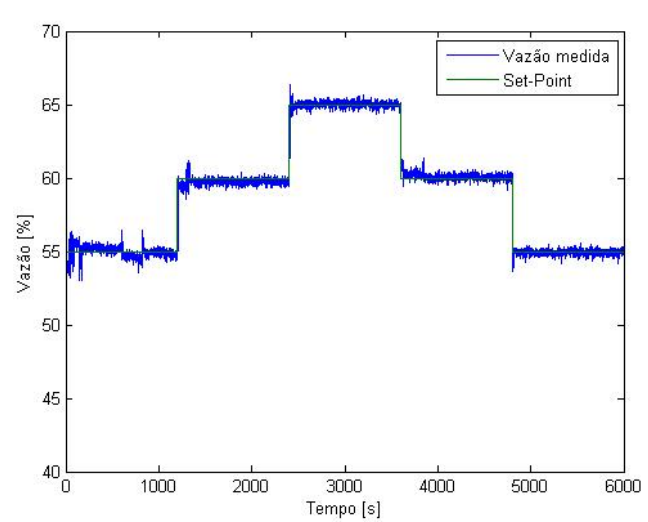

(a) Vazão

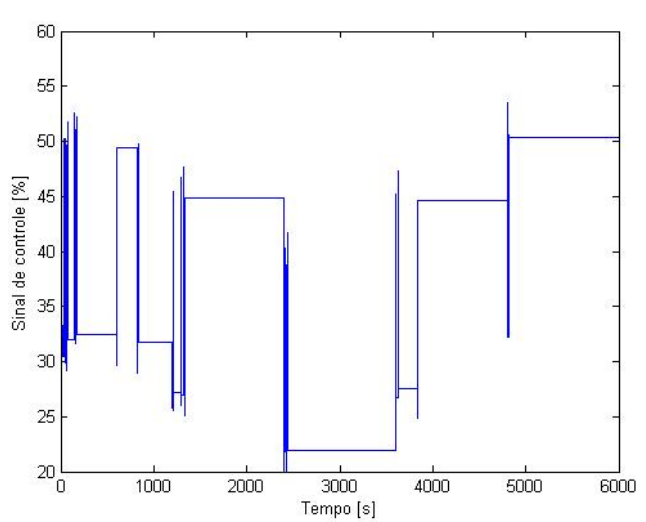

(b) Sinal de controle

Figura 57: Resultados obtidos no ensaio de acompanhamento de set-point da válvula com gaxetas de grafite com o compensador Two-move.

O compensador Two-move apresentou resultados próximos aos obtidos com os compensadores CR e Knocker em conjunto com o algoritmo de desabilitação do controle. Porém, a variabilidade na posição da haste e na pressão do atuador são levemente superiores no caso do Two-move. As Tabelas 15 e 16 apresentam todos os índices de desempenho dos testes para o problema servo.

Tabela 15: Índices de desempenho dos ensaios de acompanhamento de set-point (válvula com gaxetas de teflon).

\begin{tabular}{|c|c|c|c|c|}
\hline Ensaio & ITAE $[\%]$ & $D_{v}[\%]$ & $D_{I P}[\%]$ & $t_{r}[\mathrm{~s}]$ \\
\hline PI convencional (Síntese Direta) & 213,7376 & 78,4151 & 148,3319 & 19,875 \\
\hline PI convencional $\left(T_{i}=12\right)$ & 175,7412 & 63,9592 & 76,0415 & 84,750 \\
\hline PI convencional $\left(T_{i}=16\right)$ & 152,6927 & 74,3894 & 79,2315 & 109,250 \\
\hline CR1 & 240,7257 & 139,4258 & 750,7967 & 15,375 \\
\hline CR2 & 263,8187 & 132,3571 & 813,1765 & 11,750 \\
\hline Knocker & 331,4011 & 189,9022 & 526,1042 & 12,750 \\
\hline PI (Síntese Direta) com ADC & 238,41 & 74,4995 & 69,7395 & 18,000 \\
\hline PI (Sintonia I) com ADC & 238,4811 & 72,2666 & 69,3233 & 89,625 \\
\hline PI (Sintonia II) com ADC & 231,8373 & 74,4995 & 69,7395 & 18,000 \\
\hline CR1 com ADC & 167,143 & 75,6707 & 89,4499 & 16,500 \\
\hline CR2 com ADC & 196,1647 & 73,5362 & 89,5198 & 11,750 \\
\hline Knocker com ADC & 214,098 & 76,7053 & 78,3524 & 16,750 \\
\hline
\end{tabular}


Tabela 16: Índices de desempenho dos ensaios de acompanhamento de set-point (válvula com gaxetas de grafite).

\begin{tabular}{|c|c|c|c|c|}
\hline Ensaio & ITAE $[\%]$ & $D_{v}[\%]$ & $D_{I P}[\%]$ & $t_{r}[\mathrm{~s}]$ \\
\hline PI convencional (Síntese Direta) & 1098,7275 & 180,9013 & 786,8646 & 24,625 \\
\hline PI convencional $\left(T_{i}=12\right)$ & 624,5438 & 101,2551 & 187,9176 & 74,500 \\
\hline PI convencional $\left(T_{i}=16\right)$ & 867,4861 & 84,5418 & 163,4746 & 98,625 \\
\hline CR1 & 178,3003 & 110,289 & 2625,0390 & 13,625 \\
\hline CR2 & 177,1523 & 122,3928 & 3108,3510 & 16,875 \\
\hline Knocker & 212,699 & 118,6953 & 1736,2260 & 14,875 \\
\hline PI (Síntese Direta) com ADC & 451,3912 & 85,5513 & 258,8336 & 38,000 \\
\hline PI (Sintonia I) com ADC & 511,2583 & 89,7407 & 153,6856 & 81,875 \\
\hline PI (Sintonia II) com ADC & 614,4377 & 87,3063 & 139,4174 & 100,25 \\
\hline CR1 com ADC & 262,1648 & 81,6799 & 225,4266 & 14,000 \\
\hline CR2 com ADC & 198,8916 & 100,2512 & 363,1045 & 13,500 \\
\hline Knocker com ADC & 195,0943 & 84,7981 & 228,4126 & 16,625 \\
\hline Two-move & 216,5918 & 120,6844 & 285,315 & 13,25 \\
\hline
\end{tabular}

\subsubsection{Ensaios para o problema regulatório}

Os ensaios para o problema regulatório foram realizados com um set-point constante de $60 \%$. As perturbações foram geradas utilizando a válvula de perturbação descrita na Seção 2.2. Esta válvula permanece inicialmente aberta por $1200 \mathrm{~s}$, então é inserido um degrau no sinal de comando da válvula. Após mais $1200 \mathrm{~s}$ é enviado outro degrau de mesma amplitude e sentido inverso. Este processo é repetido uma segunda vez, mas com degraus de pequena amplitude. Nestes ensaios o tempo de subida não foi considerado entre os índices de desempenho, pois o mesmo não tem sentido para o problema regulatório.

As Figuras 58 a 63 mostram os resultados obtidos com as três sintonias do controlador PI, com e sem o algoritmo de desabilitação de controle (ADC).

Os ensaios com a válvula de alto atrito apresentaram resultados similares aos obtidos nos ensaios da seção anterior. As sintonias mais lentas apresentaram um ITAE superior, mas também têm uma variância menor na posição da haste e na pressão do atuador. O ADC também reduziu o $D_{I P}$ e o $D_{v}$ ao custo de um aumento no ITAE, quando em conjunto com a sintonia por Síntese Direta. Diferentemente do esperado, para a sintonia mais lenta, o ADC reduziu o ITAE, provavelmente devido a um melhor posicionamento da haste neste teste. Note, porém, que isto não é um efeito do algoritmo e ocorre devido ao fato de sistemas mecânicos apresentarem leves diferenças de comportamento entre um teste e outro.

Para os ensaios com a segunda válvula de controle foram constados resultados muito 


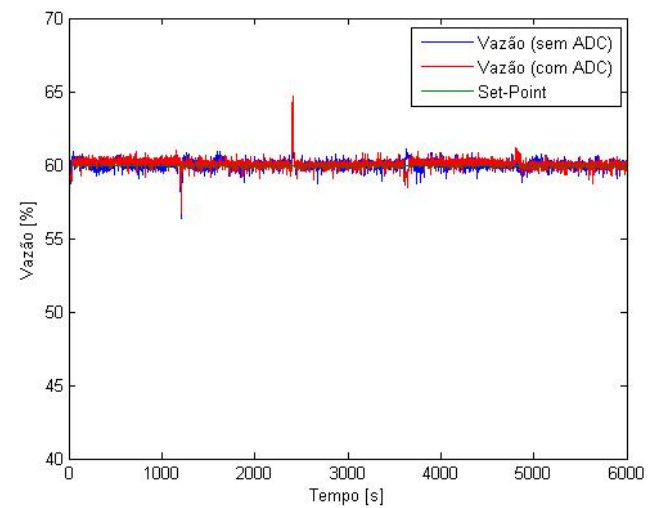

(a) Vazão

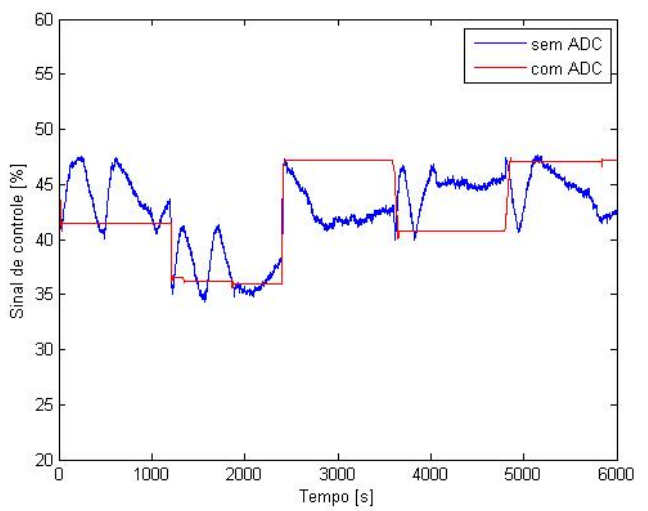

(b) Sinal de controle

Figura 58: Resultados obtidos no ensaio para o problema regulatório da válvula com gaxetas de teflon com controlador PI (Sintonia SD).

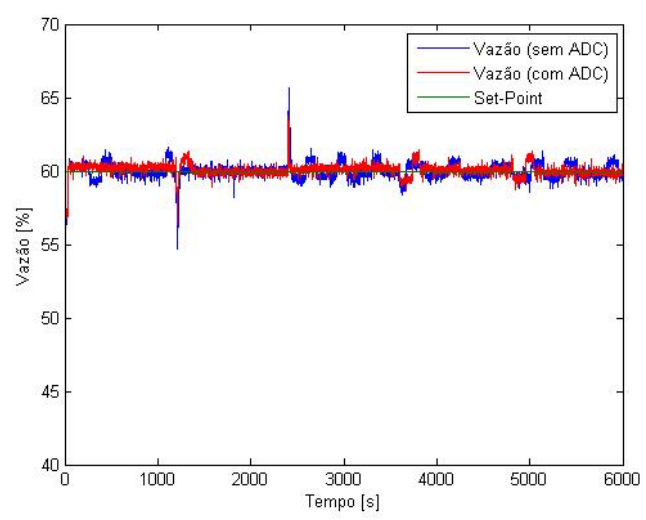

(a) Vazão

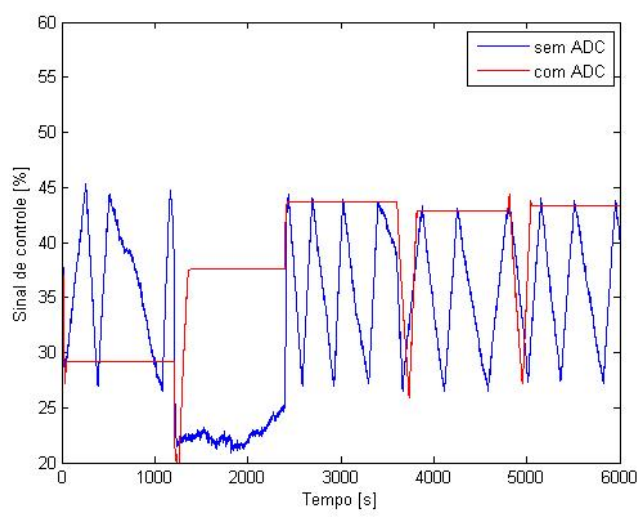

(b) Sinal de controle

Figura 59: Resultados obtidos no ensaio para o problema regulatório da válvula com gaxetas de grafite com controlador PI (Sintonia SD).

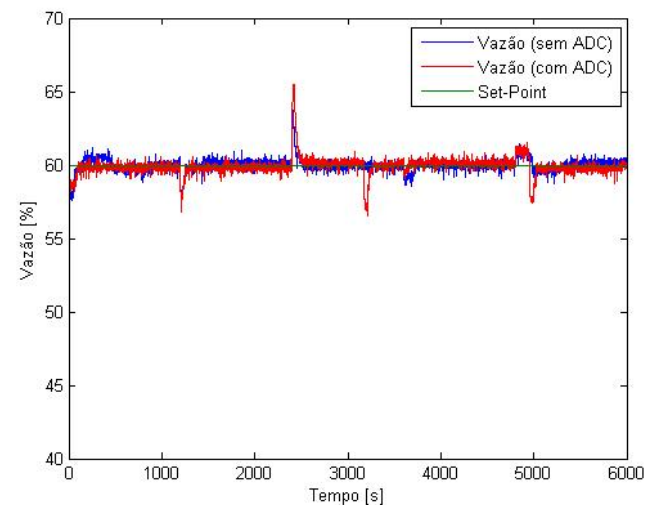

(a) Vazão

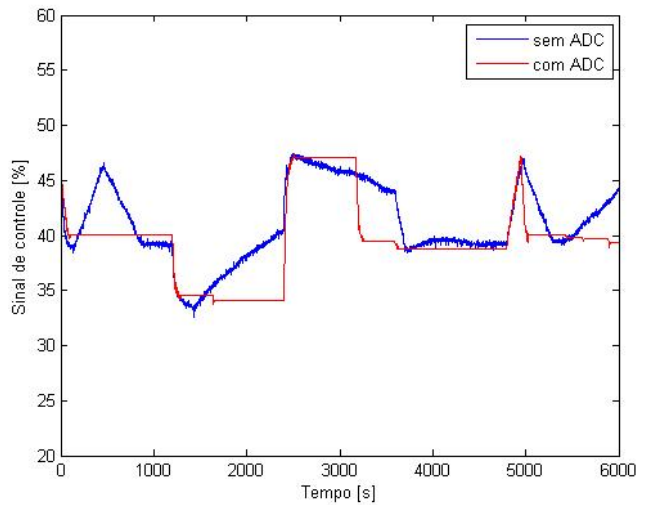

(b) Sinal de controle

Figura 60: Resultados obtidos no ensaio para o problema regulatório da válvula com gaxetas de teflon com controlador PI (Sintonia I). 


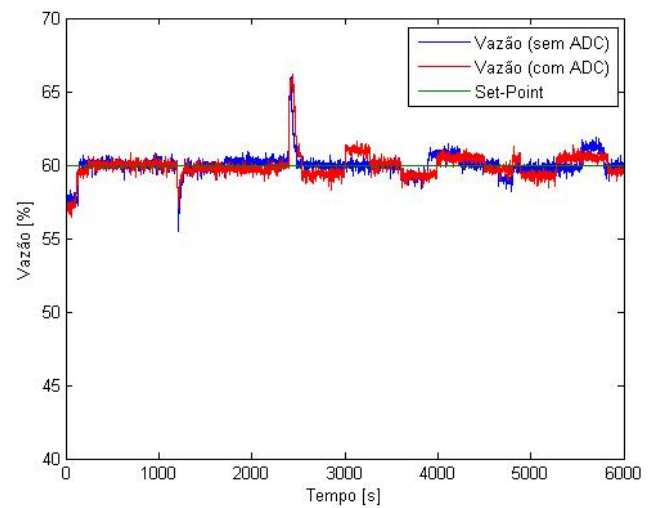

(a) Vazão

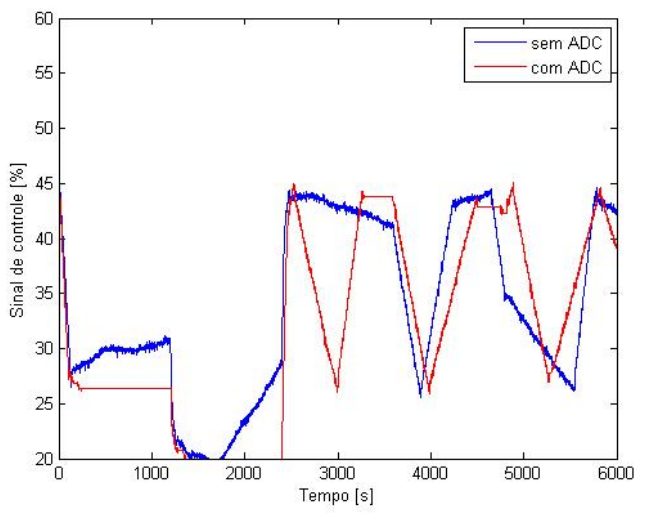

(b) Sinal de controle

Figura 61: Resultados obtidos no ensaio para o problema regulatório da válvula com gaxetas de grafite com controlador PI (Sintonia I).

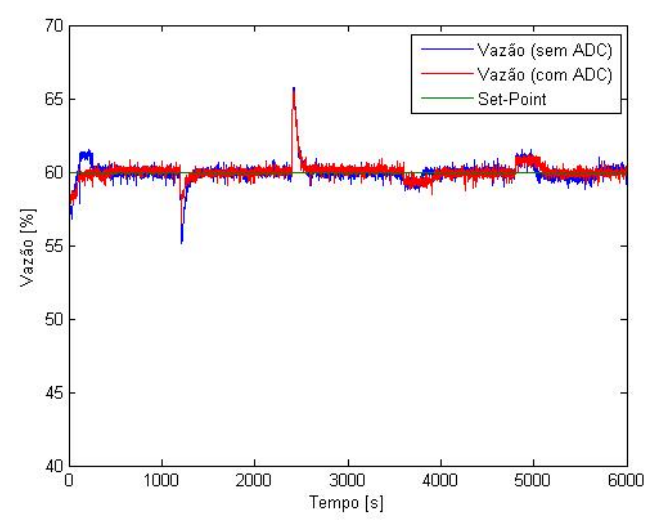

(a) Vazão

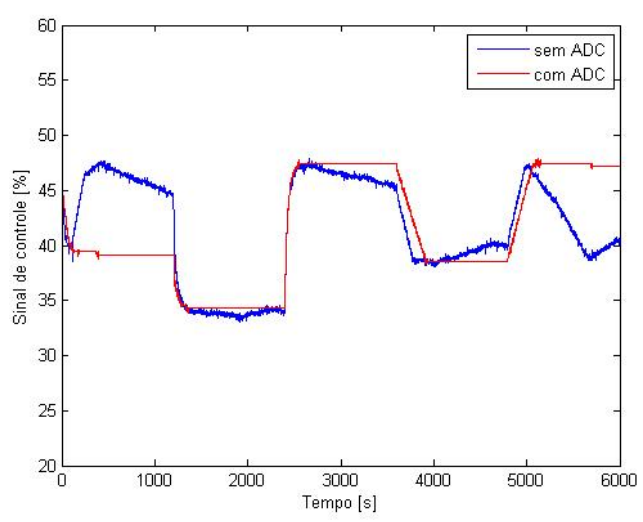

(b) Sinal de controle

Figura 62: Resultados obtidos no ensaio para o problema regulatório da válvula com gaxetas de teflon com controlador PI (Sintonia II).

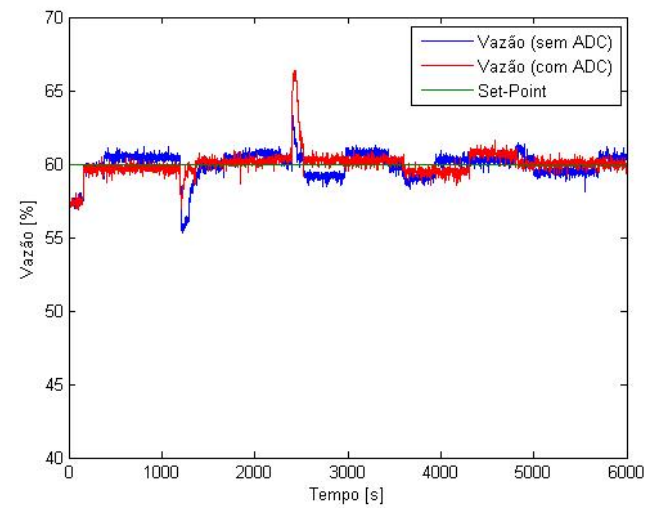

(a) Vazão

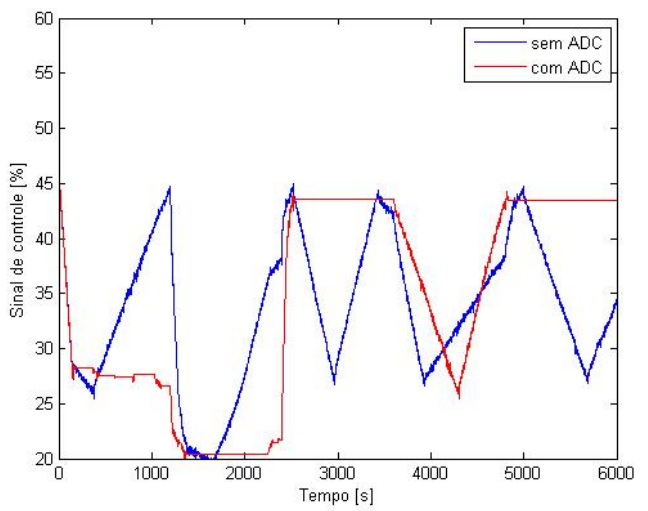

(b) Sinal de controle

Figura 63: Resultados obtidos no ensaio para o problema regulatório da válvula com gaxetas de grafite com controlador PI (Sintonia II). 
distintos dos obtidos nos ensaios para o problema servo. As sintonias SD e I apresentaram bons resultados, chegando próximo dos resultados obtidos para a válvula de baixo atrito. No caso do problema regulatório, como o processo não sofre alterações tão agressivas, a pequena banda de agarramento da válvula de alto atrito não é tão prejudicial. A sintonia II não apresentou bons resultados provavelmente porque, devido à sua resposta lenta, a haste da válvula cessou seu movimento antes de atingir a posição ideal e, posteriormente, o slip-jump impediu este erro de ser corrigido.

No caso da sintonia SD com o ADC, novamente houve um decréscimo do ITAE. O resultado foi tão bom quanto os resultados obtidos com os compensadores, como será visto mais adiante. É possível notar que o controlador conseguiu estabilizar o processo em valores próximos dos desejados em todas as regiões e o ADC manteve o processo nestas condições. Note que o mesmo resultado quase foi obtido no ensaio para o problema servo, onde em apenas uma região o conjunto PI (sintonia SD) com ADC não apresentou bons resultados. Isto ocorreu justamente na região em que a referência é $55 \%$ da vazão máxima, ou seja, a região em que o processo tem um ganho maior. Por este motivo, o slip-jump tem um efeito mais acentuado na variável controlada, o que dificulta seu controle.

As Tabelas 17 e 18 apresentam os índices de desempenho obtido com estes compensadores.

Tabela 17: Índices de desempenho dos ensaios para o problema regulatório com sintonias diferentes do controlador (válvula com gaxetas de teflon).

\begin{tabular}{|c|c|c|c|}
\hline Ensaio & ITAE $[\%]$ & $D_{v}[\%]$ & $D_{I P}[\%]$ \\
\hline PI convencional (Síntese Direta) & 155,7303 & 63,3858 & 120,3635 \\
\hline PI convencional $\left(T_{i}=12\right)$ & 205,8516 & 58,7530 & 91,6066 \\
\hline PI convencional $\left(T_{i}=16\right)$ & 203,1661 & 58,1521 & 87,8117 \\
\hline PI (Síntese Direta) com ADC & 185,5702 & 55,3148 & 68,8080 \\
\hline PI (Sintonia I) com ADC & 270,9156 & 64,7977 & 90,3279 \\
\hline PI (Sintonia II) com ADC & 187,1501 & 51,8736 & 67,9296 \\
\hline
\end{tabular}

Tabela 18: Índices de desempenho dos ensaios para o problema regulatório com sintonias diferentes do controlador (válvula com gaxetas de grafite).

\begin{tabular}{|c|c|c|c|}
\hline Ensaio & ITAE [\%] & $D_{v}[\%]$ & $D_{I P}[\%]$ \\
\hline PI convencional (Síntese Direta) & 381,2348 & 60,6194 & 308,3223 \\
\hline PI convencional $\left(T_{i}=12\right)$ & 345,4266 & 61,5715 & 121,8490 \\
\hline PI convencional $\left(T_{i}=16\right)$ & 584,2461 & 63,8480 & 135,4309 \\
\hline PI (Síntese Direta) com ADC & 214,5329 & 64,7990 & 119,8854 \\
\hline PI (Sintonia I) com ADC & 447,7785 & 61,8354 & 132,3561 \\
\hline PI (Sintonia II) com ADC & 390,0288 & 610448 & 92,3869 \\
\hline
\end{tabular}


As Figuras 64 a 70 apresentam os resultados obtidos com os compensadores de atrito. Novamente a sintonia utilizada para esses ensaios foi a obtida pelo método SD.

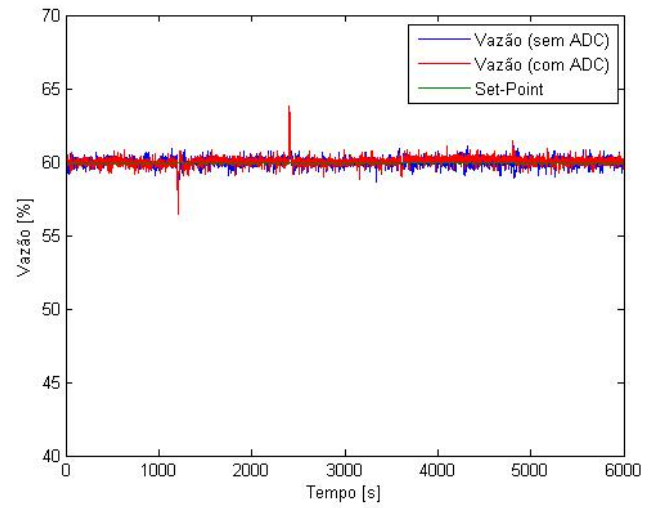

(a) Vazão

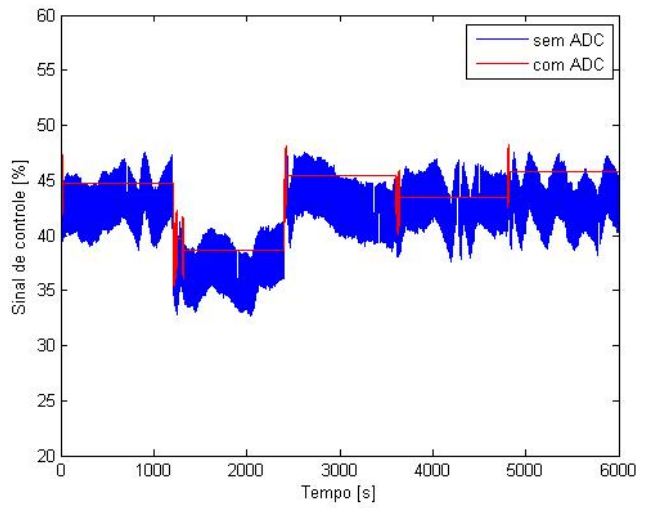

(b) Sinal de controle

Figura 64: Resultados obtidos no ensaio para o problema regulatório da válvula com gaxetas de teflon com compensador CR1.

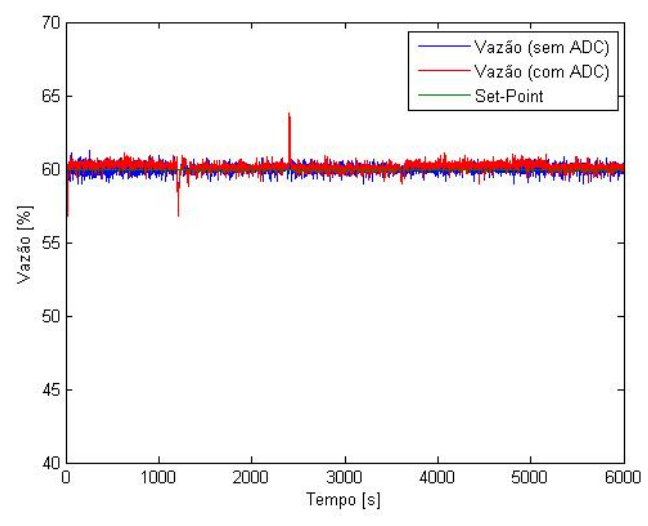

(a) Vazão

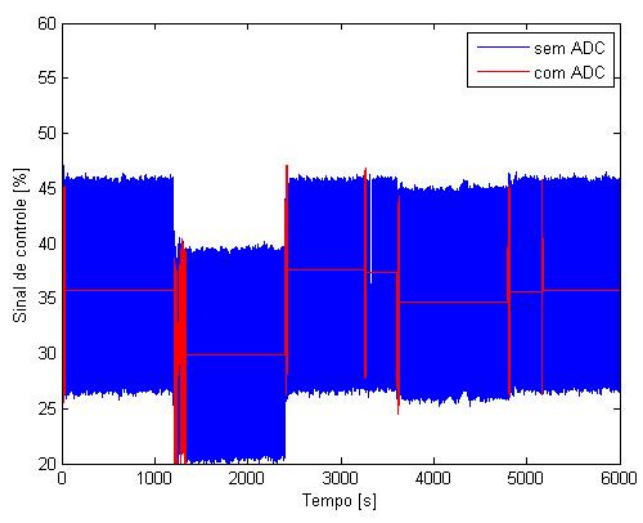

(b) Sinal de controle

Figura 65: Resultados obtidos no ensaio para o problema regulatório da válvula com gaxetas de grafite com compensador CR1.

Assim como ocorreu nos ensaios anteriores, os compensadores não apresentaram nenhum ganho significativo na válvula de baixo atrito, apenas aumentando a variabilidade da haste da válvula e da pressão no atuador. Para a válvula de alto atrito o compensador CR2 apresentou o menor ITAE, porém também apresentou a maior variabilidade na pressão do atuador. A adição do ADC aumentou o ITAE e reduziu o $D_{I P}$ e o $D_{v}$ em todos os casos, como o esperado. Porém o único compensador, operando em conjunto com o ADC, a superar o conjunto controlador (sintonia SD) e ADC foi o compensador CR2. Mesma assim, os outros compensadores também apresentaram resultados satisfatórios. O compensador Two-move apresentou um $D_{I P}$ e $D_{v}$ levemente superiores aos dos outros compensadores (em conjunto com o ADC). Os resultados estão nas Tabelas 19 e 20. 


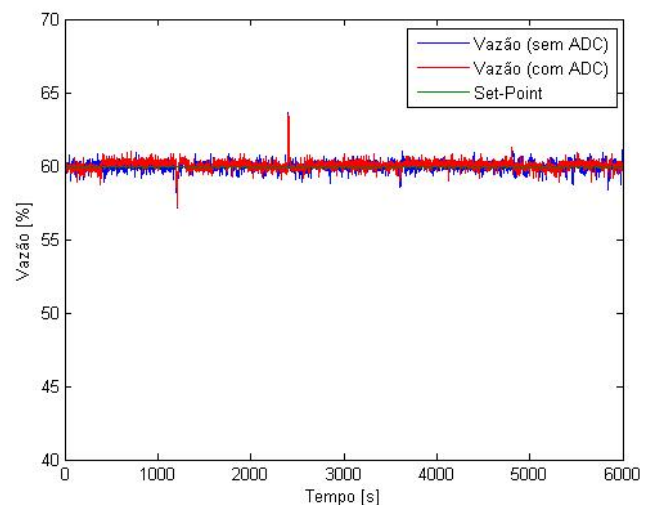

(a) Vazão

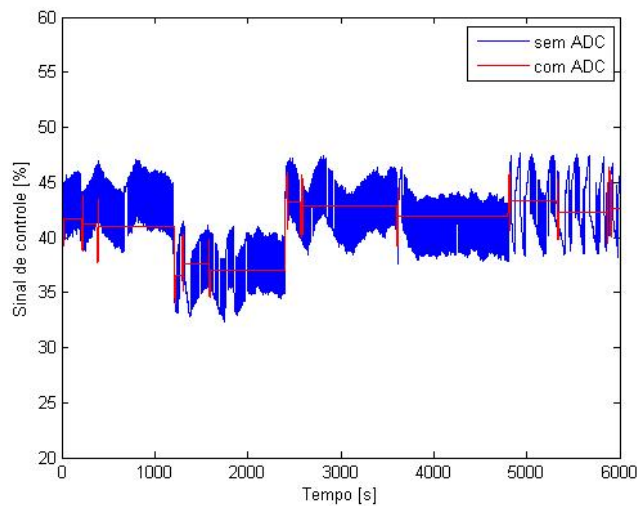

(b) Sinal de controle

Figura 66: Resultados obtidos no ensaio para o problema regulatório da válvula com gaxetas de teflon com compensador CR2.

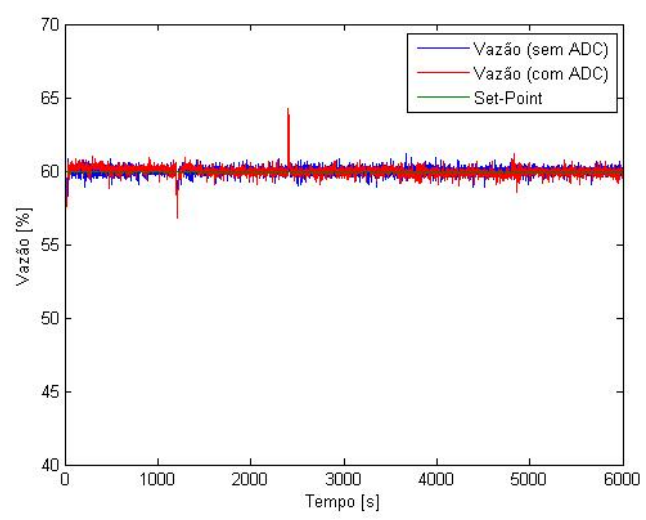

(a) Vazão

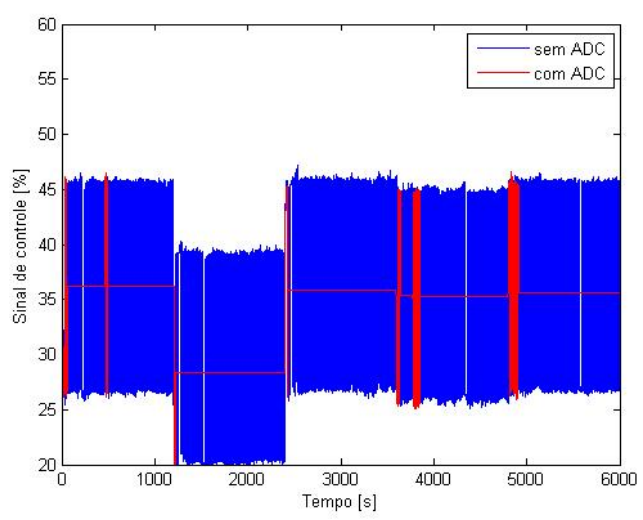

(b) Sinal de controle

Figura 67: Resultados obtidos no ensaio para o problema regulatório da válvula com gaxetas de grafite com compensador CR2.

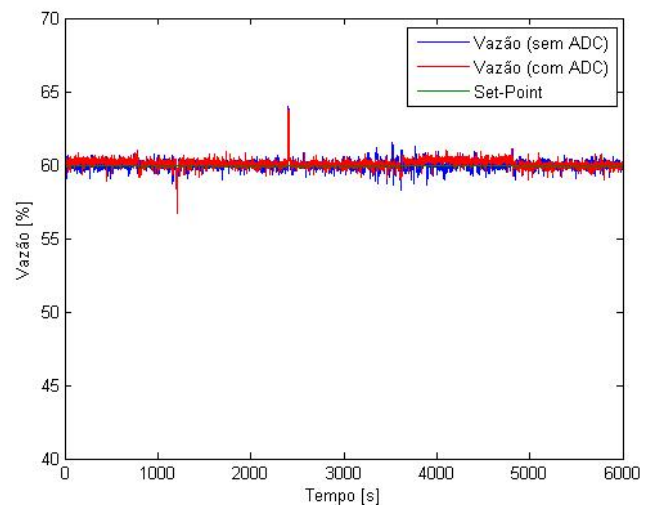

(a) Vazão

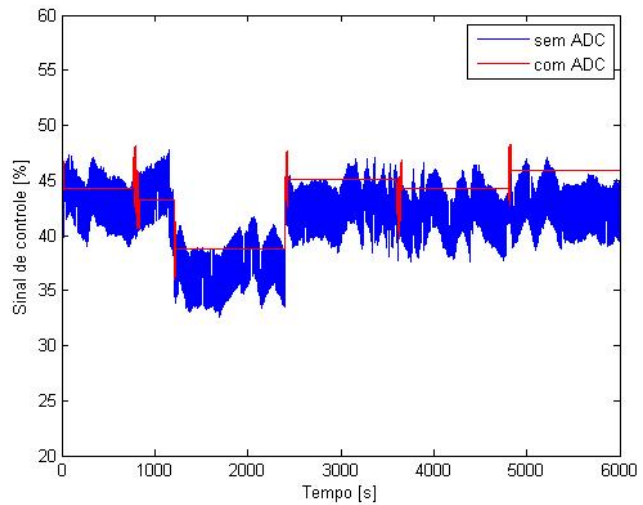

(b) Sinal de controle

Figura 68: Resultados obtidos no ensaio para o problema regulatório da válvula com gaxetas de teflon com compensador Knocker. 


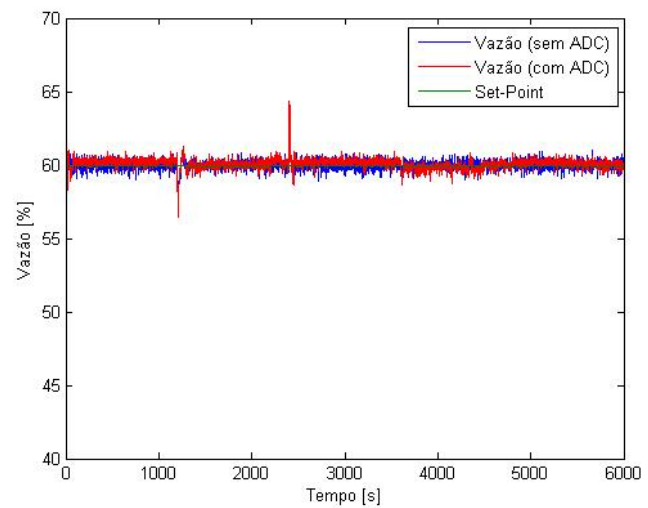

(a) Vazão

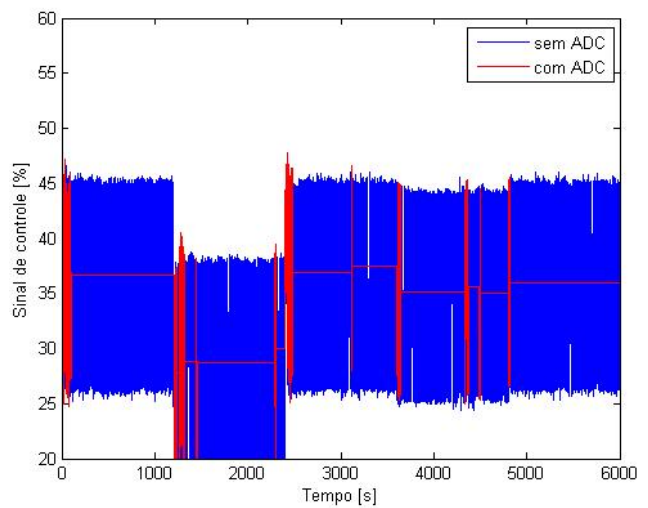

(b) Sinal de controle

Figura 69: Resultados obtidos no ensaio para o problema regulatório da válvula com gaxetas de grafite com compensador Knocker.

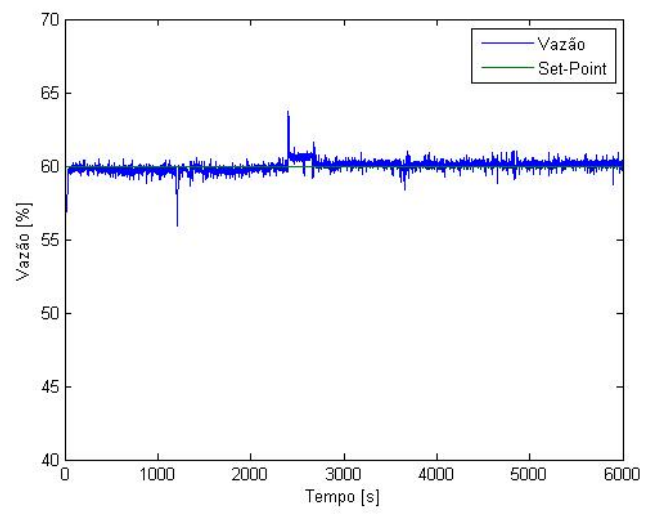

(a) Vazão

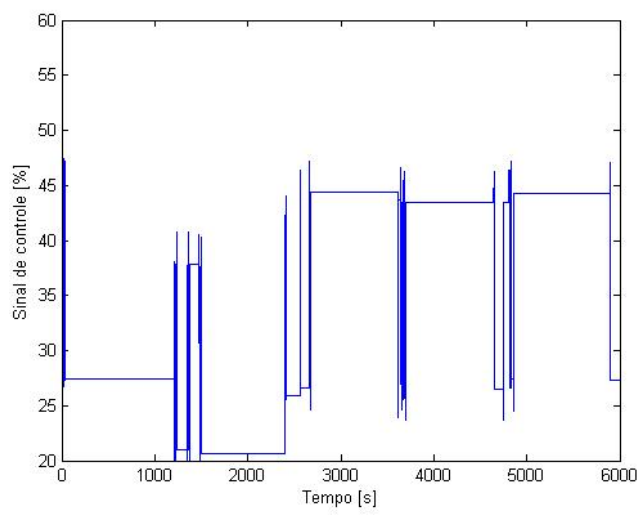

(b) Sinal de controle

Figura 70: Resultados obtidos no ensaio para o problema regulatório da válvula com gaxetas de grafite com compensador Two-move.

Tabela 19: Índices de desempenho dos ensaios para o problema regulatório (teflon).

\begin{tabular}{|c|c|c|c|}
\hline Ensaio & ITAE $[\%]$ & $D_{v}[\%]$ & $D_{I P}[\%]$ \\
\hline PI convencional (Síntese Direta) & 155,7303 & 63,3858 & 120,3635 \\
\hline PI convencional $\left(T_{i}=12\right)$ & 205,8516 & 58,7530 & 91,6066 \\
\hline PI convencional $\left(T_{i}=16\right)$ & 203,1661 & 58,1521 & 87,8117 \\
\hline CR1 & 173,5194 & 76,2299 & 788,108 \\
\hline CR2 & 186,1101 & 82,7730 & 760,4584 \\
\hline Knocker & 197,7112 & 92,3391 & 494,7729 \\
\hline PI (Síntese Direta) com ADC & 185,5702 & 55,3148 & 68,8080 \\
\hline PI (Sintonia I) com ADC & 270,9156 & 64,7977 & 90,3279 \\
\hline PI (Sintonia II) com ADC & 187,1501 & 51,8736 & 67,9296 \\
\hline CR1 com ADC & 162,2077 & 55,6887 & 81,1619 \\
\hline CR2 com ADC & 200,5919 & 74,6467 & 127,8332 \\
\hline Knocker com ADC & 198,4474 & 60,7634 & 71,2758 \\
\hline
\end{tabular}


Tabela 20: Índices de desempenho dos ensaios para o problema regulatório (grafite).

\begin{tabular}{|c|c|c|c|}
\hline Ensaio & ITAE $[\%]$ & $D_{v}[\%]$ & $D_{I P}[\%]$ \\
\hline PI convencional (Síntese Direta) & 381,2348 & 60,6194 & 308,3223 \\
\hline PI convencional $\left(T_{i}=12\right)$ & 345,4266 & 61,5715 & 121,8490 \\
\hline PI convencional $\left(T_{i}=16\right)$ & 584,2461 & 63,8480 & 135,4309 \\
\hline CR1 & 165,3164 & 95,9248 & 2688,2638 \\
\hline CR2 & 157,9430 & 80,6251 & 2763,0687 \\
\hline Knocker & 198,8948 & 103,5601 & 1701,7451 \\
\hline PI (Síntese Direta) com ADC & 214,5329 & 64,7990 & 119,8854 \\
\hline PI (Sintonia I) com ADC & 447,7785 & 61,8354 & 132,3561 \\
\hline PI (Sintonia II) com ADC & 390,0288 & 61,0448 & 92,3869 \\
\hline CR1 com ADC & 234,6998 & 71,8487 & 191,4430 \\
\hline CR2 com ADC & 173,3649 & 64,6161 & 240,6044 \\
\hline Knocker com ADC & 233,9244 & 69,1605 & 213,4208 \\
\hline Two-move & 237,7960 & 99,0005 & 356,3300 \\
\hline
\end{tabular}

\subsection{Compensadores atuando no controle de posição}

Uma alternativa para a solução apresentada na seção anterior é utilizar os compensadores em uma malha de controle de posição da haste da válvula, ou seja, atuando como posicionadores. Neste caso o set-point desta malha seria gerado por uma segunda malha de controle, que controlaria a variável do processo. Portanto, haverá dois controladores PI em cascata, mas os compensadores atuariam apenas na malha interna. Neste caso, a aplicação não seria inserir os algoritmos em um CLP ou SDCD, mas inseri-los em um posicionador. Obviamente, também seria necessário um algoritmo de estimação dos parâmetros de atrito da válvula. O objetivo destes ensaios é verificar a eficiência desta abordagem. Novamente foram realizados ensaios para o problema servo e de rejeição de perturbações com as mesmas configurações da seção anterior.

A seção anterior permitiu constatar que as sintonias com ganho integral reduzido diminuem, mas nem sempre eliminam as oscilações. Além disso, essas sintonias tornam a malha mais lenta e nesta nova aplicação é importante que a malha interna tenha uma resposta rápida em relação à malha externa. Por esse motivo o método de ressintonia do controlador não foi utilizado neste caso.

A malha de controle de vazão teve seu ciclo de operação mantido em 0,5 s, porém foi 
inserida uma zona morta de 0,5\% na ação integral do controlador. A malha de controle de posição, por sua vez, possui ciclos de 0,1 s. Também foram necessárias algumas alterações nos compensadores de atrito. A duração dos pulsos do compensador Knocker seria, de acordo com a proposta de Srinivasan e Rengaswamy (2005), o dobro do tempo de amostragem, ou seja, 0,2 s. Porém, o conversor I/P não consegue responder nesta velocidade, o que significa que a variação de pressão seria quase nula. Desta forma, se optou por utilizar pulsos de $0,6 \mathrm{~s}$ com períodos de 1,5 s. Os compensadores CR1 e CR2 também foram atualizados a cada $0,6 \mathrm{~s}$. Por fim, os dois movimentos de correção de posição do compensador Two-move terão duração de $2 \mathrm{~s}$, tempo suficiente para a haste realizar o movimento completo.

A sintonia dos controladores foi feita pelo método da Síntese Direta. Primeiramente foi levantado um modelo de primeira ordem com tempo morto da válvula (o atrito foi desconsiderado) para sintonizar o controlador de posição. Em seguida, a válvula em malha fechada também foi aproximada por um sistema de primeira ordem. A constante de tempo do processo em malha fechada escolhida para a primeira malha foi de $0,5 \mathrm{~s}$ e para a segunda foi de $20 \mathrm{~s}$. A malha de vazão foi sintonizada para ter uma resposta lenta para que as duas malhas em cascata não fossem muito agressivas, dificultando ainda mais a estabilização do sistema. A estrutura de controle da abordagem descrita está representada na Figura 71 e as sintonias utilizadas para os controladores estão nas Tabelas 21 e 22.

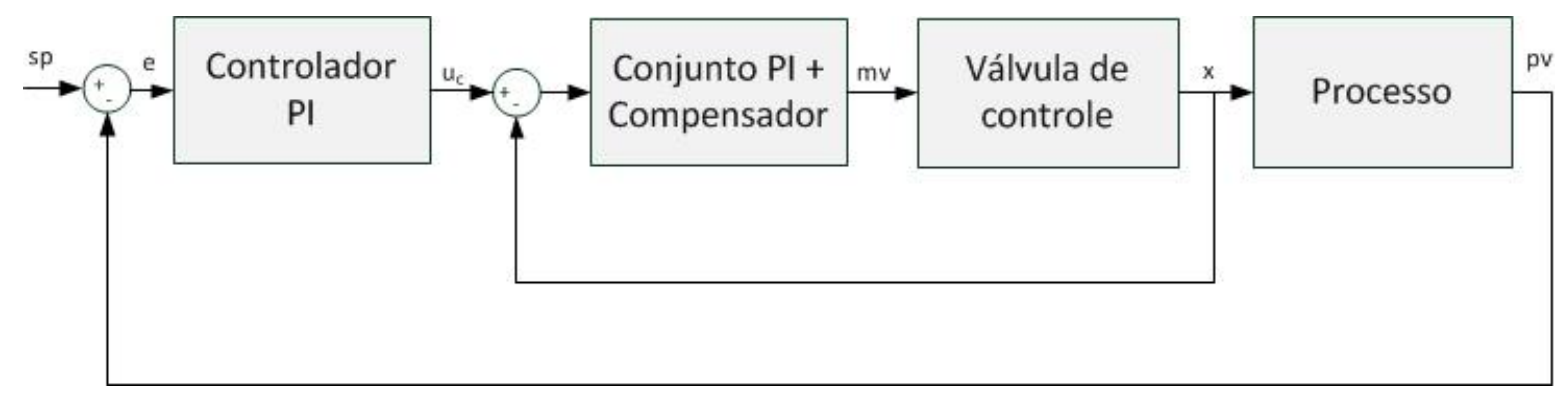

Figura 71: Estrutura das malhas de controle de posição e de vazão em cascata.

Tabela 21: Sintonias obtidas pelo método da Síntese Direta para o controlador PI de posição (controle em cascata).

\begin{tabular}{|c|c|c|}
\hline Material das gaxetas & $K_{c}$ & $T_{i}$ \\
\hline Teflon & 0,5857 & 0,4020 \\
\hline Grafite & 0,7603 & 0,5520 \\
\hline
\end{tabular}

A seguir são apresentados os resultados desta metodologia no controle da vazão. Os gráficos com a resposta da malha de controle de posição foram inseridos no Anexo A. 
Tabela 22: Sintonias obtidas pelo método da Síntese Direta para o controlador PI de vazão (controle em cascata).

\begin{tabular}{|c|c|c|}
\hline Material das gaxetas & $K_{c}$ & $T_{i}$ \\
\hline Teflon & $-0,2693$ & 4,1500 \\
\hline Grafite & $-0,2398$ & 4,5300 \\
\hline
\end{tabular}

\subsubsection{Ensaios para o problema servo}

As Figuras 72 e 80 apresentam os resultados obtidos nestes ensaios. 


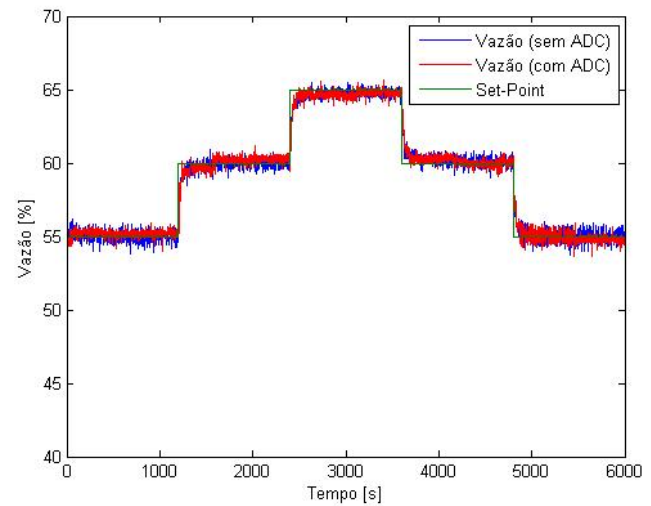

(a) Vazão

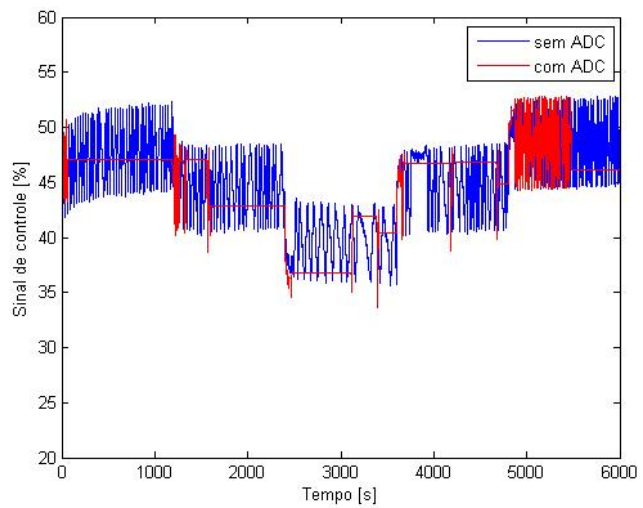

(b) Sinal de controle

Figura 72: Resultados obtidos no ensaio para o problema servo da válvula com gaxetas de teflon com controlador PI (controle em cascata).

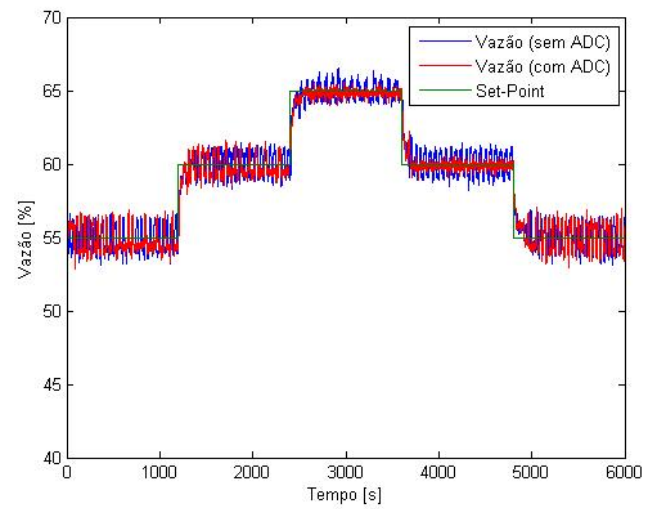

(a) Vazão

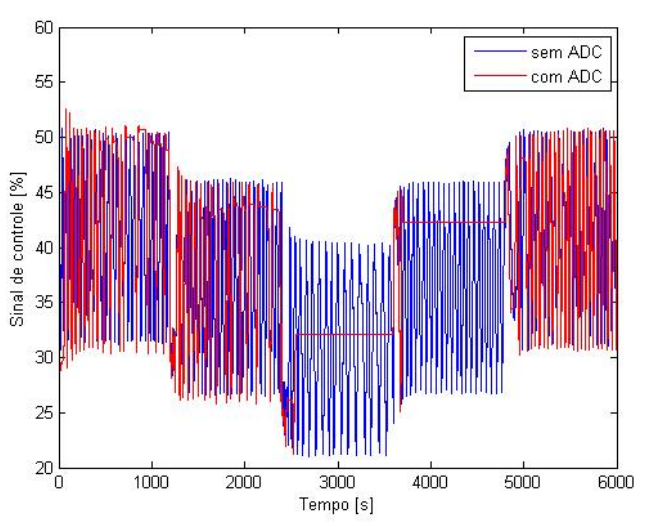

(b) Sinal de controle

Figura 73: Resultados obtidos no ensaio para o problema servo da válvula com gaxetas de grafite com controlador PI (controle em cascata).

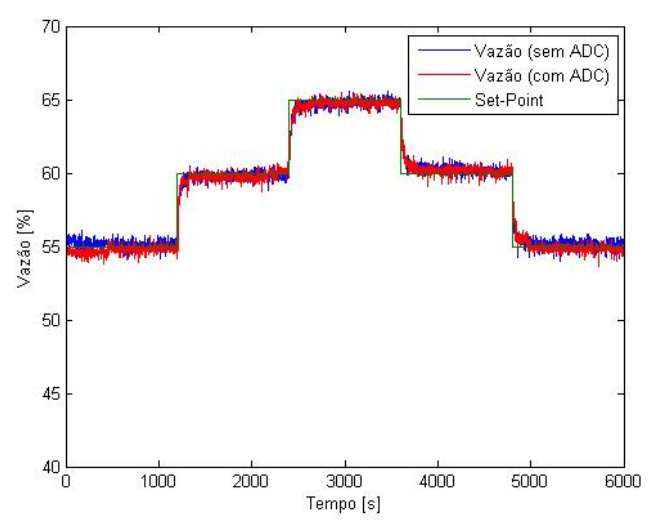

(a) Vazão

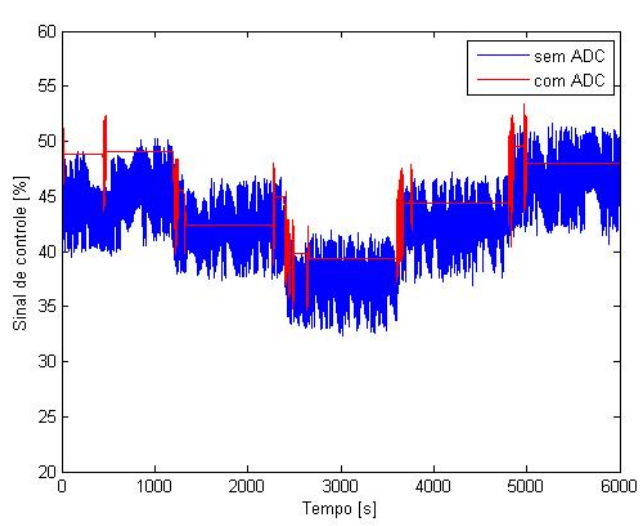

(b) Sinal de controle

Figura 74: Resultados obtidos no ensaio para o problema servo da válvula com gaxetas de teflon com compensador CR1 (controle em cascata). 


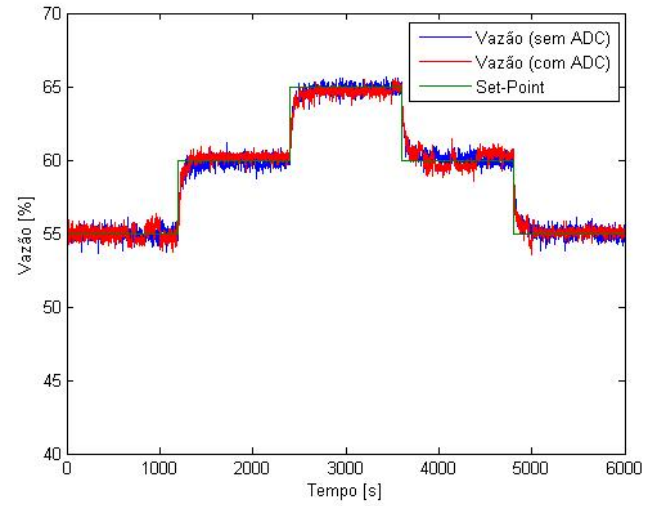

(a) Vazão

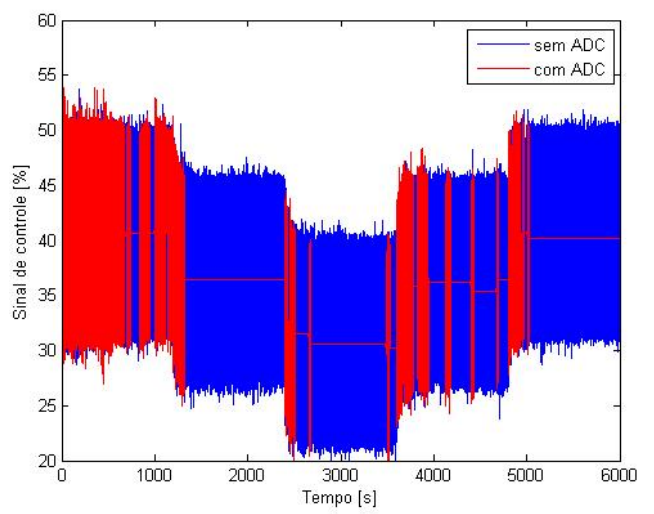

(b) Sinal de controle

Figura 75: Resultados obtidos no ensaio para o problema servo da válvula com gaxetas de grafite com compensador CR1 (controle em cascata).

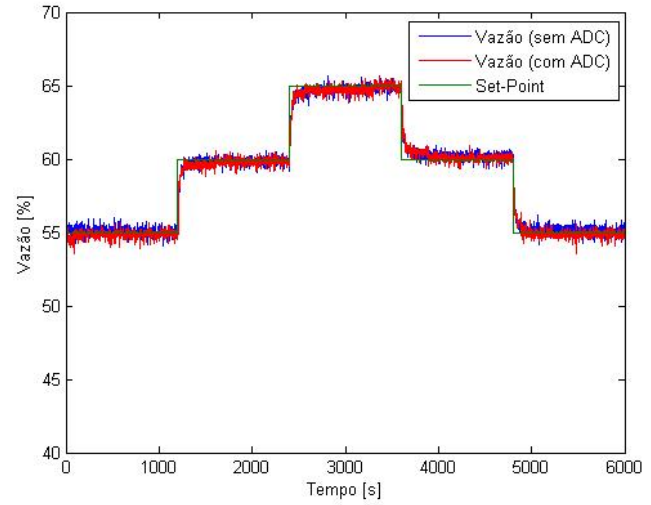

(a) Vazão

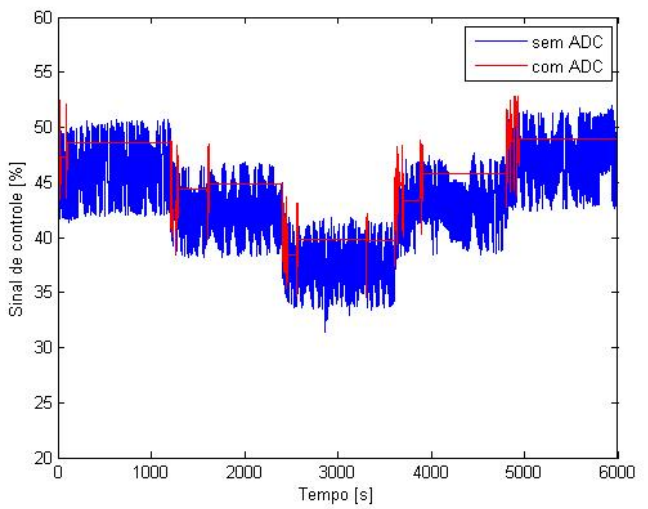

(b) Sinal de controle

Figura 76: Resultados obtidos no ensaio para o problema servo da válvula com gaxetas de teflon com compensador CR2 (controle em cascata).

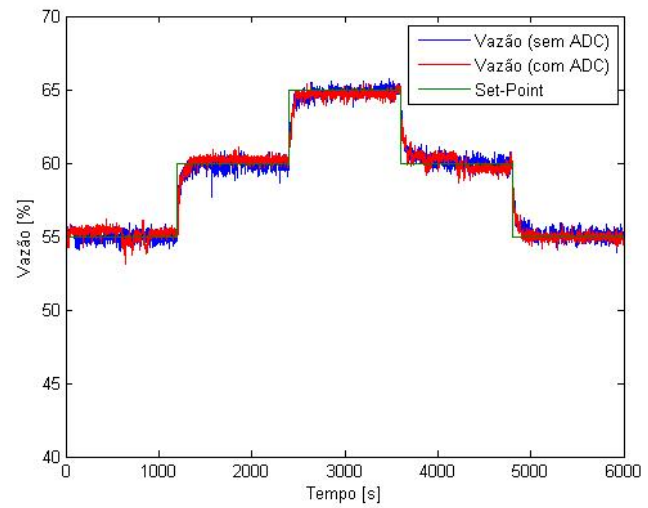

(a) Vazão

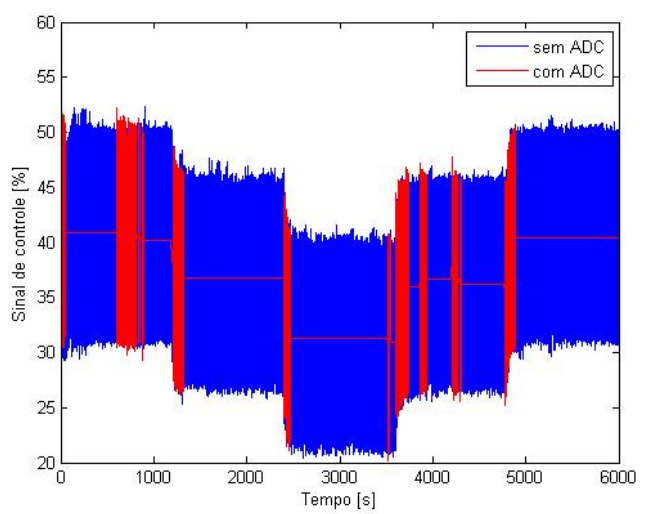

(b) Sinal de controle

Figura 77: Resultados obtidos no ensaio para o problema servo da válvula com gaxetas de grafite com compensador CR2 (controle em cascata). 


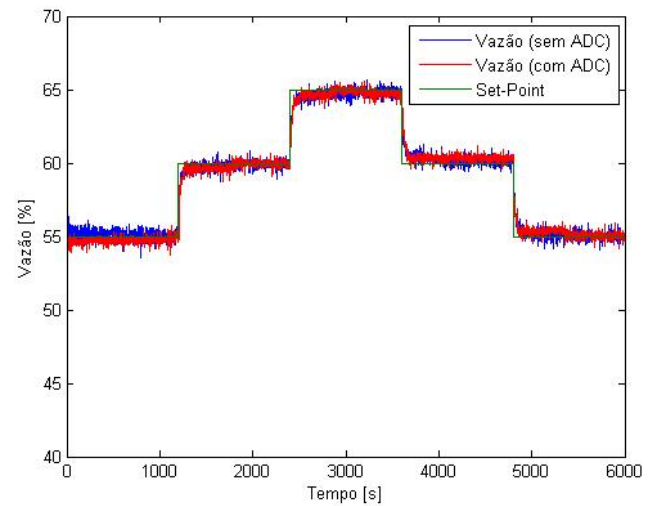

(a) Vazão

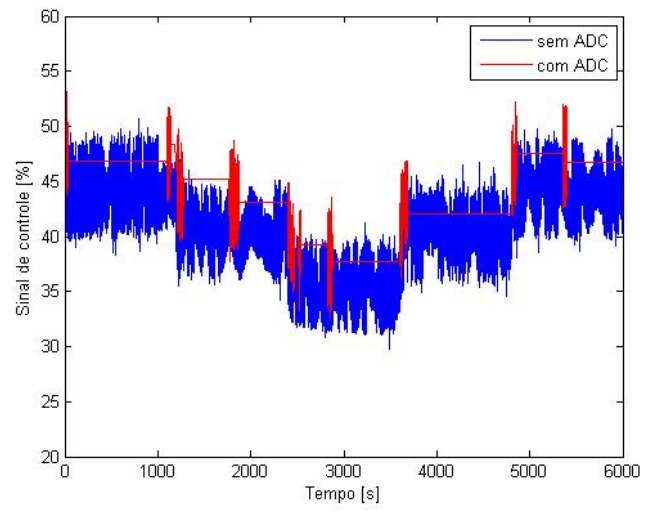

(b) Sinal de controle

Figura 78: Resultados obtidos no ensaio para o problema servo da válvula com gaxetas de teflon com compensador Knocker (controle em cascata).

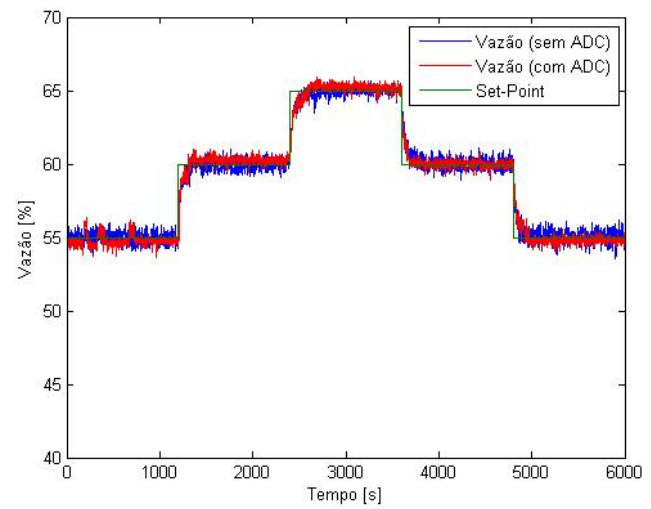

(a) Vazão

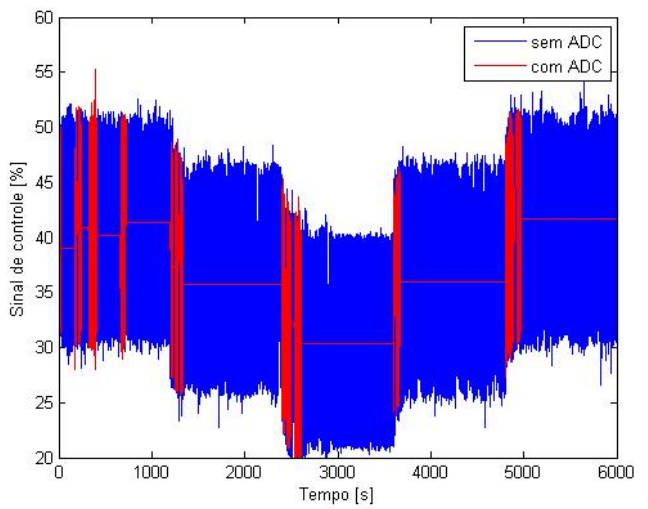

(b) Sinal de controle

Figura 79: Resultados obtidos no ensaio para o problema servo da válvula com gaxetas de grafite com compensador Knocker (controle em cascata).

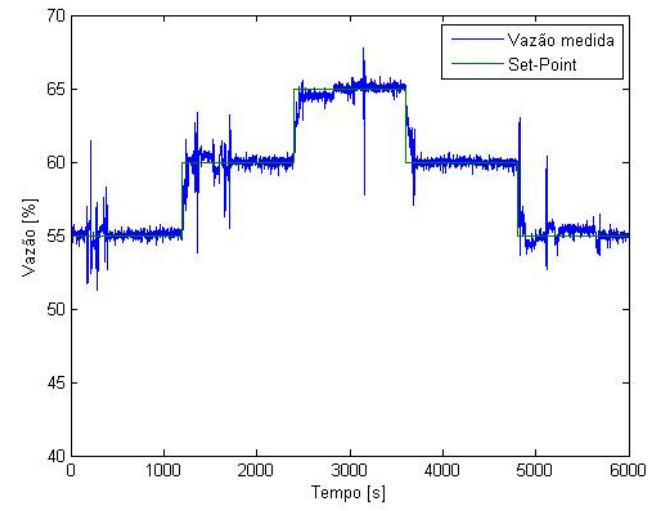

(a) Vazão

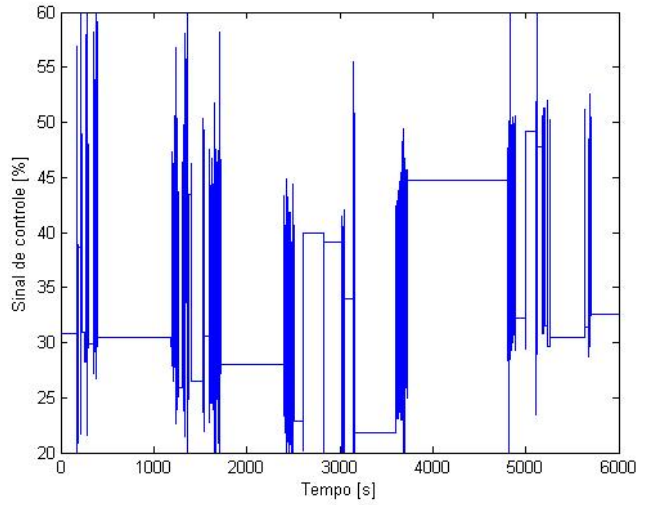

(b) Sinal de controle

Figura 80: Resultados obtidos no ensaio para o problema servo da válvula com gaxetas de grafite com compensador Two-move (controle em cascata). 
Os índices ITAE e tempos de subida desses ensaios são maiores do que os obtidos no teste da seção anterior, devido ao fato do controlador de vazão ter sido configurado para ter uma resposta muito mais lenta e devido à zona morta na ação integral. O segundo, em especial, apresenta uma grande variação dos valores obtidos, pois em alguns casos, devido novamente à zona morta na ação integral do controlador de vazão, o processo estabiliza um pouco abaixo do valor de referência e apenas posteriormente este erro é corrigido.

No caso do controle em cascata, a banda morta gerada pelo stiction também pode gerar oscilações, pois no tempo em que a malha interna está superando esta banda, o controlador externo continuará integrando o erro. Por esse motivo, os compensadores apresentaram uma melhora nos índices de desempenho, mesmo no caso da válvula de baixo atrito. Na Figura 81 é possível visualizar o efeito descrito anteriormente, onde uma parte da resposta da malha de controle de posição é apresentada. Observe que a resposta sem compensação apresenta oscilações mais frequentes do que a obtida com o compensador CR2. No segundo caso, o posição da haste é estabilizada no valor do set-point em diferentes instantes. Porém, devido ao ruído no sinal de posição e de vazão (que é transferido para o set-point de posição) o sistema volta a oscilar após algum tempo. Por esse motivo, o compensador com o ADC apresentou índices ainda melhores. Por esse motivo a resposta é ainda melhor com Ainda para esta válvula, o compensador Knocker se mostrou muito agressivo, pois inseriu uma grande variabilidade na haste da válvula.

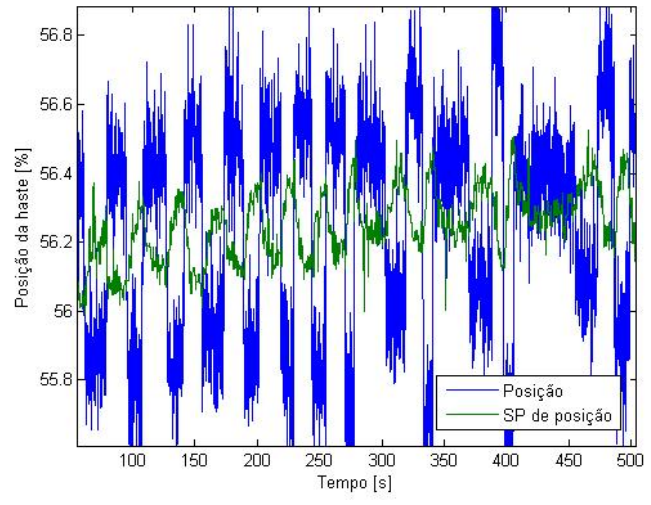

(a) PI sem compensador

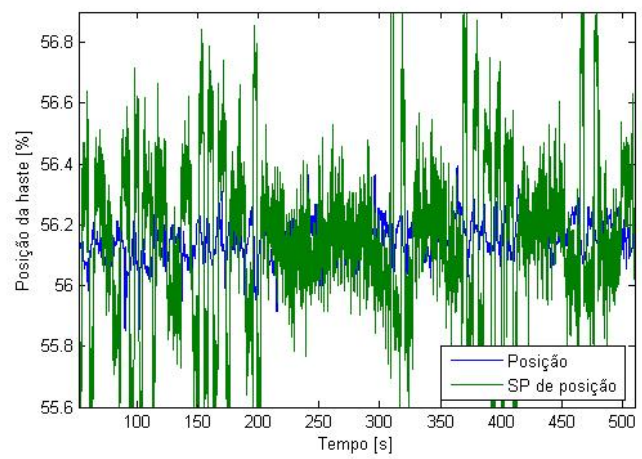

(b) CR2 sem ADC

Figura 81: Oscilações presentes na malha de controle de posição no ensaio para o problema servo da válvula com gaxetas de teflon.

No caso da válvula de alto atrito, o benefício obtido com os compensadores é muito maior. Novamente, o compensador Knocker inseriu uma grande variabilidade na posição da haste, porém quando operou em conjunto com o ADC apresentou o melhor resultado de todos os compensadores. Apesar da semelhança entre os métodos, os compensadores CR1 
e CR2 apresentaram resultados distintos. O primeiro apresentou valores mais elevados de $D_{v}$, o que indica que teve mais dificuldade em estabilizar a haste na posição desejada. Note que o método CR1 utiliza a derivada do sinal de controle, calculado a partir do erro, que neste caso é a subtração de dois sinais ruidosos (o ruído do sinal de vazão é transferida para o set-point de posição), o que pode ser a causa desta diferença. O compensador Twomove atingiu um ITAE próximo do obtido com o Knocker, mas a variabilidade, tanto na pressão do atuador, quanto na posição da haste, foi elevada. Isso se deve ao fato de que nos momentos em que o compensador está realizando os dois movimentos para ajustar a posição, apenas o controlador da malha interna é desativado. Portanto, após a correção da posição o set-point da malha interna já não será o mesmo. No laboratório seria muito simples desabilitar ambos os controladores neste momento, porém, levando em conta a aplicação proposta, isso iria significar que para usar um posicionador com este algoritmo seria necessário alterar o algoritmo de controle da planta, o que o tornaria pouco atrativo. Além disso, o posicionador teria que enviar um sinal digital ao hardware de controle, ou seja, seria necessário mais um par de fios, ou comunicação via redes industriais.

As Tabelas 23 e 24 apresentam os índices obtidos nestes ensaios.

Tabela 23: Índices de desempenho dos ensaios de acompanhamento de set-point com a estrutura de controle em cascata (válvula com gaxetas de teflon).

\begin{tabular}{|c|c|c|c|c|}
\hline Ensaio & ITAE [\%] & $D_{v}[\%]$ & $D_{I P}[\%]$ & $t_{r}[\mathrm{~s}]$ \\
\hline PI convencional (Síntese Direta) & 309,4739 & 366,7553 & 1029,8810 & 114,125 \\
\hline CR1 & 246,2307 & 498,1405 & 828,1480 & 130,625 \\
\hline CR2 & 245,9374 & 388,3886 & 921,2617 & 152,375 \\
\hline Knocker & 238,3719 & 883,7323 & 495,0643 & 118,75 \\
\hline PI (Síntese Direta) com ADC & 294,6317 & 272,7082 & 330,4757 & 75,875 \\
\hline CR1 com ADC & 252,8442 & 182,7906 & 129,4778 & 76,000 \\
\hline CR2 com ADC & 219,6670 & 179,0491 & 131,2735 & 112,375 \\
\hline Knocker com ADC & 289,8508 & 306,0959 & 104,5987 & 85,125 \\
\hline
\end{tabular}


Tabela 24: Índices de desempenho dos ensaios de set-point com a estrutura de controle em cascata (válvula com gaxetas de grafite).

\begin{tabular}{|c|c|c|c|c|}
\hline Ensaio & ITAE [\%] & $D_{v}[\%]$ & $D_{I P}[\%]$ & $t_{r}[\mathrm{~s}]$ \\
\hline PI convencional (Síntese Direta) & 899,6168 & 366,2359 & 2474,0453 & 92,500 \\
\hline CR1 & 283,5081 & 513,9446 & 2632,3457 & 107,125 \\
\hline CR2 & 274,1465 & 297,3216 & 2801,1695 & 142,875 \\
\hline Knocker & 316,3681 & 802,1764 & 1392,9742 & 98,250 \\
\hline PI (Síntese Direta) com ADC & 634,0676 & 272,5233 & 1388,2758 & 97,375 \\
\hline CR1 com ADC & 366,2370 & 477,7344 & 817,2390 & 117,625 \\
\hline CR2 com ADC & 335,3250 & 279,6057 & 462,1236 & 122 \\
\hline Knocker com ADC & 278,2993 & 292,8019 & 224,9705 & 104,250 \\
\hline Two-move & 274,4978 & 658,6821 & 660,6752 & 50,625 \\
\hline
\end{tabular}

\subsubsection{Ensaios para o problema regulatório}

As Figuras 82 a 90 apresentam os resultados dos ensaios de rejeição de perturbações com o sistema de controle em cascata.

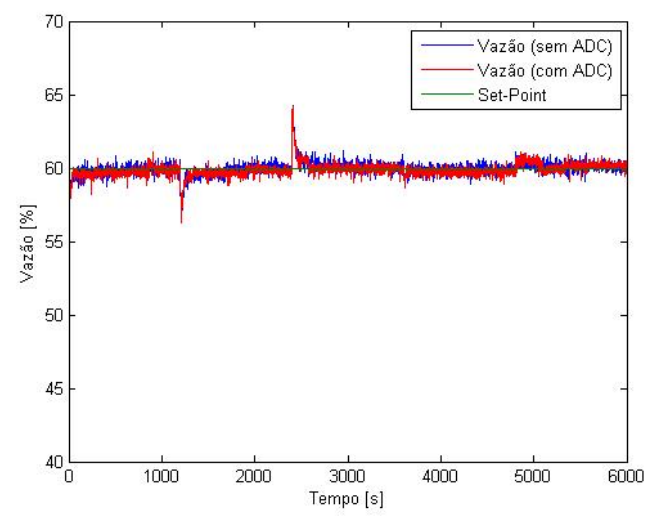

(a) Vazão

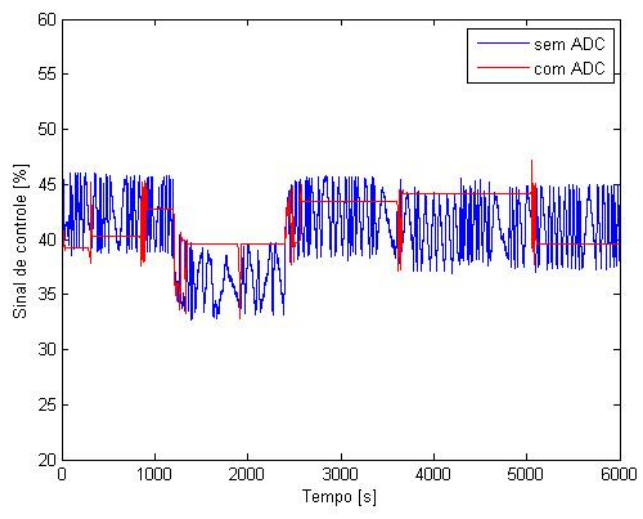

(b) Sinal de controle

Figura 82: Resultados obtidos no ensaio para o problema regulatório da válvula com gaxetas de teflon com controlador PI (controle em cascata). 


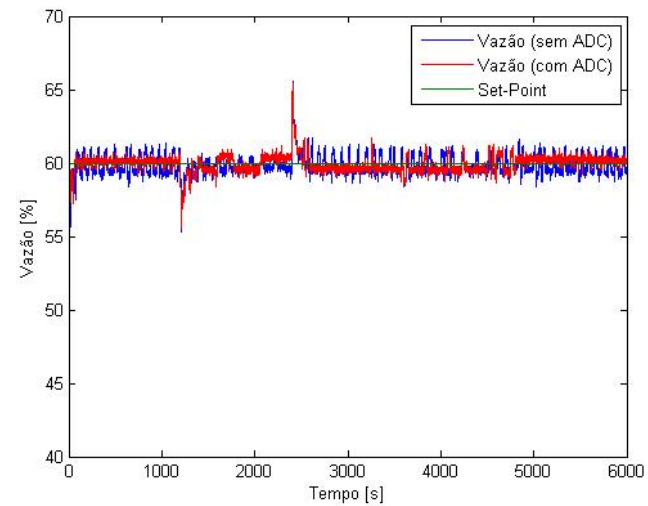

(a) Vazão

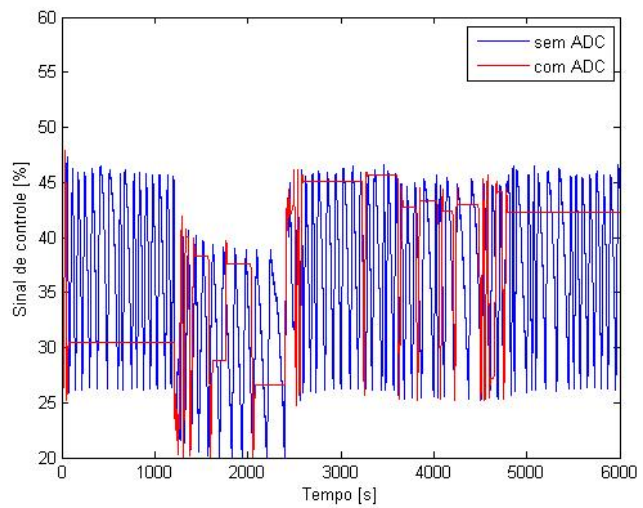

(b) Sinal de controle

Figura 83: Resultados obtidos no ensaio para o problema regulatório da válvula com gaxetas de grafite com controlador PI (controle em cascata).

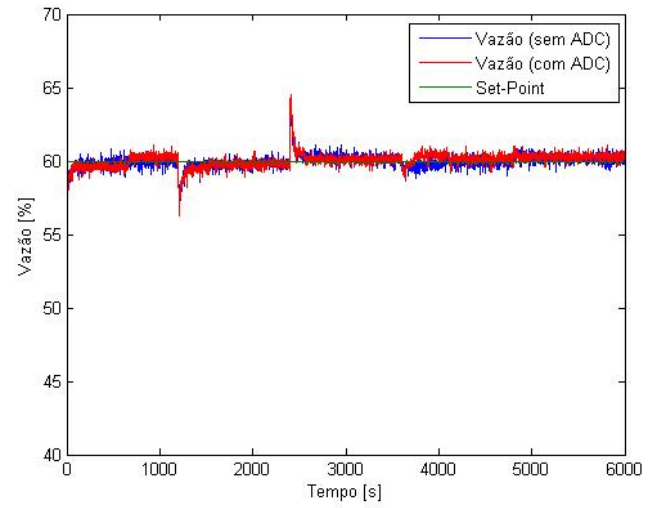

(a) Vazão

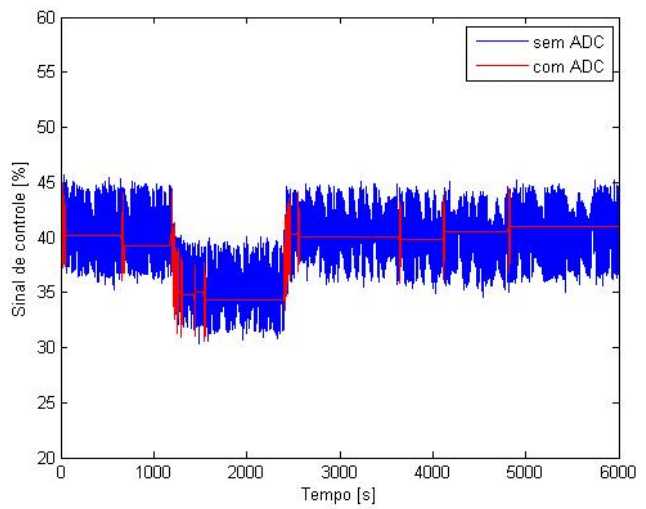

(b) Sinal de controle

Figura 84: Resultados obtidos no ensaio para o problema regulatório da válvula com gaxetas de teflon e compensador CR1 (controle em cascata).

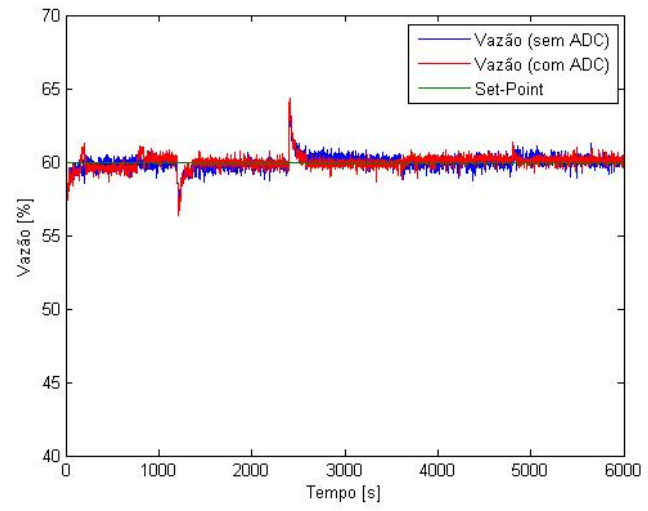

(a) Vazão

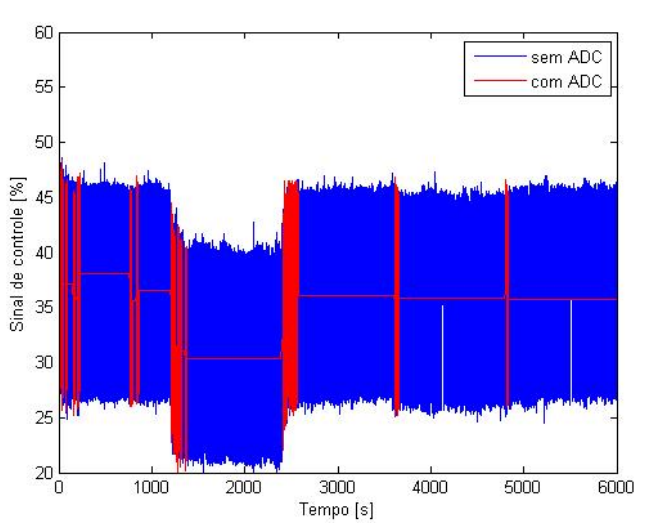

(b) Sinal de controle

Figura 85: Resultados obtidos no ensaio para o problema regulatório da válvula com gaxetas de grafite e compensador CR1 (controle em cascata). 


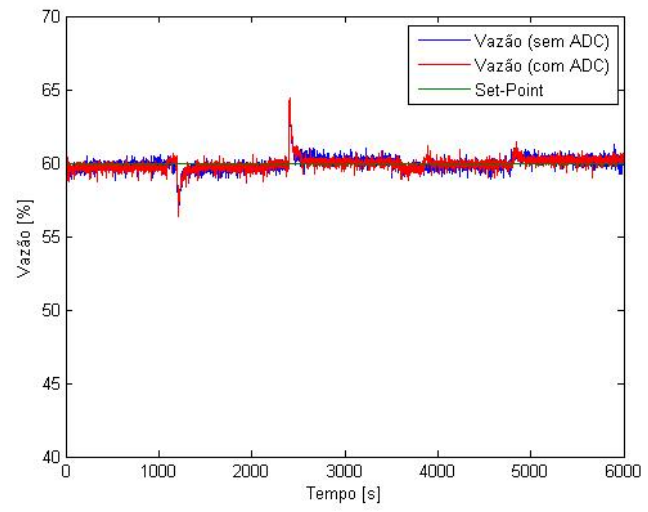

(a) Vazão

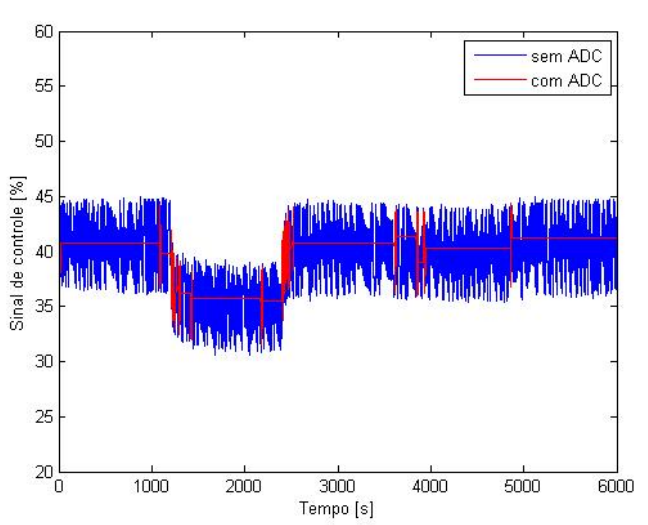

(b) Sinal de controle

Figura 86: Resultados obtidos no ensaio para o problema regulatório da válvula com gaxetas de teflon e compensador CR2 (controle em cascata).

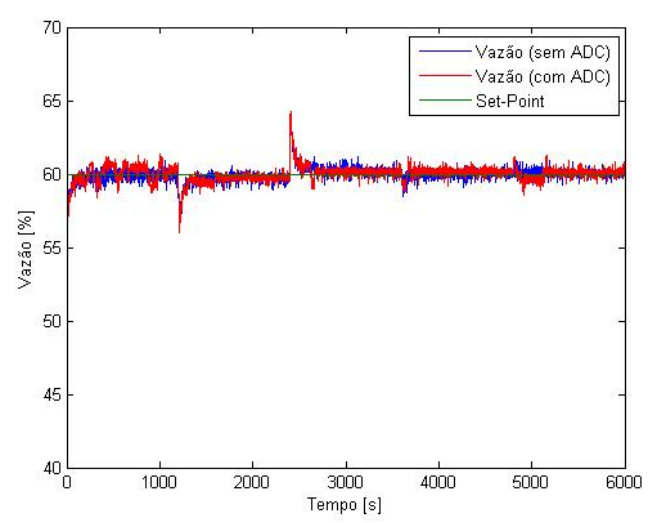

(a) Vazão

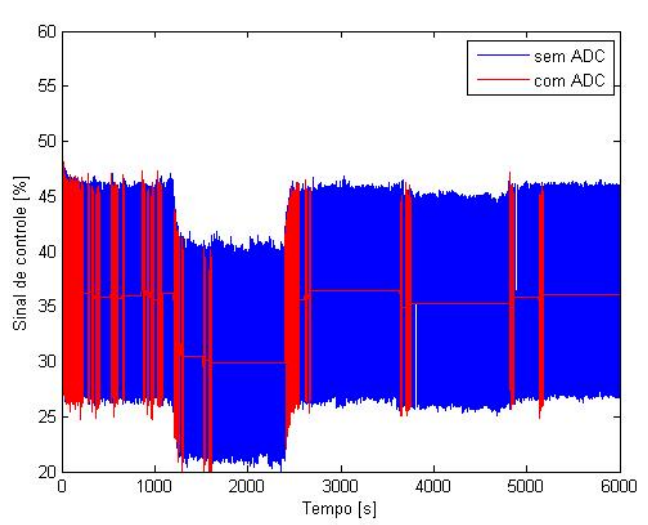

(b) Sinal de controle

Figura 87: Resultados obtidos no ensaio para o problema regulatório da válvula com gaxetas de grafite e compensador CR2 (controle em cascata).

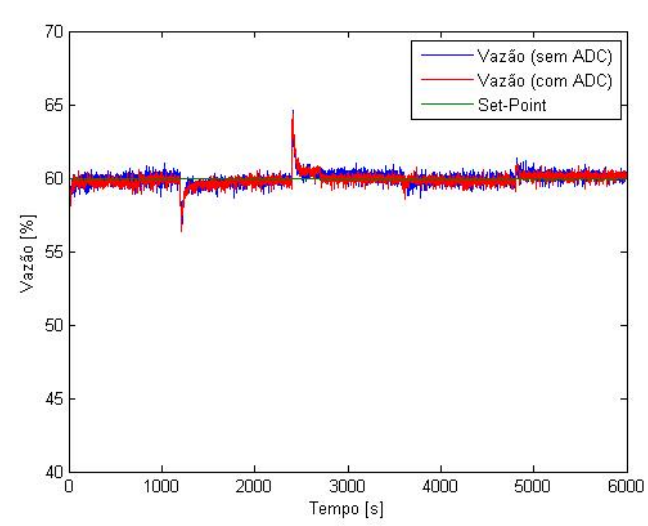

(a) Vazão

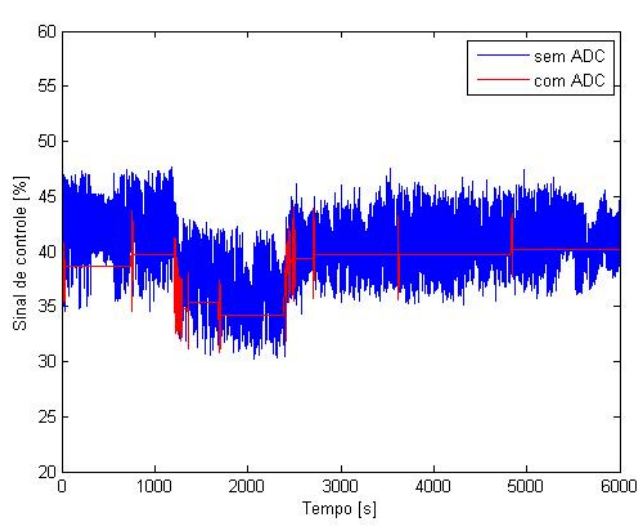

(b) Sinal de controle

Figura 88: Resultados obtidos no ensaio para o problema regulatório da válvula com gaxetas de teflon e compensador Knocker (controle em cascata). 


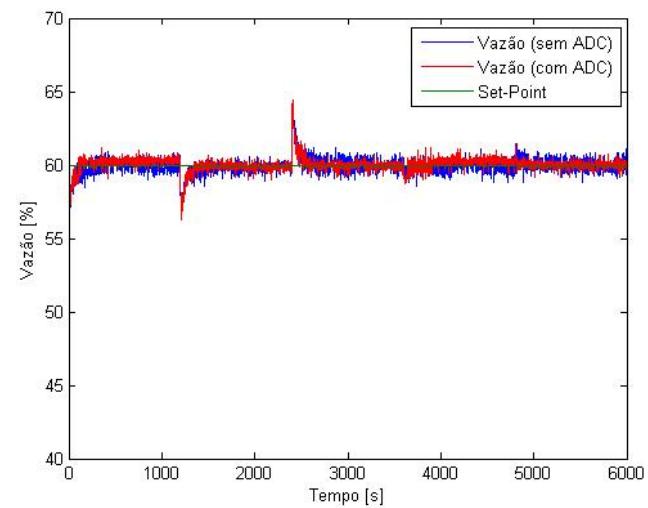

(a) Vazão

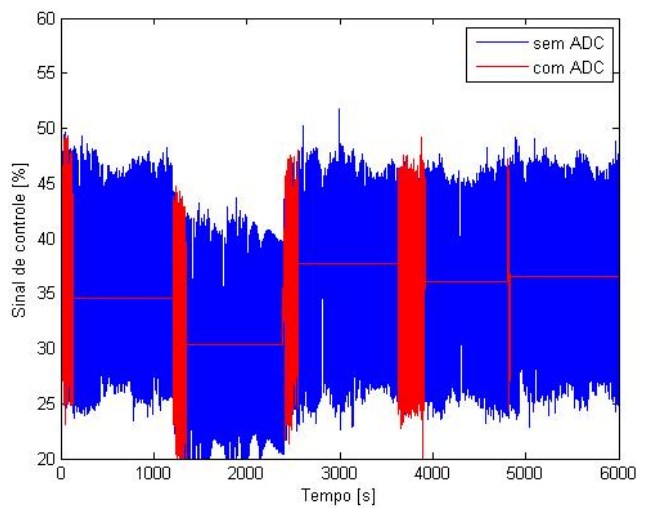

(b) Sinal de controle

Figura 89: Resultados obtidos no ensaio para o problema regulatório da válvula com gaxetas de grafite e compensador Knocker (controle em cascata).

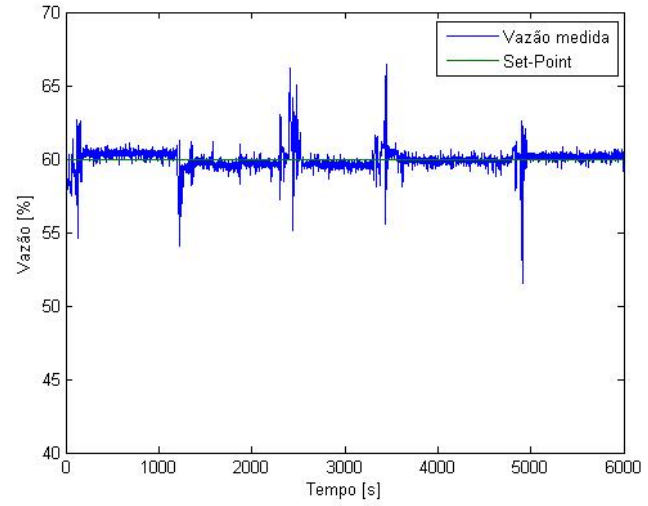

(a) Vazão

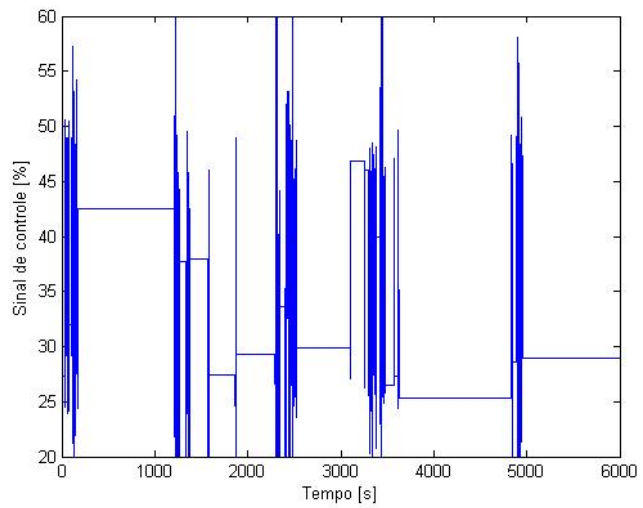

(b) Sinal de controle

Figura 90: Resultados obtidos no ensaio para o problema regulatório da válvula com gaxetas de grafite e compensador Two-move (controle em cascata).

Para os testes de rejeição de perturbações, com a válvula com gaxetas de teflon, os compensadores não melhoraram o desempenho do sistema, pois não reduziram o ITAE e aumentaram o $D_{I P}$ e $D_{v}$. Novamente, o compensador Knocker se mostrou muito agressivo para esta válvula. Quando os testes são realizados com o ADC, os compensadores apresentaram um desempenho próximo ao obtido sem compensação de atrito.

Nos testes com a válvula de alto atrito, a maioria dos métodos melhora os resultados, e quando aplicados em conjunto com o ADC, diminuíram a variabilidade da posição da haste e da pressão no atuador. O compensador Two-move não apresentou bons resultados neste teste, provavelmente devido ao problema descrito na subseção anterior. O conjunto Knocker com ADC foi o que apresentou o melhor resultado nestes ensaios. Os índices de 
desempenho obtidos por estão nas Tabelas 25 e 26.

Tabela 25: Índices de desempenho dos ensaios para o problema regulatório com a estrutura de controle em cascata (válvula com gaxetas de teflon).

\begin{tabular}{|c|c|c|c|}
\hline Ensaio & ITAE [\%] & $D_{v}[\%]$ & $D_{I P}[\%]$ \\
\hline PI convencional (Síntese Direta) & 229,8645 & 3249,2688 & 735,7585 \\
\hline CR1 & 246,4517 & 557,1654 & 825,4306 \\
\hline CR2 & 277,9705 & 270,0694 & 1016,514 \\
\hline Knocker & 252,4910 & 1396,2530 & 498,2067 \\
\hline PI (Síntese Direta) com ADC & 266,9954 & 152,9650 & 141,9248 \\
\hline CR1 com ADC & 293,6376 & 208,4019 & 95,6587 \\
\hline CR2 com ADC & 263,1585 & 186,1564 & 97,5466 \\
\hline Knocker com ADC & 249,5609 & 195,7436 & 70,8114 \\
\hline
\end{tabular}

Tabela 26: Índices de desempenho dos ensaios para o problema regulatório com a estrutura de controle em cascata (válvula com gaxetas de grafite).

\begin{tabular}{|c|c|c|c|}
\hline Ensaio & ITAE $[\%]$ & $D_{v}[\%]$ & $D_{I P}[\%]$ \\
\hline PI convencional (Síntese Direta) & 645,8122 & 232,8076 & 1687,6830 \\
\hline CR1 & 251,8786 & 307,0115 & 2599,8036 \\
\hline CR2 & 226,8205 & 214,8560 & 2716,3389 \\
\hline Knocker & 314,7397 & 753,6545 & 1407,8307 \\
\hline PI (Síntese Direta) com ADC & 424,8993 & 173,0294 & 479,0120 \\
\hline CR1 com ADC & 250,0906 & 191,9268 & 288,1193 \\
\hline CR2 com ADC & 297,8985 & 264,4518 & 508,5676 \\
\hline Knocker com ADC & 234,5219 & 261,8626 & 231,5918 \\
\hline Two-move & 401,1349 & 691,6865 & 496,1610 \\
\hline
\end{tabular}

\subsection{Ensaios de robustez dos compensadores}

Esta seção apresenta os ensaios de robustez dos controladores CR e Knocker a erros na estimação do parâmetro $S$. Foram utilizadas as mesmas configurações dos testes de acompanhamento de set-point apenas com a malha de controle de vazão. Além disso, os ensaios foram feitos apenas na válvula de alto atrito, pois é o caso em que os compensadores têm maior efeito no processo. Por serem muito parecidas, apenas a primeira implementação do compensador CR (CR1) foi utilizada. 
Os índices de desempenho obtidos com erros de $\pm 5 \%, \pm 10 \%$ e $\pm 20 \%$ na estimativa do parâmetro de atrito na válvula, considerando o valor obtido pelo método de refinamento como sendo o valor real, estão nas Tabelas 27 e 28.

Tabela 27: Índices de desempenho dos ensaios de robustez do compensador CR1.

\begin{tabular}{|c|c|c|c|c|}
\hline Erro na estimação de $S[\%]$ & ITAE [\%] & $D_{v}[\%]$ & $D_{I P}[\%]$ & $t_{r}[\mathrm{~s}]$ \\
\hline-20 & 535,0584 & 226,4007 & 2392,6851 & 25,125 \\
\hline-10 & 360,2805 & 167,6110 & 2614,13901 & 15,750 \\
\hline-5 & 199,8978 & 110,6863 & 2498,4884 & 15,875 \\
\hline 0 & 178,3003 & 110,2890 & 2625,0387 & 13,625 \\
\hline+5 & 201,7485 & 147,7498 & 2711,0891 & 9,375 \\
\hline+10 & 209,7705 & 203,3370 & 2880,3824 & 13,625 \\
\hline+20 & 259,4553 & 287,0470 & 3032,9794 & 11,375 \\
\hline
\end{tabular}

No caso do compensador CR1 é possível verificar que para os casos em que o valor de $S$ é pequeno (erros de $-20 \%$ e $-10 \%$ ) há um grande incremento no ITAE. Isto ocorre porque nestas condições o controlador teve dificuldades em estabilizar a vazão no valor de referência em diversas situações, mesmo com o auxílio do compensador. Nos gráficos da resposta dos ensaios de robustez, no Anexo B, é possível verificar que há pequenas oscilações nestas situações, o que também justifica o aumento na variabilidade da posição da haste. Para os outros casos não há uma variação tão acentuada no valor do ITAE. Porém, para erros positivos, como a variação imposta pelo compensador é superior a banda morta, cada chaveamento na saída do compensador gera pequenas movimentações na haste, ou seja, um aumento na variabilidade da posição da mesma.

O esperado para estes ensaios seria que, quanto menor o valor de $S$ utilizado para sintonizar o compensador, menor seria a variabilidade da pressão no atuador e maior seria o tempo de subida, pois o compensador iria inserir uma variação menor no sinal de controle e teria mais dificuldade em superar a banda morta. Por esse motivo, dois casos merecem ser destacados. Para erro de $-10 \%$ no parâmetro de atrito, o valor de $D_{I P}$ foi próximo ao obtido com erro nulo. Apesar de gerar variações com um erro de $-10 \%$, a frequência de chaveamento pode ter sido maior neste caso, ou ainda, devido à variabilidade da variável do processo, o controlador PI pode ter inserido uma variabilidade maior no sinal de controle. Outro caso inesperado foi o tempo de subida do ensaio com erro de $+5 \%$ ter sido o menor obtido. Caso o compensador não precise chavear sua saída no instante em ocorre um degrau no set-point (ou seja, a banda morta não precisa ser superada), o tempo de subida será menor, uma vez que, apesar da variação do compensador ser instantânea, o conversor I/P possui dinâmica. Além disso, o ruído de medição pode influenciar este índice de desempenho. 
Tabela 28: Índices de desempenho dos ensaios de robustez do compensador Knocker.

\begin{tabular}{|c|c|c|c|c|}
\hline Erro na estimação de $S[\%]$ & ITAE [\%] & $D_{v}[\%]$ & $D_{I P}[\%]$ & $t_{r}[\mathrm{~s}]$ \\
\hline-20 & 308,4491 & 135,1704 & 1773,3556 & 10,625 \\
\hline-10 & 311,5612 & 131,6110 & 1792,8127 & 14,250 \\
\hline-5 & 240,7451 & 110,8087 & 1755,73315 & 14,875 \\
\hline 0 & 212,6990 & 118,6953 & 1736,2262 & 14,875 \\
\hline+5 & 268,6174 & 126,0845 & 1761,7757 & 16,625 \\
\hline+10 & 307,7187 & 130,5122 & 1795,0975 & 16,500 \\
\hline+20 & 226,8125 & 108,6005 & 1755,5285 & 13,625 \\
\hline
\end{tabular}

Os resultados obtidos com o compensador Knocker mostram que, mesmo com erros na estimação de $S$, a eficiência do compensador não é perdida. Os valores do ITAE, $D_{v}$ e $D_{I P}$ não sofreram grandes alterações, mesmo com erros grandes no parâmetro de atrito. Dois fatos inesperados foram o baixo tempo de subida obtido para um erro de $-20 \%$ e o bom desempenho obtido para o erro de $+20 \%$ em todos os índices. Apesar dos dados da Tabela 28, uma análise visual dos gráficos obtidos nesses ensaios (Anexo C) mostra que apenas quando se utiliza o valor estimado $S$, a variável controlada está livre de pequenas oscilações.

A robustez do compensador Two-move pode ser estudada analisando o seu algoritmo. No caso em que o compensador está ajustando a posição da haste, um pequeno erro em $S$ ou $J$ não irá necessariamente impedir o primeiro movimento, pois a variação do sinal do controlador também é somada na amplitude do degrau que irá gerar este movimento. Porém o segundo movimento não irá ocorrer, o que significa que o o processo irá se afastar do set-point. Além disso, a válvula estará em uma situação em que a banda morta não foi completamente superada, portanto se uma nova correção de posição no sentido contrário for ocorrer, a situação será ainda pior. Caso os valores estimados sejam muito pequenos, nem o primeiro e nem o segundo movimento da correção de posição irão ocorrer. No caso de um erro positivo nas estimações será inserida uma variabilidade maior na haste da válvula, mas a compensação do atrito irá ocorrer normalmente.

Os compensadores CR1 (e CR2 pela semelhança dos métodos) e Knocker se mostraram robustos ao erro de $5 \%$ que os métodos de identificação apresentaram em relação aos valor obtido pelo método de refinamento. Portanto mesmo sem o refinamento das estimativas a compensação apresentaria um resultado satisfatório. Porém a análise da robustez do compensador Two-move indica que mesmo um erro de $-5 \%$ pode impedir o bom funcionamento do sistema, portanto, fora o método de refinamento, não é possível garantir a compensação do atrito, uma vez que o erro obtido pelos outros métodos pode ser positivo ou negativo. 


\section{Conclusões}

Este capítulo apresenta as conclusões obtidas. A primeira seção apresenta as conclusões referentes aos modelos de válvulas de controle sob o efeito do stiction e identificação dos seus parâmetros. Em seguida são feitas análises sobre os ensaios dos compensadores na malha de controle de vazão e, na sequência, análises dos resultados obtidos com a estrutura de controle em cascata. A última seção apresenta as conclusões sobre a robustez dos compensadores em função de um erro na estimação dos parâmetros de atrito.

\subsection{Modelos de atrito em válvulas de controle e iden- tificação de parâmetros de atrito}

Os dois modelos testados neste trabalho apresentaram resultados muito semelhantes, assim como os métodos de identificação dos seus parâmetros, o que condiz com os resultados obtidos em (GARCIA, 2008) e (ROMAnO; GARCIA, 2007). Porém, a estimação utilizada para sintonizar os compensadores foi a obtida pelo método de refinamento da Seção 3.5, onde os parâmetros $S$ e $J$ são estimados experimentalmente com base em suas definições, ou seja, os parâmetros estimados são de fato a maior variação (de forma brusca, como é realizado pelos compensadores) no sinal de controle que não gera movimento na haste no sentido contrário e no mesmo sentido do último movimento, respectivamente. Desta forma é esperado que estes valores apresentem os melhores resultados possíveis para os compensadores de atrito.

As técnicas de identificação, da maneira como foram implementadas, dificilmente seriam aplicadas em um processo real. Idealmente, a técnica de identificação teria que operar com a válvula operando no processo e realizando alterações mínimas no mesmo, ou utilizando dados históricos. O algoritmo proposto por Romano e Garcia (2008) poderia ser aplicada em dados históricos, porém necessita da medida da posição da haste, o que não é uma prática comum na ambiente industrial. O método de Kano et al. (2004) é o único que pode ser aplicado a dados históricos, sem a necessidade de medir a posição da 
haste, porém, as estimações podem ser afetadas pela dinâmica do processo e perturbações. Outro problema desta abordagem é que apenas o valor de $S$ é estimado.

Existem diversas técnicas de identificação presentes na literatura que podem ser utilizadas em um ambiante industrial (ver Seção 1.3), porém é necessário avaliar a precisão das estimativas obtidas e seu efeito na compensação.

\subsection{Análise dos compensadores de atrito atuando na malha de controle de vazão}

Os resultados experimentais com os compensadores na malha de controle de vazão indicam que o aumento do tempo integral do controlador PI diminui a frequência e amplitude das oscilações causadas pelo alto índice de atrito na válvula de controle. Porém, estas oscilações não são totalmente eliminadas, pois mesmo que a variável controlada atinja, inicialmente, um valor próximo da referência, eventualmente o sistema irá começar a oscilar. Se originalmente $T_{i} \leq(\theta+\tau)$, o incremento deste parâmetro irá resultar em uma diminuição do erro médio e da variabilidade do sistema, ao custo de uma diminuição da velocidade de resposta. Porém no teste de rejeição de perturbações foi possível verificar que para sintonias muito suaves, a haste em algumas situações se move muito lentamente, o que ocasiona paradas antes de atingir a posição ideal. Se estas paradas ocorrerem perto da posição de erro nulo, que é uma situação provável, uma vez que a movimento da haste tende a ser mais lento, conforme a variável do processo se aproxima da referência, as oscilações voltam a ocorrer devido ao slip-jump.

Os compensadores CR1, CR2 e Knocker eliminam as oscilações, diminuindo o erro médio e o tempo de subida do sistema, porém aumentam a variabilidade do sinal de controle. Isto significa uma menor expectativa da vida útil dos atuadores e, portanto, um aumento no custo de manutenção dos equipamentos. Estes compensadores são mais interessantes se forem usados de forma paliativa. Quando um equipamento começar a apresentar altos índices de atrito, estes métodos podem ser utilizados até que ocorra uma parada programada da planta e a válvula possa ser removida para manutenção.

Os três métodos de compensação apresentam resultados semelhantes, porém o Knocker gera uma variabilidade menor no sinal de controle do que os outros dois. Este resultado foi obtido porque, enquanto o Knocker foi parametrizado para inserir um pulso de $1 \mathrm{~s}$ de duração a cada 2,5 s no sinal de controle, os outros compensadores podem inserir um degrau a cada 1 s. Se o período de atualização dos compensadores CR1 e CR2 for aumen- 
tado, a variabilidade do sinal de controle será menor. Porém este processo pode diminuir também a eficiência dos métodos.

O algoritmo de desabilitação do controle diminui a variabilidade do sinal de controle, removendo a desvantagem das três técnicas citadas. Desta forma, é possível compensar o efeito na malha de controle sem um desgaste excessivo dos equipamentos. Mesmo quando utilizado apenas com o controlador PI, o sistema apresenta uma melhora no seu desempenho. A sintonia mais agressiva (SD) foi a que apresentou o melhor resultado quando opera em conjunto com o ADC. Em especial, no caso dos ensaios para o problema regulatório, os resultados para a válvula de alto atrito dos compensadores em conjunto com o ADC e do controlador atuando apenas como ADC foram muito semelhantes. Porém, o bom desempenho desta abordagem não é garantido, pois depende do controlador estabilizar a haste em uma posição de erro pequeno. Note que, se o sistema for constantemente perturbado ou as mudanças no set-point forem frequentes, o algoritmo terá uma efeito muito pequeno.

O compensador Two-move foi eficiente em remover as oscilações da haste, inserindo uma variabilidade menor na pressão do atuador e posição da haste do que os três compensadores anteriores. Porém se estes compensadores estiveram atuando em conjunto com o ADC, o Two-move apresenta um desempenho pior neste quesito.

Em resumo, para os compensadores atuando na malha de controle de vazão, o conjunto Knocker com ADC apresentou os melhores resultados. Porém, não é possível afirmar que o compensador é melhor, uma vez que os resultados poderiam ser diferentes com outras sintonias do controlador. Além disso, existem algumas variáveis dos compensadores que são ajustadas pelo usuário e, portanto, também podem afetar os resultados. Outro ponto importante é que estes resultados foram obtidos com um processo não integrativo, com constante de tempo próximo à da válvula de controle. Outros processo podem apresentar comportamentos distintos com as mesmas técnicas discutidas neste trabalho. Porém, Cuadros (2011) também obteve os melhores resultados com o compensador Knocker, o que também indica que está é a melhor escolha de compensador.

Para válvulas com baixo índice de atrito o uso de compensadores não é justificado, pois os benefícios, quando existem, são muito pequenos. 


\subsection{Análise dos compensadores de atrito atuando na malha de controle de posição em cascata com a malha de controle de vazão}

Como na seção anterior, para a válvula de alto atrito os compensadores apresentam uma grande melhora no desempenho do processo. Porém, neste caso foi possível observar que mesmo a banda morta da válvula de baixo atrito pode gerar oscilações no processo, o que significa que, inserir um posicionador com um algoritmo PID padrão pode gerar oscilações que antes não existiam em um processo não integrativo. Por esse motivo, os compensadores foram benéficos também para válvula de baixo atrito nos ensaios de acompanhamento de set-point.

Não é possível comparar os índices desempenho dos compensadores neste ensaio com o obtido nos ensaios da seção anterior, pois foi utilizada uma sintonia muito mais lenta para o controlador de vazão no primeiro caso.

A alta variabilidade da haste nos testes com os compensadores CR1, CR2 e Knocker indica que a sintonia da malha de controle de posição está muito agressiva. As variações inseridas pelos compensadores são somadas à variação entre a saída do controlador no ciclo anterior e a saída no ciclo atual. Quanto mais agressiva for a sintonia do controlador, maior serão essas variações. Se estes valores forem muito grandes, os compensadores irão gerar movimentos muito grandes na haste, aumentando a variabilidade. Portanto, não é indicado utilizar sintonias muito agressivas com estes compensadores de atrito.

A alta variabilidade obtida com o compensador Two-move pode ser explicada pelo fato da malha externa continuar operando quando o compensador está realizando os dois movimentos de correção da posição. Mesmo apresentando um baixo valor de ITAE, este compensador não é uma boa opção para atuar em um posicionador. Além disso, o mesmo problema pode ocorrer em processos integrativos, pois durante a correção da posição da haste o processo pode se afastar do ponto de referência. A sintonia também pode ter influenciado este resultado, uma vez que os próprios autores do modelo sugerem que se utilize uma sintonia suave com este compensador.

\subsection{Robustez dos compensadores}

O compensador CR1 apresentou resultados ruins quando o valor de $S$ é muito subestimado. Porém, para erros baixos ou erros positivos na estimação, o compensador ainda 
se mostra eficiente. Entretanto, para valores muito grandes de $S$, a variabilidade da haste aumenta. Pela semelhança entre os métodos se espera que o compensador CR2 tenha um desempenho semelhante. O compensador Knocker se mostrou mais robusto, porém os erros de estimação também causam pequenas variações na posição da haste, mas em menor escala. Já o compensador Two-move se tornar ineficiente para valores de $S$ e $J$ abaixo do real, por tanto para garantir seu funcionamento seria necessário superestimar ambos os valores, aumentando a variabilidade do sistema. Como o desempenho deste compensador não é superior ao dos outros (com ADC), não faz sentido utilizá-lo.

\subsection{Proposta de trabalhos futuros}

A seguir são apresentadas algumas propostas para trabalhos futuros.

- Neste trabalho foram apresentados alguns ensaios de robustez dos compensadores em função do erro de estimação dos parâmetros de atrito. Um estudo interessante para complementar os resultados obtidos seria uma avaliação do erro obtido com as diversas técnicas de estimação presentes na literatura mais indicadas para a aplicação em um processo real. Desta forma seria possível avaliar quais poderiam ser usadas para sintonizar os compensadores de maneira eficiente.

- Os testes realizados neste trabalho foram feitos em um processo não integrativo e com constante de tempo dominante próxima da constante de tempo da válvula. Resultados diferentes podem ser obtidos ao se realizarem ensaios em processos com constantes de tempo altas ou processos integrativos.

- Para o caso dos algoritmos atuando em posicionadores, não há a necessidade de que os mesmos sejam simples, pois seriam implementados em um hardware dedicado. Portanto, o seu desempenho nesta aplicação poderia ser comparado com o de algoritmos de controle não lineares.

- Os algoritmos estudados neste trabalho teriam que ser implementados em equipamentos industriais. A implementação e avaliação destes algoritmos nestes equipamentos seriam de grande valia.

- Por fim, posicionadores eletropneumáticos são equipamentos comuns, que embora não solucionem completamente os problemas gerados pelo stiction, minimizam seus efeitos. Porém, quando a atuação é feita por meio destes equipamentos, a teoria por trás dos compensadores estudados neste trabalho não a valida. Portanto, uma linha de pesquisa possível, seria avaliar novas abordagens para esta situação. 


\section{ANEXO A - Resposta da malha de controle de posição na estrutura de controle em cascata}

Neste anexo são apresentados os gráficos do comportamento da malha de controle de posição quando se utiliza a estrutura de controle em cascata apresentada na Seção 5.2.

\section{A.1 Ensaios de acompanhamento de set-point}

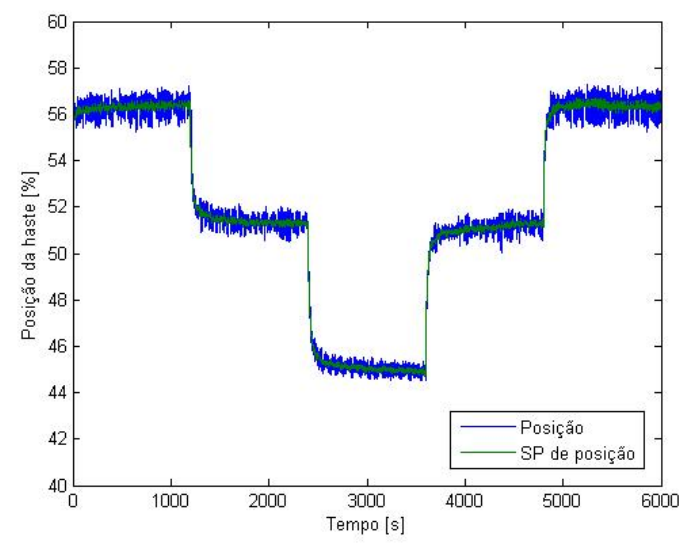

(a) Sem ADC

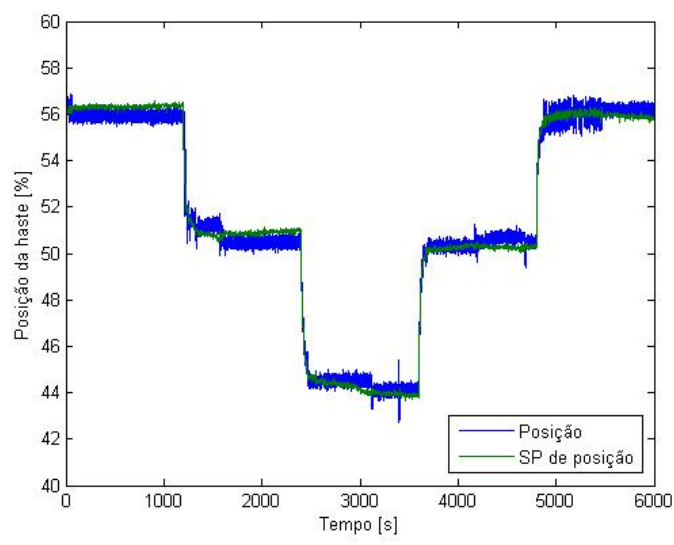

(b) Com ADC

Figura 91: Resposta da malha de controle de posição no ensaio para o problema servo da válvula com gaxetas de teflon com controlador PI (controle em cascata). 


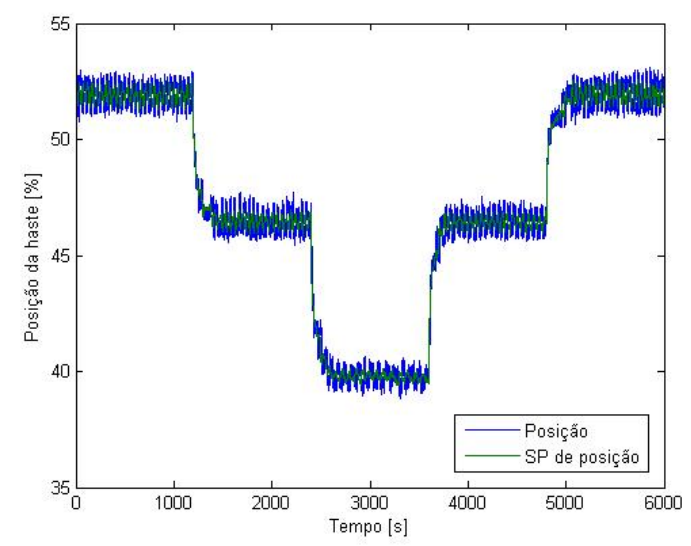

(a) Sem ADC

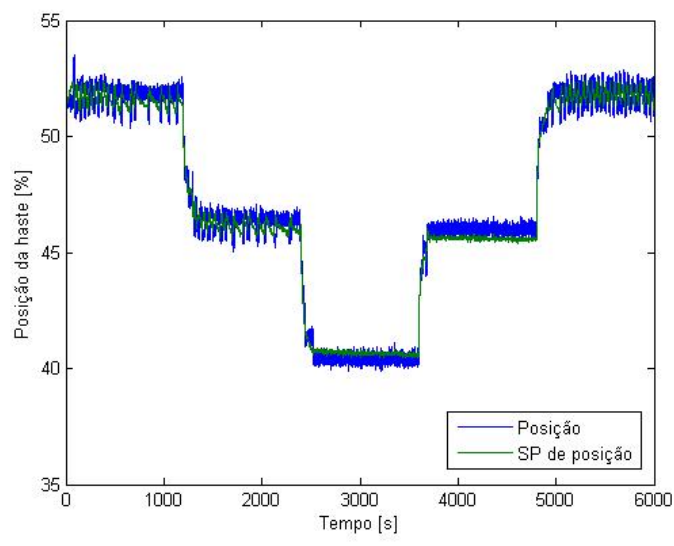

(b) Com ADC

Figura 92: Resposta da malha de controle de posição no ensaio para o problema servo da válvula com gaxetas de grafite com controlador PI (controle em cascata).

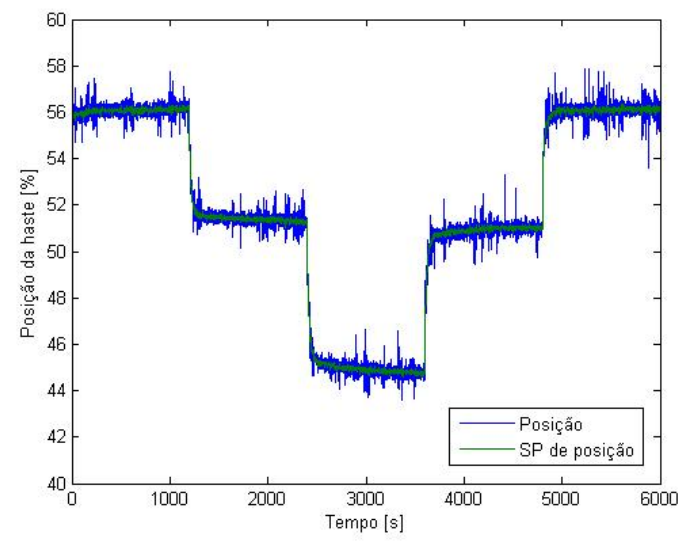

(a) Sem ADC

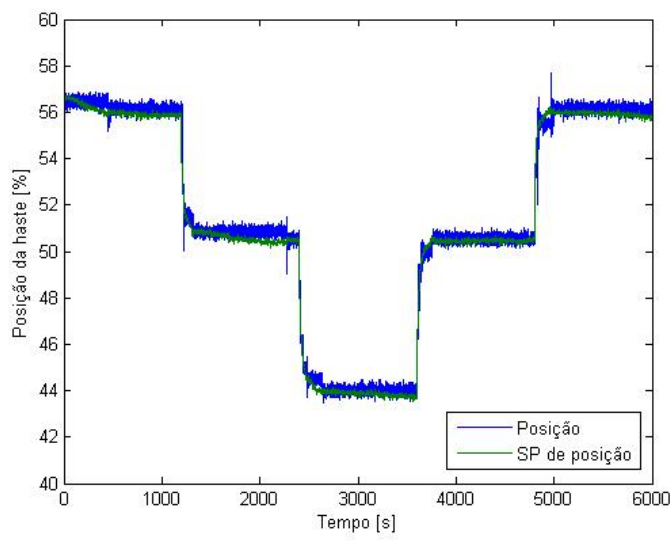

(b) Com ADC

Figura 93: Resposta da malha de controle de posição no ensaio para o problema servo da válvula com gaxetas de teflon com compensador CR1 (controle em cascata).

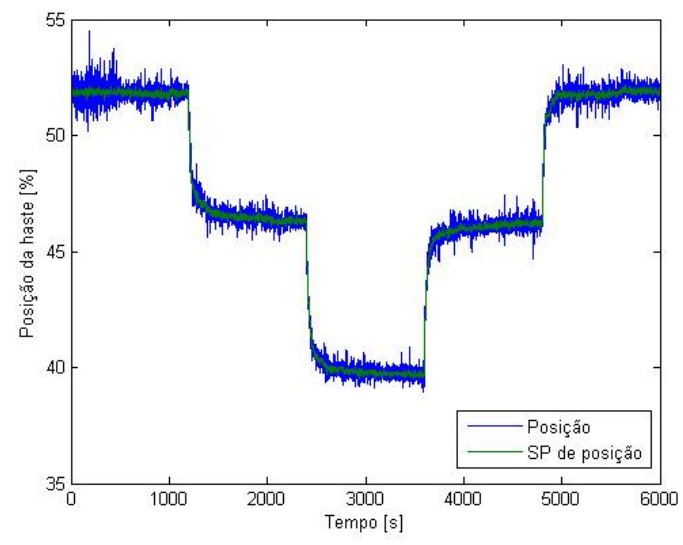

(a) Sem ADC

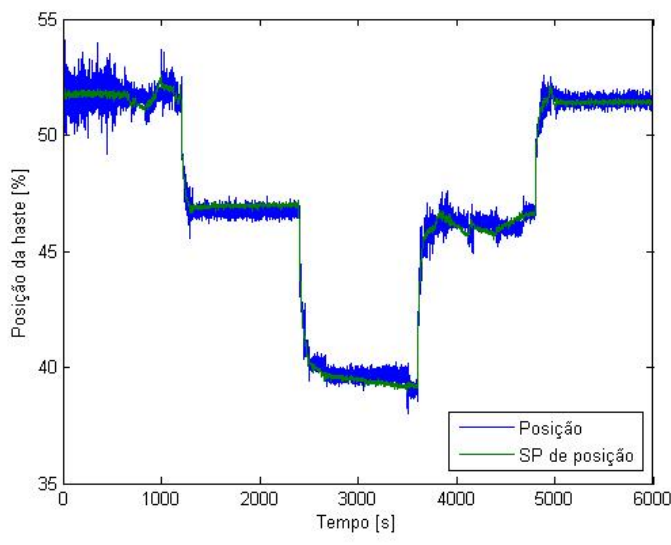

(b) Com ADC

Figura 94: Resposta da malha de controle de posição no ensaio para o problema servo da válvula com gaxetas de grafite com compensador CR1 (controle em cascata). 


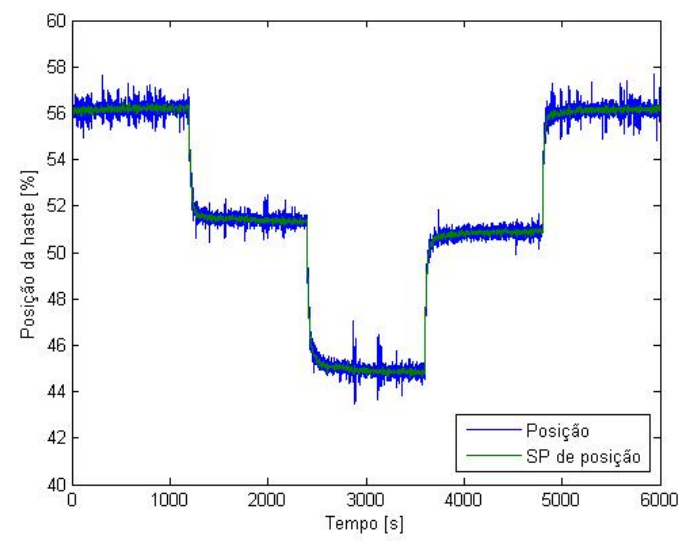

(a) Sem ADC

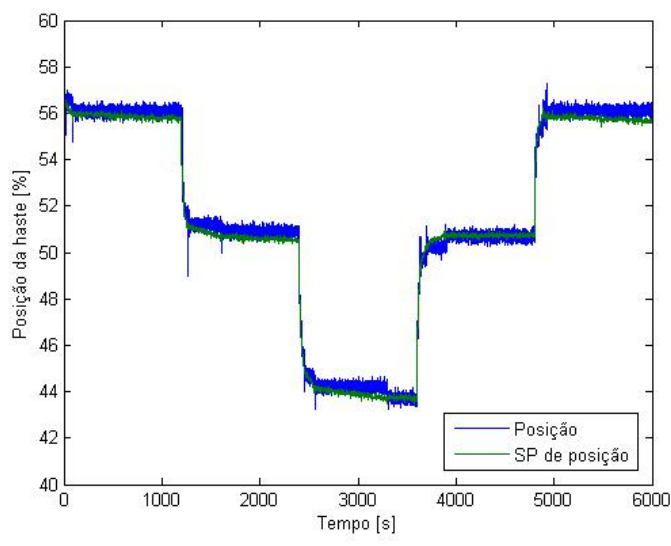

(b) Com ADC

Figura 95: Resposta da malha de controle de posição no ensaio para o problema servo da válvula com gaxetas de teflon com compensador CR2 (controle em cascata).

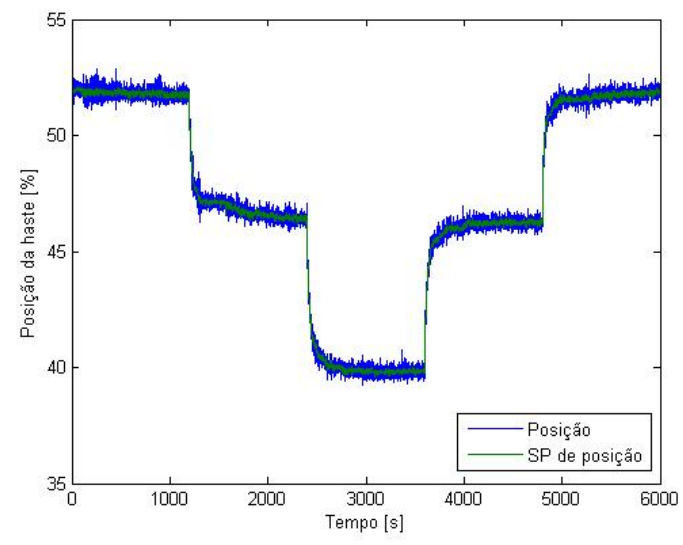

(a) Sem ADC

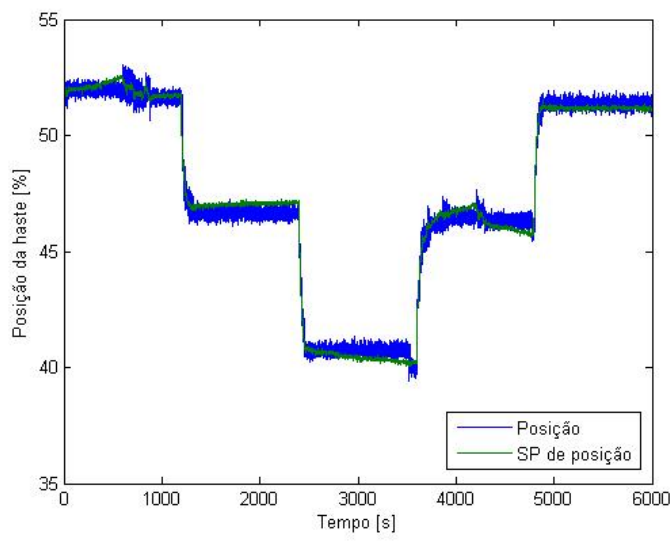

(b) Com ADC

Figura 96: Resposta da malha de controle de posição no ensaio para o problema servo da válvula com gaxetas de grafite com compensador CR2 (controle em cascata).

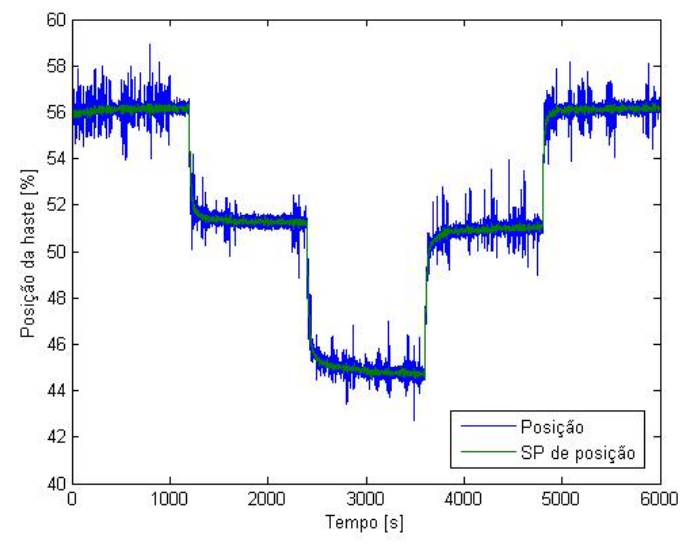

(a) Sem ADC

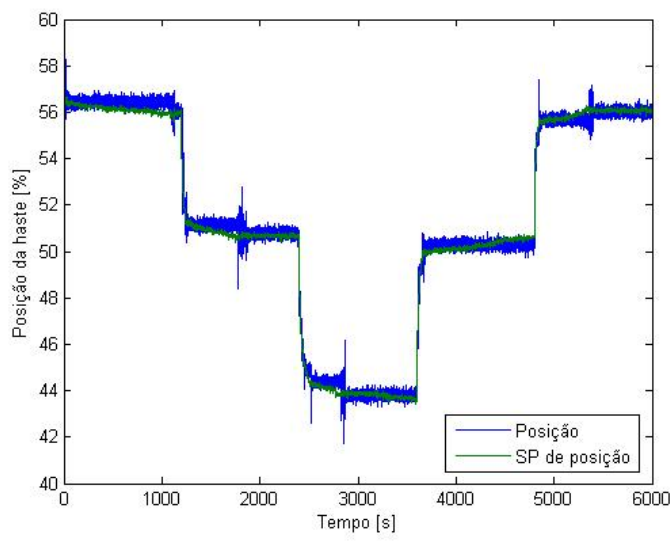

(b) Com ADC

Figura 97: Resposta da malha de controle de posição no ensaio para o problema servo da válvula com gaxetas de teflon com compensador Knocker (controle em cascata). 


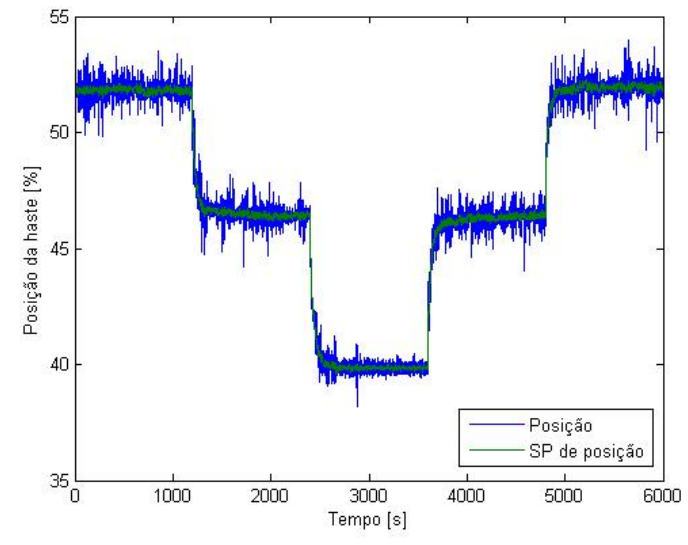

(a) Sem ADC

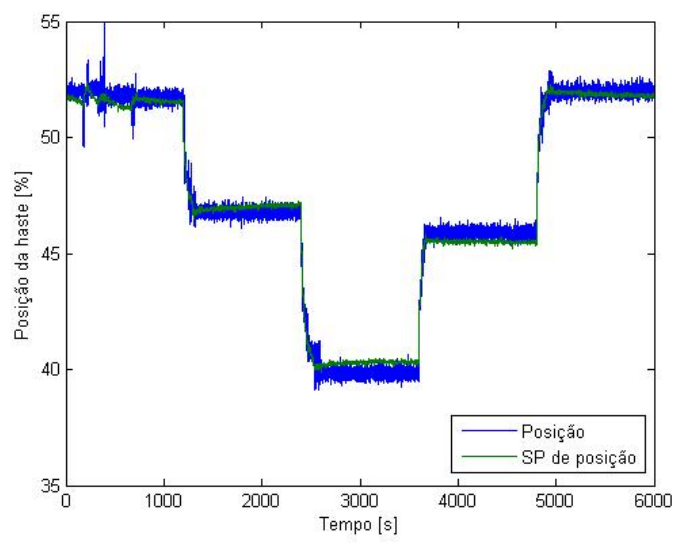

(b) Com ADC

Figura 98: Resposta da malha de controle de posição no ensaio para o problema servo da válvula com gaxetas de grafite com compensador Knocker (controle em cascata).

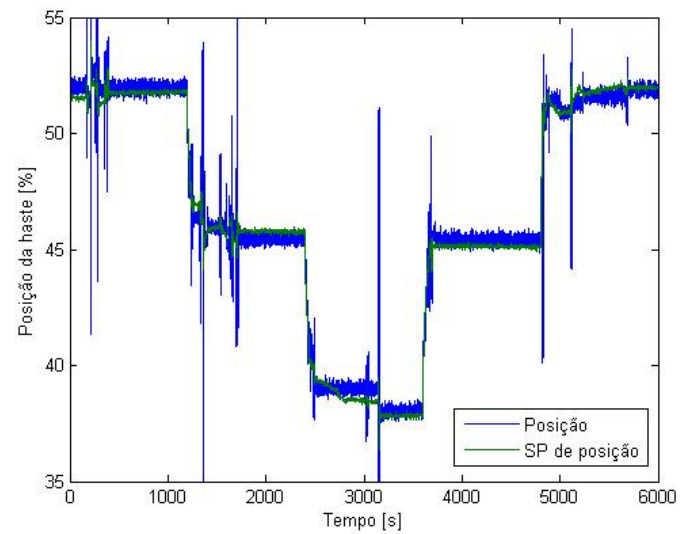

Figura 99: Resposta da malha de controle de posição no ensaio para o problema servo da válvula com gaxetas de grafite com compensador Two-move (controle em cascata). 


\section{A.2 Ensaios para o problema regulatório}

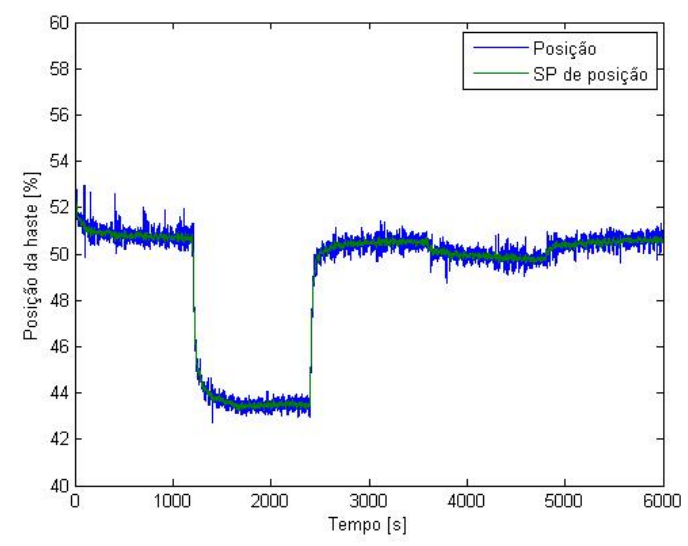

(a) Sem ADC

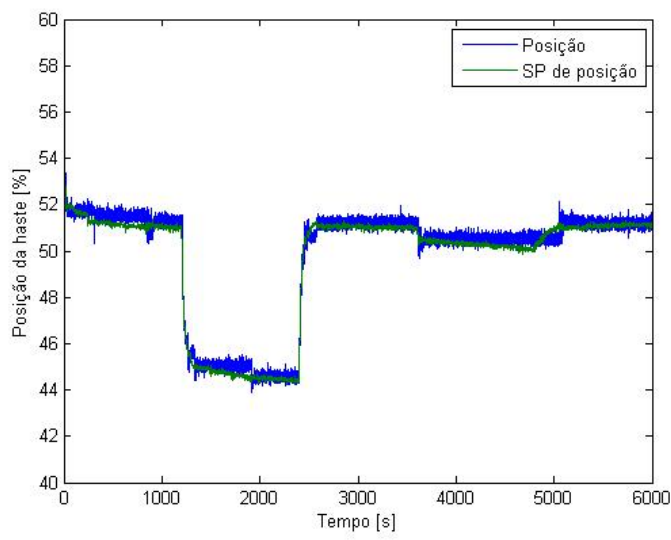

(b) Com ADC

Figura 100: Resposta da malha de controle de posição no ensaio para o problema regulatório da válvula com gaxetas de teflon com controlador PI (controle em cascata).

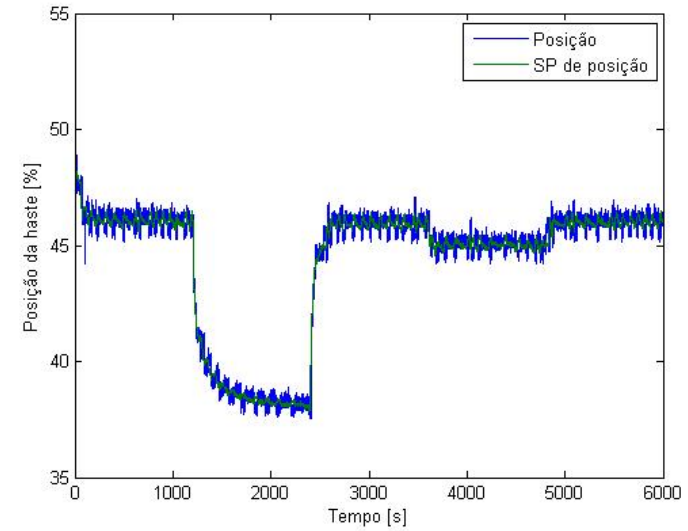

(a) Sem ADC

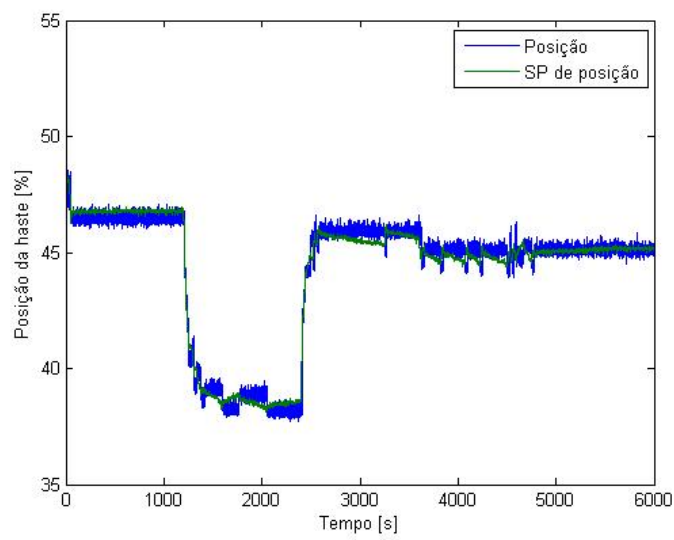

(b) Com ADC

Figura 101: Resposta da malha de controle de posição no ensaio para o problema regulatório da válvula com gaxetas de grafite com controlador PI (controle em cascata). 


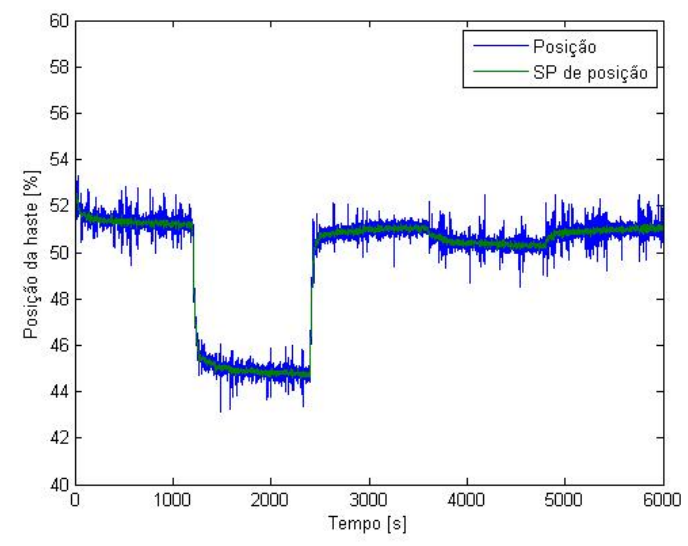

(a) Sem ADC

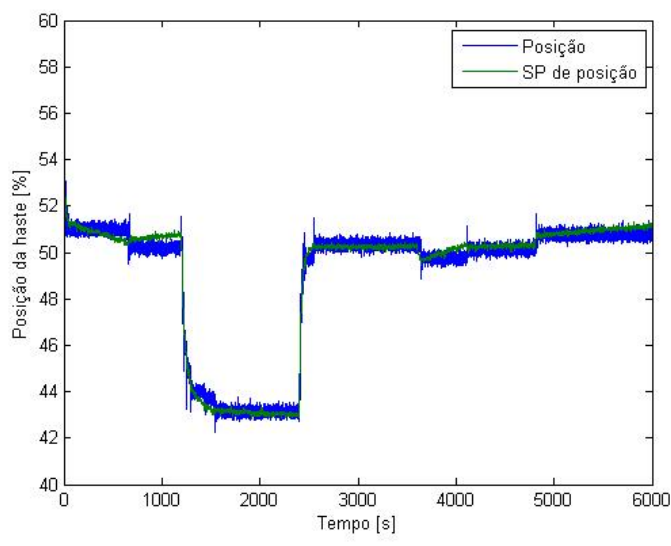

(b) Com ADC

Figura 102: Resposta da malha de controle de posição no ensaio para o problema regulatório da válvula com gaxetas de teflon com compensador CR1 (controle em cascata).

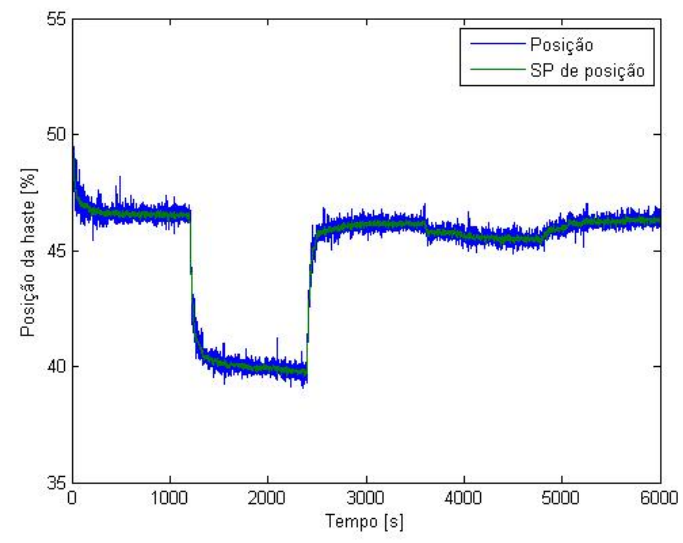

(a) Sem ADC

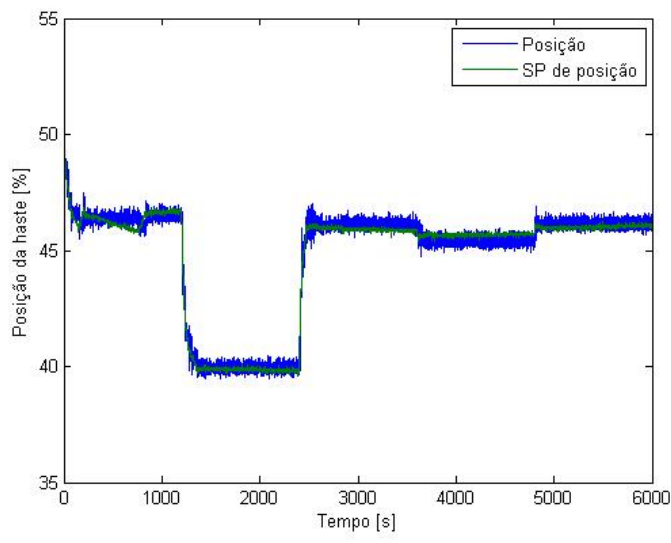

(b) Com ADC

Figura 103: Resposta da malha de controle de posição no ensaio para o problema regulatório da válvula com gaxetas de grafite com compensador CR1 (controle em cascata).

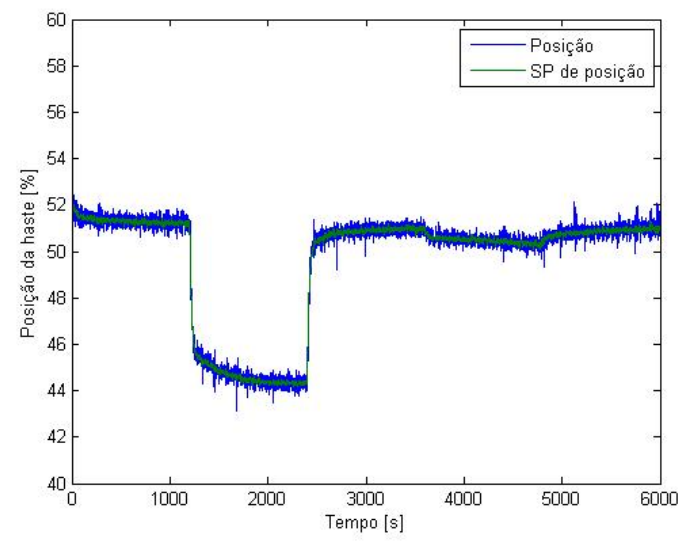

(a) Sem ADC

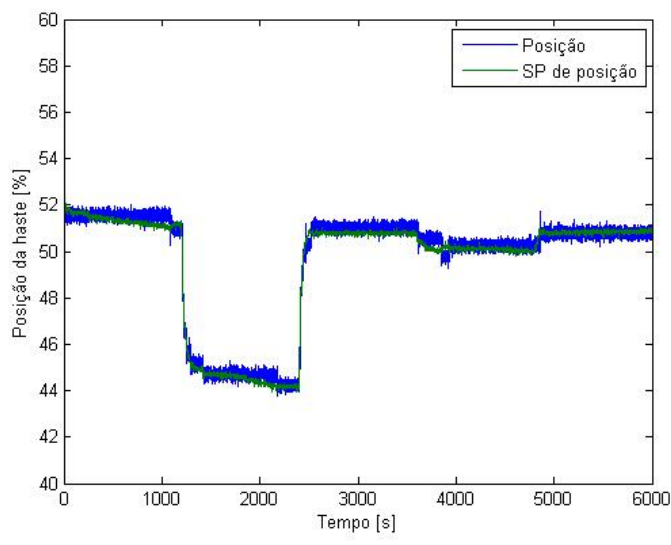

(b) Com ADC

Figura 104: Resposta da malha de controle de posição no ensaio para o problema regulatório da válvula com gaxetas de teflon com compensador CR2 (controle em cascata). 


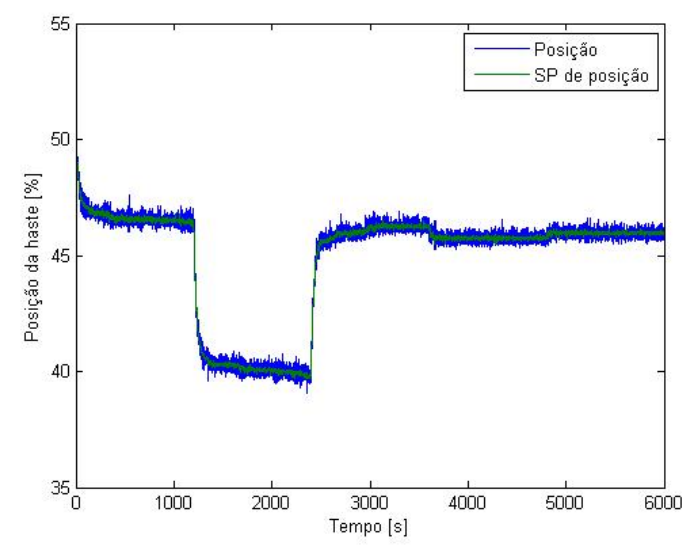

(a) Sem ADC

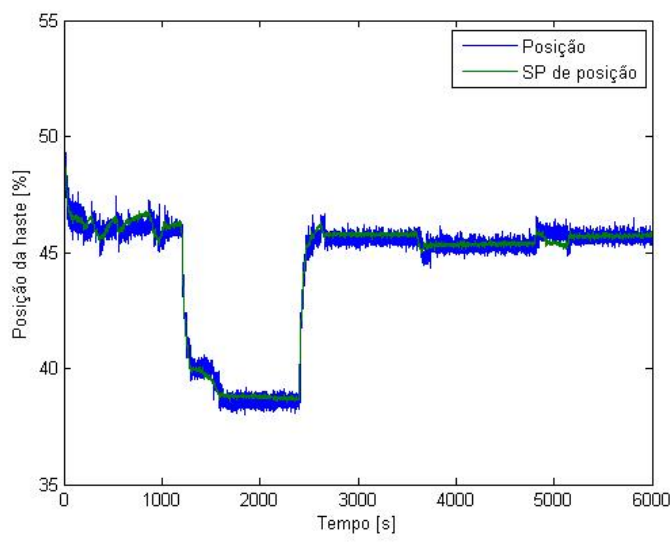

(b) Com ADC

Figura 105: Resposta da malha de controle de posição no ensaio para o problema regulatório da válvula com gaxetas de grafite com compensador CR2 (controle em cascata).

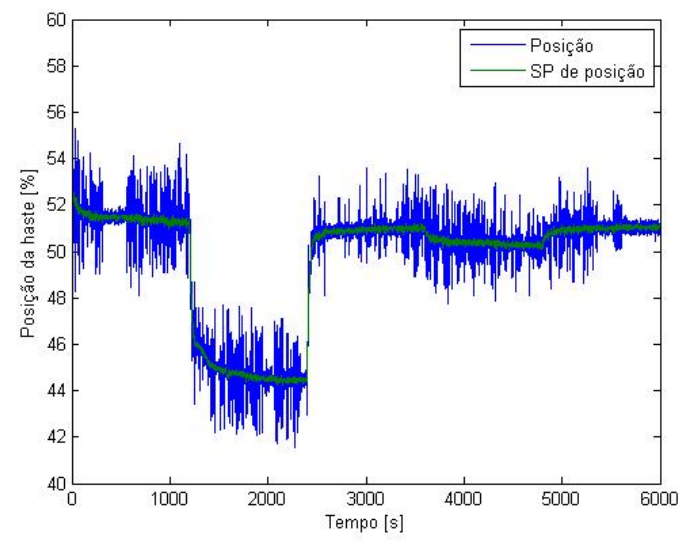

(a) Sem ADC

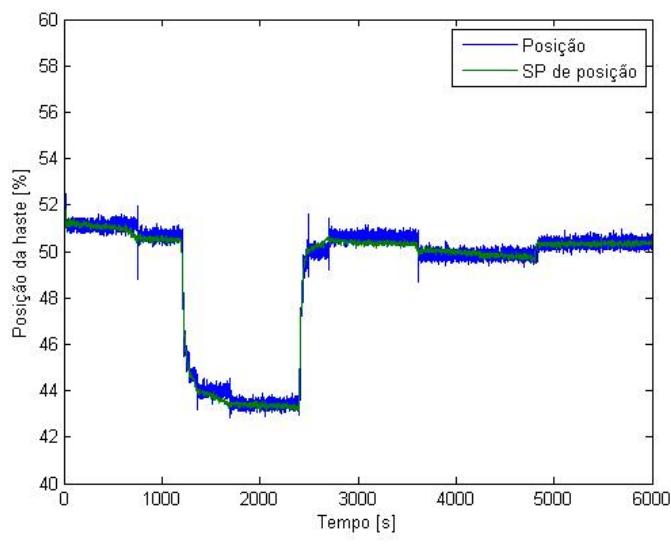

(b) Com ADC

Figura 106: Resposta da malha de controle de posição no ensaio para o problema regulatório da válvula com gaxetas de teflon com compensador Knocker (controle em cascata).

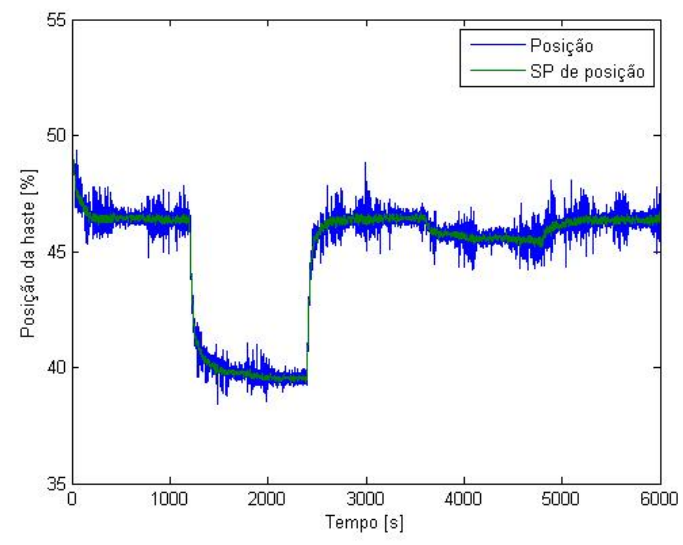

(a) Sem ADC

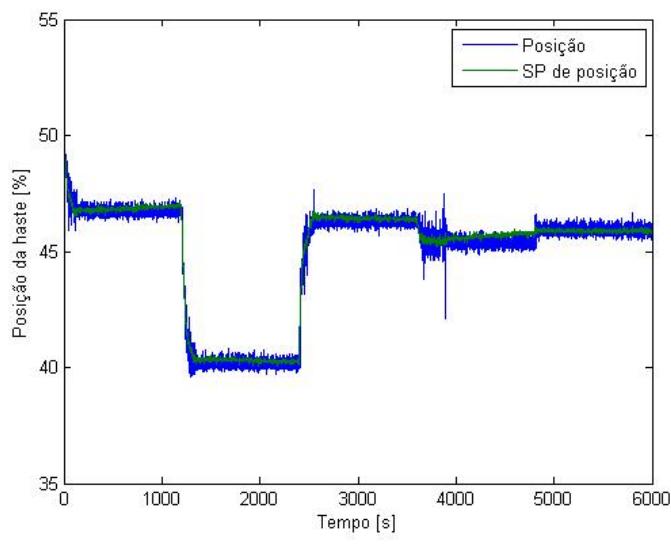

(b) Com ADC

Figura 107: Resposta da malha de controle de posição no ensaio para o problema regulatório da válvula com gaxetas de grafite com compensador Knocker (controle em cascata). 


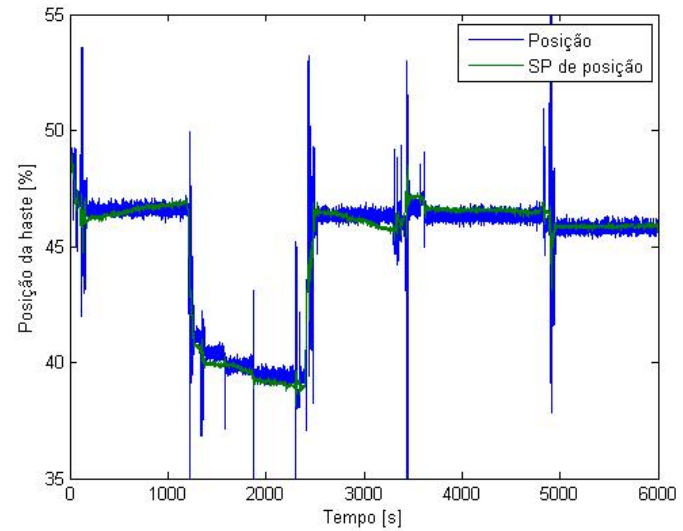

Figura 108: Resposta da malha de controle de posição no ensaio para o problema regulatório da válvula com gaxetas de grafite com compensador Two-move (controle em cascata). 


\section{ANEXO B - Gráficos dos ensaios de robustez do compensador CR1}

Este anexo apresenta os gráficos dos resultados obtidos nos ensaios de robustez do compensador CR1, mencionados na Seção 5.3.

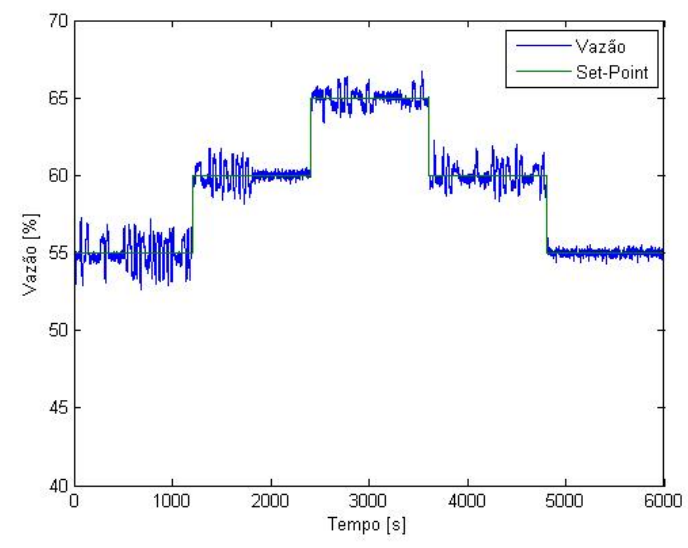

(a) Vazão

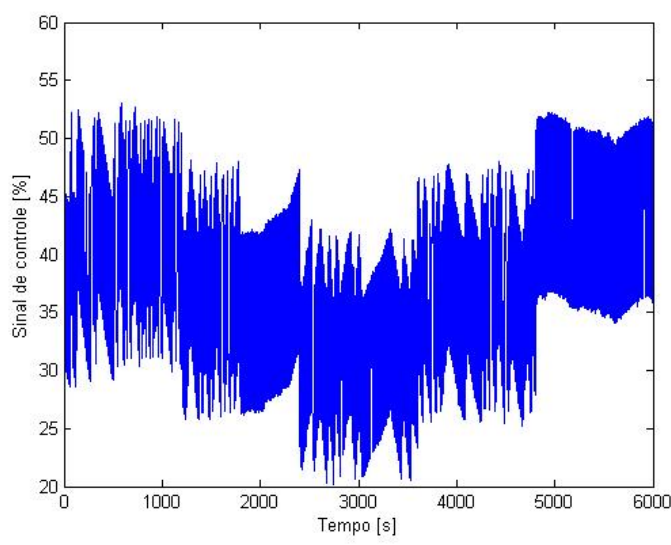

(b) Sinal de controle

Figura 109: Resultados obtidos no ensaio para o problema servo da válvula com gaxetas de grafite com compensador CR1 (considerando erro de $-20 \%$ na estimação de $S$ ). 


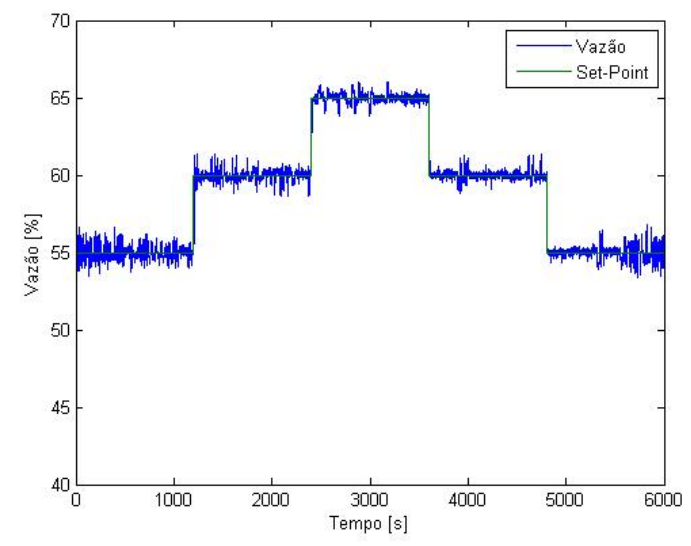

(a) Vazão

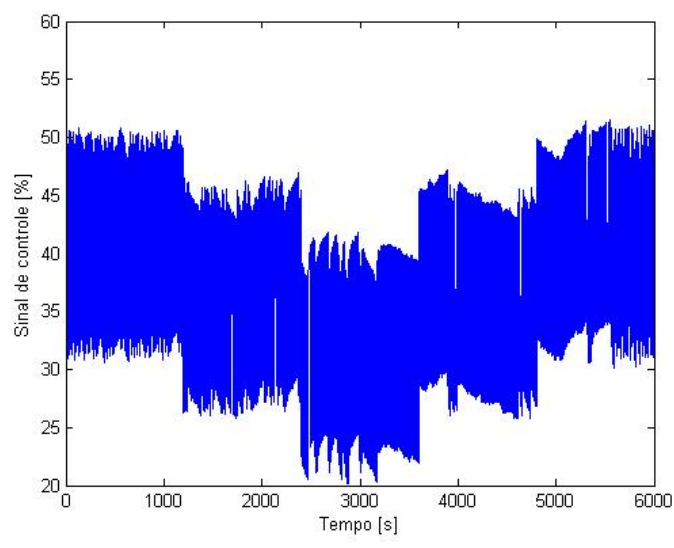

(b) Sinal de controle

Figura 110: Resultados obtidos no ensaio para o problema servo da válvula com gaxetas de grafite com compensador CR1 (considerando erro de $-10 \%$ na estimação de $S$ ).

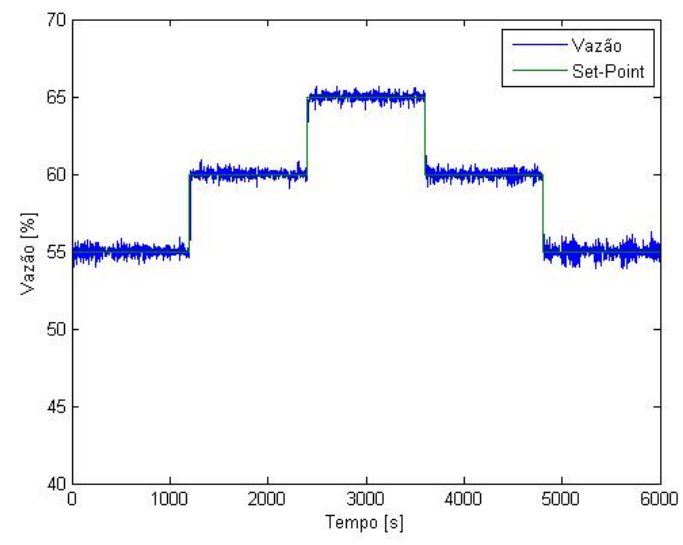

(a) Vazão

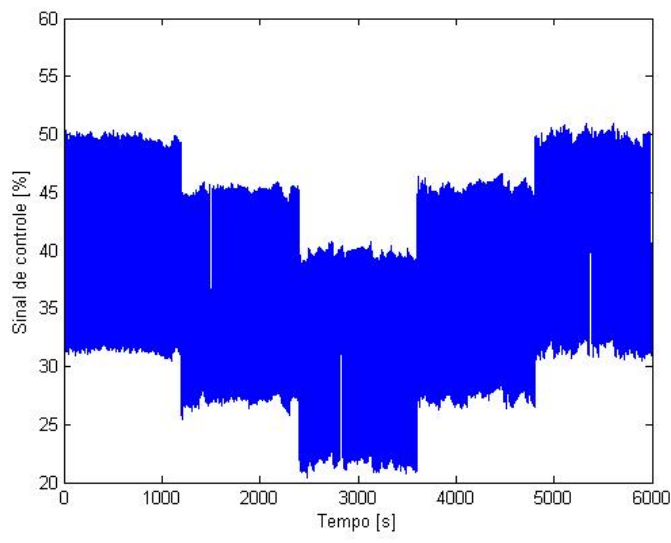

(b) Sinal de controle

Figura 111: Resultados obtidos no ensaio para o problema servo da válvula com gaxetas de grafite com compensador CR1 (considerando erro de $-5 \%$ na estimação de $S$ ).

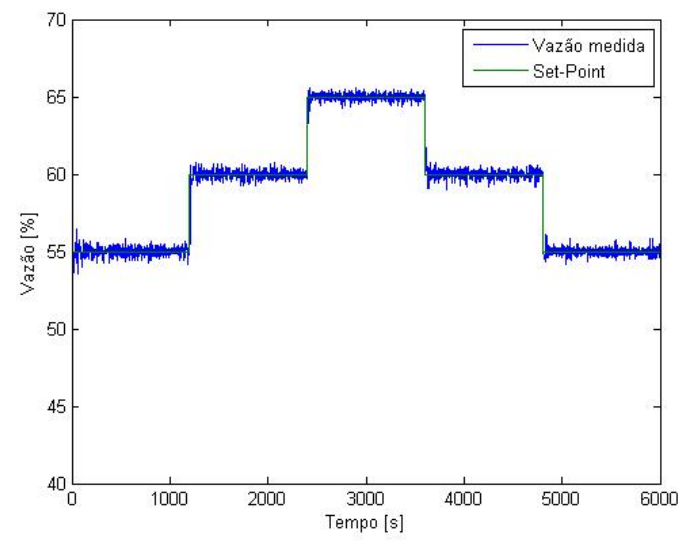

(a) Vazão

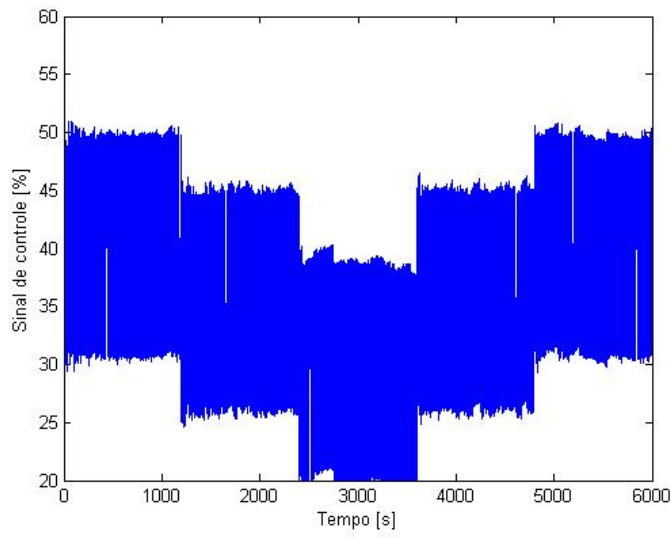

(b) Sinal de controle

Figura 112: Resultados obtidos no ensaio para o problema servo da válvula com gaxetas de grafite com compensador CR1 (sem considerar erros na estimação de $S$ ). 


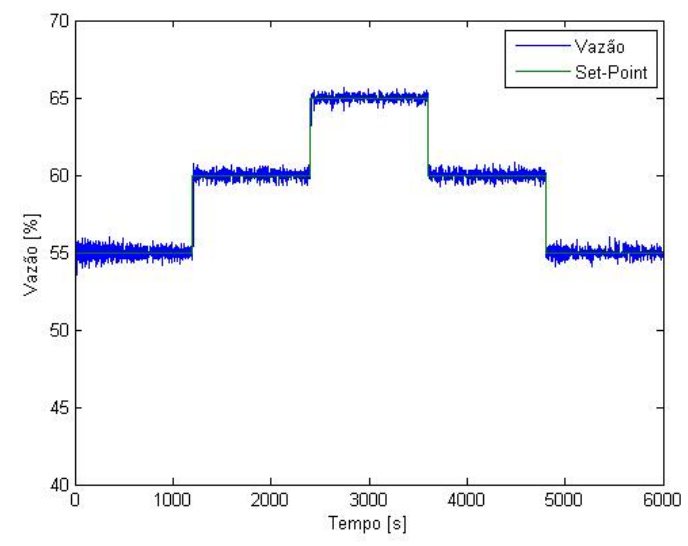

(a) Vazão

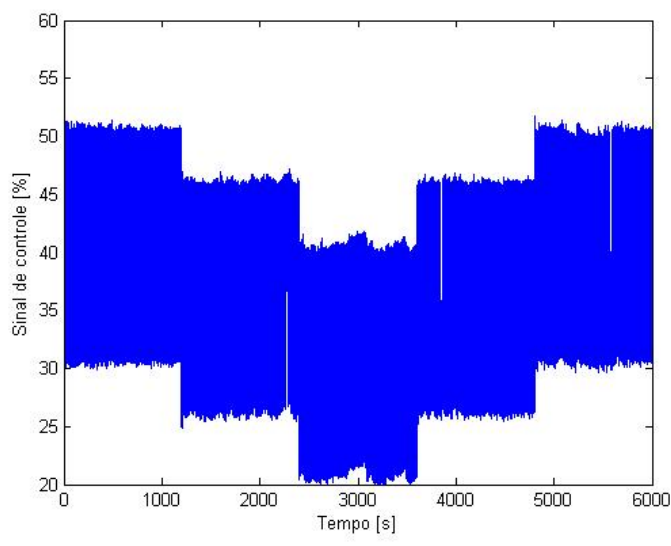

(b) Sinal de controle

Figura 113: Resultados obtidos no ensaio para o problema servo da válvula com gaxetas de grafite com compensador CR1 (considerando erro de $+5 \%$ na estimação de $S$ ).

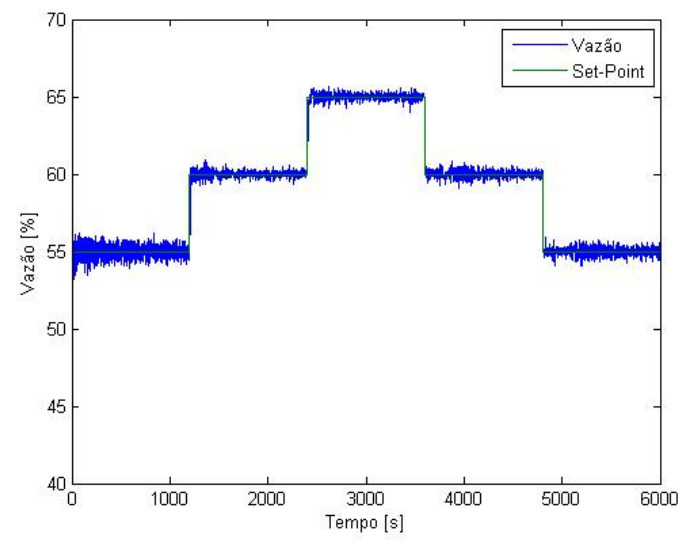

(a) Vazão

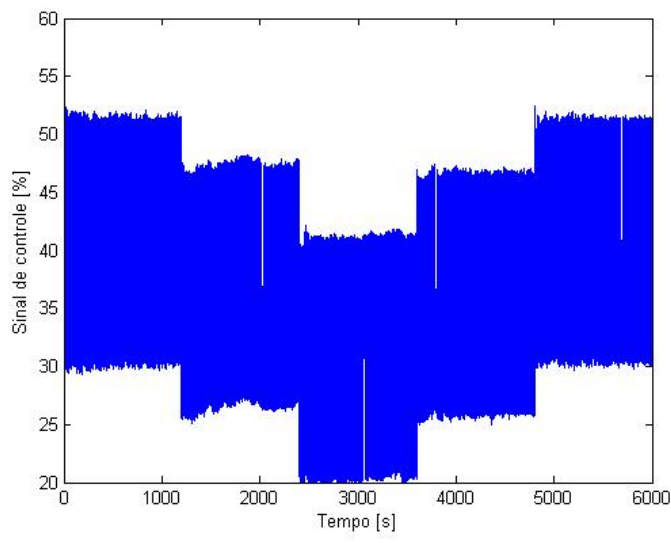

(b) Sinal de controle

Figura 114: Resultados obtidos no ensaio para o problema servo da válvula com gaxetas de grafite com compensador CR1 (considerando erro de $+10 \%$ na estimação de $S$ ).

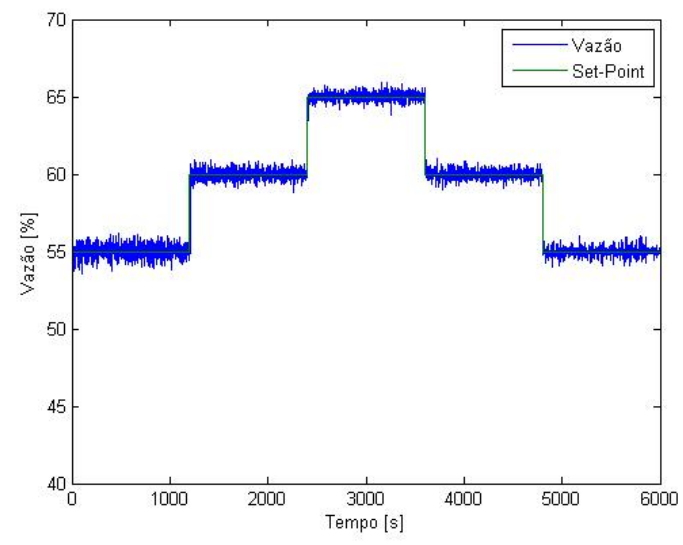

(a) Vazão

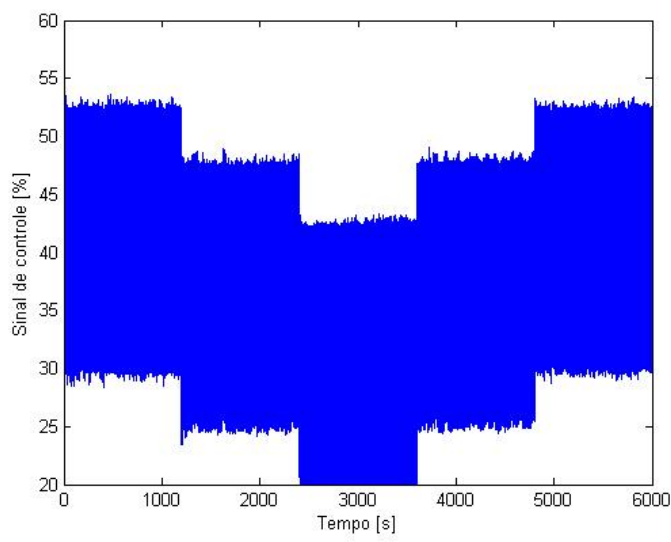

(b) Sinal de controle

Figura 115: Resultados obtidos no ensaio para o problema servo da válvula com gaxetas de grafite com compensador CR1 (considerando erro de $+20 \%$ na estimação de $S$ ). 


\section{ANEXO C - Gráficos dos ensaios de robustez do compensador Knocker}

Este anexo apresenta os gráficos dos resultados obtidos nos ensaios de robustez do compensador Knocker, mencionados na Seção 5.3.

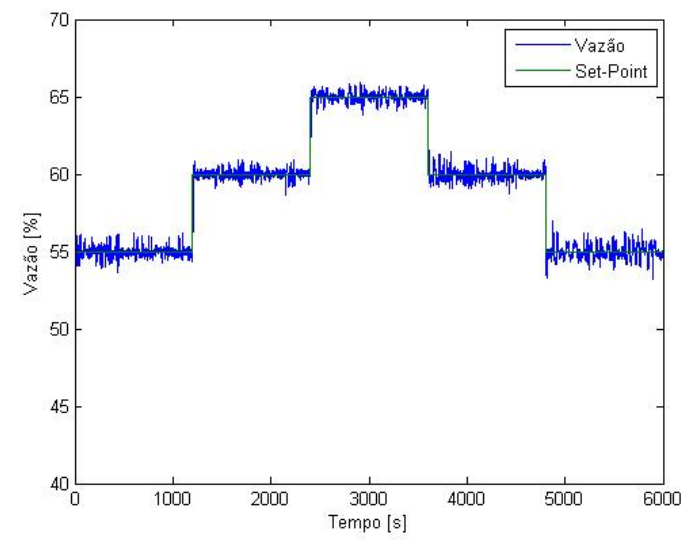

(a) Vazão

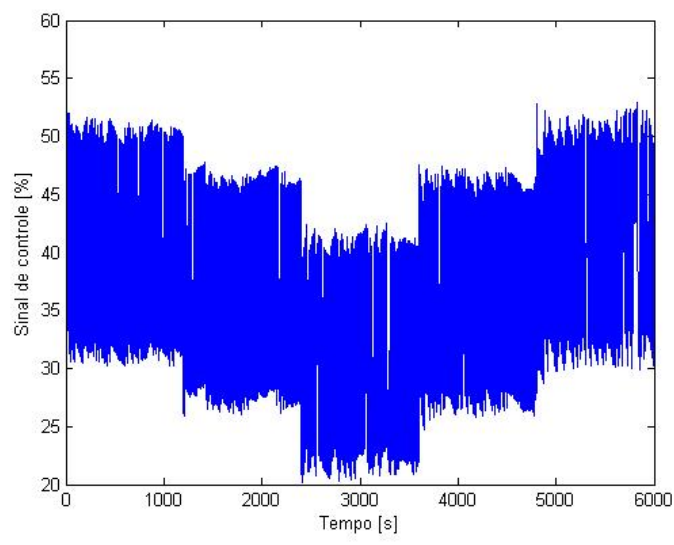

(b) Sinal de controle

Figura 116: Resultados obtidos no ensaio para o problema servo da válvula com gaxetas de grafite com compensador Knocker (considerando erro de $-20 \%$ na estimação de $S$ ). 


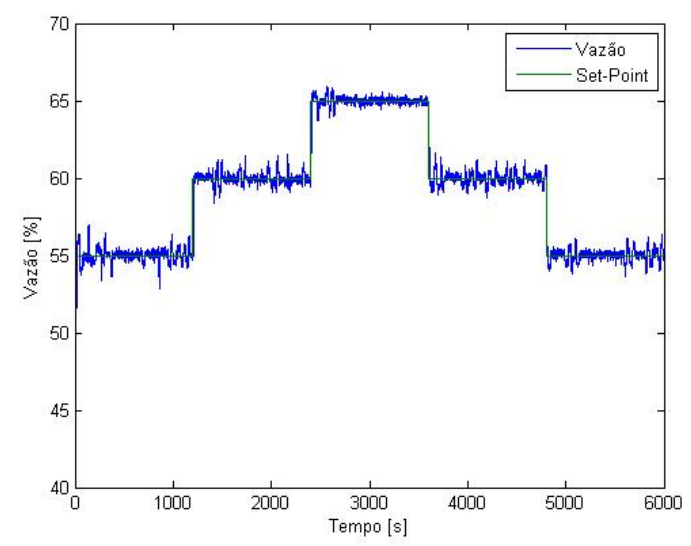

(a) Vazão

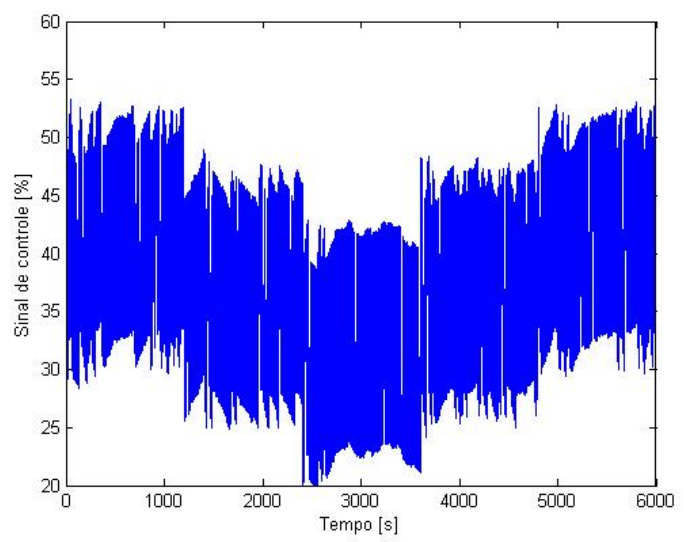

(b) Sinal de controle

Figura 117: Resultados obtidos no ensaio para o problema servo da válvula com gaxetas de grafite com compensador Knocker (considerando erro de $-10 \%$ na estimação de $S$ ).

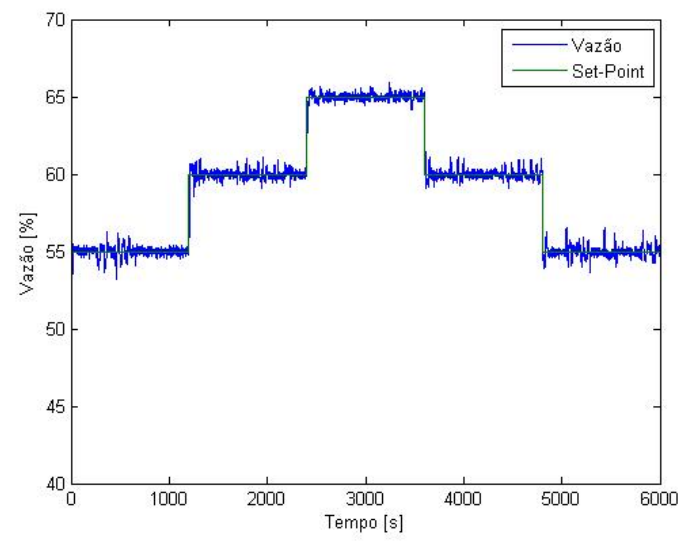

(a) Vazão

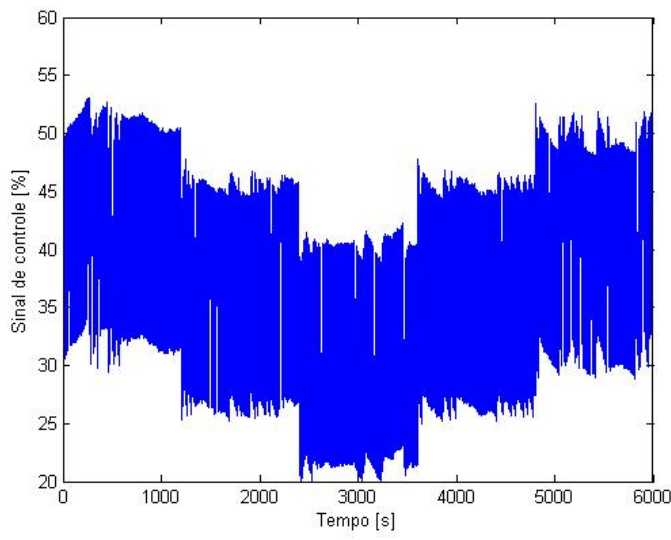

(b) Sinal de controle

Figura 118: Resultados obtidos no ensaio para o problema servo da válvula com gaxetas de grafite com compensador Knocker (considerando erro de $-5 \%$ na estimação de $S$ ).

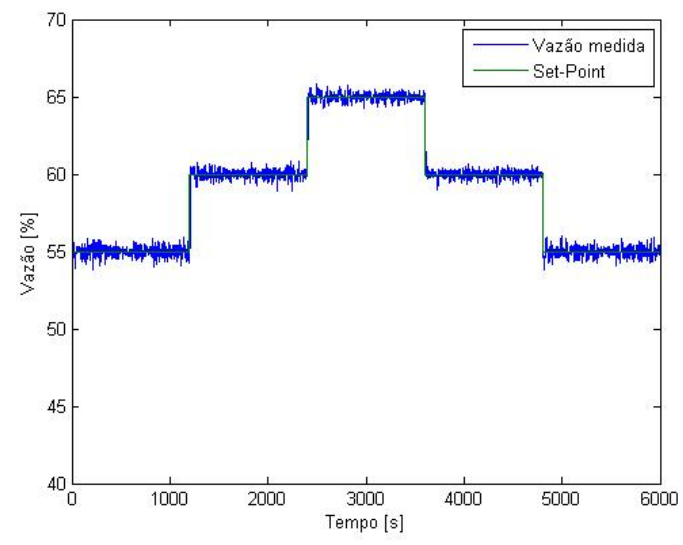

(a) Vazão

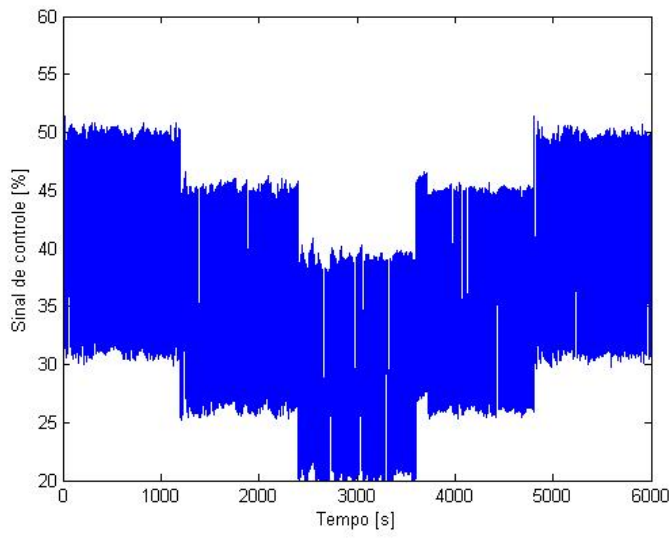

(b) Sinal de controle

Figura 119: Resultados obtidos no ensaio para o problema servo da válvula com gaxetas de grafite com compensador Knocker (sem considerar erros na estimação de $S$ ). 


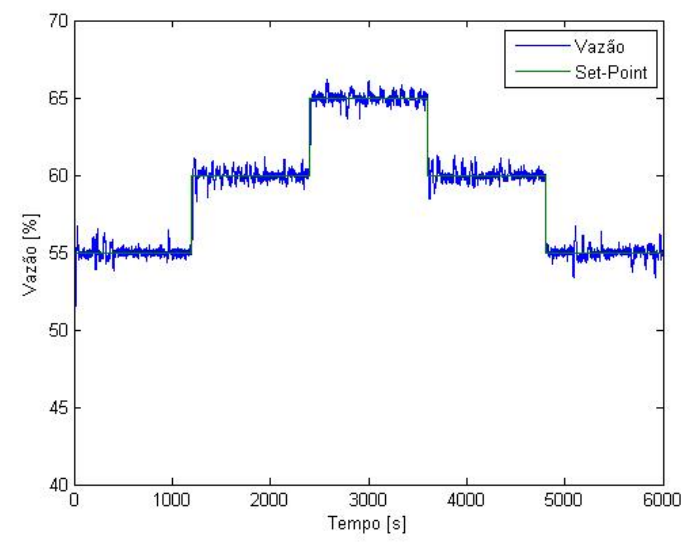

(a) Vazão

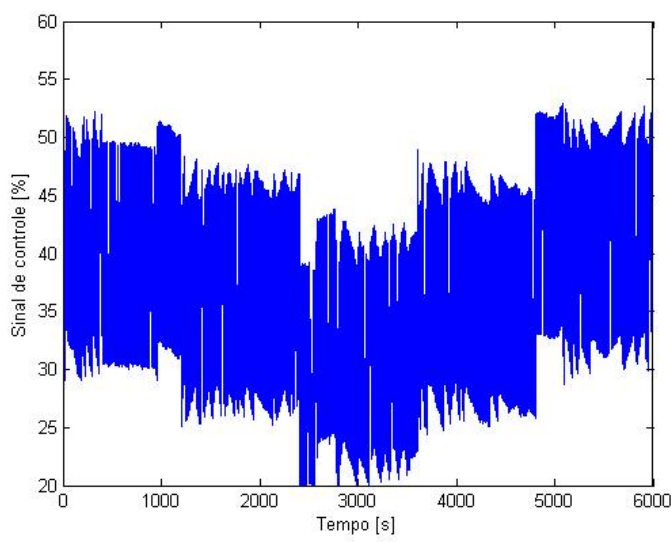

(b) Sinal de controle

Figura 120: Resultados obtidos no ensaio para o problema servo da válvula com gaxetas de grafite com compensador Knocker (considerando erro de $+5 \%$ na estimação de $S$ ).

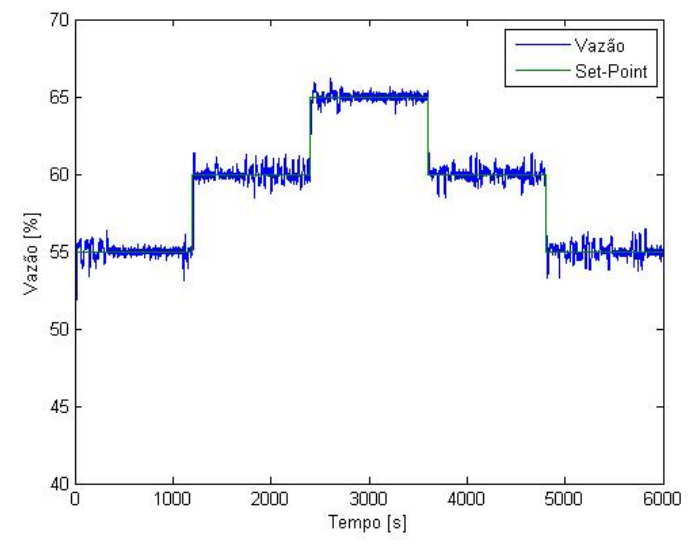

(a) Vazão

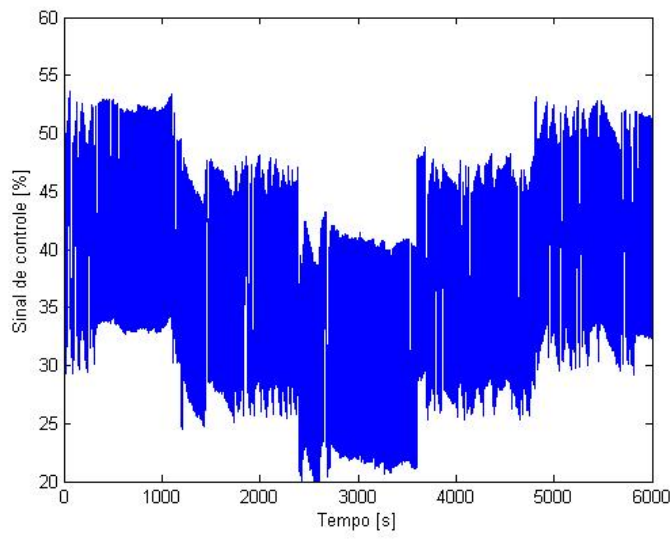

(b) Sinal de controle

Figura 121: Resultados obtidos no ensaio para o problema servo da válvula com gaxetas de grafite com compensador Knocker (considerando erro de $+10 \%$ na estimação de $S$ ).

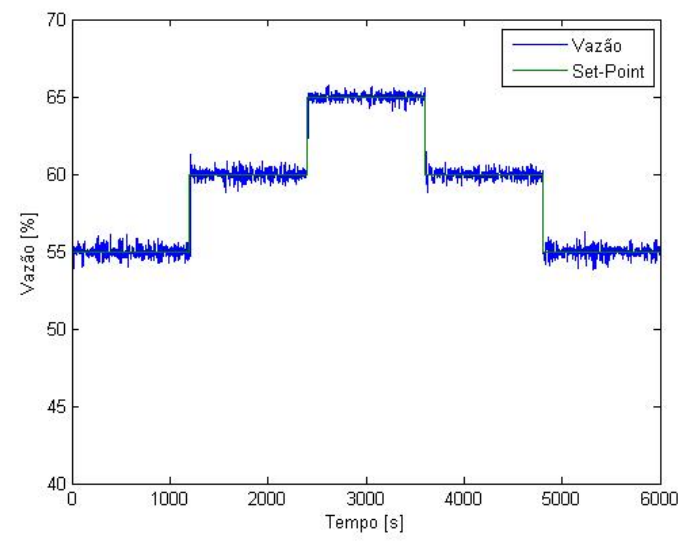

(a) Vazão

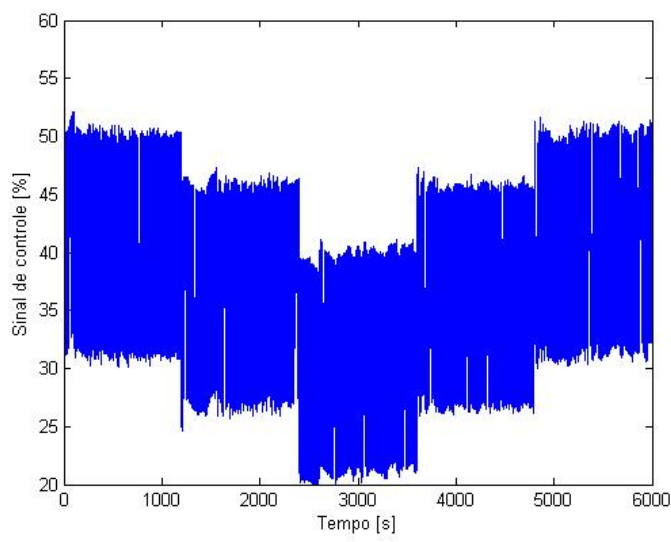

(b) Sinal de controle

Figura 122: Resultados obtidos no ensaio para o problema servo da válvula com gaxetas de grafite com compensador Knocker (considerando erro de $+20 \%$ na estimação de $S$ ). 


\section{Referências Bibliográficas}

ARMSTRONG-HÉLOUVRY, B. Control of Machines with Friction. [S.l.]: Kluwer Academic Publishers, 1991.

ARMSTRONG-HÉlOUVRY, B.; DUPONT, P.; WIT, C. C. de. A survey of models, analysis tools and compensation methods for the control of machines with friction. Automatica, v. 30, n. 7, p. 1083-1138, 1994.

BAEZA, J. R. Controle Não Linear Aplicado a Malhas de Controle com Válvulas de Alto Atrito. Dissertação (Mestrado) - Escola Politécnica da USP. Departamento de Telecomunicações e Controle., 2013.

CHOUDHURY, M. A. A. S.; JAIN, M.; SHAH, S. L. Stiction - definition, modelling, detection and quantification. Journal of Process Control, v. 18, p. 232-243, 2008.

CHOUdHuRY, M. A. A. S.; SHAH, S. L.; THORNHILL, N. F. Diagnosis of poor control-loop performance using higher-order statistics. Automatica, v. 40, p. 1719-1728, 2004 .

CHOUDHURY, M. A. A. S. et al. Automatic detection and quantification of stiction in control valves. Control Engineering Practice, v. 14, p. 1395-1412, 2006.

CHOUDHuRY, M. A. A. S.; THORNHILL, N. F.; SHAH, S. L. Modelling valve stiction. Control Engineering Practice, v. 13, p. 641-658, 2005.

CUADROS, M. A. de S. L. Quantificação e Compensação de Atrito em Válvulas de Controle Pneumáticas. Tese (Doutorado) - Centro Tecnológico da Universidade Federal do Espírito Santo, 2011.

ELY, V. E.; LONGHI, L. G. S. Desenvolvimento e implementação de um compensador de agarramento para válvulas de controle. In: $15^{\circ}$ Congresso Internacional de Automação, Sistemas e Instrumentação. [S.l.: s.n.], 2011.

GARCIA, C. Friction model parameter estimation for control valves. 8th IFAC DYCOPS, 2007.

GARCIA, C. Comparison of friction models applied to control valves. Control Engineering Practice, v. 16, p. 1231-1243, 2008.

GURY, C. G. L. Compensação de atrito em válvulas de controle. Dissertação (Mestrado) - Escola Politécnica da USP. Departamento de Telecomunicações e Controle., 2008.

HÄGGLUND, T. A friction compensator for pneumatic control valves. Journal of Process Control, v. 12, p. 897-904, 2002. 
HÄGGLUND, T. Automatic on-line estimation of backlash in control loops. Journal of Process Control, v. 17, p. 489-499, 2007.

HE, Q. P. et al. A segmentation-based method for detection os stiction in control valves. Industrial \& Engineering Chemistry Research, v. 46, p. 4549-4560, 2007.

HORCH, A. A simple method for detection of stiction in control valves. Control Engineering Practice, v. 7, p. 1221-1231, 1999.

HORCH, A. Condition Monitoring of Control Loops. Tese (Doutorado) - Royal Institute of Technology., 2000.

ISA. Process instrumentation terminology. [S.1.], 1979. Technical Report ANSI/ISAS51.1-1979.

IVAN, L. Z. X.; LAKSHMINARAYANAN, S. A new unified approach to valve stiction quantification and compensation. Industrial \&6 Engineering Chemistry Research, v. 48, p. 3474-3483, 2009.

JELALI, M. Estimation of valve stiction in control loops using separable least-squares and global search algorithms. Journal of Process Control, v. 18, p. 632-642, 2008.

KANO, M. et al. Pratical model and detection algorithm for valve stiction. In: 7th IFAC DYCOPS. [S.l.: s.n.], 2004.

KARNOPP, D. Computer simulation of stick-slip friction in mechanical dynamics system. Journal of Dynamic Systems, Measurement and Control, v. 107, p. 100-103, 1985.

KAYIHAN, A.; DOYLE III, F. J. Friction compensation for a process control valve. Control Engineering Practice, v. 8, p. 799-812, 2000.

MOHAMMAD, M. A.; HUANG, B. Compensation of control valve stiction through controller tuning. Journal of Process Control, v. 22-9, p. 1800-1819, 2012.

OLSSON, H. Control Systems with Friction. Tese (Doutorado) - Lund Institute of Technology, 1996.

RAVANBOD-SHIRAZI, L.; BESANÇON-VODA, A. Friction identification using teh karnopp model, applied to an eletropneumatic actuator. Proc. Instn. Mech. Engrs., Part I: Journal of Systems and Control Engineering, v. 217(2), p. 123-138, 2003.

ROMANO, R. A. Identificação de processos não-lineares e quantificação de atrito em válvulas de controle. Tese (Doutorado) — Escola Politécnica da USP. Departamento de Telecomunicações e Controle., 2009.

ROMANO, R. A.; GARCIA, C. Comparison between two friction model parameter estimation methods applied to control valves. 8th IFAC DYCOPS, 2007.

ROMANO, R. A.; GARCIA, C. Karnopp friction model identification for a real control valve. In: 17th IFAC World Congress. [S.l.: s.n.], 2008.

ROMANO, R. A.; GARCIA, C. Valve friction and nonlinear process model closed-loop identification. Journal of Process Control, v. 21, n. 4, p. 667-677, 2009. 
ROSSI, M.; SCALI, C. Automatic detection of stiction in actuators: a technique to reduce the number of uncertain cases. In: 7th IFAC Dycops. [S.l.: s.n.], 2004.

SAVITZKY, A.; GOLAY, M. J. E. Smoothing and differetiation of data by simplified least squares procedures. Analytical Chemistry, v. 36, p. 1627-1639, 1964.

SMITH, C. L.; CORRIPIO, A. B.; MARTIN JR., J. Controller tuning from simple process models. Instrumentation Technology, v. 22, n. 12, p. 39-44, 1975.

SRINIVASAN, R.; RENGASWAMY, R. Stiction compensation in process control loops: A framework for integrating stiction measure and compensation. Industrial \& Engineering Chemistry Research, v. 44, p. 9164-9174, 2005.

SRINIVASAN, R.; RENGASWAMY, R. Approaches for efficient stiction compensation in process control valves. Computers \& Chemical Engineering, v. 32, p. 218-229, 2008.

STENMAN, A.; GUSTAFSSON, F.; FORSMAN, K. A segmentation-based method for detection os stiction in control valves. International Journal of Adaptive Control and Signal Processing, v. 17, p. 625-634, 2003.

STRIBECK, R. Die wesentlichen eigenschaften der gleit und rollenlager - the key qualities of sliding and roller bearings. Zeitschrift des Vereines Seutscher Ingenieure, v. 46(38,39), p. 1342-48, 1432-37, 1902.

TUSTIN, A. The effects of backlash and of speed-dependent friction on the stability of closed-cycle control systems. Journal of the Institution of Eletrical Engineers Part 1 General, v. 94, p. 143-151, 1975.

UEHARA, D. Deteç̧ão e Quantificação de Atrito em Válvulas de Controle. Dissertação (Mestrado) - Escola Politécnica da USP. Departamento de Telecomunicações e Controle., 2009.

UEHARA, D.; GARCIA, C.; ROMANO, R. A. Comparação e equivalência dos modelos de atrito de kano e karnopp aplicados a válvulas de controle. In: $17^{\circ}$ Congresso Brasileiro de Automática. [S.l.: s.n.], 2008.

WIT, C. C. de et al. A new model for control of systems with friction. In: IEEE Transactions of Automatic Control. [S.l.: s.n.], 1995. 